\title{
Short-term prediction of local wind conditions
}

\author{
Landberg, Lars
}

Publication date:

1994

Document Version

Publisher's PDF, also known as Version of record

Link back to DTU Orbit

Citation (APA):

Landberg, L. (1994). Short-term prediction of local wind conditions. Risø National Laboratory. Denmark. Forskningscenter Risoe. Risoe-R No. 702(EN)

\section{General rights}

Copyright and moral rights for the publications made accessible in the public portal are retained by the authors and/or other copyright owners and it is a condition of accessing publications that users recognise and abide by the legal requirements associated with these rights.

- Users may download and print one copy of any publication from the public portal for the purpose of private study or research.

- You may not further distribute the material or use it for any profit-making activity or commercial gain

- You may freely distribute the URL identifying the publication in the public portal

If you believe that this document breaches copyright please contact us providing details, and we will remove access to the work immediately and investigate your claim. 


\section{DK940 9236

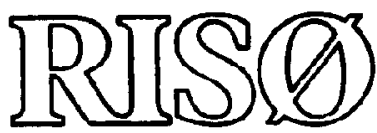

Risø-R-702(EN)

\section{Short-term Prediction of Local Wind Conditions}

\section{Lars Landberg}

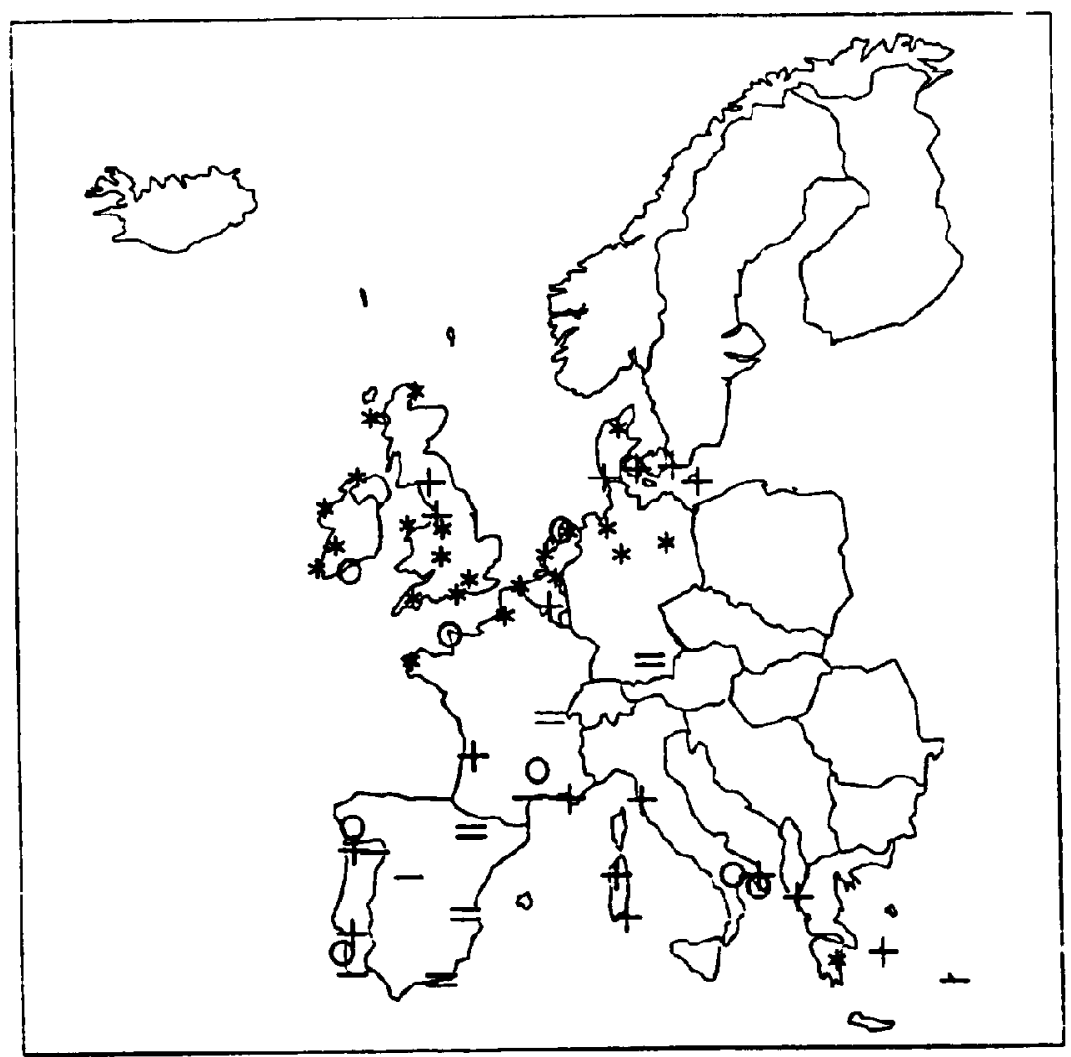




\section{Short-term Prediction of Local Wind Conditions}

\section{Lars Landbers}


Abatract This report describes the development and evaluation of different methods for predicting the wind locally. The look-ahead time of the forecasts ranges from 3 to 36 hours. The main model developed here is based on forecasts from a numerical weather prediction model. In this study HIRLAM (HIgh Resolution Limited Area Model) has been used. The HIRLAM forecasts are transformed to the surface using the geostrophic drag law and the logarithmic wind profile in their neutral versions. To take local effects : ' , account, corrections output from WAP (Wind Atlas Analysis and Application Program) are used. The conclusion is that the model developed bere performs significantly better than persistence. The model performs best when applied to sites in Northern Europe (having high wind speeds). When using MOS (Model Output Statistics) it is possible to improve the forecasts, mainly those that do not perform well.

This report is - with a few minor changes - a copy of my thesis submitted to the University of Copenhagen in partial fulfillment of the requirements for the PhD-degree.

ISBN 87-550-1916-1

ISSN 0106-2840

Grafok Service - Rin - 1994 


\section{Contents}

1 Intraduction 7

\section{Basic Equations 9}

2 The coostrophic dras law 11

2.1 The velocity-defect law 11

2.2 The law of the wall 19

2.3 The matched equations 11

2.4 Theory for the stability dependence of $A$ and $B \quad 17$

2.5 Empirical expressions for $A(\mu)$ and $B(\mu) \quad 20$

2.6 Stability dependence of the velocity profile 24

\section{The Applied Models 25}

3 Introduction $2 \gamma$

4 WAP 27

s The model for flow in complex terrain 90

5.1 Zooming grid 94

5.2 Verification of the flow model 94

- Model for the efiect of roughneas changes $\$ 5$

7 Shelter from obatacles 97

7.1 Theory 97

7.2 Measurements 10

7.3 WASP te

- imanam 49

8.1 The equations 43

8.2 The model 44

8.3 Accuracy of HIRLAM 44

8.4 New version of HLRLAM 4

- Neural networte 46

9.1 The formal neuron 16

9.2 The neural network 16

III Prediction of Local Wind Conditions

10 Introduction 55

11 Evaluntion of the models 54

11.1 Evaluation parameters $5 \%$

11.2 Perrintence 59 
12 Input to the modeb 61

12.1 Output from HIRLAM 61

12.2 Output from WAsP 69

13 The neutral model 69

13.1 First-guess model 69

13.2 The resulting neutral model 70

13.3 Results $\% \gamma$

14 Model output statiatics 87

14.1 Sensitivity to the local corrections 88

14.2 Statistical properties of the observed data 88

14.3 Oth order system 89

14.4 Neural networks 89

14.5 Conclusions MOS 94

13 The stability-dependent model 96

15.1 The model 96

16 Other prediction methods $10 \mathrm{z}$

16.1 Statistical methods 102

16.2 Conclusion, statistical models 109

16.3 Using the UK Meso-scale model 105

17 Summary and conclusions 106

17.1 Comparing the 8 models 106

17.2 Conclusions 107

17.3 Using the models 111

Acknowled_ements 119

Dansk sammendrag 114

References 115

A Detalled liating of the stations 119

B The WAPP-matrices for ench otation 121

C Revalte station by station 136

C.1 The neutral HIRLAM/WNP model 196

C.2 The linear prediction model 110

C.3 Sensitivity to the local corrections 111

C.4 Directional dependent neural network for MOS 142

D The ereet of data resolution 149

\section{List of Figures}

1 Sketch of the planetary boundary layer (PBL). 11

2 Different neutral values of $A$ and $B$. 16

$3 \quad A(\mu) \quad 22$ 


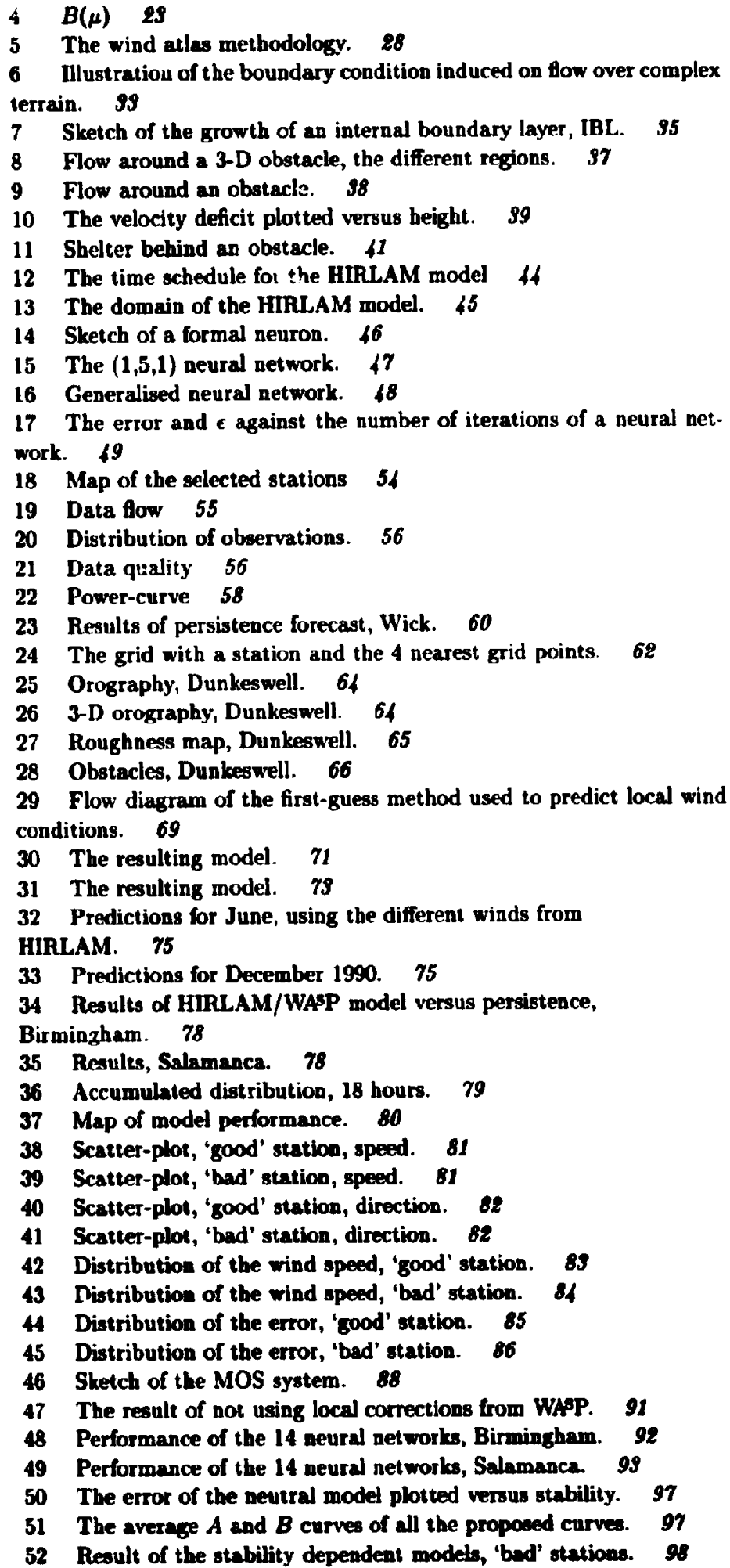


53 Result of the stability dependent models, 'good' stations. 99

$G$ plotted versus $u$. 100

Variation of model error and fluxes. 101

Sensitivity of linear model. 103

Sensitivity of neural network. 104

Comparison of HIRLAM and UK MESO. 105

Overview of the different prediction models. 106

Results Abbeville 108

Results Salamanca 108

Results Bragança 109

Results München 109

Results Manchester 110

Results Birmingham 110

The available forcasts from HIRLAM 111

7 The implementation of the neutral model. 112

\section{List of Tables}

1 Different empirical evaluations of the $A$ and $B$ functions,

stable. 21

2 Different empirical evaluations of the $A$ and $B$ functions, unsta-

ble. 22

3 The selected stations. 55

Roughness rose, Dunkeswell. 65

Obstacles, Dunkeswell. 66

Result file, Dunkeswell. 67

Prediction of RAF Dunkeswell. 68

Model score. 76

Yearly model comparison. 76

10 Statistical properties of the observations 91

11 The different neural networks used for MOS. 92

12 MOS resuits. 95

13 List of the stability dependeat models. 100

14 Country codes 119

15 Results BIRLAM/WAPP model. 196

16 Results HIRLAM/WAP model. 197

17 Results HIRLAM/WAPP model. 198

18 Results HIRLAM/WAS model. 199

19 Results from the linear prediction model. 140

20 The HIRLAM/WMPP model without the beal corrections. $1 / 1$

21 Results for the directional dependent neural network MOS model

$(1,5,1) . \quad 142$ 


\section{Introduction}

The purpose of this study is to develop and evaluate methods to predict the wind speed, but also the direction, locally. The maximal look-ahead time (ie the maximal forecast range) is $\mathbf{3 6}$ hours. The predictions can be used in many different situations, eg on the site of a wind farm or in connection with chemical, radioactive and biological warning systems. Most attempts to sclve this problem base themselves on statistical methods. This project will, however, use a physical model. Two 'tools' will be used:

- The High Resolution Limited Area weather prediction Model (HIRLAM) which was developed during the last few years as a joint effort between the mereo slogical institutes in Denmark, Finland, Iceland, Norway, Sweden and The Netherlands, see Machenhaver (1988).

- The siting model WASP which was developed at Ris National Laboratory in connection with the now completed European Wind Atlas project, see Troen and Petersen (1989) and Mortensen et al (1993)

The basic idea is that in order to make forecasts, a prognostic model is needed. This model must cover an area, which is so big, that within the maximal forecast range $(+36$ hours $)$ the weather systems that are found when the model is initiated are not advected out of the area, and its modelling powers must be such that it can model meteorological events happening in the area within its prediction range. A model that fulfills these criteria for Europe is the HIRLAM model.

Because of the size of the IImLAM model domain it is impossible now, and also in the nearer future, to obtain a resolution so fine that local effects, such as the speed-up on small hills, the shelter from obstacles, and the change in roughness lengths on a local scale (say tens to hundreds of metres) are modeled - if one wants to predict in real time. This is mainly limited by the available computer technology. Since the local effects are of crucial importance in calculating the wind locally, we introduce the WASP model, which takes exactly the effect of these phenomena into account. WASP is a diagmostic model, so it is necessary to use both models in order to make forecasts on a local scale.

The idea laid out bere is thus building on state-of-the-art models, ie the best models presently available. Whether using this is good enough for the applicatiuns is another question, this study will try to answer.

The reason why this work is carried out here and now, is that in the World, but within the European Community, especially, it is foreseen that an increasing amount of electricity will be produced by wind energy. To be able to harness this energy, it is necessary to know, in advance, the expected power produced by the wind energy plants. This is done in order to save conventional fuel (oil, gas) more efficiently.

In Part I the basic equations will be derived, Part II covers the applied models, and in Part III the forecasting model will be developed. The evaluation will also be done in Part III.

Since quite a few models are presented and tested, an overview of all the models is given in Section 16. 
Rino-R-T0e(EN) 


\section{Part I}

\section{Basic Equations}




\section{The geostrophic drag law}

The geostrophic drag law is a result of a merging (or matching) of the wind in two different layers of the atmosphere: the surface layer and the free atmosphere (see Figure 1). This matching is necessary because the wind is geostrophir (ie derived from the pressure field only) in the free atmosphere, and the geostrophic wind does not fulfill the boundary conditions at the surface (the no-slip condition). The exact mathematical solution to this problem, which will be given in the next section, is based on the singular perturbation method, and is very elegantly given in Blackadar and Tennekes (1968). For a short non-rigorous derivation, see Tennekes and Lumley (1983), Chapter 5. In passing, it should be mentioned that the results obtained in the following, were first found in a somewhat different form by Rossby and Montgomery (1935) in a very thorough paper.

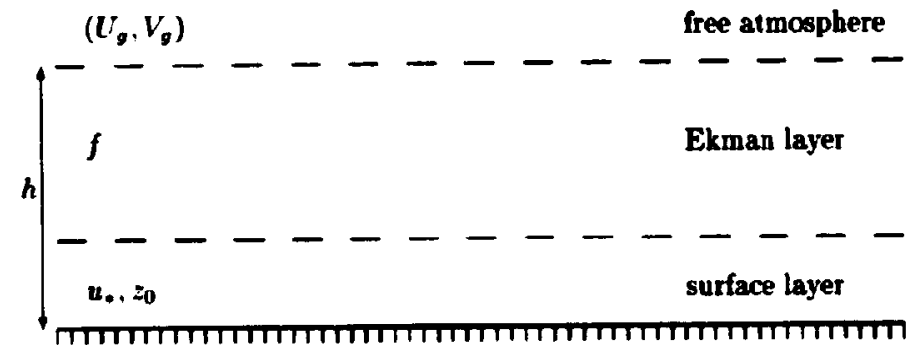

Figure 1. The planetary boundary layer (PBL) (or the atmospheric boundary loyer (ABL)) of height $h$ with its different layers, and some characteristic quantities having influence in each of the layers. Some name, what here is called the PBL, the Ekman layer, in that case the layer named the Ekman layer here, ws called the outer Ekman layer.

\subsection{The velocity-defect law}

The equations of motion in the free atmosphere (ie the part of the atmosphere where the presence of the surface is not felt), express the balance between the Coriolis force and the pressure gradient force, called the geostrophic balance, and are given by, assuming that the flow is steady, horizontal, berotropic', adiabatic (no heat is exchanged with the surroundings), and homogeneous in horizontal planes:

$$
-f V_{s}=-\frac{1}{\rho} \frac{\partial p}{\partial x}
$$

and

$$
f U_{s}=-\frac{1}{\rho} \frac{\partial p}{\partial y}
$$

where $\boldsymbol{f}=2 \Omega \sin \phi$ is the Coriolis parameter, $\mathbf{\Omega}$ the angular velocity of the Earth, $\phi$ the latitude. $U_{g}$ and $V$, are the $x$ - and $y$-components of the geostropbic wind, respectively, and $p$ the pressure.

\footnotetext{
IA harotropic atmoephere is an atmoephere where the density is a function of preasure only, $\rho=A(p)$, a oppoead to a buroclinic atmaphere where the dencity is a function of temperature, too. The implication of thin being that the thermal wind cquation give thet the gootrophic wied is emelant with height.
} 
Since theotrophic wiad does wot meet the no-elip boundary condition at the surface (ie that the wiad gpoed vaniabes there) a trancition layer mort exiat, where the wiad adjuets to this cosdition. This layer is called the Bthen layer (ct Figure 1). The equations of motion in this layer are given by

$$
-f V=-\frac{1}{\partial z} \frac{\partial_{p}}{\partial z}+\frac{d}{d z}(-\mathrm{Ex})
$$

and

$$
f U=-\frac{1}{\rho} \frac{\partial_{p}}{\partial y}+\frac{d}{d x}(-\bar{w})
$$

where $U$ and $V$ are the $x$ - and $y$-component of the actud wind, and $\bar{E}$ and wis are the correlation of the $x$ - and $y$-conponent of the fuctuation of the boriontal wind with the vertical wiad, respectively. Thene quantitiea are aloo called the Reysolds ctreases. If is through the Reyould streases, that the presence of the surfince is felt. Using the expression for the geostrophic wiad, the equations can be rewritten

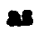

$$
-f\left(V-V_{0}\right)=\frac{d}{d z}(-w)
$$

and

$$
f\left(U-U_{0}\right)=\frac{d}{d z}(-U w)
$$

We anoune that the coordinate-system is rotated in such a way that, at the surfince, the stres vector bas no y composent, so that in the limit, $z \rightarrow 0$,

$$
-\overline{v 0}=u_{*}^{2}, \quad \text { and, } \quad-\overline{v 0}=0
$$

Gewerally, when tow in the wicinity of a boundary is considered, it is posible to detive a law, dearribing the behavior of the nom-dimensionalised difierence between the velocity (properly acaled) in the layer infuenced by the boundary and the velocity in the aninfeenced loser a a function of the characteristic scales, this type of buw is called a velacity-defect bow, and has the form

$$
\frac{\left(U-U_{0}\right)}{U_{0}}=F(\eta)
$$

where $n$ is a nom-dimensional measure of the distance from the boundary, and $u$. - is this cane - is a characterintic velocity ecale.

We proced by trying to fad the approprinte scales for the equations govening the for in the atwophere. For the velocition we anume that the friction velocity,

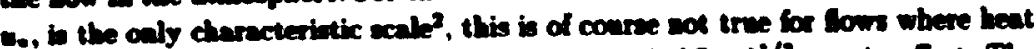

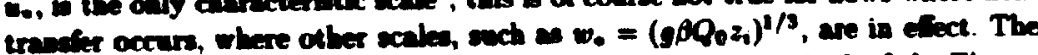
Reysold atrenes are of ordex $u^{2}$. As a scatiog weidt, the beight $h$ of the Ekman

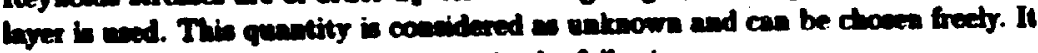
is eor ponible to scale the equations in the following way:

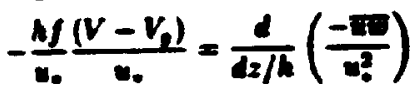

and

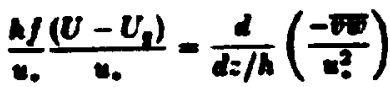

the beight $h$ is chowen to be

$$
h=c \frac{e}{f}
$$

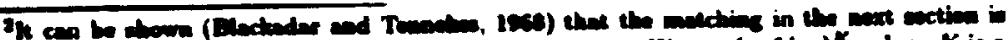

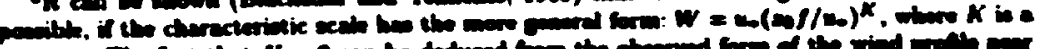

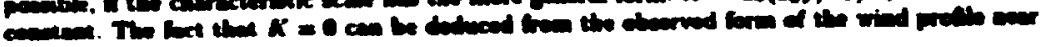
oneresen. 
where $c$ is a constant. Now it can be seen that Eqp. 9 and 10 can be written as a velocity defect law

$$
\frac{U-U_{Q}}{u_{*}}=F_{u}\left(z f / u_{*}\right)
$$

and

$$
\frac{V-V_{2}}{w_{*}}=F_{*}\left(z f / w_{0}\right)
$$

Instead of using the geostrophic wind, the actual wind components at the top of the PBL can be used, see of Byrun (1991) and Clarke and Heos (1974).

\subsection{The law of the wall}

Generally, it is also possible to derive a non-dimensional relation for the sume kind of tow as the one mentioned in the previous section, for the velocity in the flow in the layer directly affocted by the boundary, this relation is called the law of the wall, and has the general form:

$$
\frac{U}{u}=f(\alpha)
$$

where $a$ is a dimensionkes distance parameter.

In the surface layer the proper height scale is not $h$, because now the flow is under influence of the presence of the rough surfice. Ruther, the beight scale is the roughness length $z_{0}$, if the condition that $z_{0} w_{.} / \nu>1$ is fulfilled, where $\nu$ is the kinematir viamaity. $\nu / u$. is another combination of characteristic scales that has the dimension of a length. Now the nondimensional equations of motion in the boundary layer read

$$
-\frac{z_{0} f}{u_{0}^{2}}\left(V-V_{1}\right)=\frac{d}{d z / z_{0}}\left(\frac{-\pi}{w_{0}^{2}}\right)
$$

and

$$
\frac{z_{0} f}{u_{0}^{2}}\left(U-U_{0}\right)=\frac{d}{d z / z_{0}}\left(\frac{-w_{0}}{u_{0}^{2}}\right)
$$

Detennining the order of the kef-hand side of the equations, using atmospheric vales, gives that it is small ( $O$ order $3 \times 10^{-4}$ ), so amall that the beft-hand side can be set equal to sero. This leads to the fact that the surface layer is a layer of cometand streas, and thereby independent of the Coriolis parameter, $f$. To male the picture of the surface layer complete, it has to be noted that at the surficce the frictional force is balasced solely by the presure gredient force, see Arya (1835). The ouly independent mom-dimenaional parameter leh is $2 / 20$. The law of the wall thesefore reads, remermbering that the cocrdiante syatem is rotated so that the $y$ component of the atrese at the surfece is sero

$$
\frac{U}{u_{*}}=f_{u}\left(z / z_{0}\right)
$$

and

$$
\frac{v}{u_{0}}=0
$$




\subsection{The matched equations}

Matching the two lawa derived in the previous sections is done by using the fact that there exists a layer where the equations dewcribing the large-scale fow and the small-acale fow are valid simultaneousty (see es Blackadar and Tennebes, 1938). This layer, called the matched layer, is situated at the bottom of the Ekman layer, and at the top of the surface layer (cf. Figure 1). Its existence is based on Kaplun's extension theorem (Van Dyke, 1964).

The following notation is nom introduced:

$$
\left.\zeta=\frac{z}{z_{0}}, \quad \frac{z_{0} f}{u_{*}}=\phi(R)\right), \quad \frac{z f}{u_{*}}=\zeta \phi
$$

where $R_{0}=G f / z_{0}$ is the Roesby number, and $G$ the modulus of the gecotroptic wind.

The two expressions for $U / \%$, are now matched, by incerting the equations for the law of the wall into the equations for the velocity defect law:

$$
F_{v}(\zeta \phi)=f_{v}(\zeta)-\frac{U_{l}}{u_{0}}
$$

Doing a partial differentiation with respect to the two independent variables, Ro and $C$, we get

$$
\partial / \partial \zeta: \quad \phi F_{u}^{\prime}(\zeta \phi)=f_{u}^{\prime}(\zeta)
$$

and

$$
\partial / \partial R_{0}: \quad \zeta \frac{d \phi}{d R_{0}} F_{v}^{\prime}(\zeta \phi)=-\frac{d}{d R_{0}}\left(\frac{U_{\ell}}{u_{0}}\right)
$$

where prime indicates differeatiation of the function with respect to its argument. Eliminating $F_{*}^{\prime}$, gives

$$
\zeta f_{L}^{\prime}(\zeta)=-\left(\frac{d \ln \phi}{d R o}\right)^{-1} \frac{d}{d R o}\left(\frac{U_{Q}}{u_{*}}\right)
$$

It can be seen from this equation that the left-hand side is only a function of $\zeta$, and the right-hand side only of Ro. This implies that the two sides are constant. The constant is traditionally set equal to $1 / \kappa$. If the left-hand side of the equation is integrated with reopect to $\zeta$ from $\zeta_{0}\left(=z_{0} / L\right)$ to $\zeta$, and inserted in Eq. 16, and the difierential equation on the right-band side is solved, we get

$$
\begin{aligned}
& \frac{U}{u_{0}}=\frac{1}{\alpha} \ln \left(\frac{z}{z_{0}}\right)+C \\
& \frac{v_{2}}{u_{0}}=\frac{1}{\alpha} \ln \left(\frac{z_{0}}{f z_{0}}\right)-\frac{A}{\alpha}
\end{aligned}
$$

The bogarithmic profile is ideatified in Dq. 18 by setting $C=0$. It therefore reads:

$$
\frac{U}{u_{0}}=\frac{1}{x} \ln \left(\frac{z}{2}\right)
$$

where $\alpha$ is the Von Karmed conetent equal $100.4 \pm 0.01$ (Hogetrom, 1938).

Matching oon the equations for the y-conponeat of the wiad, it is wew that siace $V$ vanisbes at the surfice, $F$, muin be equal to a contant:

$$
\frac{V_{Q}}{u}=-\frac{B}{\pi}
$$

It in sow posible to derive an equation for the magnitude of the geoctrophic wiad, $G=\sqrt{U_{q}^{2}+V_{g}^{2}}$, by combining Bq. 19 and $21^{3}$ :

$$
\frac{G}{u_{0}}=\frac{1}{\kappa} \sqrt{\left[\ln \left(\frac{\omega}{f \nu_{0}}\right)-A\right]^{2}+B^{2}}
$$

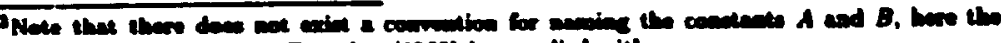

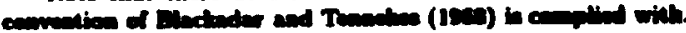


this equation is called the geostrophic drag law. The angle, $a$, between $G$ and the x-axis (pointing in the direction of the velocity at the surface) is given by

$$
\tan \alpha=+\frac{V_{0}}{U_{0}}=\frac{-B}{\ln \left(\frac{y_{2}}{x_{0}}\right)-A}
$$

To resolve any directional ambiguity this angle is compared with the angle calculated by

$$
a=\sin ^{-1}\left(\frac{V_{0}}{G}\right)=\frac{-B}{\sqrt{\left[\ln \left(\frac{u_{0}}{f z_{0}}\right)-A\right]^{2}+B^{2}}}
$$

Another way of writing the dras law, aloo found in the literature, is

$$
\ln R_{0}-A=\sqrt{\left(\frac{\kappa G}{u_{*}}\right)^{2}-B^{2}}-\ln \frac{u_{*}}{G}
$$

and

$$
\sin \alpha=\frac{-B}{\kappa} \frac{w_{0}}{G}
$$

As can be seen form $E_{4} 22$ is it not possible to use the drag law at (or near) Equator, where $f=0$. In WAsP (described later) this is handled by setting all lattitudes, less than \pm 5 degrees equal to plus or minus 5 . Whether this can be justified in this study, has not been tested, since no stations near Equator were available.

\section{The neutral value of $A$ and $B$}

A great deal of experiments have been carried out to determine the neutral values of the two constants, $A$ and $B$, in the geostrophic dras law, see es Clarbe and Hese (1974) (the Wangarn experiment) and Billard et al (1981) (the 'VOVES' experiment). A complete overview of these estimates up until 1988 is given by Zilitinlevich (1989), these values are plotted in Figure 2. In this figare the average values of these $A$ 's and $B$ 's (1.7 and 4.5, respectively) are abo plotted. It is inferesting to note that no single experiment fods these vilues. In another recent study by Troen and Petersen (1909) it is found that the beat fit to the data from the stations in the Europena Wind Atlas is obtained with

$$
A=1.8 \text { and } B=4.5
$$

thin point is also shown in the figure. It is this last get of values that will be

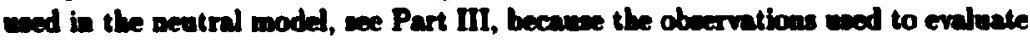
the model are then from this sot of stations and becase the stations are reprecentative of a wide range of landecapea, areas dominated by bocal-thermal efects ac. 


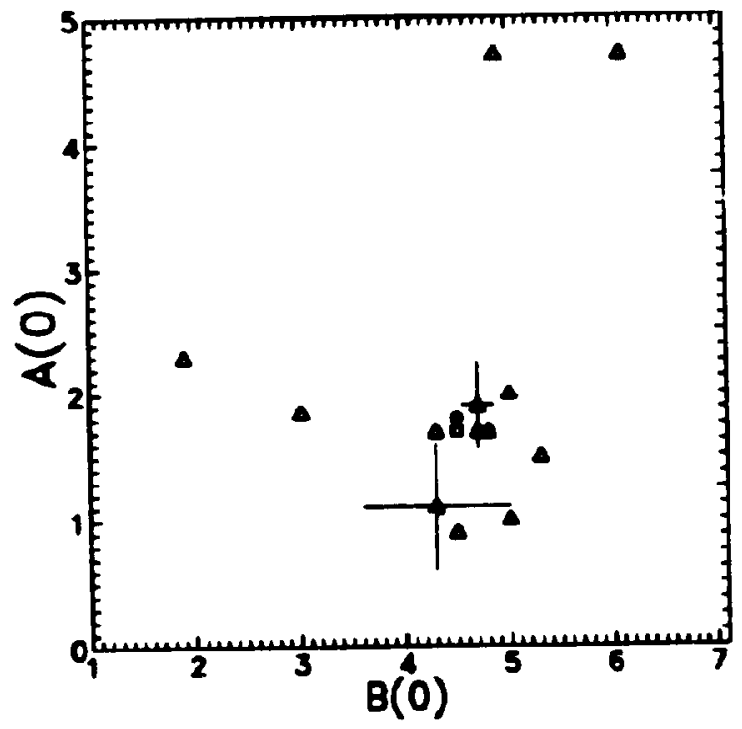

Figne 2. Different newind wabues of $A$ and $B(\Delta)$ from zibitinbevich (1Sas). The moen whe of these is marbed by $D$. Purthermore, the value found by Thoen and Petereen (1989) is shown (0). In two of the experiments, (Descon, 1975, end Clerte and Hess, 1971), en eatimate of the experimental scatter was deo given, these are shown if the horimontal and wertical tines. 


\subsection{Theory for the stability dependence of $A$ and $B$}

The stability dependence of $A$ and $B$ have been derived by several using the matching technique, see eg Csa nady (1972) and Zilitinkevich (1975). The following is derived along the lines in Long and Guffey (1977), since they have reported their derivation in some detail.

The stability dependence of the drag law is given by the variation of $A$ and $B$ with stability, as proposed by Kazansti and Monin (1960), in their Rossby similarity theory'. Another competing theory is the similarity theory proposed by Deardorf (1972), the major diference between this and the Rossby similarity theory is that in the latter, the height of the boundary layer, $h$, is considered as an independent variable. This latter line of thoughts is not followed here, because there is evidence based un measurements (see Clarke and Hess, 1974) that scaling the height by $u_{*} / f$ is more relevant than by $h$. Furthermore, because of the layered structure and relatively coarse resolution of any (gridpoint-based) numerical model, it is difficult to get an accurate estimate of $h$. An objection to the Rossby similarity theory is that due to the action of the buoyancy source at the surface, and the thereby connected origin of an unstable stratified zone, it is very unlikely that the PBL will reach an equilibrium height in daytime unstable conditions (see eg Byun, 1991 and Zilitinkevich, 1989). Despite these arguments Arya (1975) compares $A$ and $B$ as functions of $\mu$ and $\mu_{1}=h / L$ and finds (in agreement with Clarke, 1970, and Billard et al, 1981) that there is no improvement in the correlation of empirical data, when using $\mu_{1}$ instead of $\mu$. The equations therefore reads

$$
\begin{aligned}
& \frac{U_{0}}{u_{*}}=\frac{1}{\kappa} \ln \left(\frac{u_{*}}{f z_{0}}\right)-\frac{A(\mu)}{\kappa} \\
& \frac{v_{g}}{u_{*}}=-\frac{B(\mu)}{\kappa}
\end{aligned}
$$

where the stability parameter is defined as $\mu=\kappa u_{0} / \int L ; L=u_{*}^{3} / \kappa\left|B_{0}\right|$ the Monin-Obukhow lengths, and $B$, the near-surface value of the vertical buoyancy tux, defined as

$$
B_{1}=\beta \frac{H_{S}}{c_{p} \rho}+0.608 \frac{g H_{L}}{L_{c} \rho}
$$

where $\beta=g / \theta$ is the buoyancy parameter, $H_{S}$ the sensible heat flux, $c_{p}$ the heat capacity of air at constant pressure, $\rho$ the density, $g$ the fravitational acceleration, $H_{L}$ the latent heat flux, and $L_{c}$ the latent beat of condensation.

The atmoephere is now divided into 3 regions: $R_{1}: 2 \sim z_{0}, R_{2}: 2 \sim L$, and $R_{3}: z \sim h$, where $h$ is the beight of the planetary boundary layer. The governing equation in region $R_{1}$ is the law of the wall, Eqs. 16 and 17 . In region $R_{2}$ the equation is a velocity defect law similar to Eqs. 12 and 13 , given by

$$
\frac{U-\Delta U}{u_{*}}=x(\zeta), \quad \frac{V}{u_{*}}=0
$$

where $\Delta U=U(z=L)$ is the value of the mean wind at $z=L$ and $\zeta=z / L$. It is assumed that $z_{0}<L<h$, thereby excluding the near-neutral case (where $L>h)$.

Matching the equations in $\boldsymbol{R}_{1}$ and $\boldsymbol{R}_{2}$, ie using the principle laid out in the previous section, acsuming that

$$
\frac{\Delta U}{u_{*}}=m_{1}(\eta, \mu)
$$

\footnotetext{
Tor completesen it should be memioned that the stability dependence of the temperature profiles is found to be dependeat on a third function: $C$. Not to be confued with the conateat $C$ in the previous extion.

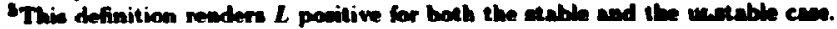


where $\eta=2_{0} / L$, which is a quite general expreasion, gives the logarithmic profile for the mean wiad, $U$, see Eq. 20. For $\Delta U$, the following equation is found

$$
\frac{\Delta U}{u_{*}}=\frac{1}{\kappa} \ln \eta+A_{1}
$$

where $A_{1}$ is a universal constant. As can be seen from this, $\Delta U / u$. does not explicitly depend on stability.

Differentiating the logarithmic profile with reapect to $z$, gives

$$
\frac{z U^{\prime}}{u_{*}}=\frac{1}{x}
$$

In region $R_{3}$ the velocity defect law can generally be written

$$
\frac{U-\Delta U}{u_{\bullet}}=F\left(\frac{f z}{\kappa u_{*}}, \mu, \eta\right)
$$

Since $\boldsymbol{\mu}$ is very large and $\boldsymbol{\eta}$ very small, they can be neglected in $F$ by doing a proper scaling of the velocity defect and the beight. $\eta$ (ie 20 ) is not a scaling parameter in this case, but $\mu$ is. We therefore write

$$
\frac{U-U_{2}}{u_{*}}=\mu^{n_{1}} F_{*}\left(\frac{f z}{\kappa u_{*} \mu^{2}}\right), \quad \frac{V-V_{q}}{u_{*}}=\mu^{n_{1}} F_{*}\left(\frac{f z}{\kappa u_{*} \mu^{2}}\right)
$$

where $h=\kappa u_{*} \mu^{*} / f$. The same exponent $\left(n_{1}\right)$ on the multipliers of $F_{w}$ and $F_{u}$ have been used, because contrary to regions $R_{1}$ and $R_{2}$, tha two components of the wind is expected to be of the same order of magnitude in $\boldsymbol{R}_{3}$.

Generally the gecostrophic wind can be written

$$
\frac{U_{2}}{u_{*}}=p_{1}(\mu, \eta), \quad \frac{V_{2}}{u_{*}}=p_{2}(\mu, \eta)
$$

In region $R_{2}$ it can be seen from Eq. 29 that $U^{\prime}$ is not a function of $z_{0}{ }^{\circ}$. Therefore $U^{\prime}$ can be written as a function of $\zeta$ only:

$$
U^{\prime}=\frac{\kappa}{u_{*}^{2}} f(\zeta), \quad V^{\prime}=0
$$

Integrating from $\zeta=1$ to $\zeta$ using Eq. 31 we get

$$
\begin{aligned}
& \frac{U}{u_{*}}=f_{1}(\zeta)-\frac{1}{\kappa} \ln \eta+A_{1} \\
& \frac{V}{u_{*}}=0
\end{aligned}
$$

where

$$
f_{1}(\zeta)=\int_{1}^{\zeta} f(\zeta) d \zeta
$$

with $f_{1}(1)=0$.

So far it has nol mattered whether the atmosphere was stable or unstable, from nom on, however, a dietinction has to be made.

The unatable cace

Uaing similarity arguments dating back to Prandt] (1932) and Pricatly (1959), the function $f_{1}$ for an soa-roluting, unatable atmonphere can be written

$$
f_{1}(\zeta)=B_{1}\left(\zeta^{-1 / 3}-1\right)
$$

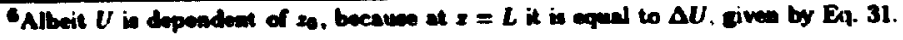


where $B_{1}$ is a universal constant. Using this and matching regions $R_{2}$ and $R_{3}$, we get

$$
\begin{aligned}
& \mu^{n_{1}} F_{2}\left(\frac{\zeta}{\mu^{\alpha+1}}\right)=B_{1}\left(\zeta^{-1 / 3}-1\right)-\frac{1}{\kappa} \ln \eta+A_{1}-p_{1}(\mu, \eta) \\
& \mu^{n_{1}} F_{v}\left(\frac{\zeta}{\mu^{\alpha+1}}\right)=-p_{2}(\mu, \eta)
\end{aligned}
$$

Diferentiating these with respect to $\eta$, gives

$$
\frac{\partial p_{1}}{\partial \eta}=-\frac{1}{\kappa \eta}, \quad \frac{\partial p_{2}}{\partial \eta}=0
$$

Integrating, assuming that $p_{1}(\mu, \eta)$ can be regarded as a combination of two functions, the one being dependent on $\eta$, and the other, $\gamma_{1}$, on $\mu$, yields

$$
p_{1}(\mu, \eta)=-\frac{1}{\kappa} \ln \eta+A_{1}-B_{1}+\gamma_{1}(\mu)
$$

Hence the equations in the matched region are

$$
\begin{aligned}
& \mu^{n_{1}} F_{u}\left(\frac{\zeta}{\mu^{\alpha+1}}\right)=B_{1} \zeta^{-1 / 3}-\gamma_{1}(\mu) \\
& \mu^{n_{1}} F_{v}\left(\frac{\zeta}{\mu^{2+1}}\right)=-p_{2}(\mu)
\end{aligned}
$$

Eliminating $F_{\mathrm{u}}$ by cross-differentiation with respect to $\zeta$ and $\mu$ gives

$$
n_{1}\left[B_{1} \zeta^{-1 / 3}-\gamma_{1}(\mu)\right]+\gamma_{1}^{\prime}(\mu) \mu=-\frac{1}{3}(s+1) B_{1} \zeta^{-1 / 3}
$$

Comparing terms dependent on $\zeta$ reveals that $n_{1}=-\frac{1}{3}(s+1)$, and of $\mu$ that $\gamma_{1}=D_{1} \mu^{-f(s+1)}$, where $D_{1}$ is an universal constant. Combining Eqs. 35 and 43 yields

$$
\frac{U_{2}}{u_{*}}=\frac{1}{\kappa} \ln \left(\frac{L}{z_{0}}\right)+A_{1}-B_{1}+D_{1} \mu^{-\$(\cdot+1)}
$$

Comparing this with Eq. 26, the following expression can be derived

$$
A(\mu)=\ln \mu+a_{1 \mu}+\beta_{1 \mu \mu}-\$(s+1)
$$

where $\alpha_{1 \mathrm{x}}=\ln \kappa-\kappa\left(A_{1}-B_{1}\right)$ and $\beta_{1 x}=-\kappa D_{1}$. For the $y$-component it can be seen from Eq. 45 that $F_{v}=$ constant $=-D_{2}$, where $D_{2}$ is a univeral constant. Inserting this in Eq. 34 and comparing with Eq. 27 leads to

$$
B(\mu)=\beta_{2 \kappa} \mu^{n_{1}}
$$

mbere $\beta_{2 u}=-\kappa D_{2}$.

To close the unstable case a determination of $s$ is needed: The equation of motion can be written

$$
\frac{d T_{z}}{d z}=-f\left(V-V_{g}\right)
$$

where the kinematic momentum fux is given by $r_{z}=-\overline{u^{\top} w^{\prime}}$. Integrating from $z=0$ to $z=h$, and using the fact that $\tau_{*}$ vanishes at $h$ by definition, gives

$$
-r_{x}(z=0)=-f \int_{0}^{h}\left(V-V_{0}\right) d z
$$

Estimating the integral by using Eq. 34 it is found to be of order $u_{*} \mu^{n} h$, this jields

$$
u_{*}^{2} \sim f w_{*} \mu^{n_{1}} h
$$

since $-r_{z}(z=0)=z_{0}^{2}$. Using that $h$ is of order $v_{*} \mu^{*} / f$ gives

$$
u_{0}^{2} \sim u_{0}^{2} \mu^{n_{1}+1}
$$


the conclusion of this being that $n_{1}=-s$. Note, that this is not dependent on stability, and is therefore valid for both the stable and the unstable case.

For the unstable case (where $\left.n_{1}=-\frac{1}{3}(s+1)\right) n_{1}=-\frac{1}{2}$ and $s=\frac{1}{3}$, and the stability dependent similarity functions can be written ${ }^{7}$

$$
\begin{aligned}
& A(\mu)=\ln \mu+\alpha_{1 u}+\beta_{1 * \mu^{-1 / 2}} \\
& B(\mu)=\beta_{2 u} \mu^{-1 / 2}
\end{aligned}
$$

\section{The stable case}

The derivation for the stable case proceeds much like that for the unstable case; the matching of $R_{1}$ and $R_{2}$ gives the logarithmic profile:

$$
\frac{U}{u_{*}}=\frac{1}{\kappa} \ln \left(\frac{z}{z_{0}}\right)
$$

and

$$
\frac{\Delta U}{u_{*}}=-\frac{1}{\kappa} \ln \eta+E_{1}
$$

where $E_{1}$ is a universal constant. Using the theory of Obukhov (1946), that as $z / L$ becomes large, $U^{\prime}$ becomes a constant, and therefore that $U$ can be written as a constant times $\zeta$, yields

$$
\frac{U}{u_{*}}=-\frac{1}{\kappa} \ln \eta+E_{1}+F_{1}(\zeta-1)
$$

with $F_{1}$ being a universal constant. Matching now regions $R_{2}$ and $R_{3}$ gives

$$
\begin{aligned}
& \frac{U_{1}}{u_{*}}=-\frac{1}{\kappa} \ln \eta+E_{1}-F_{1}+H_{1} \mu^{s+1} \\
& \frac{V_{q}}{u_{*}}=H_{2} \mu^{*+1}
\end{aligned}
$$

where the exponent of $s+1$ comes about using the fact that $h / L \sim \mu^{s+1}$, and therefore that $n_{1}=s+1$ for the stable case, $H_{1}$ and $H_{2}$ are universal constants, using that $n_{1}=-s$, it can be seen that for the stable case $n_{1}=\frac{1}{2}$ and $s=-\frac{1}{2}$. Comparing these equations to Eqs. 26 and 27, the similarity functions for the stable atmosphere reads

$$
\begin{aligned}
& A(\mu)=\ln \mu+a_{1, \mu}+\beta_{1, \mu} \mu^{1 / 2} \\
& B(\mu)=\beta_{2, \mu^{1 / 2}}
\end{aligned}
$$

where $\alpha_{1 s}=-\ln \kappa-\kappa\left(E_{1}-F_{1}\right), \beta_{18}=-\kappa H_{1}$, and $\beta_{20}=-\kappa H_{2}$.

\subsection{Empirical expressions for $A(\mu)$ and $B(\mu)$}

Havng the grent scatter of the experimental values of $A$ and $B$ 's neutral value in mind, we now proceed to obtain estimates of the stability dependence of theoe two coeficients. This is important since the atmosphere is very seldom in a nevtral state, and the efiect of stability on the fow, expecially the direction, is strong. Here

$$
\mu=\frac{\kappa u_{n}}{|f| l}
$$

is used as a measure of atability, where $\kappa_{*} w_{-} / f$ is the boundary layer beight, and $L=$ $-n_{*}^{3} / K B_{\text {, is }}$ the Monin-Obuthor length. Note that this is the standard definition

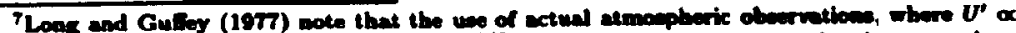

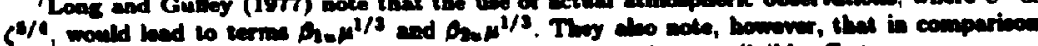

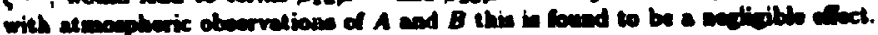


of $L$, so now $L$ is positive for stable conditions and negative for unstable, because $B_{2}$ is positive, when the fux is directed upwards.

In order to determine the stability dependence of the $A-, B$-, (and $C$-) functions a number of experiments have been carried out, many of which can be found in the list of experiments to determine the neutral value of $A$ and $B$. There are two 'classical' expetiments: the WANGARA experiment near Hay, Australia (see Clarke et al, 1971, for details) analysed by Clarke and Hess (see eg Clarke and Hess, 1974), and the Great Plains experiment carried out near O'Neil. Nebraska (see Lettau and Davidson, 1957, for details) analysed by Zilitinkevich and Chalikov (1968). However, the two stability dependent functions found in these two papers differ significantly, originally explained by the large experimental scatter. This issue was taken up by Arya (1975) who completely reanalysed the twc data sets, including a procedure to reject 'bad' runs, and he found that the scatter was significantly reduced. The functional dependence of $A$ and $B$ on stability found by Arya (1975) is given in Table 1 for the stable case, and in Table 2 wr the unstable case. The functions are fitted to the WANGARA data, whi h as: found to be taken in a more homogeneous terrain than the Great Pl: it: clata. Note again that the neutral values of $A(=1.01)$ and $B(=5.14)$ are ditrercalt 'rom the ones conmonly used.

There have been a number of other attempts, theoretical as well as experimental, to determine $A(\mu)$ and $B(\mu)$, the results of which are shown in Table 1 for the stable atmosphere and in Table 2 for the unstable atmosphere

Table 1. Dhfferent empirical evaluations of the $A$ and $B$ functions in Egs. 26 and 27, for the stable case.

\begin{tabular}{ll}
\hline Arya (1975) & $A(\mu)=1.01-0.105 \mu-9.9 \times 10^{-4} \mu^{2}+8.1 \times 10^{-7} \mu^{3}$ \\
& $B(\mu)=5.14+0.142 \mu+1.17 \times 10^{-3} \mu^{2}+3.3 \times 10^{-6} \mu^{3}$ \\
Arya (1977) & $A(\mu)=2.96+\ln \mu^{1 / 2}-1.52 \mu^{1 / 2}$ \\
& $B(\mu)=1.1+1.82 \mu^{1 / 2}$ \\
Billard et al (1981) & $A(\mu)=-0.024 \mu-1.67$ \\
& $B(\mu)=0.051 \mu+8.06$ \\
Jensen et al (1984) & $A(\mu)=1-1.58 \mu^{1 / 2}$ \\
& $B(\mu)=5+1.58 \mu^{1 / 2}$ \\
Long and Guffey (1977) & $A(\mu)=\ln \mu+23.3-5.28 \mu^{1 / 2}$ \\
& $B(\mu)=2.55 \mu^{1 / 2}$ \\
Zilitinkevich (1975) & $A(\mu)=\ln \mu-4 \mu^{1 / 2}$ \\
& $B(\mu)=4 \mu^{1 / 2}$ \\
Zilitinkevich (1989) & $A(\mu)=\ln \left(1+0.88 \mu^{1 / 2}\right)-2.55 \mu^{1 / 2}+1.7$ \\
& $B(\mu)=1.76 \mu^{1 / 2}+4.5$ \\
\hline
\end{tabular}

- linear regreasional fit to data.

Note, that the Zilitinkevich curves are from the O'Neil data at, before the correction by Arya (1973).

Not shown in figures since only the dependence in the atable cawe is given.

Here two things are worthwhile taking notice of: firstly, that the functions are discontinuous in zero (neutral), and secondly, that again the neutral values are not equal to the ones normally choses. Note, however, that in cases of near-neutral stability, the neutral version of the drag law should be used. A plot of the different $A$ 's and $B$ 's is shown in Figures 3 and 4.

As can be seen from both figures, the diferent functional expressions give somewhat different results. Since this is the case, and there exists no single commonly acknowledged profile, it has been found necessary to test all these different modets, in order to find the one that will give the best rasults for the set of stations 
Table 2. Different empirical evaluations of the $A$ and $B$ functions in Eqs. 26 and 27, for the unstable case.

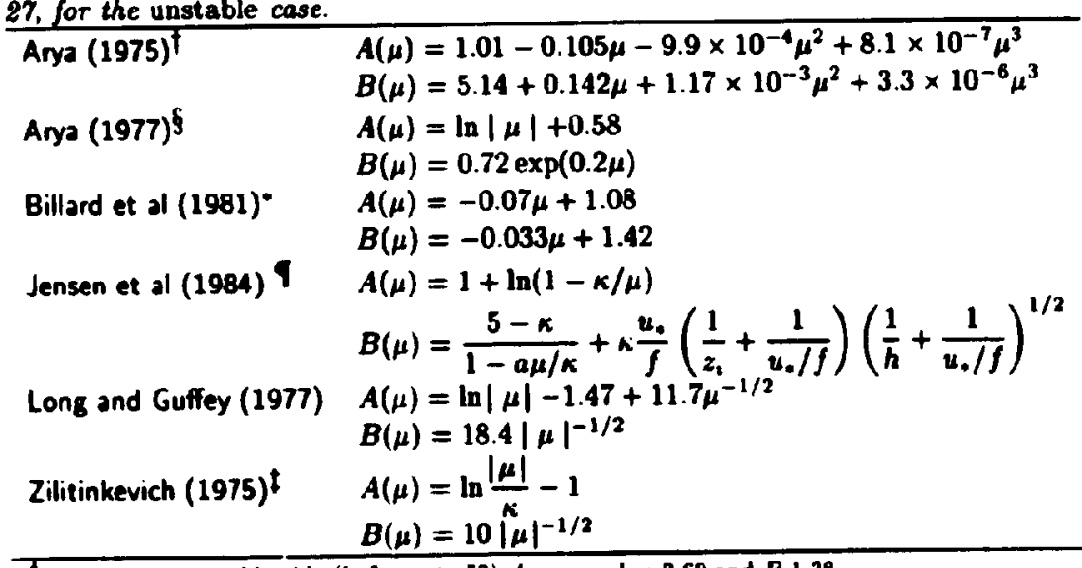

Fon the very unstable side (ie for $\mu<-50$ ) $A$ approaches 3.69 and $B 1.38$.

Where the $h$ in the paper has been approximaled with au. /f.

- linear regreacional fit to data.

$T_{a}=1 / 25$.

I Note that the Zilitinkevich curves are from the O'Neil data set, before the. correction by Arya (1975).

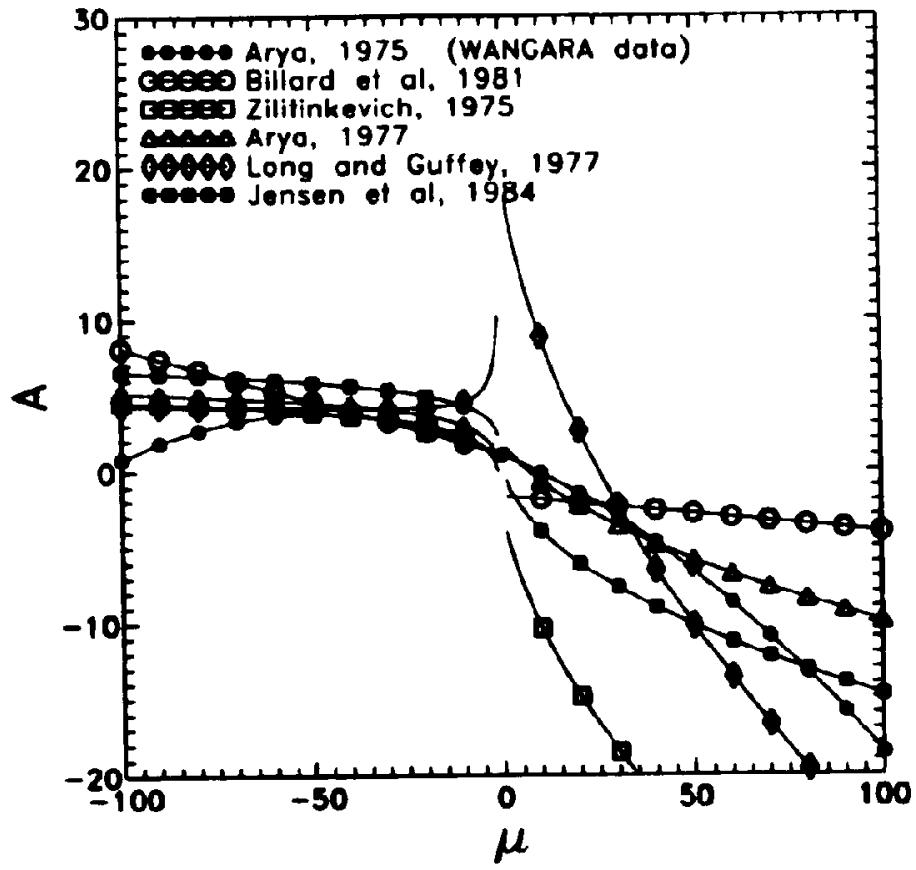

Figure 3. The functional dependence of $A$ on stability, $\mu=\kappa u, /|f| L$. 


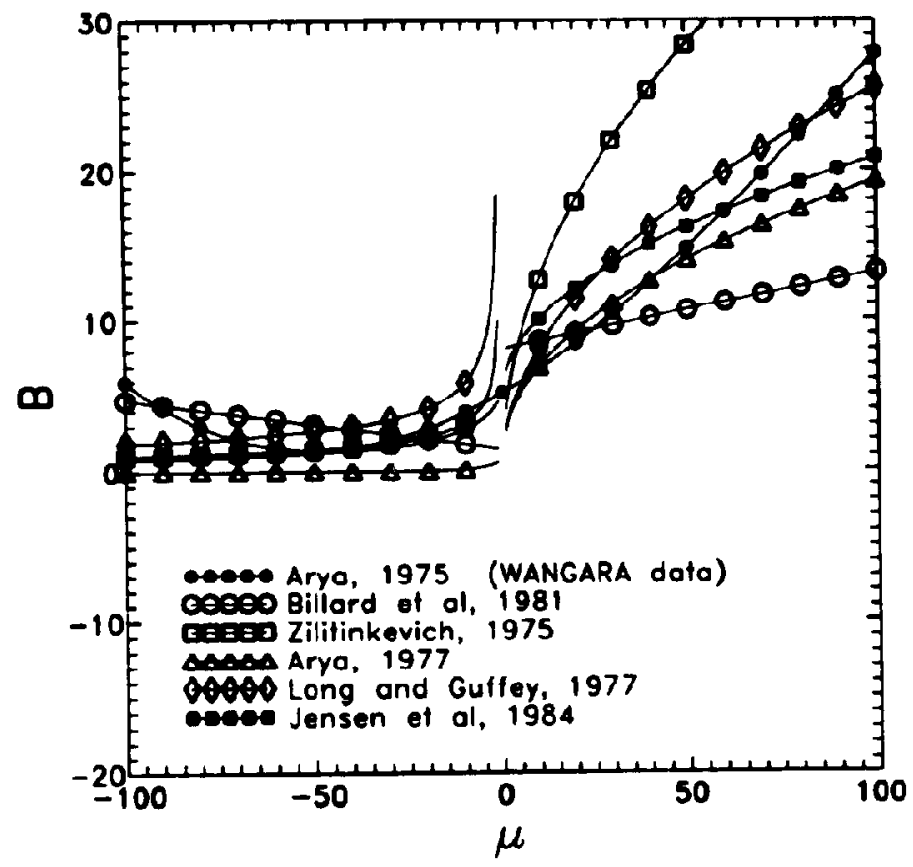

Figure 4. The functional dependence of $B$ on stability, $\mu=\kappa u_{*} /|f| L$.

studied here. This will be done in Part III.

\section{Influence of baroclinicity}

Many researchers (sec eg Yordanov and Wippermann, 1972) have suggested that the large scatter still present can be lessened by including baroclinicity dependence in the $A$ and $B$ functions, viz. $A=A(\mu, S)$, and $B=B(\mu, S)$, where

$$
\mathbf{S}=\left(S_{x}, S_{y}\right)=\frac{\kappa^{2}}{f}\left(\frac{\partial w_{e}}{\partial z}, \frac{\partial v_{q}}{\partial z}\right)
$$

represents the linear effect of baroclinicity. Billard et al (1981) tried to take this effect into account, and they conclude that it is not very likely that baroclinicity is an important parameter in Rossby similarity theory. They note also, however, that their conclusions are based on a rather limired set of data, and as a consequence of this that more experimental evidence is needed to sustain their statement. Clarke a) : Hess (1974) assumed that $A$ and $B$ depend on baroclinicity in the following way:

$$
A^{\prime}=\frac{\partial A}{\partial \mu} \mu^{\prime}+\frac{\partial A}{\partial S_{x}} S_{x}^{\prime}+\frac{\partial A}{\partial S_{y}} S_{y}^{\prime}
$$

and

$$
B^{\prime}=\frac{\partial B}{\partial \mu} \mu^{\prime}+\frac{\partial B}{\partial S_{x}} S_{x}^{\prime}+\frac{\partial B}{\partial S_{y}} S_{y}^{\prime}
$$

The least-squares lechnique is used to determine the coeficients. Clarke and Hess (1974) emphasise that these values are tentative, because of measurement dificulties and the effect of unsteadiness in the atmosphere. They compare their values to the ones found by Wippermann (1972) and find considerable disagreement; they find qualitative agreement with Blaclondar (1965) and Fiedler (1972). Because of 
the weak dependence (maximum value of the coeficients is $\approx 0.2$ ) and the dis. agreement found in the literature, the effect of baroclinicity will not be taken into account in this study.

\subsection{Stability dependence of the velocity profile}

Contrary to the $A$ - and $B$-function there is better agreement concerning the stability dependence of the velocity profile. The most recent and reliable profiles are the ones given by Högström (1988). They have been found by using reported profiles from almost all known measurements, and modified to take dynamical flow distortion into account, since this is suspected to be the single major cause of the differences in the different profiles. The profiles are given by:

$$
\frac{z}{u .} \frac{\partial u}{\partial z}=\frac{1}{\kappa} \phi_{m}(\zeta)
$$

where $\zeta=z / L$ is a non-dimensional measure of stability, and

$$
\phi_{m}= \begin{cases}1+4.8 \zeta & \text { for } \zeta \geq 0 \\ (1-19.3 \zeta)^{-0.5} & \text { for } \zeta<0\end{cases}
$$

is the modified Dyer gradient (Dyer, 1974). Högström (1988) concludes that the expression for the stable case could as well be: $\phi_{m}=1+6 \zeta$, which is the modified Kansas profile. For neutral stratification $(\zeta=0)$, it can be seen that these expressions collapse to the logarithmic profle. Integrating Eq. 65 from $z=z_{0}$ (where $u=0$ ) to $z$, we get the velocity profilt as:

$$
u(z)=\frac{u_{*}}{\kappa}\left[\ln \left(\frac{z}{z_{0}}\right)-v_{m}(\zeta)+v_{m}\left(\frac{z_{0}}{L}\right)\right]
$$

wherc

$$
\psi_{m}= \begin{cases}-\beta_{m} \zeta & \text { for } \zeta \geq 0 \\ 2 \ln (1+x)+\ln \left(1+x^{2}\right)-2 \tan ^{-1}(x) & \text { for } \zeta<0\end{cases}
$$

and $\beta_{m}=4.8$ and $x=(1-19.3 \zeta)^{1 / 4}$.

These profiles will replace the logarithmic profile in the stability dependent versions of the neutral model, to be developed in the following. 


\section{Part II}

\section{The Applied Models}




\section{Introduction}

In onder to predict boal wind up wo 33 bours alveed, two thinge are needed:

1. A forecast wodel taking spoptic scale symens into sccount. To do this for Europe a model covering all of Europe and mon of the Atlantic Ocean is noeded. This is to enaure that systems that are likely to afect the site will be present in the initial andyais.

2. A moded thine the local efects, such as the local topography, the local roaghnewes and changen in ronghwen, and the sheter trom mearby obetacles (nech - Houses, trees, etc), into scoount.

The reason why these two models can not be combined ineso one, generally, is than thin would demand compoter pomer and storage of data, far beyond the possibilitite of todar's techaclogy.

The idee is then 10 do the forecont in two steps: First to calculate the geseral lage-acale ton pattern, and thea calculate the detailed tow pattern at the site only. To do this, two recently developed nodeb are waed. They are:

BILLAM High Resolution Limited Aren Model, developed by the meteorological institutes in Denmart. Finland, loeland, Norway, Sweden, and The Netherlands (Macbewinaret, 1983).

WAP Wind Atla Anabyis and Application Progran, developed by Rim Na. tional Laboralory (Mortensen et al, 1993).

In the following sertions these two models will be described. with most of the weight on the theory behiad WAP. At the ead of this Part a short sunasary of the theary behind neurl network will aloo be given, siare these will be wed in some of the pretiction modets.

\section{WAsP}

WAPP is a program to make wind atlenes. $A$ wind atlos is a generalined wiad

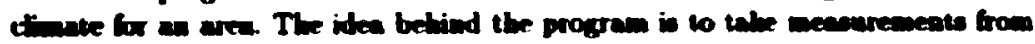

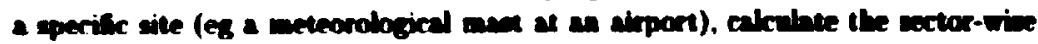
dimeribution of the wind (described by the two-paraneter Weibull dimetribution, of Widtrll. 1951). and 'ctean' this for the followite efiects, in the onder stated:

1. Shelue from obandes in the vicinity of the dive.

2. Changer in the rongheres of the surface.

3. Orograpiny.

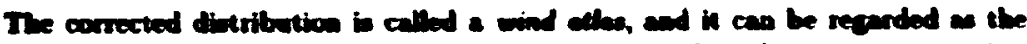

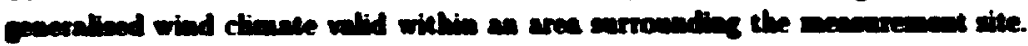
The the of this asea is depeadeat an the complecity of the rasain and the type

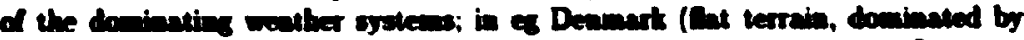

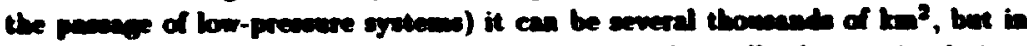

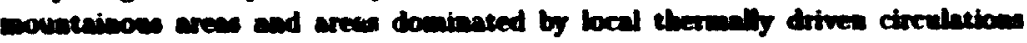

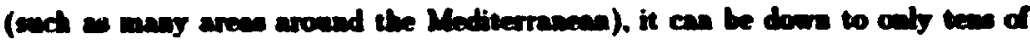

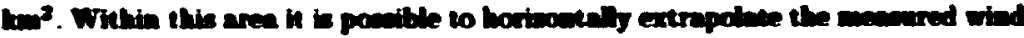

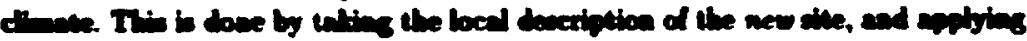

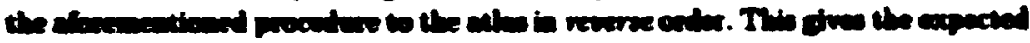




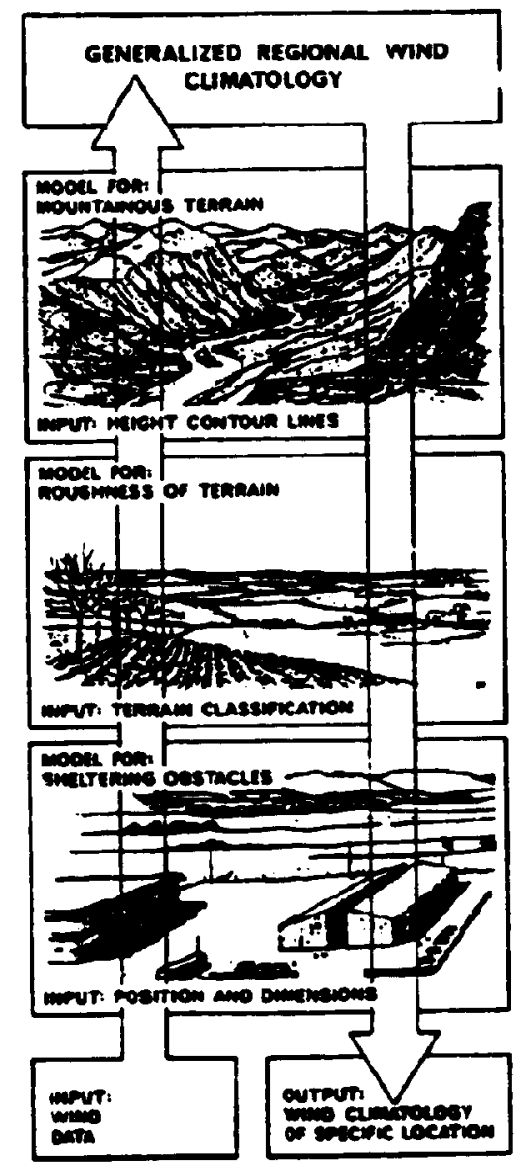

Figure 5. The basw adea of WASP and the Europeun Wind Alles From Trun and Prtersen (1989).

wind climate at the new site. The procedure. calbed the unnd atlas mothodolagy. is depicted in Figure 5

Sipce WAsP cperates on wind speed distributions, and mot, as is nererd in this investigation, on time series, it is mecessury to extract intermediate results from the modets in WAP. This is done by using the dump optiesn in WAsp"

The WASP nufel consists of 3 main parts. modelligg the aforementioned effects.

I A moilel for fow in romplex terran

2 A tuculel the taking roughness aud roughums-changes into arcount

3 A model deseribing the influence of abstacles on the thow

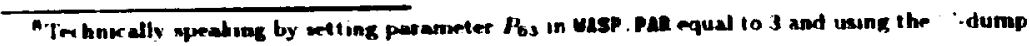
conmmand
} 
Parthermose, the climatic variation of the stablits is tahen into scoount. The leory, which these 3 modele are beed upon, will be decaribed in the following. 


\section{The model for flow in complex terrain}

When the wind passes a topographical fenture, such as a bill, an excarpment, or a valley, its magnitude and direction will undergo a change. In the case of a hill the wind will acceletate at the top and decelerate at the foot; while part of the wind will be deflected. The fact that the wind is acceletated at a bill top, is used extensively in the siting of wind turbines. In a valley the wind is decelerated and channeled in the direction of the villey. The bow over an eacarpment is also accelerated at the top, and decelerated at the fool, bowever, no change in direction is found, because of the two-dimensional anture of the problem.

The fact that the sow separates after the pasage of a hill/eacarpment, steeper than a certain value, has a frm empirical background. see of Finnigan (1988) and de Bans (1990); bowever, this effert is not modeled in the model described belum This is due to the fact that this model models potential for only (ie based on equations dependent on a potential only), because it is meant to be simple in order to get a fast calculation of the right answer (in most cases). More complex models (as the $K-e$ model) are able to simulate the separation, see es de Bans (1990).

The idea for modelling potential som, presented here, was first laid out by Jackson and Hunt (1975) and has since then been used and refined by several: Mason and Sykes (1979), Mason and King (1985), Taylor et al (1983), and Walmsley et al (19e6). The idea has also been used in the complex terrain model in the European Wind Atlas (Troen and Petersen, 1989).

In the Jackson and Hunt paper (Jackson and Hunt, 1975) the flow over a twadimpensional hump was considered. Their idea was that there existed two different fow regions: an inner region, where the flow is induenced by the hill, resulting in a tow perturbation increasing with beight, caused by turbulent transports, and an outer region, where the basic fow is independent of height, and the perturbed fow is inviscid and decaying with height. The height separating these two flow regimes is of order $l_{\varepsilon}=C_{m}, / U$, where $C$ is a characteristic borizontal length scale, $\boldsymbol{U}$ a characteristic tow speed, and $\boldsymbol{u}$. the friction velocity

The derivation of the expremions in this model is described very clearly in Troen (1990). Starting from the governing equations for the horsontal dow in a seutral atmoophere a scale analysio (see eg Holton, 1979, Chap. 2) gives that these equations read:

$$
\begin{aligned}
& \frac{d U}{d t}-f V=-\frac{1}{\rho} \frac{\partial p}{\partial x} \\
& \frac{d V}{d t}+f U=-\frac{1}{\rho} \frac{\partial p}{\partial V}
\end{aligned}
$$

where $U$ and $V$ are the $x$ - and y-component of the horivoatal wiad, respectively, $f$ the Coriolis parameter, $\rho$ the desicity, and o the preasure.

Writing now the equations of notion in their Anx form, using the continuity equation and averaging (sce of Halton, 1979, Chap 5), we get the followiag oqua. tions be the mean flow:

$$
\begin{aligned}
& \frac{d U}{d}-f V=-\frac{1}{\partial p} \frac{\partial p}{\partial x}+\frac{1}{\partial r_{2}} \frac{\partial z}{\partial z} \\
& \frac{d V}{\partial}+f U=-\frac{1}{\partial p}+\frac{1}{\partial r_{1}} \frac{\partial r_{2}}{\partial z}
\end{aligned}
$$


where all quantities are mean quantition, and $\tau=\left(\tau_{x}, \tau_{y}\right)=\left(-\rho \overline{w^{\prime} w^{\prime}},-\rho \overline{v^{\prime} w^{\prime}}\right)$, I denotes averaging of $x$, and ' the deviation from the mean cansed by the turbulent eddies.

Asouming that the Corialis terms (ie terms containing $f$ ) can be neglected, since we are very close to the surfuce where the frictional force is balanced by the pressure gradient, and assuming that the flow is stationary, the equations read

$$
\begin{aligned}
& U \frac{\partial U}{\partial x}+V \frac{\partial U}{\partial y}+W \frac{\partial U}{\partial z}=-\frac{1}{p} \frac{\partial p}{\partial x}+\frac{1}{\rho} \frac{\partial \tau_{z}}{\partial z} \\
& U \frac{\partial V}{\partial x}+V \frac{\partial V}{\partial y}+W \frac{\partial V}{\partial z}=-\frac{1}{p} \frac{\partial p}{\partial y}+\frac{1}{\rho} \frac{\partial \tau_{x}}{\partial z}
\end{aligned}
$$

Assuming now that the effect of a hill on the flow can be described as a perturbation $(u=(u, v, w))$ to the known horizontal mean fow $\left(U_{0}=\left(U_{0}(z), V_{0}(z), 0\right)\right)$ (ie $U=U_{0}+u, V=V_{0}+v, W=w$ ) we get, where, for convenience, we only look at the $x$-component of the equation

$$
\left(U_{0}+u\right) \frac{\partial\left(U_{0}+u\right)}{\partial x}+\left(V_{0}+v\right) \frac{\partial\left(U_{0}+v\right)}{\partial y}+w \frac{\partial\left(U_{0}+u\right)}{\partial z}=-\frac{1}{\rho} \frac{\partial p}{\partial x}+\frac{1}{\rho} \frac{\partial \tau_{x}}{\partial z}
$$

Expanding this, we get

$$
\begin{aligned}
& U_{0} \frac{\partial U_{0}}{\partial x}+U_{0} \frac{\partial u}{\partial x}+u \frac{\partial U_{0}}{\partial x}+u \frac{\partial u}{\partial x}+V_{0} \frac{\partial U_{0}}{\partial y}+V_{0} \frac{\partial u}{\partial y}+v \frac{\partial U_{0}}{\partial y}+v \frac{\partial u}{\partial y}+w \frac{\partial U_{0}}{\partial z}+w \frac{\partial u}{\partial z} \\
& =-\frac{1}{\rho} \frac{\partial p}{\partial x}+\frac{1}{\rho} \frac{\partial \tau_{x}}{\partial z}
\end{aligned}
$$

Since $U_{0}=U_{0}(z)$, all derivatives with respect to $x$ and $y$ are zero, and further assuming that products of perturbations are small $(=0)$, the equation becomes

$$
U_{0} \frac{\partial w}{\partial x}+V_{0} \frac{\partial w}{\partial y}+w \frac{\partial U_{0}}{\partial z}=-\frac{1}{\rho} \frac{\partial p}{\partial x}+\frac{1}{\rho} \frac{\partial x}{\partial z}
$$

Using $\boldsymbol{h}$-theory, stating that

$$
r=p u^{2}
$$

and

$$
\frac{\partial u}{\partial z}=\frac{\omega_{0}}{\kappa z}
$$

which combined with the definition that

$$
r=\rho K \partial x / \partial z
$$

dives

$$
\boldsymbol{K}=\boldsymbol{\alpha}, \boldsymbol{\kappa z}
$$

and seglecting vertical advection terms (ie terms of the form of $\frac{1}{8}$ ), we finally get

$$
v_{0} \frac{\partial x}{\partial x}+V_{0} \frac{\partial w}{\partial y}=-\frac{1}{\partial x} \frac{\partial p}{\partial x}+K \frac{\partial^{2}}{\partial x^{2}}
$$

If the sune procedure is followed for the $y$ - and $z$-componcals, we get

$$
v_{0} \frac{\partial v}{\partial x}+v_{0} \frac{\partial v}{\partial v}=-\frac{1}{\partial p} \frac{\partial p}{\partial y}+K \frac{\partial^{2} v}{\partial z^{2}}
$$

and

$$
U_{0} \frac{\partial w}{\partial x}+V_{0} \frac{\partial w}{\partial y}=-\frac{1}{\rho} \frac{\partial p}{\partial z}+K \frac{\partial^{2} w}{\partial z^{2}}
$$

The cominuity equation becomes

$$
\frac{\partial u}{\partial z}+\frac{\partial v}{\partial y}+\frac{\partial v}{\partial z}=0
$$


since $U_{0}=\left(U_{0}(x), V_{0}(x), 0\right)$.

We have now equations in four unkwown perturbations: $v, v$, $v$, and $p$. The perturbations are now trandormed into Fourier integrabs in the two borinontal directions.

Applying this procedure to the terms and equations, gives the following set of equations for the wave number $k=(k, l)$, where the phaco-apace perturbations, for convenience, are now written using the same notation as for the perturbationa in phyaical space:

$$
\begin{aligned}
-i k U_{0} u-i l V_{0} w & =i k p+K \frac{\partial^{2} u}{\partial z^{2}} \\
-i k U_{0} v-i l V_{0} v & =i l p+K \frac{\partial^{2} v}{\partial z^{2}} \\
-i k U_{0} w-i l V_{0} w & =-\frac{\partial p}{\partial z}+K \frac{\partial^{2} w}{\partial z^{2}} \\
-i k u-i l u+\frac{\partial w}{\partial z} & =0
\end{aligned}
$$

where $p$ now is redefined as the pressure divided by the density, $\rho$.

The solutions to these quations are a sum of exponentials of the form: $\exp \left(a_{1} z\right)$. This can be seen by inserting the expression in the equations. The $a_{i}$ 's can be determined from the following set of matrices

$$
\left(\begin{array}{cccc}
\Omega & 0 & 0 & -i k \\
0 & \Omega & 0 & -i l \\
0 & 0 & \Omega & a \\
-i k & -i l & a & 0
\end{array}\right)\left(\begin{array}{c}
w \\
v \\
w \\
p
\end{array}\right)=0
$$

where $\Omega=-i k U_{0}-i l V_{0}-K a^{2}$. This matrix has solutions if the determinant of the coefficient matrix is equal to sero:

$$
\left(a^{2}-|k|^{2}\right) n^{2}=0
$$

This equation has two solutions

$$
\begin{aligned}
& a_{1}= \pm|k| \\
& a_{2}=\sqrt{-i \frac{h \cdot U_{0}}{K}}
\end{aligned}
$$

where the positive root in the $a_{1}$-eolation is disconated, becunse it leads to nonphysical exposential growth.

The two solutions, $\alpha_{1}$ and $a_{2}$, represeats two 'canonical' scalea induced by the equations of motion: an onter scale, $L=-1 / a_{1}$ and an inner $\ell=1 / a_{2}$.

If the outer scale is exanined lrot, $a=|k|$ is inerted into the s-component of the equation of motion, foring

$$
\text { Ru }=\text { ilpp }
$$

where

$$
\Omega=-i k \cdot U_{0}\left(|z|^{-1}\right)-K|z|^{2}
$$

anowing that the relevent beight in $z=\left.|k|\right|^{-1}$, and therefore that the advection apeed is the speed at that beight. If furthermore, the expreacion for $K$ in inserted, we get

$$
\Omega=-i k \cdot U_{0}\left(|k|^{-1}\right)-\alpha w_{*}|k|
$$

The two terms in $\Omega$ can som be evaluated

$$
\frac{\left|k \cdot U_{0}(L)\right|}{U_{0} k|k|}=\frac{\ln (L / 20)}{\alpha^{2}}|\cos \phi|<1
$$


where $\cos \phi=U_{0} \cdot k /\left|U_{0} \| k\right|$. The inequality is valid if $L$ (the outer rcale) is much greater than $2_{0}$ (the roughness length), which is the same as saying that the borizontal acales in queation have to be much larger than 20 . Furthermore, the wave number vector must not be perpendicular to the background wind - making $\cos \phi=0$. The following analysis will show that the perturbation in this case is exactly zero. This means that for the outer scale, $L$, the diffusion term may be neglected.

The inner solution can be written, assuming this time that the beight is equal tol

$$
a_{2}=\sqrt{-i \frac{k \cdot v_{0}(l)}{u_{*} k l}}
$$

It is now possible to establish a relation between the outer scale $L$, and the inner scale $\ell$, viz.

$$
\kappa^{2} L=\ell \ln \left(\ell / z_{0}\right)
$$

Cooking back at the equations of motion, it is seen that since the inner scale is associated with $\mathbf{\Omega}=0$, the pressure (perturbation) must be equal to zero. Meaning that the pressure is determined solely by the outer solution.

The lower boundary condition for flow over complex terrain is that the terrain undulations induce a vertical flow, proportional to the slope of the terrain, see Figure 6. Since it is the pressure field that drives the flow, and only the outer fow has a non-zero pressure field, it is the outer scale that is the relevant scale, and thereby the outer velocity scale, $U_{0}(L)$. The boundary condition can be written

$$
\omega_{0}=U_{0} \cdot \nabla h(x, y)=-i k \cdot U_{0}(L) h(k)
$$

where $h(x, y)$ is the altitude of the surface, and $h(k)$ is it's Fourier transform. From this equation it can be seen that if $k \cdot U_{0}=0$, the perturbation will be exactly zero.

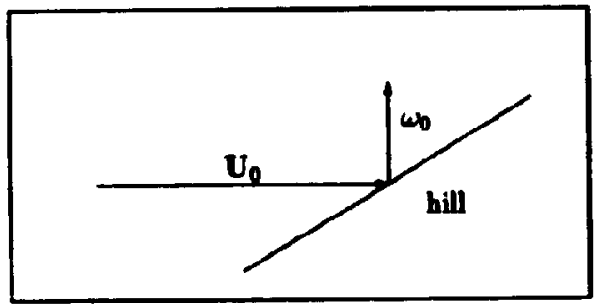

Pigere 6. Ithustration of the boundery condition induced on flow over complex cerrain.

The schution for the prescure feld is then given by

$$
H(k, z)=\frac{\left(k \cdot U_{0}(L)\right)^{2}}{|k|} h(k) \exp (-z / L)
$$

Following Mneos and Sybe (1979) in solving for 1 and $v$, the preanure fold is introdeced in the original equations: (76) to (79). For the coter scale (ie $2<L$ ) the recilt for the borisontal velocity is

$$
w(k, z)=-\frac{k}{|k|} \frac{\left|U_{0}(L)\right|}{\left|U_{0}(z)\right|} \mathbf{k} \cdot \mathbf{U}_{0}(L) h(\mathbf{k}) \exp (-z / L)
$$

For the inner scale the same procedure can be followed obhaining analytical colutions. A simpler solution is attained, boweves, in the BZ-model (Troen and

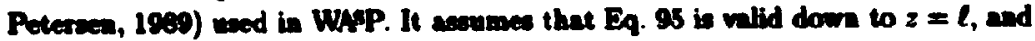
bejor this beight ile direction of the perturbation wibd vector does wot change irailicantly, and the relative speed change is conatant. 


\subsection{Zooming grid}

A special feature of the flow moded in WAP is that it uses a sooming grid, ie a radial grid where the radial resolution decreases away from the center with a constant factor of 1.06. Using this grid has two advantages:

1. Near tne station the resolution is very high, typically around 1 metre

2. A large area cun be covered

To use the zooming grid the equations need to be transformed into a polar coordinate system. In this coordinate system the velocity perturbation is related to a potential by:

$$
\mathbf{u}=\nabla x
$$

and the potential is, assuming that it vanishes at given outer model radius, $R$, expressible as a sum with terms of the form

$$
x_{j}=K_{n j} J_{n}\left(c_{j}^{n} \frac{T}{R}\right) \exp (i n \phi) \exp \left(-c_{j}^{n} \frac{z}{R}\right)
$$

where $K_{j}^{n}$ are arbitrary coefficients, $J_{n}$ the Bessel function of $n$th order, $r$ radius, $\phi$ azimuth angle, $z$ height, and $c_{j}^{n}$ are the $j$ th zero of $J_{n}$.

\subsection{Verification of the flow model}

As a result of the Workshop on Modelling of the Atmospheric Flow Field, held at ICTP, Trieste, ltaly in May 1988, an article (Walmsley et al, 1990) was published, comparing four models (one of which being WAPP) of surface boundary-layer flow with measurements made at Blashaval Hill, North Uist, Scotland. The experiment is described in Mason and King, 1985. In summary, the results of this test are that 1) the models are very alike in performance, and 2) that all of the models compare well with the measurements, both with respect to the speed at the top of the hill and the distribution of the wind. For WAsP the largest error in the speed half way up the hill normalised with the speed at the foot, was $3 \%$.

The analysis of the shape of the hill resulted in that separation of the flow could be expected in the wake of the hill. Since WAP (and the rest of the models) performed well, the separation - if it indeed occurred - had no effect on the low at the measuring points. 


\section{Model for the effect of rough- ness changes}

When the roughness of the terrain changes, say from water (smooth) to land (rough), the surface stress chan ,es immediately (in this case it rises), this results in an upward convergence of inomentum, leading to a deceleration of the air. Decelerating air causes a fal' in the surface stress, which therefore falls toward its original value, a new equilibrium is reached with a surface stress higher than the original. When the air decelerates, the vertical wind shear in the layers above grows, causing an increase in turbulence intensity, and as a consequence the stress higher up increases, too, resulting in upward convergence of momentum, and so on.

If the situation is as in Figure 7, with the change of roughness along a line at right angles to the wind, the air can conceptually be divided into two layers: a layer where it has 'felt' the change, and a layer where it has not. An internal boundary layer, IBL, is said to have developed. The vertical speed with which this layer grows is, according to Miyake (1965), proportional to the friction velocity:

$$
\frac{d h}{d x}=B \frac{u_{*}}{\bar{u}(h)}
$$

where $h$ is the height of the internal boundary layer, and $B$ a constant.

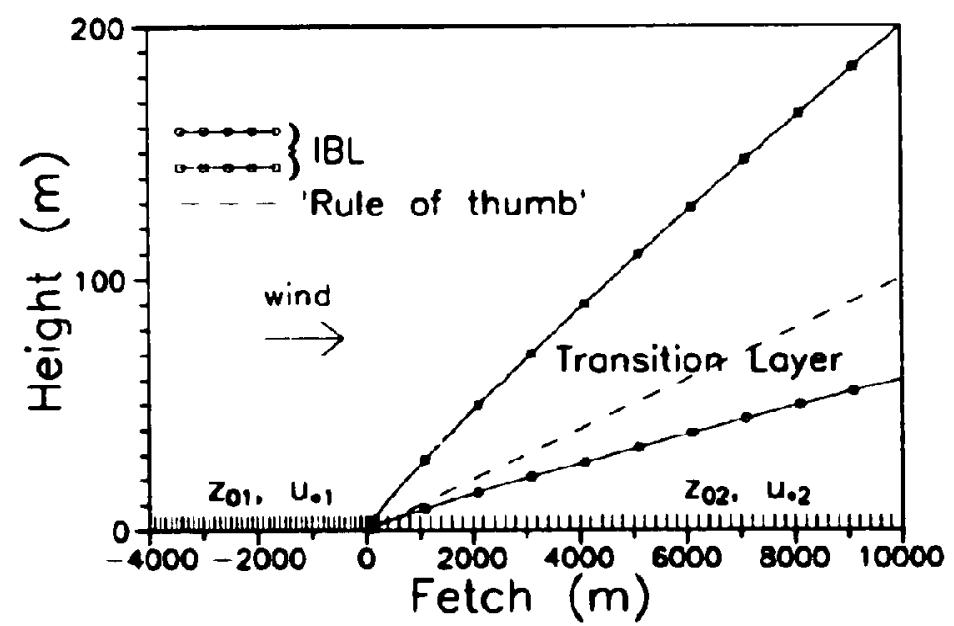

Figure 7. Ilustration of the growth of an internal boundary layer, IBL. The hne where the roughness of the surface changes is perpendicular to the wind. The dashed line refers to the rule of thumb saying that the IBL grows as 1:100.

If the stability of the boundary layer is assumed neutral, the logarithmic wiad profile can be substituted for $a(h)$ in Eq. 96. Integrating this, we get

$$
\frac{h}{z_{0}}\left(\ln \frac{h}{z_{0}}-1\right)=A \frac{x}{z_{0}}
$$

where $h$ is the beight of the IBL at distance $x$ from the change, and $A$ a constant equal to 0.6 in Panofiky (1973). Later experiments gave a value of 0.9 (Larsen et $d$, 1932). The best fit of the equation is obtained, if $z_{0}$ is set equal to the roughness leagth of the rougher terrain. 
It is now posible to find the surface friction velocity inside the IBL, $u_{* 2}$. It is empirically found to be

$$
\frac{u_{* 2}}{u_{-1}}=\frac{\ln \left(\boldsymbol{h} / z_{01}\right)}{\ln \left(\boldsymbol{h} / z_{02}\right)}
$$

where $u_{* 1}$ is the frictional velocity outside the IBL. This is equal to matching two neutral logarithmic profiles at the beight $h$.

In one of the first papers on this subject (Panofsky, 1973) the resulting velocity profile was composed of two logarithmic profiles: one with the roughness length equal to the upstream roughness outside the IBL, and one equal to the downstream roughness length inside the IBL. Recent measurements (Semprevive et al, 1990) and numerical simulations (Rao et al, 1974) have shown, however, that the perturbed wind profile is more likely to have the following form

$$
u(z)= \begin{cases}\frac{u_{-1}}{\kappa} \ln \left(\frac{z}{z_{01}}\right) & \text { for } z \geq c_{1} h \\ u^{\prime \prime}+\left(u^{\prime}-u^{\prime \prime}\right) \frac{\ln \left(z / c_{2} h\right)}{\ln \left(c_{1} / c_{2}\right)} & \text { for } c_{2} h \leq z \leq c_{1} h \\ \frac{u_{+2}}{\kappa} \ln \left(\frac{z}{z_{02}}\right) & \text { for } z \leq c_{2} h\end{cases}
$$

where $u^{\prime}=\left(u_{+1} / \kappa\right) \ln \left(c_{1} h / z_{01}\right)$ is the velocity at the boundary of the upper layer, $u^{\prime \prime}=\left(u_{* 2} / \kappa\right) \ln \left(c_{2} h / z_{02}\right)$ is the velocity at the boundary of the lower layer, $c_{1}=$ 0.3 , and $c_{2}=0.09$.

In other words, the experiments show that the height of the layer influenced by the downwind roughness length is only $0.09 h$. The layet influenced by the upwind roughwess length penetrates down to $0.3 h$. The velocity in between these two layers is found by interpolation.

If there is more than one roughness length change, Eq. 99 is used successively. There are, however, some limitations: roughness changes must not occur too close to each other, since the flow must have been in contact with the new surface for some time, for the fiow to reach equilibrium and - as a consequence - for Eq 99 to be valid The following rule applies (Troen and Petersen, 1989): If $x_{n}$ is the distance to the $n$th change in surface roughness, then the upstream roughness must be estimated as an average covering the area between the distance $x_{n}$ and $2 I_{n}$ in the aximuth sector considered.

The factor 2 is more or less arbitrary, and the rule may be deviated from in cases where clear roughness boundaries are found, ef at a coastline.

As mentioned in the beginning of this section the boundary layer reaches equilibrium with the new surface after some time, this is not incorporated in Eq. 99 To take the weakening influence with distance into account, a weighting factor is included. The idea is that the roughness change boses importance as $x / D$, where $D$ is the equilibrium distance. Typically this distance is taken to be $10 \mathrm{~km}$. So instead of considering a change from $z_{0}$ to $z_{0 n+1}$ at a distance $x_{n}$, the value

$$
\ln \left(z_{0_{n}}\right)+\exp \left(-\frac{x_{n}}{D}\right) \ln \left(\frac{z_{0 n+1}}{z_{0 n}}\right)
$$

subetitutes $\ln (20 n+1)$ 


\section{Shelter from obstacles}

Wheu an undisturbed flow meets an obstacle (eg a house or a shelter belt) the flow is disturbed by the presence of the obstacle. The main effect is that downstream (in the wake) of the obstacle lee is generated. This effect has been used by many (eg agriculturalists, architects). but has not been studied in great scientific detail, until just a few decades ago. The picture that has emerged is that for 2-dimensional objects the flow (ie the stream-lines) is lifted above the object. In front and behind of the object exists a separation zone in which the flow is confined. Further downstream a turbulent wake is generated. The low near the object is highly dependent on the shape of the object, whereas the flow in the wake fulfills a general theory. In the 3-dimensional case the picture is more or less the same, with the important difference that vortices are generated at the edges of the object, and that the separation zone is not a cavity, so mixing close to the object is driven by convection A sketch of the 3-dimensional Bow is shown in Figure 8. As the porosity (ie the ratio of the open area to the total area) increases this recirculation eddy is weakened. and it disappears when the porosity gets above 0.3 .

In the following sections the theory, measurements, and the application in WASP will le' described.

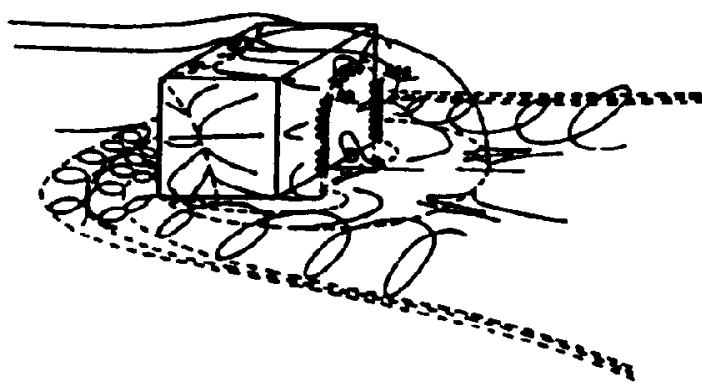

Figure 8 . A sketch of the flow around a 9-dimensional obstacle in a turbulent boundary layer, from Hunt et al (1978).

\subsection{Theory}

The cornerstone in the theoretical work regarding two-dimensional wakes in turbulent flows is the work by Counihan et al (1074)9. This work has its basis in the theory for wakes in lominar flows by Hunt (1971). It assumes that the flow around the obstacke is as depicted in Figure 9.

Furthermore the following assumptions are made:

- If $k, h$ and $\delta$ are the heights of the roughneas elements in the incident boundary layer, of the obstacle, and of the boundary layer, respectively, then

$$
k<h<0
$$

Moreover the shape of the obstacle must be such as to cause a well-defined turbulent separation bublte in its lee.

- At some distance (greater than the length of the wake, $X$, but not so great that the structure of the boundary layer changes) downstream, the mean velocity returns to its value in the undisturbed layer.

\footnotetext{
Actually, Counihan did the experiment, and Humt and Jackeon the theoretical work.
} 


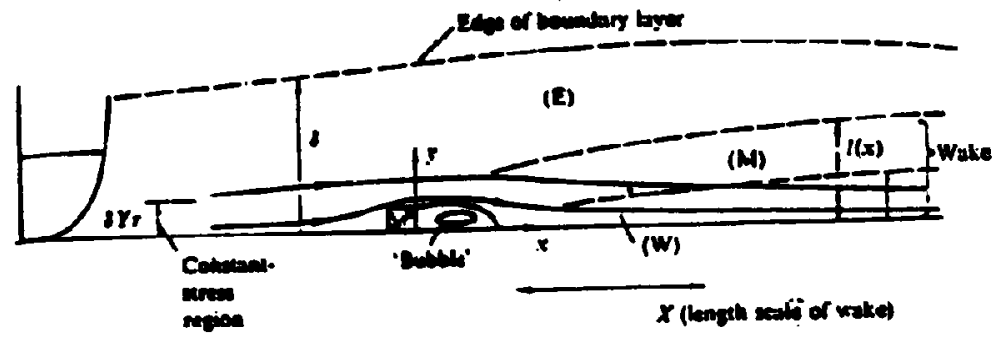

Figure 9. The flow anownd an obstacle in a turbulent boundary layer, from Counihon et al (1974).

- The velocity profile in the upotream boundary layer can be deacribed by a power law:

$$
U(z)=U_{\infty}\left[\left(z-z_{1}\right) / \delta\right]^{n}
$$

where $U_{\infty}$ is the wind speed outside the boundary layer, and $z_{1}$ the zero displecement. However, very close to the roughness elements (ie when $z \approx k$ ) the logarithmic profile

$$
U(z)=\frac{z_{*}}{x} \ln \left(\frac{z-z_{1}}{z_{0}}\right)
$$

must apply. $\kappa(=0.4)$ is the von Karmin constant, $u$, the friction velocity, and $z_{0}$ the roughness kength.

- and finally, that the for can be divided into 3 regions, marked $E, M$, and $W$ for External, Mixing, and Wall region, on the sluetch. Each region has its own physical interpretation.

The region of interest bere is the $M$ region. This is because a general model is wanted and the flow close to an obstucle (leas than $10 \mathrm{~h}$ away) is very dependent on the actual shape of the obstacle, see of Taylor (1938) and Peterbet al (1935) for an overview.

In the $M$ region the perturbation stress $\tau$ has to be related to the perturbation mean velocities. This relation is found by scaling consideration and is asanmed to be

$$
T_{x z}=\rho 2 v_{0}(z=h) \partial w / \partial z
$$

where $\nu_{0}(z=h)=T_{z 1} /(d / d z)$, and $T_{z z}$ the mean stress in the undiaturbed boundary layet. This ascumption is bered on reasoning by Bradihner (1971) and Townsend (1972) concerning the eddy viscority.

These anumptions bead to that the equation of motion can be written

$$
\left.U_{\infty}\left(\frac{z^{n}}{\delta}\right) \frac{\partial x}{\partial x}+U_{\infty} n\left(\frac{z^{n-1}}{\delta}\right) \frac{v}{\delta}=-\frac{1}{\partial x} \frac{\partial x}{\partial x}+2 n\right) \frac{\partial^{2}}{\partial z^{2}}
$$

with the dieplackeneat height $z_{1}$ onitted, which is of so consequence becaune the $M$ region is 20 far fon the aurface that $z>x_{1}$.

The following solution to this equation is proponod:

$$
\begin{aligned}
\frac{v}{U(h)} & =\frac{\hat{v}}{x^{m}} \frac{d}{d n} \\
\frac{v}{U(h)} & =\frac{\hat{v}}{z^{m+1}}\left[m f-\frac{z}{l} \frac{d}{d z}\left(f-n f^{\prime}\right)\right]\left(\frac{1}{h-z_{1}}\right) \\
\frac{p}{d^{2}(h)} & =\frac{\hat{m}}{z^{m}}\left(\frac{1}{h-z_{2}}\right)
\end{aligned}
$$


where $x=x /\left(h-z_{1}\right)$ and $\eta=z / l(x)$. It can be seen that these equations deacribe a self-preserving fow, ie a 10 in which (citing Townsend, 1956) "motions at difereal sections difer oaly in velocity and length scales, and are dynamically similar in thoee aspects of motion controlling mean velocity and Reynolds stress".

After elaborating quite a bit on this, the foilowiug solution for the velocity deficit in the $M$ region is found

$$
\frac{w}{U(h)}=-\frac{\dot{C} / I(n)}{K\left(h-z_{1}\right)^{2} U^{2}(h)}\left(\frac{h-z_{1}}{x}\right) \frac{d}{d \eta}\left[\eta^{2}{ }_{1} F_{1}\left(\frac{2-n}{2+n} \cdot \frac{n+4}{2+n}, \frac{-\eta^{n+2}}{(n+2)^{2}}\right)\right]
$$

where

$$
I(n)=\frac{(1+n)(2+n)^{(4+n) /(2+n)} \Gamma\left(\frac{1+n}{2+n}\right) \Gamma\left(\frac{1-n}{2+n}\right)}{\Gamma\left(\frac{2-n}{2+n}\right)}
$$

baving a typical value of 7.08 for $n=0$, and 7.95 for $n=0.2, \bar{C}$ is a constant given by

$$
-\int_{0}^{\infty} z U(z) \bar{u} d z
$$

which is only valid if the wall region is ignored; this can be shown to cause only a small error. ${ }_{1} F_{1}$ is the confluent hypergeometric function, defined in Abramowitz and Stegun (1964). This solution for the velocity deficit is the basis for most theoretical and empirical work done in wake theory.

Note that Eq. 105 implies that the eficiency of the shelter belt, $s=-u / U(h)$, is proportional to $(x / h)^{-1}$. Another result from the theoretical model is that the perturbation shear stress in the $M$-region, $-\left(\tau_{x z}\right)_{z=0}$, is proportional to $(x / h)^{-3 / 2}$. $A$ plot of the velocity deficit in the $M$ region versus the height $\eta$ is shown in Figure 10.

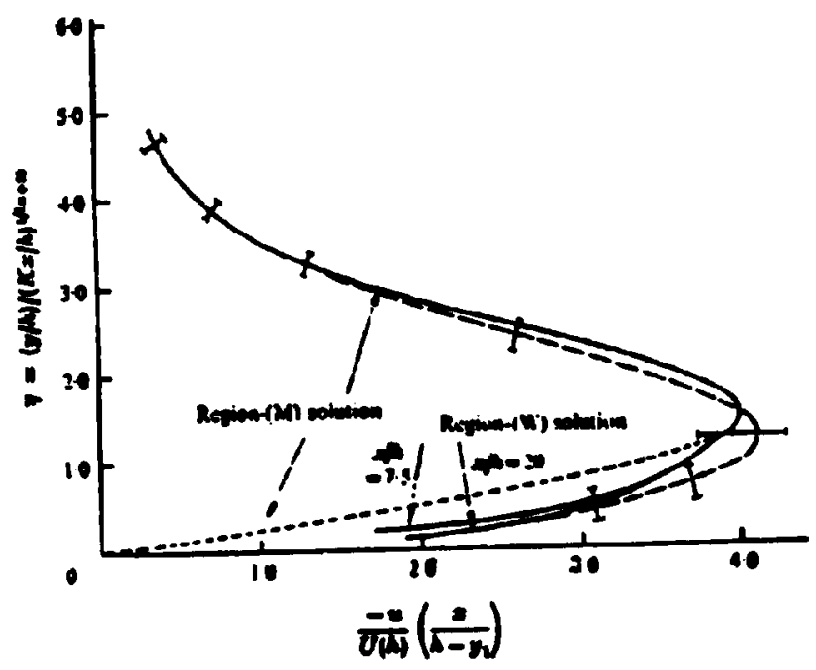

Pigure 10. The velocity deficil plotted verams height, from Counsiban et al (197)).

Porocity

The porosity, $P$, of an obotacle is the ratio of the open area to the total area, a sold wall thercfore has a porosity of 0 . It is a important quantity, both in 
wind-tunnel experiments (where it is eneily controlled, by for instance boles in the plates), and in full-scale ditto. Here the problem is that it is dificult 10 anew the poroaity exactly: there will always be a cerrin amount of subjectivity in the determination. A more objective method has been tried by Lindwolm et al (1988). They used photos of the wind breats taken at $4 \mathrm{~m}$, and proceaned these images with a computer-based image analysis system, to determine the proportion of the background. They found that only "2-dimensional" gape were rejistered, rendering the optical porcosity smaller than the real porocity.

As a general guideline the following table for the porosity of windbreaks can be used (Troen and Petersen, 1989):

\begin{tabular}{lc}
\hline Apperance & Porosity $P$ \\
\hline Solid & 0 \\
Very dense & $\leq 0.35$ \\
Dense & $0.35-0.50$ \\
Open & $\geq 0.50$ \\
\hline
\end{tabular}

The efiect of the porasity of an obstacle on the velocity deficit, is that it is decreased by multiplication with the factor $(1-P)$.

\subsection{Measurements}

Most of the research regarding shelter has been done experimentally. In the following, results from a few experiments will be presented. They are divided into experiments carried out in wind-tunnels and full-scale.

\section{Wind-tunnel experiment:}

When conducting experiments in the wind-tunnel it is critical that the fow fulfills a similarity constraint; namely that the ratio of the height of the fence to the roughness length is the same as in full-scale experiments.

Couniban et al (1974) also conducted experiments in connection with the theoretical derivation, referenced above. The experiments were carried out in a windtunpel at C.E.R.L. (Central Dlectric Research Laboratories), Sor details see Counjhan (1999). The power-law and the logarithmic law fitting the mearurements best, with the logarithmic law being margially better, were found to be

$$
\begin{aligned}
& \frac{U(z)}{U_{\infty}}=0.805(z / \delta-0.02)^{0.12} \\
& \frac{U(z)}{U_{\infty}}=0.125 \mathrm{ln}\left(\frac{z / \delta-0.01}{0.0003}\right)
\end{aligned}
$$

Conparing the meavuremeats with theory they found that the adf preservation

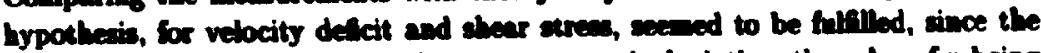
scatter of the data shomed so indicative syatematic deviation, the value of $n$ being f. Moreover, they Sound that the theoretically derived expresions, for velocity deficit and shear arreas, were in good scoordance with the menarements. They abo found that the maximum value of $u(x)$ fill of as $x^{-1}$.

Pesera (1981) did wind tunbel measurements of a simulated rural atmoopheric bonadary layer with solid and porous (op to $P=0.5$ ) fences inmersed in it. They tried diferent formen of boles in the fance, and fond that for the same poromity, the fore of the boles hed so infwesce. Furthermore, and mose inportant, they fousd 


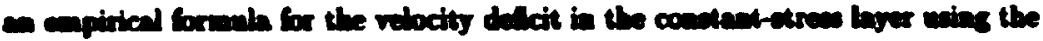

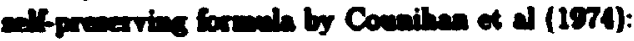

$$
\Sigma=9.75(1-P) \text { mexp }\left(-0.677^{1.8}\right)
$$

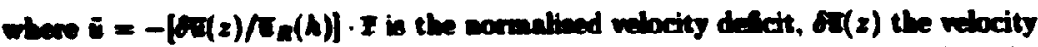

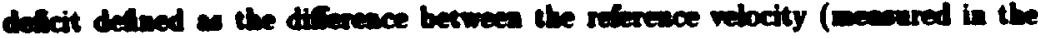

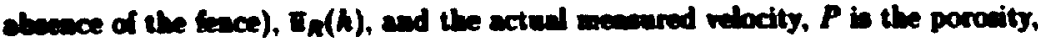
and

$$
\nabla=\frac{z}{h-d}(\kappa x)^{-1 /(n+2)}
$$

where $n$ in the exponeat of the approuch relocity prodke, wormally then to be

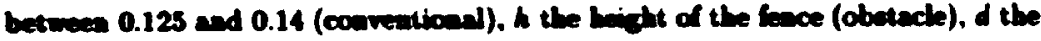
nero dioplecenceat leagth, $I=x /(h-d)$, and

$$
K=\frac{2 x^{2}}{\ln ((h-d) / 2 n)}
$$

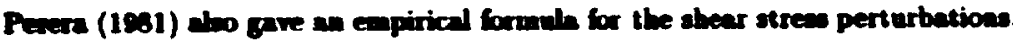
A plot of Eq. $100 \mathrm{cas}$ be sece in Figure 11.

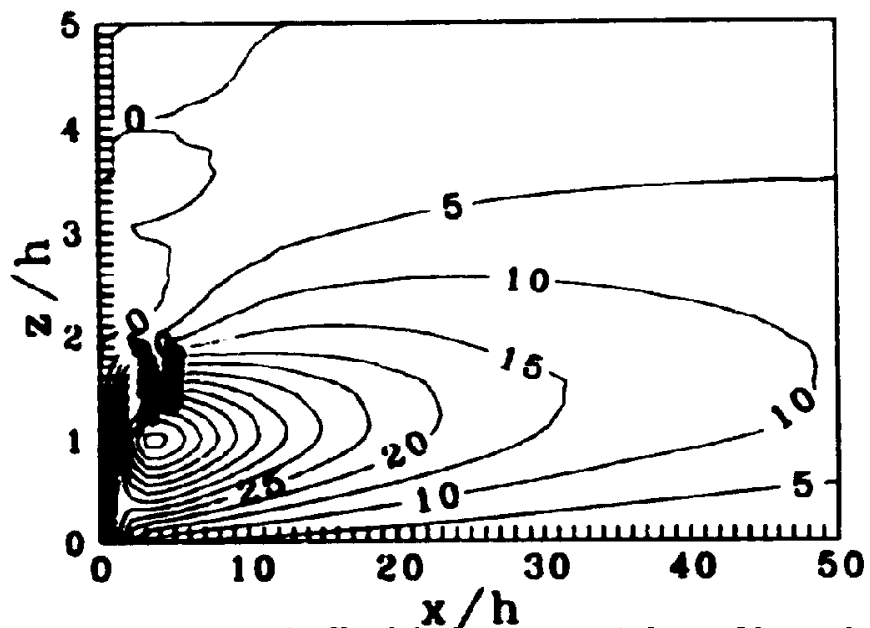

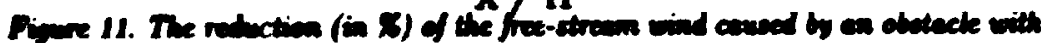

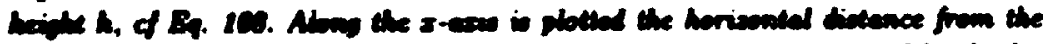

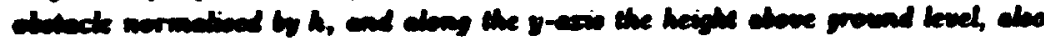

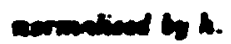

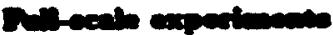

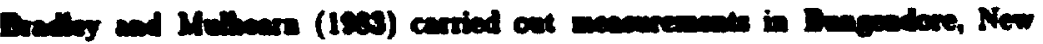

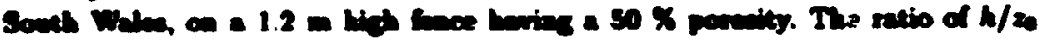

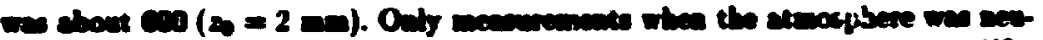

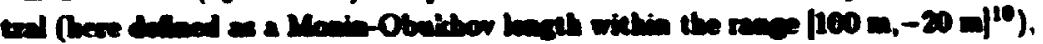

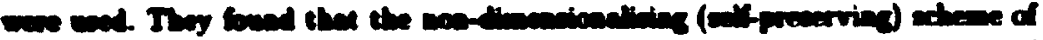

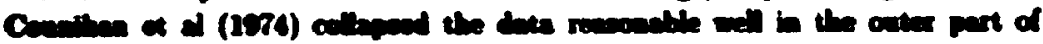

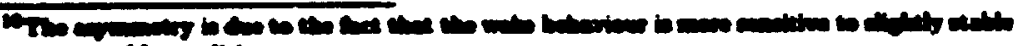

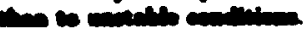


the son. The forad that $\Delta u / u n$ lmax in proportional so $(x / h)^{-1}$. However, they found that the Reynolds stres perturbation date did not agree with the $(x / h)^{-1}$ decay found by Cautro (1979) and Perere (1981), bat more along the lines of the theoretical prediction $\left((x / h)^{-3 / 2}\right.$, Counihan et $\left.d, 1974\right)$ with an even more rapid decay.

In another experimeat, Nord (1991) did in sitv full-scale messurements at 4 different beations in southern Sweden. Only horizontal profiles were considered, the measurements were taken at $2 \mathrm{~m}$. Both single and multiple rows of trees were chosen. The porosity was determined by two methods: the alorementioned photographic method by Lindbolm et $1(1988)$ and in a wind tunnel, where the mearured profiles were reconstructed by changing the porouity. An interesting fact appeared, samely that it was aecesary to have different poroaities in the lowet part, than in the upper part of the abelter belt The results were not compared quantitatively to ocher measurements, but come interesting finding mere done Firstly, they found that the reduction of the wind in the summer in the lee of the shelter belt was dependeat on the incoming wind speed: the bigher the wind the higher the porcaity (iv the les dense). This was more prononnced for a thin single row of trees than for dense multiple rown. This can be explained by the presence of the baves. Another finding was that this effect was dependent on stability, in the sense that under unstable conditions the influence was less than under neutral conditions.

\subsection{WASP}

In WAPP the empirical formula by Perera (1981) is used, but some modifications had to be applied because the formula was derived for a 2-D obotacle and obstacles are generally considered 3-dimensional in WAPP. Fist of all, were situations in the wear wake (ie wevet closer than 5 obstacle beights and in the first one half obstacle height, not closer than 10 beights) nor taken into acconnt, since the tow here is entirely dependent on the actual shape of the obstucle To tabe the finite extension of the obstacle into account, a reduction of the shetter because of lateral mixing a the edges ras taken into account. Furthermore, the fact that several objects could generate shelter from the same direction (when viewed from the site) was treated by adding the shelter from the individual obotacles. 


\section{HIRLAM}

All forecasting of the wind in this work, baved on physical modets, will be dowe by BIRLAM (HIgh Resolution Limited Area Model). The development of this model was started in 1985 a \& joint project between the motoorological institutes in Denmark. Finland, Iceland, Norway, Sweden and The Netheriands. The main objective was to develop an operational high resolution dats-asimilation and forecant model system to be utilised for short-range forecasting, Machenhaver (19es).

HIRLAM is primarily based on ECMWF's (European Center for Medium-range Weather Forecasts) operational analysing system ${ }^{11}$ and grid point model. HRLAM bas been operational in Denmark siace autumn 1990.

\subsection{The equations}

The basic equations in HIRLAM are the primitive equations, which have the bllowing form in the $(x, y, \sigma)$ coordinate system:

Momentum equation:

$$
\frac{d V}{d l}+f k \times V=-\nabla \Phi+\frac{\sigma}{p_{2}} \nabla p_{0} \frac{\partial \Phi}{\partial \sigma}
$$

Continuity equation:

$$
\nabla \cdot\left(p_{0} V\right)+p_{0} \frac{\partial \dot{b}}{\partial \sigma}+\frac{\partial p_{i}}{\partial t}=0
$$

Hydrostatic approximalion

$$
\frac{\partial}{\partial p}+a=0
$$

Thermodyaumic energy equation:

$$
\frac{\partial t}{\partial t}+V \cdot \nabla \theta+\dot{\partial} \frac{\partial \theta}{\partial \sigma}=\frac{\theta}{c_{p}} \frac{d s}{d t}
$$

where $\sigma \equiv p / p_{0}, p$ the pressure, $p_{o}(x, y, t)$ the surface pressure, $V$ the horizontal wiad, $f$ the Coriolis paraweter, I the vertical unit vector, I the geopotentiad,

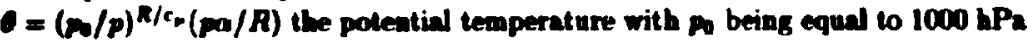
(conmally) and $a=1 / p$. Here the hotal derivative is defised as

$$
\frac{d}{d}=\frac{\partial}{\partial t}+v \cdot \tau+\frac{\partial}{\partial \theta}
$$

The advantage of the o coondinate syatem over the ibobaric is that the prob-

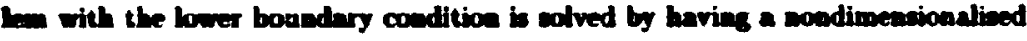
vertical coordiante. The boundary condition wow reade

$$
0 \text { a } 0 \text { at } \sigma=0.1
$$

herder to clone the systen, a last equation is neodod, it combines the bousdary conditions with the continuity oquation, and it reade

$$
\frac{\partial p_{0}}{\partial t}=-\int_{0}^{1} \nabla \cdot(p, v) d \sigma
$$

The vertical grid in HilluAM is actually a o/presonre hybrid courdiante system, so the equations wed in the model difier sonewhat from the ones bere stated.

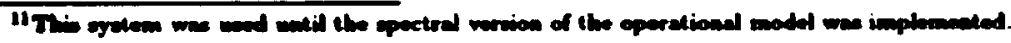




\subsection{The model}

The time schedule for BIRLAM is shown in Figure 12, the model need in this project is GR-HIRLAM (GR for Greenland), which has the bisser of the two model domains sbown in Figure 13. This model is wed for duty work for Greenland, and is run twice a day at 002 and 122 . The reacon why the model baced on aberervations from $00 Z$ is not run until 4:30Z is that observations (made at 00Z) for areas critical for the forecant for Greenland are not received till this time. The reason that GRHIRLAM is used is that forecasts are wanted out to $\mathbf{3 6}$ bours, and therefore it is important to have as great an area as poscible, in order to catch systems advected into the area.

The horizontal grid consists of $162 \times 136$ grid points with a wesh width of $0.51^{\circ}$ (approx. $57 \mathrm{~km}$ ), and it is rotated so that the pole is at $180^{\circ} \mathrm{E}, 25^{\circ} \mathrm{N}$, which meane that the grid is almost equidiatant over Europe. The vertical grid has 16 levels. The time step is $6 \mathrm{~min}$ ( $5 \mathrm{~min}$ in the winter time), and the physical tendencies are computed every third time step.

As boundary values are used the newest available ECMWF forecasts with 6 hour intervals. To get values in between the ECMWF forecasts linear interpolation is used.

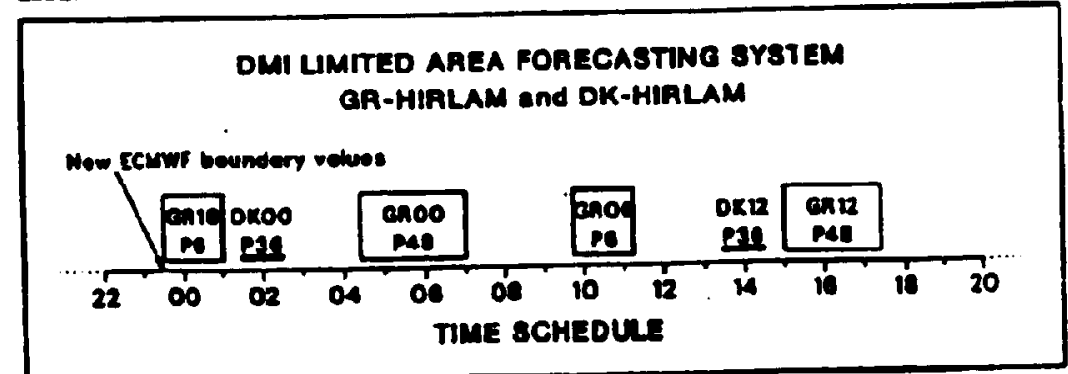

Figure 12. The time schedule for the HIRLAM model.

\subsection{Accuracy of HIRLAM}

Many apects of HIRLAM's prediction abilities have been evaluated by several (Jochen (1990), Autsen (1991) and Hall (1987)). A recent survey of, anong otbers, the 10 metre wind ha been given in Mectrenbaner et al (1991), where the $10 \mathrm{~m}$ forecast of HIRLAM wa compared to tha of UK Limited Area Model (grid resolution in the comparion: 1.25 dagrees). It is found thet the bienes, the mean aboolute error, and the RMS error were geserally of smalles or equal sime as those of the UKJAM.

\subsection{New version of HIRLAM}

Recently a new verion of HIRLAM, BIRLAM 2, ha been developed as the Dan-

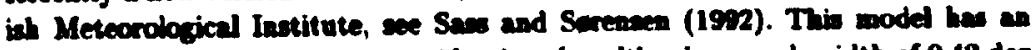
improved recolution: $194 \times 163$ grid poimes (reating is a mech width of 0.42 des or appeox. $47 \mathrm{~km}$ ) and 31 vertical levels. The time step is reduced $204 \mathrm{~min}$. The abrementioned volnes are valid for GRV.HIRLAM.

It is expected that using this wew version will improve the forecasts given in the following, in the same manner, but not to the same extent, st the higher resolution UK MEsO model weed in Section 15.3. 


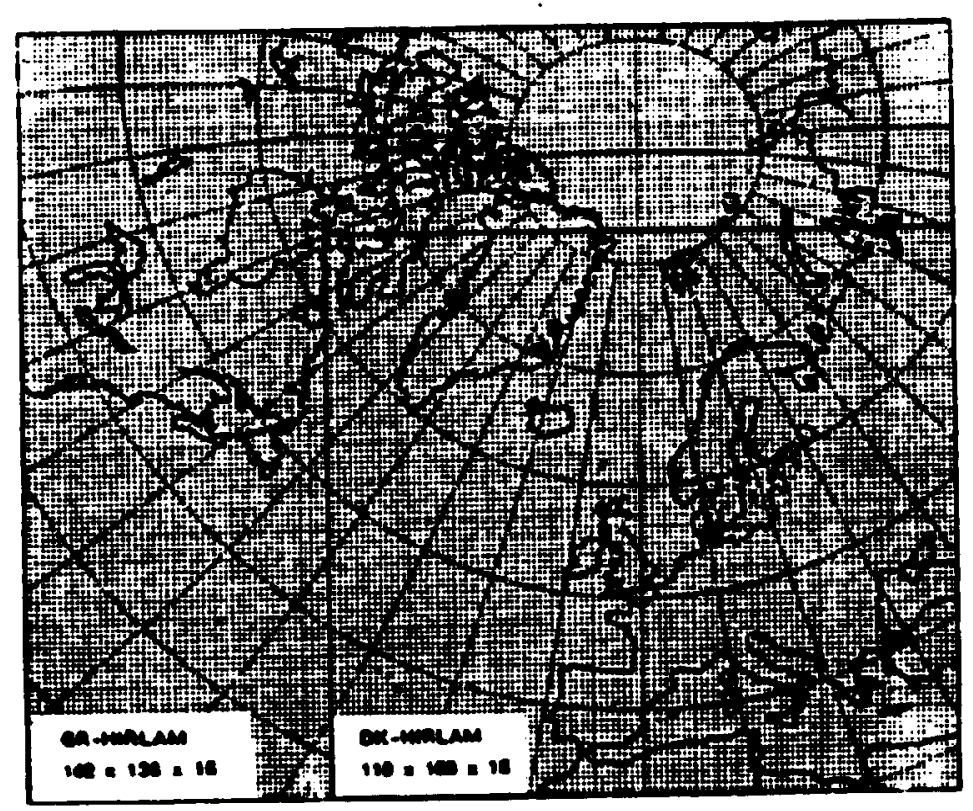

Figue 1s. The domein of the HIRLAM model. 


\section{Neural networks}

A seural petwork is a (large) number of simple computational units (called formal or model neurons) mascively connected. The ides behind neural networks is based on bow the brain was thought to work in the fifties and early sixties. Neural networks have been described in several publications, see eg Rumelhart et al (1986). For publications deacribing applications of neural networks to time series, see es Lapedes and Farber (1987) and Landberg (1992).

\subsection{The formal neuron}

A formal neuron can have a number of inputs and one output. The output can be (and normally is) transferred to several other neurons. A shetch of a model neuron is shown in Figure 14.

The resulting inpur, net, to the ith neuron is given by

$$
\text { net }_{1}=\sum_{,} W_{i} O_{2}-T_{2}
$$

where $W_{i j}$ is the weight applied to the output from neuron $j, O$, and $T_{1}$ is the threshold of the ith neuron.

The output from the ith neuron, $O_{1}$, is given by

$$
O_{1}=f_{i}\left(\text { net }_{i}\right)
$$

where $f_{1}$ is a function specific to the ith neuron, called the acturation function. Normally two different functions are used: a linear function for the input and output neurons ${ }^{12}$

$$
f_{i}(x)=x
$$

and a sigmoid ${ }^{13}$ for the hidden neurons, given by

$$
f(x)=0.5(1+\tanh x)
$$

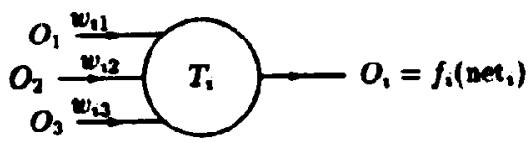

Figure 14. A stetch of the ith formal newron. This neuron has I imputs: the output from neuron $1, O_{1}$, from newron \&, $O_{2}$, and from newron $3, O_{3}$. Eech of these inputs is meighted with an individual weight, $w_{11}, w_{i 2}, w_{i s}$, respectively. The output from this newron, $O_{i}$, is here given by $f_{i}\left(\mathrm{set}_{i}=\sum_{j=1}^{3} w_{i j} O_{j}-T_{i}\right)$.

\subsection{The neural network}

When a number of neurons are connected, a peural networt is formed. A nenral network is characterived by the followias

- The architecture

- The aignal propagation

- The traiaing algocithm

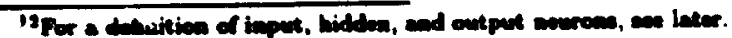

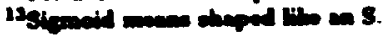


The architecture The architecture of a neural network determines which neurons are connected to which. For networks solving problems in connection with time series a layered network is normally uned. A layered network is a network where the neurons form layers connected with each other, the neurons in a layer are not inter-connected, see Figure 15. The layer where the time series is being presented to the network is called the input layer, and the layer from which the output from the network comes is called the output layer. Any layer which is not an input nor an output layer is called a hidden layer. A layered network is identified according to the following syntax:

(\#input, \#hidden layer $1, \ldots$, \#hidden layer $N-1, \#$ output)

where \# inpul is the number of neurons in the input layer, \#hidden layer $k$ the number of neurons in the $k$ th hidden layer, and \#output the number of neurons in the output layer. A $(1,5,1)$ network would therefore be a three layered network. with 1 neuron in the input layer, one hidden layer with 5 neurons, and 1 output neuron, cf Figure 15.

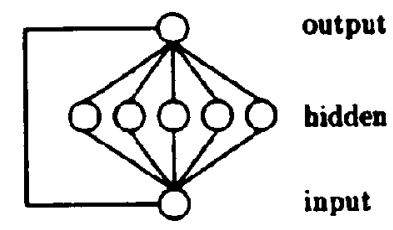

Figure 15. A $(1,5,1)$ neural network with a direct connection from the input loyer to the output layer. See text for details.

The algal propazation There are two possible ways that the signal can traverse from the iaput layer to the output layer: either it can go directly from layer to layer. or it can return to a layer it has already been sent out from. The first case is called feed-forword, and the second recursion. A foed-forward layered neural setwork is also called a perceptron, and it is networks constructed in this way that will be used in the following.

The training alforithm One of the characteristic features of wevral networks in that they, in order to perform any tack, must be trained. This can be dose in several ways, the one etilised bere is the delta rule or steepest descent method. The idea is 10 minimive the error that the neural network makes when presented to a kbown pattern. This is dowe by minimining the toul erroe given by

$$
E_{\text {tot }}=\sum_{p} E_{p}
$$

where the erroc made by the setwork whem presented for the pth input/output-pair in given by

$$
E_{p}=\sum_{i}\left(O_{i}^{(p)}-\operatorname{targ}_{i}^{(p)}\right)^{2}
$$

where $O_{1}^{(p)}$ is the ectual outpat from the ith outpet seuron and $\operatorname{targ}_{i}^{(p)}$ is the vented output trom this colput neuron. 
The minimiantion algorithm statee that a minimum of any quadratic function, $S\left(x_{1}, x_{2}, \ldots, x_{n}\right)$, can be found by moving one step in the oppoaite direction of the gradient, so the new pocition in phase-space, $x_{i}^{(t+1)}$, is given by

$$
x_{i}^{(t+1)}=x_{i}^{(t)}-e \frac{\partial S}{\partial x_{i}}
$$

where $c$ is a small podtive number.

In the case of neural networks the quadratic function is the total error, $E_{\text {hot }}$, which is a function of the weights, $W_{i j}$, and the thresholds, $T_{i}$. Finding the derivative of $E_{i d}$ with respect to $W_{i j}$ and $T_{i}$, gives that the weights and thresholds one step closer to a minimum are given by (we of Landberg, 1992)

$$
W_{i j}^{i+1}=W_{i j}^{t}+\Delta W_{i j}
$$

and

$$
T_{i}^{t+1}=T_{i}^{t}+\Delta T_{i}
$$

where

$$
\Delta W_{1}=\epsilon w\left(-\frac{\partial E_{t a l}}{\partial W_{i j}}\right)=\epsilon w \sum_{p} \delta_{i}^{(p)} o_{j}^{(p)}
$$

and

$$
\Delta T_{1}=\epsilon T\left(-\frac{\partial E_{(a)}}{\partial T_{i}}\right)=-\epsilon T \sum_{p} \delta_{i}^{(o)}
$$

where

$$
\delta_{i}^{(\infty)}=-2\left(O_{1}^{(\infty)}-\operatorname{targ}_{i}^{(s)}\right) f_{i}^{\prime}\left(\text { net } t_{i}^{(\infty)}\right),
$$

if the ith neuron is in the output layer, and

$$
\delta_{1}^{(p)}=f_{i}^{\prime}\left(\text { oet }{ }_{i}^{(p)}\right) \sum_{j \in M_{1+1}} \delta_{j}^{(p)} V_{j},
$$

if the ith neuron is not in the output layer. For a definition sketch see Figure 16.

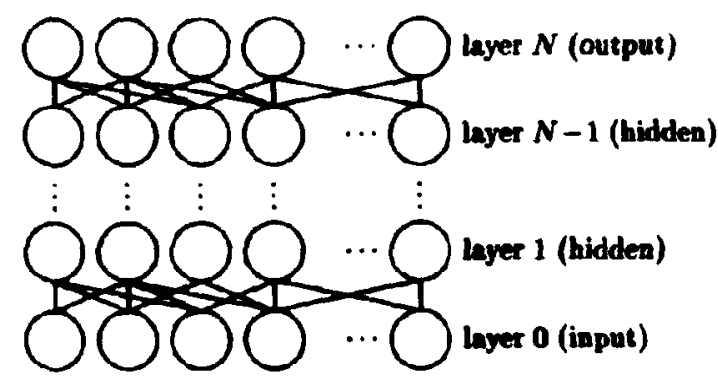

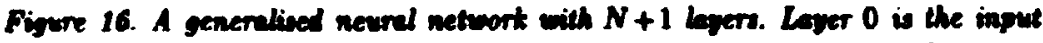
leyer, and legyer $\boldsymbol{N}$ the output layer. Onty a few of the connections are shown.

The minimining method ned bere (the steepest descent) has some problems in connection with it. Firstly, the method finds the nearest minimum, this is not secesuarily the wanted global minimum. To avoid that the training of the neural setwort is belas trapped in a presumed boal miaimum, a method has been developed. When a situation occurs where the error seems to converge (this can mean two thing: the gobal minimum bas been reacived, in which care the woights 
and thresholds have been stored, or that a local minimum is encountered), the weights and thresholds are stored, and a big (10 times the present) step is taken. this should take the error out of the local minimum. The error is said to converge when it has not changed significantly during a certain period (normally $\mathbf{5 0}$ presentations). The iteration is then continued from the new position. The big step normally leads the system to a position with a higher error, and the system will oscillate for some time before a new minimum is reached. In order to keep the system stable, the time after which the algorithm allows another big jump is made longer and longer. Normally it is not a big problem with local minima, and the method proposed here seems to take care of the problem when it occurs.

Another problem with steepest descent is that the convergence is slow. A method for speeding up the convergence is therefore utilised here. The method is as follows: every time a step is taken and the error decreases, $c$ is m'itiplied ${ }^{14}$ with 1.05 . This larger value sometimes increases the error, in which case $c$ is divided by 1.10 . After a number of iteration (normally $\mathbf{5 0 0}$ ) $\mathrm{e}$ is not allowed to change, since it is assumed that the system is converging, and only finer and finer steps are neerted. A plot of a training session using this method is shown in Figure 17 .

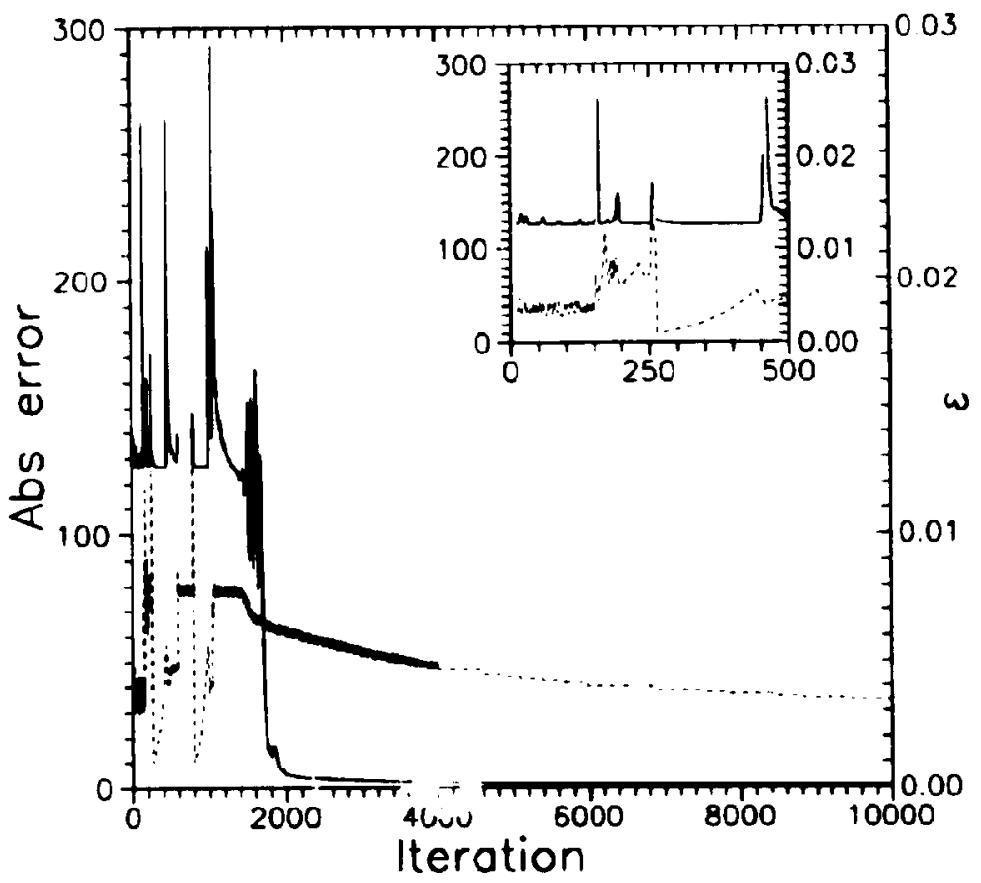

Figure 17. An example of the error (solid line) and (dashed line) plotted versus the number of iterations for a complete training session of a neut al networt trained on the Fiegenbaum series (ie $x_{i+1}=4 x_{1}\left(1-x_{i}\right)$ ). The left $y$-axis refers to the error and the right to $e$. The peaks in the emor are where the error is about to diverge (explode), as seen this is detected by the training algorithm and $e$ is decreased. The insert shows the first 500 iterntions in more detail.

\footnotetext{
II In the traditional steepent deacent e is conotant.
} 
Rin-R-702(EN) 


\section{Part III}

\section{Prediction of Local Wind Conditions}




\section{Introduction}

In this part models for forecasting local wind conditions will be developed and evaluated. They are all based on the theory laid out in the preceding sections. It must be kept in mind that the goal is that any of the models must be able to run on a PC, so that they can be used practically anywhere (as es by the operator of even a small power plant). The time spent doing the calculations must also be small, to be of any practical use. In order to determine the quality of one mondel as opposed to another, a framework for evaluating model results is constructed.

Trying to predict the wind locally is not a new thing, especially with the advancement of NWP (Numerical Weather Prediction) models. Using HIRLAM (also used in this study) Machenhauer et al (1991) predicted - among others - the wind speed at two stations (Copenhagen and Paris) using the $10 \mathrm{~m}$ wind from the model. They lound high correlations $(>0.8$ ) between the observed and predicted wind speeds at the two stations, for the +24 hour forecast. Forecasting of the wind with relation to wind esergy has also be done by Watson and Halliday (Landberg et al, 1993) using a linear regression model, regressing on the wiud speed, wind direction, time of day, rainfall output from the UK Met. Office mesoscale model. Another method, similar to the one presented here, was used by Palutikof et al (1985) . 5 predict the wind for a selection of stations in the UK. Finally, a study by Söder (1988) was carried out to assess the influence of using forecasts of the wind energy produced power in Sweden.

This part begins with a section on evaluation. Since several models will be proposed it is necessary to develop a common framework for measuring the quality (ie how well they predict the observed values) of the models. To that end, observations from 50 (originally 60 ) stations scattered all over Europe have been obtained. Three measures have been chosen in the quantitative evaluation: the mean of the error, the absolute value of the mean error, and the root-mean-squared (rms) error. There is a certain overlap between the rms error and the absolute value of the error.

Thereafter 3 models will be described and evaluated. The first is a model building in essence on the neutral geostrophic dras law, the second is a model based on the staisility dependent dras $\mathrm{law}$. The third is a model using either neural setworks or a linear relation for MOS (Model Output Statistics) on the neutra model. Furthermore, the neural networks and the linear model will be used to do furecasts, having knowledge only of the timeseries itself. Finally, a conclusion will be given, including a proposed model to do short-term prediction of local wind conditions. 


\section{Evaluation of the models}

In this exction the framework, within which the differeat modeb will be evaluated, are presented. In order to mabe the evaluation as representative as possible, a number of stations scattered all over Europe have been selected, situated at difercant geographical locations. The stations can be grouped as follows:

- contal/ron-cosstal,

- mountrinous/anon-mountainous,

- in areas where local thermally driven winds (anabatic/latabatic) previl.

The selected atations are shown in Figure 18 and listed in Table 3; a more detailed listing can be found in Appendix A. As can be seen, stations from all the countries in the EEC are present. The stations are all stations analysed in the European Wind Atlas (Troen and Petersen, 1989). A complication is that one of the stations (Exeter) has been moved during the period, this station will therefore be dealt with separately in Section $\mathbf{1 2 . 2}$.

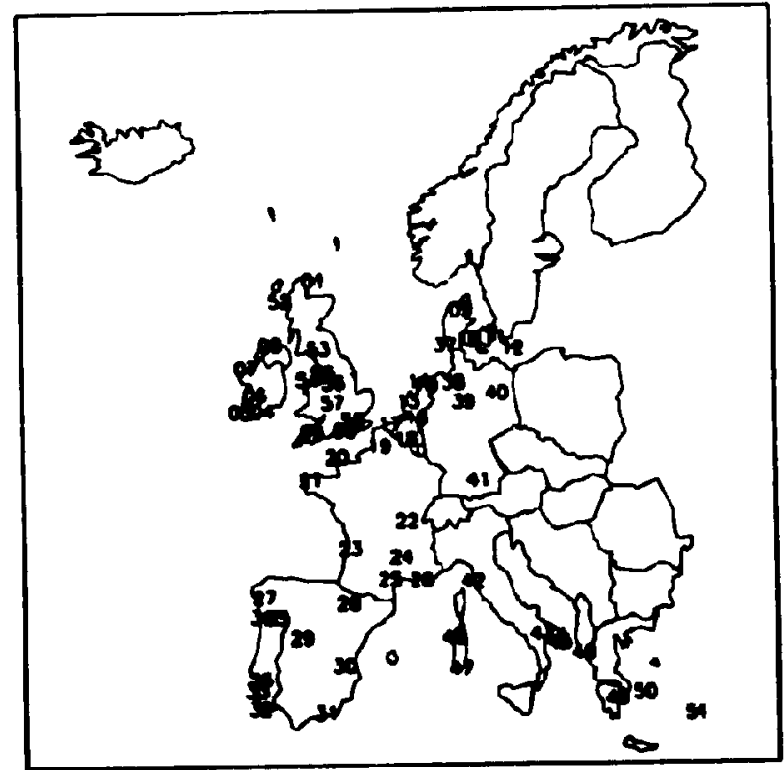

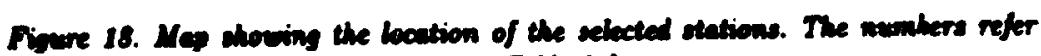
is the numbers vead in this stwd. See Talle 9 for nemes.

The ohervations cove the pesiod from Decesber 1a, 1900 wo November 31st,

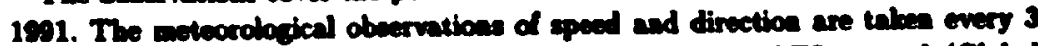
bour ( given a 10 minnte averag) and are reported to the GTS-metrock (Global Trunk System). Moet of the stations compty with WMO senadurd and report at $10 \mathrm{~m}$ ad.; for exoptions, Appeadix $\mathrm{A}$.

The data fow in this study, during the year when date was collected, was a Follows: the Denish Meteorologieal Institute gets the obervation fron the GTSwhork, the dala are collected here and seat os - together with the ontpret from

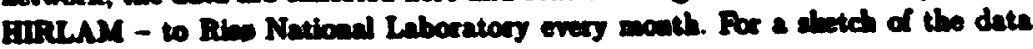

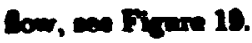


Tall 5. The selected stations, the numbers in parentheses are the numbers assigned to the stations in this study, a more detailed description can be found in Appendix A. Stations marked with an asterisk ( ) are stations that were originally selocted, but beter rejected becouse of lack of data.

\begin{tabular}{|c|c|c|c|}
\hline Beljum & Middelkertu(17) & Florennes (18) & \\
\hline Denmark & $\begin{array}{l}\text { Beldringe(10) } \\
\text { Abong(9) }\end{array}$ & Kostrud (11) & $R_{\text {mand }}(12)$ \\
\hline France & $\begin{array}{l}\text { Breat(21) } \\
\text { Bordeaux(23) } \\
\text { Lyon(22) } \\
\end{array}$ & $\begin{array}{l}\text { Chertourg(20) } \\
\text { bere(26) } \\
\text { Mont Aigoual(24) }\end{array}$ & $\begin{array}{l}\text { Abbeville(19) } \\
\text { Carcasionne(25) }\end{array}$ \\
\hline Germany & $\begin{array}{l}\text { List/Sylt(37) } \\
\text { München(41) }\end{array}$ & $\begin{array}{l}\text { Bremen(38) } \\
\text { Bertin(40) }\end{array}$ & Hannover(39) \\
\hline Great Britain & $\begin{array}{l}\text { Benbecula(52) } \\
\text { Boumemouth(60) } \\
\text { London(58) } \\
\text { Wick(1) }\end{array}$ & $\begin{array}{l}\text { Birmingham(57) } \\
\text { Eskdalemuir(53) } \\
\text { Manchester(56) }\end{array}$ & $\begin{array}{l}\text { Blackpool(55) } \\
\text { Exeter(59) } \\
\text { Volley(54) }\end{array}$ \\
\hline Greace & $\begin{array}{l}\text { Naxos }(50) \\
\text { Athing }(49) \\
\end{array}$ & Rodoe(51) & Kerhyra(48) \\
\hline Ireland & $\begin{array}{l}\text { Belmullet }(7) \\
\text { Roches Point }(4)^{*}\end{array}$ & $\begin{array}{l}\text { Valentia(5) } \\
\text { Malin Head(8) } \\
\end{array}$ & Shannon(6) \\
\hline thaly & $\begin{array}{l}\text { Brindisi(44) } \\
\text { Al-hero(46) }\end{array}$ & $\begin{array}{l}\text { Pisa(42) } \\
\text { Gioiz del Colle(43) }\end{array}$ & $\begin{array}{l}\text { Cadiari(47) } \\
\text { Lecca Galatina(45) }\end{array}$ \\
\hline $\begin{array}{l}\text { The } \\
\text { Netherlands }\end{array}$ & $\begin{array}{l}\text { Schipol(13) } \\
\text { Terchellind }(14)^{*}\end{array}$ & Eindhoven(16) & Eelde(15) \\
\hline Pontugal & $\begin{array}{l}\text { Bracanca(35) } \\
\text { Viano do Castelo(34) }\end{array}$ & $\begin{array}{l}\text { Lisboa(36) } \\
\text { Sinea }(33)^{\circ}\end{array}$ & Sagrea (32) \\
\hline Spain & $\begin{array}{l}\text { Abacete(30) } \\
\text { Sant. de Compos. (27) }\end{array}$ & $\begin{array}{l}\text { Ameria(31) } \\
\text { Sabamanca(29) }\end{array}$ & Zaragaed(28) \\
\hline
\end{tabular}

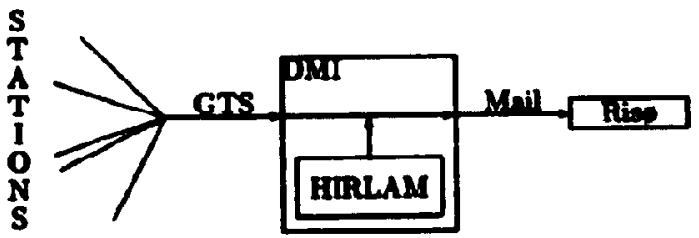

Figure 19. The date frow from the seteorological stations to the Denidh Meteorobyical Institute in the GIS-metwort, and from DUI to Aivs National Laboratory lo mail.

When anemin the sccurecy of the direvent modal it wut be borne in saind

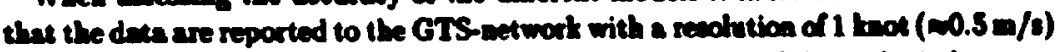
onby, cf Figure 20. This means that even a periect frrecant of the real rish, way have an abeolute error of $0.25 \times 1 \mathrm{knot}(=0.13 \mathrm{~m} / \mathrm{s})$ and a rms error of $1 /(2 \cdot \sqrt{3})$ $(=0.15 \mathrm{~m} / \mathrm{s})$. These numbers are calculated avoning that the dibtribetion is stepwhe nniform, see Appeadix D. The direction is given with a realution of 10 degrees.

An andysis of the station data quality, $Q$, defined bere ot the ratio of the

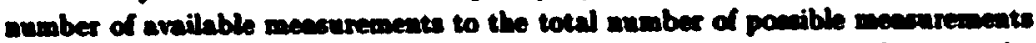

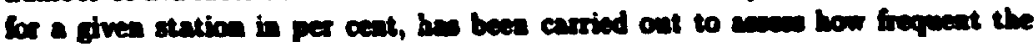




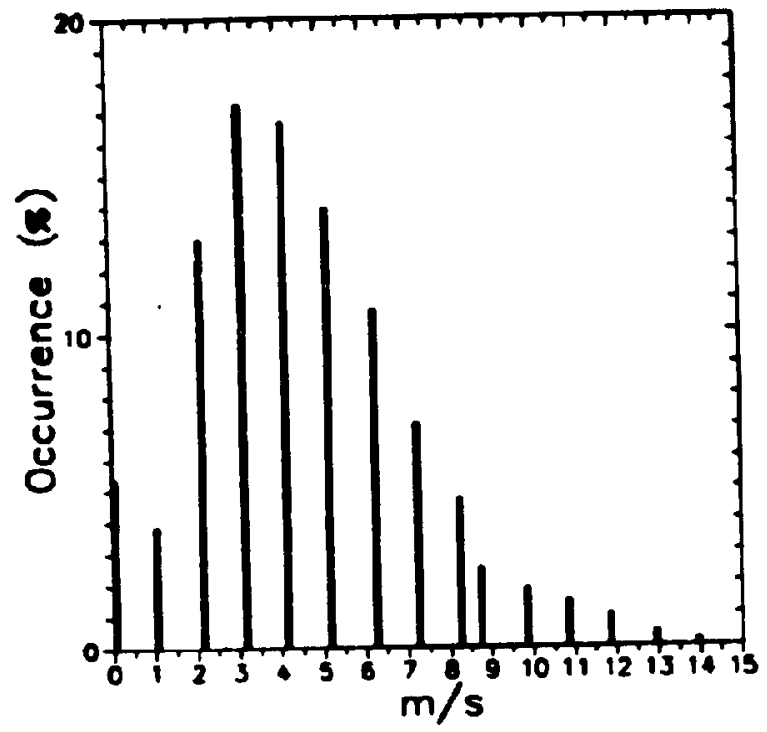

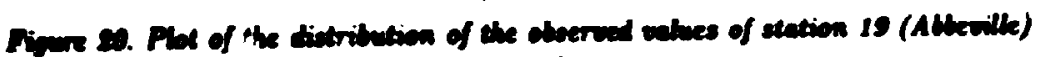
for the endive geriol. The binowing is $0.1 \mathrm{~m} / \mathrm{s}$.

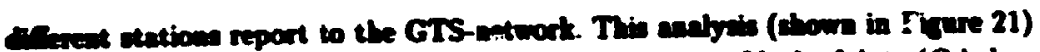

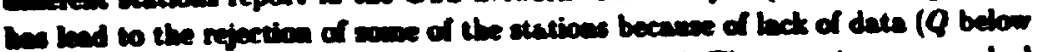

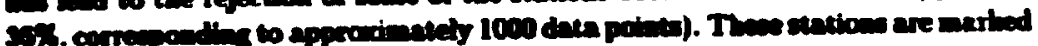

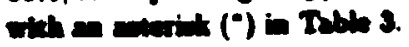

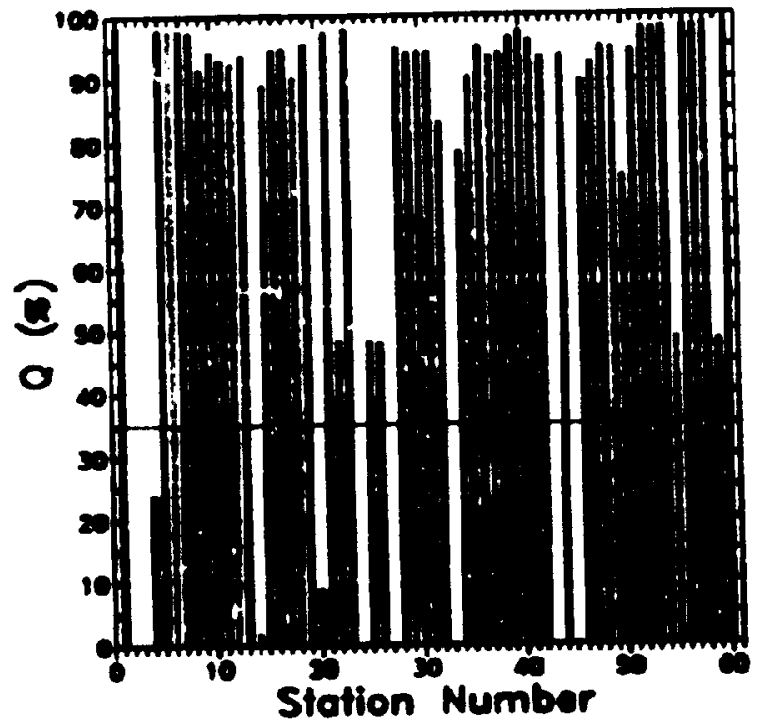

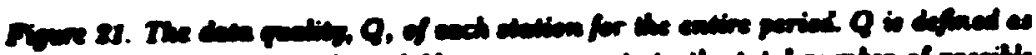

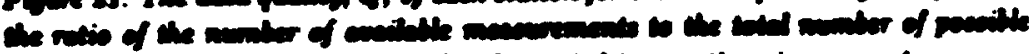

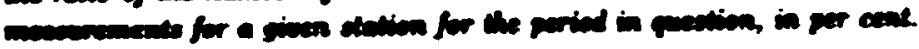




\subsection{Evaluation parameters}

To evelente the quality of the difenteat models, they were run for each of the abovepentioned stations for one year ranging from December 1 st 1920 to November 30 h 1901, and the forecats were compared with the observetions, eing the following gantitica a meaviement of the quality:

- The man vilue of the error for the ath atation.

$$
e_{n}=\frac{1}{N} \sum_{i=1}^{N} e^{(i)}
$$

where $N$ is the aumber of forecants (typically around 720 per station per bol. alead time), $e^{(i)}=x^{(i)}-x_{\text {dil }}^{(i)}$ the error of the ill preseatation, $x$ (i) ith frecant made by the model, and $x_{\text {di }}^{(i)}$ the correoponding observation.

- The mean vilue of the abolute error for the sth station,

$$
\left|e_{0}\right|=\frac{1}{N} \sum_{i=1}^{N}\left|e^{(i)}\right|
$$

where $\left|e^{(i)}\right|$ is the sbolute value of $e^{(1)}$.

- The rook-mean-squared (rms) error of the forecant for the sth station,

$$
\mathrm{RMSE}_{s}=\sqrt{\frac{1}{N-1} \sum_{i=1}^{N}\left(x_{1}^{(1)}-x_{\alpha b}^{(1)}\right)^{2}}
$$

- Ine standard devintion of the error for the oth station,

$$
\sigma_{. .}=\sqrt{\frac{1}{N-1} \sum_{i=1}^{N}\left(e^{(0)}-e_{*}\right)^{2}}
$$

For the more generel evoluation of the difeceat modeb a number of compound ganatitios are aloo deifind:

- The average wean error for all station,

$$
\left\langle e_{1}\right\rangle=\frac{1}{s} \sum_{n=1}^{s} e_{0}
$$

where $O$ indicntes averegins over all atations, and $S$ the number of stations ( $\infty 50)$.

- The standard deviation of the nean error be ench station with renpect to the nean entor,

$$
\sigma_{e_{0}}=\sqrt{\frac{1}{s-1} \sum_{i=1}^{g}\left(e_{0}-\left(e_{e}\right)\right)^{9}}
$$

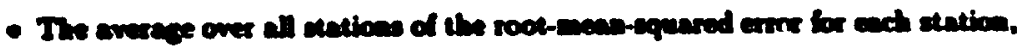

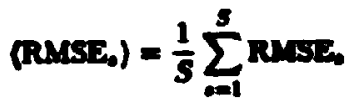


Other parameters are also typically used to evaluate predictions of wind speed and direction (es the vector error), but since we are dealing solely with wind predictions for wind turbines, which turn themselven into the wind, the abovemeationed parameters (all focusing on the speed) have been choeen.

In wind energy meteorology, the wind in often weighted by a typical powercurve for a wind turbine (ie a curve giving the power output from a turbine as a function of the wind speed). This means that wind speeds below a certain threshold, the cut-in speed, will not be taken into account, because the turbine will not be rotating. Speeds above the cut-ont speed will also be rejected, because the turbine is stopped to avoid structural filures. In between these two speeds, the wind energy is converted into power, sccording to the power-curve of the turbine. An example of a power-curve is give in Figure 22. This method has not been used in this study. An example of its use on the forecants generated in this study, can be found in Landberg and Ingham (1992).

A more elaborate evaluation of the performance of the forecasts from this study can be found in Landberg et al (1993), where the forecasts have been used as input to the Reading University/Rutherbord Appleton Laboratory National Grid Model, which is a model modelling the English and Welsh electric grid. This model has been run with different degrees of penetration of wind energy (up to 40 per cent).

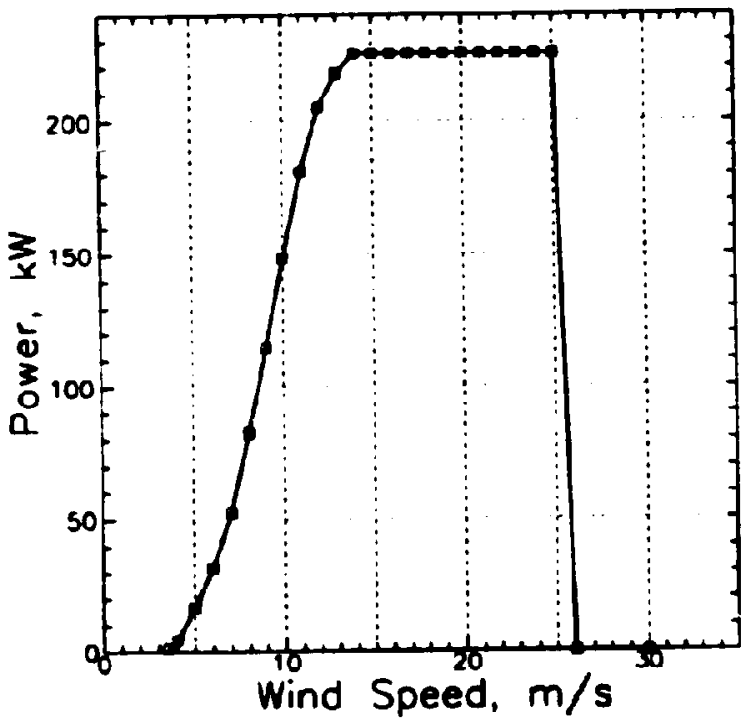

Fipure 22. A power-curve for a typical $225 \mathrm{kWF}$ wind borbine (Veates V27). The cul-in wind speed is $3 \mathrm{~m} / \mathrm{s}$, and the cut-out speed is $25 \mathrm{~m} / \mathrm{s}$.

The error in diraction is not directly anemed, but dince the correct prediction of the wind is tightly bibed to the direction (becance the comections in WMP are direction dependent) it is evaluaced through the evaluation of the speed. To get a iden of the enor in the brecasted disection, acutter plote of forecanted versus oberved direction will be wed.

The correlation cocincient has also been loobed into; it was found, however, that it wee sol able to diatinguish mell between good and bad predictions. 


\subsection{Persistence}

In order to estublish a refierence model, the persistence model has been chowen. The persistence model is the worst enemy of any forecast model in meteorology (and in many other fields, tool). It has the advantage of beine simple (very simple). and that it quite often gives good results. The model is as collows:

$$
\begin{aligned}
& u_{t+1}=u_{1} \\
& \theta_{t+l}=\theta_{i}
\end{aligned}
$$

This equation can easily be stated in words: the quantity one wants to forecast is the same $\ell$ hours abead as it is now. The reason why this is a good approximation to How in the atmosphere, is that the atmosphere can be considered quasi-atationary, ie changing very slowly. A characteristic time scale in the atmosphere is $f^{-1}$ where $f$ is the Coriolis parameter. Using $10^{-1} s^{-1}$ for $f$ gives that thes scale is approximately 3 hours.

In this study the persistence model will be used as a frame of reference, because if the developed models are not better than persistence, they can not be considered as modelling the actual process, and certainly not be recommended for forecasting. Another reason is that most predictions for scheduling purposes presently are using this model.

In the statistical evaluation following, the mean error of the persistence model will typically be very small; this can easily be explained, since it follows from the definition of tbe erroe that:

$$
e_{\text {porain }}=\frac{1}{N-l}\left(\sum_{i=1}^{\ell} x_{i}-\sum_{i=N-\ell+1}^{N} x_{i}\right)
$$

where $l$ is the look-ahead time and $x_{\text {, the }}$ ith value of the timeseries. As can be wen from this expreasion, the mean error depends only on the 'head' and 'tail' of the time series, so is the series of a certain extent, ie $N$ large, $t<N$, and the bead of the series is of the sume magnitude as the tail, the mean error will be very suall. The rus error, on the other hand, can get quite big: when $\ell$ is so large that the series can be considered un(autojocrrelated the peraistence model's standard deviation of the erroc, becomes equal to the rtandard deviation of the timeseries times $\sqrt{2}$.

As an example of the abilities of the persiateace model, the persiatence forecast 6or Wick (stanion 1) is shown in Figure 23. As can be seen from this figure the rms cror in quite sall for the frat 6 boura, it then rives to a certuin level and stays there. For all the station there wemas to be a rall dip at 24 bours, this is also neen in the figne. A posaible explanation of this is that the atmosphere to a very

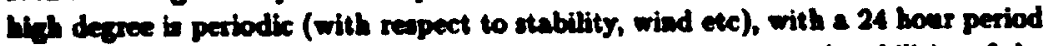
(drive by the solas heating). It is more intereating 10 compare the abilities of the modet developed in the following to the abilitien of the peraidence model, this will be dowe in everal places in the following. 


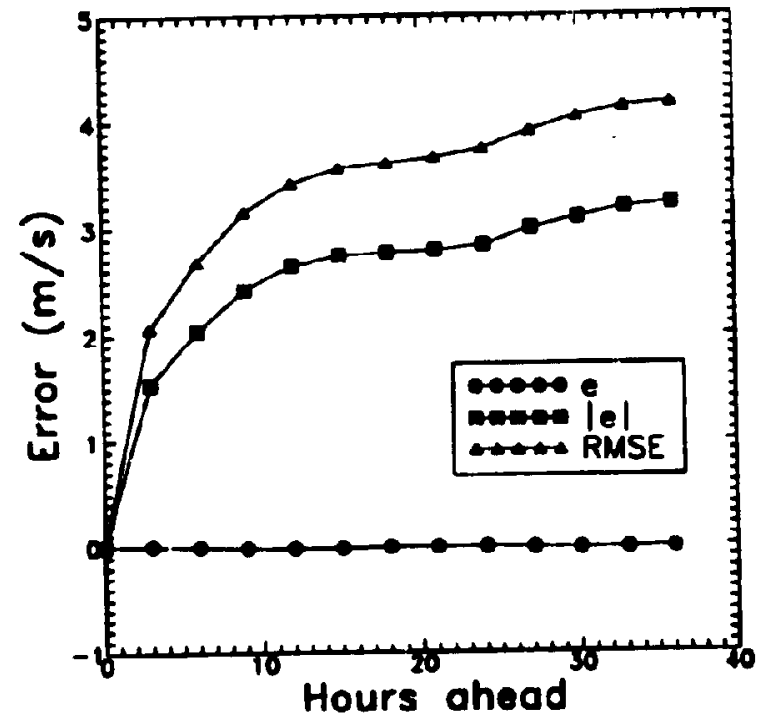

Figure 23. The mean error, e, mean ebobule error, | e l, and mis errer, RMSE, (all in $\mathrm{m} / \mathrm{s}$ ) verow forecact length in howe for the persiatence madel for Wiet

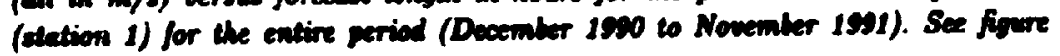
for legend. 


\section{Input to the models}

In the following the input to the diferent models used to predict the wind losally will be described. The input to these models, are the output from HIRLAM and WAsP.

\subsection{Output from HIRLAM}

All models using meteorological forecasts use the output from HIRLAM. In order to have the possibility of trying out different models, as eg stability dependent models, or models using different winds (geostrophic/non-geostrophic), the following quantities have originally been selected:

At the surface:

- The surface temperature over land, $T_{s}^{\text {land }}$

- The surface temperature over water, $T$ water

- The sensible beat flux over land, $H_{a}^{\text {land }}$

- The sensible heat flux over water, $H_{i}^{\text {water }}$

- The latent heat Aux over land, $H_{i}^{l a n d}$

- The latent heat flux over water, $H_{i}^{\text {water }}$

- The $x$ - and $y$-components of the geostrophic wind, $v_{y}^{(0)}$

In the model levels at $30,137,359,724,1266,1979 \mathrm{~m}$ above the surface in the HIRLAM grid:

- The $x$ - and $y$-components of the actual HIRLAM wind, $U_{A}^{(1)}$

- The $x$ - and $y$-cumponents of the geostrophic wind, $U_{g}^{(1)}$

- The potential remperature, $\theta$

- The pressure, $p$

- The humidity, $Q$

- The vertical wiad, $\boldsymbol{w}$

For each station all of the above quantities are extracted in the four surrounding grid-points, and then interpolated to the location of the station, using bi-linear interpolation (cf Figure 24).

\section{Conversion of the HIRLAM data}

Since the physiral quantitices of HIRLAM are reported following normal mathematical conventions for vectors (ie the direction of the vectors are is the direction they point, angles are defined sc that 0 degrees is due cast and increasiag counterclockwive) and the obervations are reported wing (he meleorolugical conventions (iv the direction of the vector is from whore it is coming, having 0 degrees due worth and angels increasing clockwise) it is mecenary to traneform from the one system to the other. This is done in the following way:

In the HIRLAM coordinate system we have the $x$ - and $y$-components of the wind, $(U, V)$, these are converted into polar coordiales by:

$$
\begin{aligned}
r & =\sqrt{U^{2}+V^{2}} \\
& =\tan ^{-1}\left(\frac{V}{U}\right)
\end{aligned}
$$

Converting this set of equations into polar coordinates in the meteonological coordinate aytem, we get 


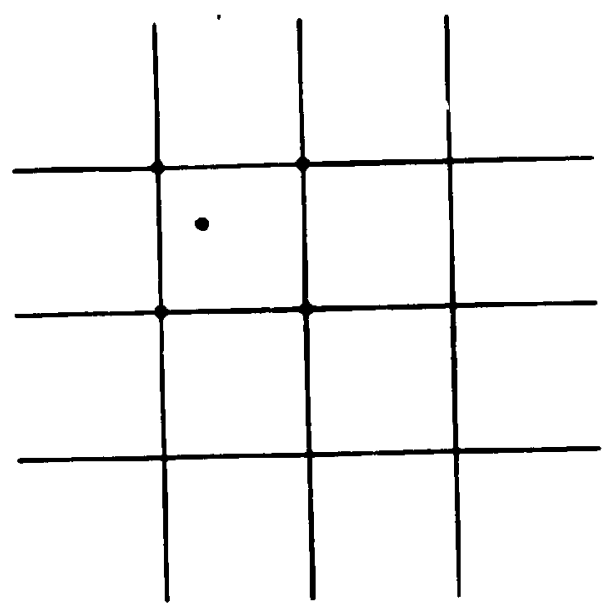

Figure 24. The grid with a station (solid circle) and the \& nearest grid points (circles) wed to interplate the physical puentities at the stations. The interpolation in done by bi-linear interpolation.

$$
\begin{aligned}
& r_{\text {met }}=r \\
& t_{\text {met }}=90-0+180
\end{aligned}
$$

where $+\infty 0$ and the minus on are to coavert to the new coardinate sjetem, and +180 b to comply with the metocrological dosinition of the direction, ic the direction from which the wind comes. This leads to, that the $x$ - and $y$-componento of the wind in the weteorological syatem, $\left(U_{\text {met }}, V_{\text {met }}\right)$, are given by

$$
\begin{aligned}
U_{\text {mat }} & =r_{\text {met }} \cos \left(\theta_{\text {met }}\right) \\
& =r \cos (90-\theta+180) \\
& =-r \sin (0) \\
& =-V \\
V_{\text {met }} & =r_{\operatorname{met}} \operatorname{din}\left(\theta_{\text {met }}\right) \\
& =r \sin (90-\theta+180) \\
& =-r \cos (0) \\
& =-U
\end{aligned}
$$

and

rimetivaly. 


\subsection{Output from WAsP}

The WAP model is run for each of the 80 atations to make a correction matrix for the beal effects at the site. Note that this is not the normal way of using the program, since no horizontal extrapolation is made, only a calculation of the difierent iocal effects at the site. To perform these calculations a description of the following is needed for each station:

- The dimensions (beight, width, depth, and porosity) and positions of cloce-by obstacles.

- The roughness rose, ie the sector-wise distribution of the roughness, of the site.

- The orography of the surrounding terrain, in the form of a digitised map.

All the information concerning the stations is taken from the work done in preparing the European Wind Atlas (Troen and Petersen, 1989). For eacn of the stations a file containing the effect of the aforementioned information (as calculated by WAP) plus a 'meso-scale' roughness (calculated using the formula in Eq. 100) in twelve 30-degree sectors has been generated, the matrices are listed in Appendix B. Note, that an implicit assumption, is that the free-stream wind is blowing in a fiat terrain, with no obstacles, and a uniform rougnness.

The only station that has been analysed in this study is station 59 (first Exeter). since this station has been moved during the selected period. The analysis of the new site, RAF Dunikeswell, will be described in the following.

\section{WAP analysis of RAF Dunkeswell}

In the following the station will be andysed along the lines laid out in the European Wind Atlas. Such an analysis includes: an overview description of the site, and deacription of the orography, roughness and obstacles.

To carry out this analysis, the site has been visited and photographed and 1:50000 and 1:25000 scale maps have been studied and digitised.

Deacription The meteorological station at RAF Duabeswell (WMO code 3840) is situated at position: $3^{\circ} 14^{\prime}$ W and $50^{\circ} 52^{\prime} \mathrm{N}$ (UTM: $312782 \mathrm{mE},(6) 107496 \mathrm{mN}$ ), the height above mean sea level in $250 \mathrm{~m}$. The mast is $10 \mathrm{~m}$ high and is equipped with a cup anemometer and a wiad vase both at $10 \mathrm{~m}$ agl. The station sturted operating on of June 1st, 1991, and took over from Exeter (WMO code 3839), shich eaded operation on the May 31st, 1991. The station in at an airield on a plateau, and is surrounded by quite a fer bow building.

Orography The orography of the station's surronading terrain has been dighthed wing the following mapa: Landranger 181 (Orduance Survey): Minebead \& Brendoa Hill area, scale 1:50000, Landranger 192 (Ordannce Survey): Exeter, Sidwonth \& surrounding area, scale 1:50000, Pathlader 12:0 (Ordnance Survey): Honiton \& Collompton, cale 1:25000. The digiticed map is showa in Figure 25. If is made in such a way that the resolution close to the site is maximal (ie beight increments of $5 \mathrm{~m}$ ), further away from the site the resolution in decrensed $1010 \mathrm{~m}$, furtbeat away, it is decreased even further to $25 \mathrm{~m}$. This is in compliance with the idea behind the zooming grid in the orographic model of WAP, neection 5.1 . A 3-dimensional plot of this map is shown in Figure 28.

Roupheen From studying tho terrain and the mapa mentioned in the previous paregraph, the following roughrees ctane in the surrounding sea bave been ideatilied: 


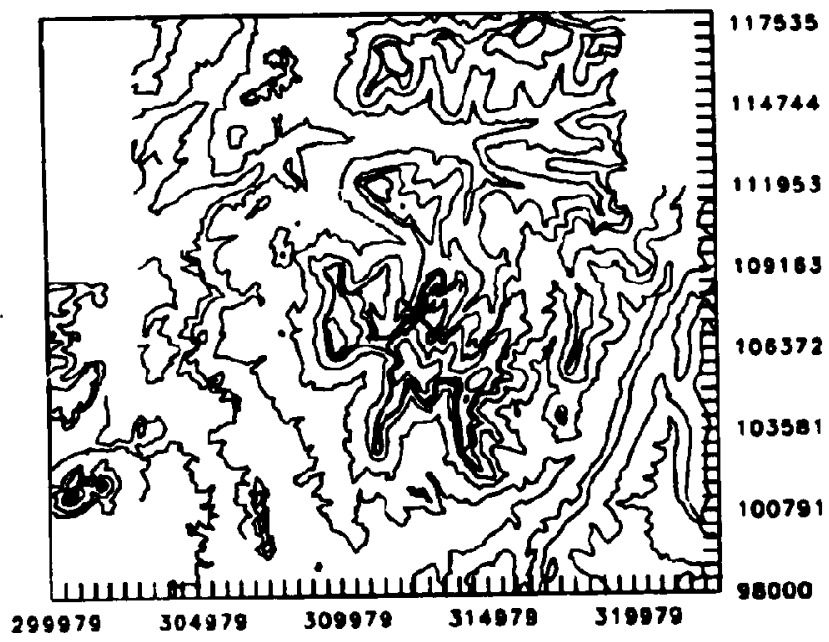

Figure 25. The digitised orography of RAF Durkeswell. The mast is at (912782,107496), marked with a cross.

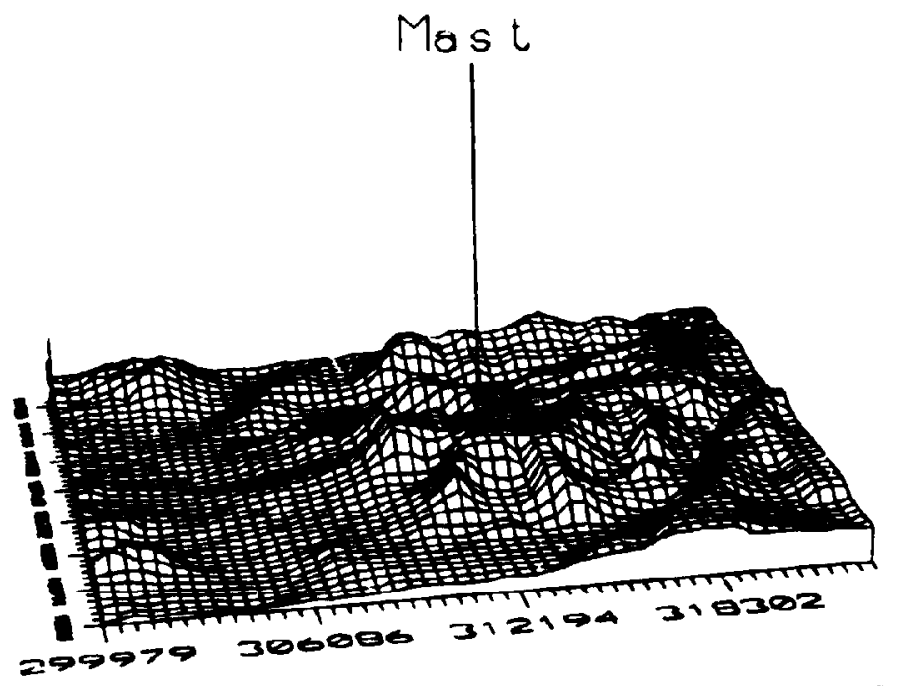

Figure 25. The 9-dimencional plot of the digitived onography of RAF Dunteswell. The vertical exasperation is 10.

- Water (roughness length: $0.0 \mathrm{~m}$ )

Ia Farmiland (roughneas leagth: $0.1 \mathrm{~m}$ )

III Villages (roughwee length: $0.5 \mathrm{~m}$ )

IIIb Small villages (roughnew leagth: $0.4 \mathrm{~m}$ )

IIIc Plantation, non-coniferous (roughnea length: $0.3 \mathrm{~m}$ )

IIId Plantation, coniferous (soughnew length: $0.4 \mathrm{~m}$ )

IIle Plantation, mixture of IIlc and IIId (roughness length: $0.3 \mathrm{~m}$ )

Noce that in WASP water is given the roughnea leagth $0 \mathrm{~m}$. This is for WAP to be able to creat anbility over water (which is difereat foon ove li. di correctly. 
A plot of the digiticed ronghnes map is shown in Figure 27 and the resulting roughneas rose of the mant is shown in Table 4. As can be seen from this, the basic Indscape type is farmiand, osly slightly perturbed by the presence of the woods and villages.

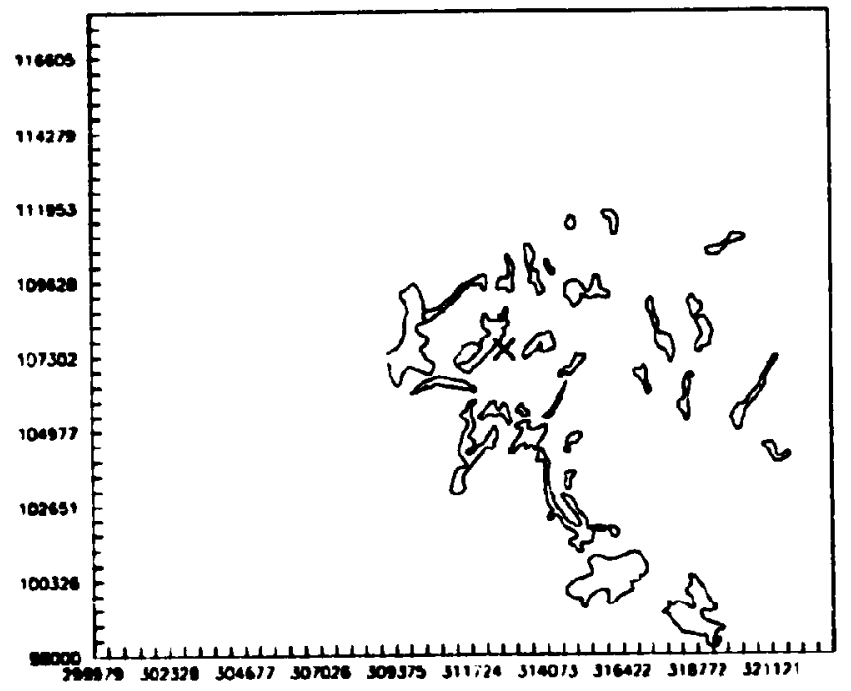

Figure 87. The map showing the different identified roughness areas of the surroundings of RAF Dunkeswell. The mast is located at the cross.

Talle 4. The roughness rose, ie che sector-wise distribution of the roughness length, of RAF Dunkeswell, derived - by WAP- from the map ahoun in Figure 27. 20 is the aerodynamic roughness length (in $m$ ) afier the ith roughness change and $d(i)$ the distance (in $m$ ) to the ith roughnes change.

\begin{tabular}{|c|c|c|c|}
\hline secter & $8^{(0)}$ & (1) & $2|1\rangle$ \\
\hline 0 & 0.1060 & & \\
\hline 30 & $0.108 s$ & & \\
\hline 60 & 0.1046 & & \\
\hline 90 & 0.1077 & & \\
\hline 120 & 0.1016 & & \\
\hline 150 & 0.1140 & 20920 & 0.0000 \\
\hline 180 & 0.1053 & 20350 & 0.0000 \\
\hline 210 & 0.1052 & & \\
\hline 240 & 0.1034 & & \\
\hline 270 & 0.1977 & 3461 & 0.1001 \\
\hline 300 & 0.2634 & 806 & 0.1057 \\
\hline 330 & 0.2398 & 1049 & 0.1016 \\
\hline
\end{tabular}


Obutacles From photos taked on-rite and mape of the aren, the obstacles (in this case only houses) listed in Table 5 and shown in Figure 28 have been identified. The dimension (beight, width, and depth) have been determined from the on-site photes.

Table 5. The obstacles at RAF Dunkeswell. $\alpha_{1}$ and $a_{2}$ are the angles of the two closest corners of the obstacle (in degrees from north), $r_{1}$ and $r_{2}$ are the distances to the aforementioned corners (in $\mathrm{m}$ ), $h$ is the height of the obstacle (in $\mathrm{m}$ ), $d$ the depth (in $\mathrm{m}$ ), and $P$ the porosity ( 0 means solid).

\begin{tabular}{rrrrrrrr}
\hline & $a_{1}$ & $r_{1}$ & $a_{2}$ & $r_{2}$ & $h$ & $d$ & $P$ \\
\hline 1 & 83 & 25 & 97 & 25 & 3 & 15 & 0.00 \\
2 & 113 & 100 & 123 & 100 & 5 & 9 & 0.00 \\
3 & 146 & 147 & 148 & 147 & 5 & 10 & 0.00 \\
4 & 157 & 261 & 163 & 261 & 6 & 6 & 0.00 \\
5 & 164 & 112 & 166 & 112 & 3 & 2 & 0.00 \\
6 & 23 & 281 & 30 & 281 & 5 & 15 & 0.00 \\
7 & 50 & 360 & 58 & 360 & 8 & 20 & 0.00 \\
8 & 6 & 385 & 19 & 398 & 6 & 8 & 0.00 \\
9 & 124 & 126 & 126 & 124 & 6 & 8 & 0.00 \\
\hline
\end{tabular}

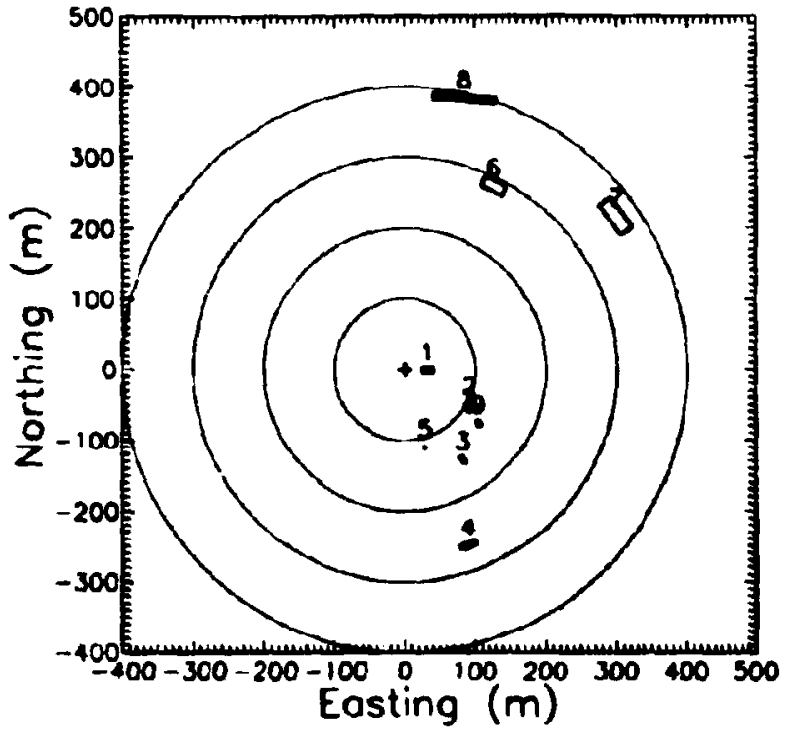

Pigure 28. Plot of the obstacles identified at RAF Dunkenmell. The mast is situnted at $(0,0)$.

Renult the The resulting correction matrix, to be used in this study, is listed in Table 6. As ran be seen from this, the local corrections with respect to obstacles a well as roughness are quite small. The orography - on the ofher hand - does huve come infuence (an increase of the undiaturbed wind of, at the most, $20 \%$ and a turing of the wiad of 7 degrees). 
Table 6. The correction matrix used in the models based on the geostrophic drag law. $z_{0}$ is the roughness used in this law, and is an avereged ('meso-scale') raughness. For each local efject, the percentage of over/under-speed (0 means thet the local effect in question has no influence on the free-stream wind) and the tuming (positive clock-wise) are given. All correction are given per sector (to be found in the column marked 'Dir').

\begin{tabular}{rrrrrrrrr}
\hline Dif & \multicolumn{1}{l}{ Obstacles } & \multicolumn{3}{l}{ Roughness } & \multicolumn{3}{c}{ Orography } & $z_{0}$ \\
\hline 0 & -1.126 & 0.000 & 0.000 & 0.000 & -0.198 & -5.868 & 0.1060 \\
30 & -1.702 & 0.000 & 0.000 & 0.000 & -4.855 & -1.008 & 0.1036 \\
60 & -2.102 & 0.000 & 0.000 & 0.000 & -2.960 & 4.612 & 0.1045 \\
90 & -0.792 & 0.000 & 0.000 & 0.000 & 7.658 & 6.276 & 0.1077 \\
120 & -6.417 & 0.000 & 0.000 & 0.000 & 20.801 & 1.331 & 0.1016 \\
150 & -2.275 & 0.000 & -7.980 & 0.000 & 12.092 & -5.341 & 0.0521 \\
180 & -0.546 & 0.000 & -8.121 & 0.000 & -0.198 & -5.868 & 0.0468 \\
210 & 0.000 & 0.000 & 0.000 & 0.000 & -4.855 & -1.008 & 0.1052 \\
240 & 0.000 & 0.000 & 0.000 & 0.000 & -2.960 & 4.612 & 0.1094 \\
270 & 0.000 & 0.000 & -4.752 & 0.000 & 7.658 & 6.276 & 0.1203 \\
300 & 0.000 & 0.000 & -7.561 & 0.000 & 20.801 & 1.331 & 0.1142 \\
330 & 0.000 & 0.000 & -7.058 & 0.000 & 12.092 & -5.341 & 0.1106 \\
\hline
\end{tabular}

\section{Porecasting RAF Dunkeswell}

In this section, a brief discussion of using the HIRLAM forecasts given for Exeter together with the local corrections for RAF Dunkeswell, evaluated on the data from RAF Dunkeswell, will be given. The distance between the two masts is approx $20 \mathrm{~km}$. Since only forecasts of the large-scale fow from the old site are available, it is expected that this separation will result in quite large errors on the forecasts. Studying Table 7 this is seen to be the case, since the HIRLAM/WASP model at no time performs better than the persistence model.

These results give an idea of the sensitivity of HIRLAM, because there is seen a marked diference between the forecast at Exeter (where the HIRLAM forecast and the WASP matrix are valid), see Appendix C, and then using the same forecast only $20 \mathrm{~km}$ away, bearing in mind that the resolution of HIRLAM is $51 \mathrm{~km}$. We can conclude that the bi-linear interpolation (as compared to eg just taking the nearest grid point) is needed for the forecasts to be as accurate as poesible. 
Table 7. The result of predicting RAF Dunbeswell woing HIRLAM forecante for Breter and the WAP matrix for RAF Dunbeowell ('IIRLAM/WAP') compared to the persidtence forecast ('Persistence'). The period evaluated is from June 1991 to November 1991. The caluma labelad ' $F$ ' is the forecasting time (in houra), ' $E$ ' is the mean of the error, $\mid \mathrm{el}$ ' is the mean of the abeohte error, and the column ineled 'RMSE' is the rms error of the forecant. The cutries marted ' $N / A$ ' denote that the to hour peraistence foncenst is not defined.

\begin{tabular}{|c|c|c|c|c|c|c|}
\hline \multirow[b]{2}{*}{$+P$} & \multicolumn{3}{|c|}{ HIRLAN/NMP } & \multicolumn{3}{|c|}{ Perristance } \\
\hline & $e$ & lel & RMSE & e & $|e|$ & RMSE \\
\hline 0 & -0.400 & 2.053 & 2.697 & N/A & N/A & $N / A$ \\
\hline 3 & -0.146 & 2.137 & 3.015 & -0.004 & 1.030 & 1.443 \\
\hline 6 & 0.020 & 2.118 & 2.756 & 0.001 & 1.384 & 1.855 \\
\hline 9 & 0.169 & 2.025 & 2.748 & -0.001 & 1.601 & 2.127 \\
\hline 12 & -0.178 & 2.153 & 2.871 & -0.000 & 1.753 & 2.202 \\
\hline 15 & -0.087 & 2.151 & 2.012 & 0.003 & $1.7 \%$ & 2.342 \\
\hline 18 & 0.045 & 2.155 & 2.700 & -0.001 & 1.794 & 2.398 \\
\hline 21 & 0.172 & 2.100 & 2.630 & -0.0013 & $1.7 \mathrm{0}$ & 2.398 \\
\hline 24 & -0.169 & 2.252 & 2.934 & -0.010 & 1.795 & 2.390 \\
\hline 27 & -0.113 & 2.180 & 2.763 & -0.014 & 1.00 & 2.454 \\
\hline 30 & $0.0: 9$ & 2.238 & 2.811 & -0.018 & 2.012 & 2.575 \\
\hline 33 & 0.187 & 2.129 & 2.658 & -0.019 & 2.117 & 2.00 \\
\hline 39 & -0.172 & 2.18 & 2.831 & -0.017 & 2.122 & 2.100 \\
\hline
\end{tabular}




\section{The neutral model}

In this rection, the analysis leading to the development of the forecasting model will be deacribed. The model is basad on the gecotrophic drag law and the logarithmic wind profile in their neutrel form. This model will form the basis of the models developed later on.

\subsection{First-guess model}

The general method of predicting the local wind, ie the wind where the local effect of the shelter trom obatacles, che change in the roughneas of the surface, and of the orography are taben into account, when knowing the meteorological conditions at another place, is depicted in Figure 5. This method has been developed by Troen and Petersen (1989) for use in the European Wind Atlus. Here the method was used to make a horizontal extrapolation of the wind climate fom a measuring site to a site of intereat, where no mensurements existed. In this project the tentative idea is to apply this method to the HIRLAM forecast, ie clean the forecast for the efiect of the low resolution orography and roughness descriptions, and then insert a high-resolution map of both the orography and the roughness, coveriag the area around the site of intereat. This is depicted in Figure 29. The difference between this method and the Wind Aths Methodology is that we are not doing a horizontal extrapolation here, but a carrection of the wind at the sile. The individual steps are analysed in detail in the following.

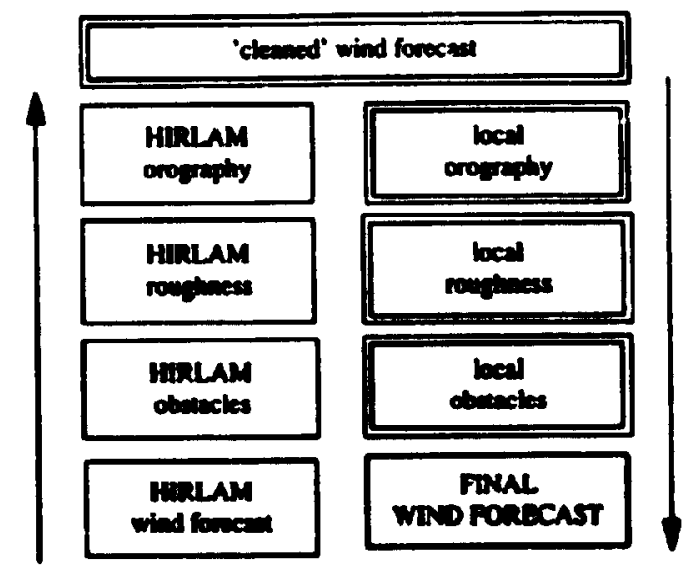

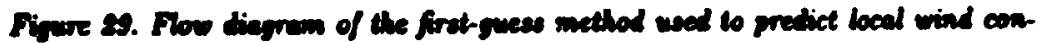

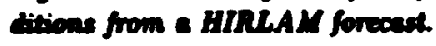

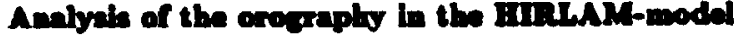

By calculating the local efect at the site of the orogrephy in the BIRLAM-model by wing the fow modd frow WNP, it is found that even in the moot monntainous

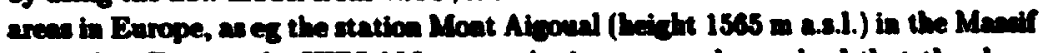

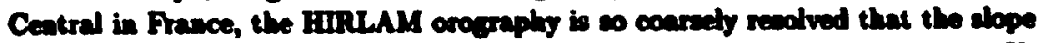

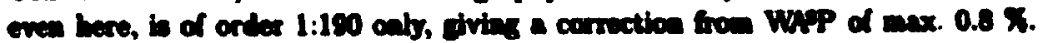

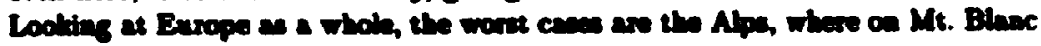




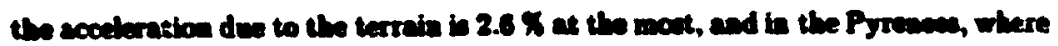

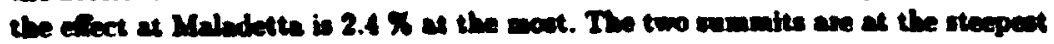

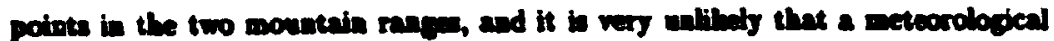
ant, and eves more wo a whed turbine, will be pleced there. Thi meand that the bo lobelad "HIRLAM orography" in Figure 20 ean be resoned in this atedy". This does not mean that the orography he no flect in the BlliLAM wodel, on the contrary: on the hrge scale it hes cardiad elect, which is one of the remons why a

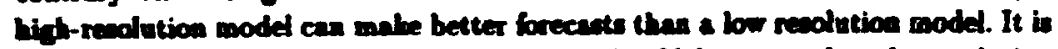

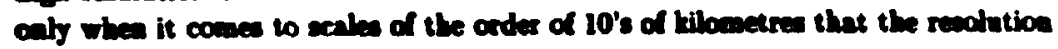
of BillulM is not reficiont.

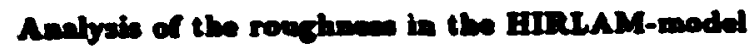

In the framework build so far, the eneration of internal boundary layers by changes in ronghisen, tas to be considered. However, since the geveration and frowh of these layes is not modebed is BIRLAM - becawe of the locality of ouch an effect - it would be wrong to correct the wind from HIRLAM for this efect. Arocker appect of this, is that the ronghowes in IIRLAM are given in grid-points, and wot a bives desoting the change in the ected roughreas, any number of changes in ronghnes can therefore be generated, jeat by increasing the reolution of the contours drawn. This means that the box hbeled "HIRLAM roughers" in Figare 20 has to be deleted.

Anabrab of abalter from obetacles in the MIILAM-moded

Becance of the relative bo recolution in FIRLAM, it is withont moaning to include sheter from obtacles, since this efect is an a - by br - too mall scale, and since so obatedes of any bind are modeled in BIRLAM. Beace, the box in Figare 29 bicled "HIRLAM-obotacies" mant alo be left out.

\subsection{The resulting neutral model}

The conclusions draw from the andycls of the FIILAM wodel in the previowe

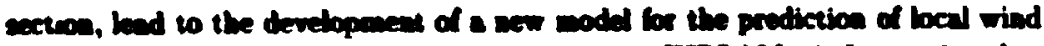

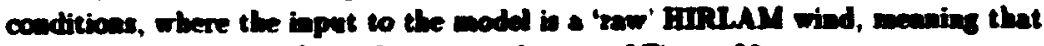

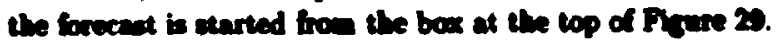

To be sure and to introduce any umend boudary-laye elect from the HIR-

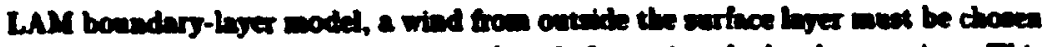

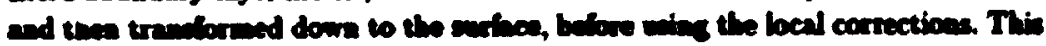

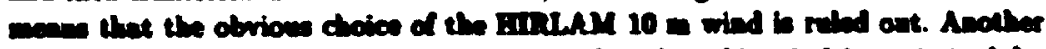

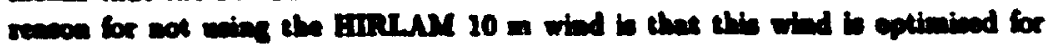

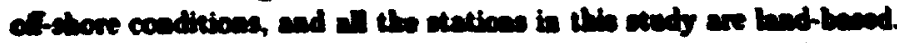

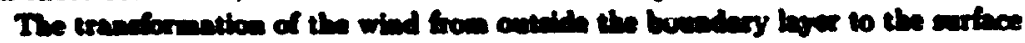

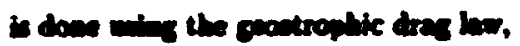

$$
\frac{G}{a_{0}}=\frac{1}{x} \sqrt{\left[b\left(\frac{m_{0}}{f_{n}}\right)-A\right]^{2}+B^{2}}
$$

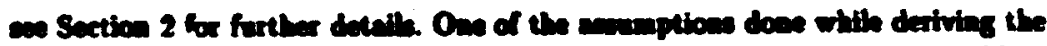

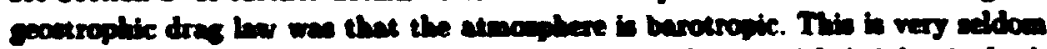

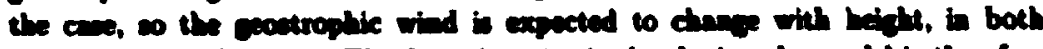

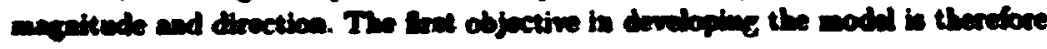

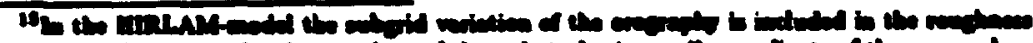

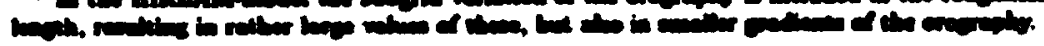


to decide the beight from which the wind should be taken. Beades, since the vertical coordinate syntem in HIRLAM is of the sigm-preasure hybrid type, ie with preanure surfaces (delined differently with height) as the horizontal layers, leading to dificulties in calculating the geostrophic wind, it must aleo be resolved whether it is the goostrophic wind or the actual wind from the model, that is the beat approximation to the theoretical geostrophic wind, $G$, used in the dras Lw. Note, that in the expression for the geontrophic wiad, there is no beight dependence, 20 there is a freedom of choice, at least a priori.

Having found the proper wind from HIRLAM, the model will be as follows (cf Figure 30): Taking the forecasted wind from HIRLAM that represents the beat approximation to the theoretical geostrophic wind, and entering this wind into

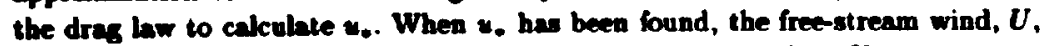
at the site of intereat is calculated using the logarithmic wind profile:

$$
\frac{U}{u_{0}}=\frac{1}{\kappa} \ln \left(\frac{z}{z_{0}}\right)
$$

Finally the free-stream wind is corrected for the effects of the local topography; as found by WASP. The resulting wind is the local wind.

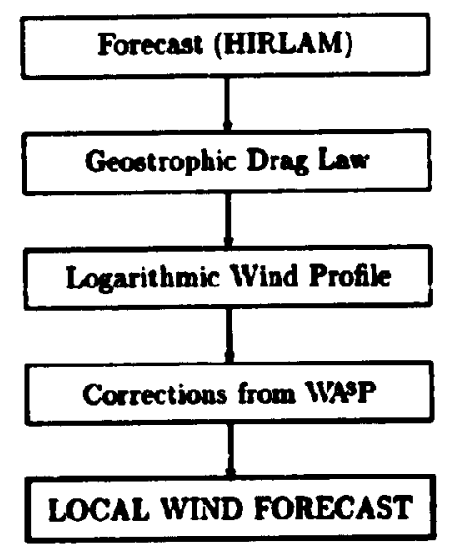

Figure 30. A simple sletch of the resulting model.

The sodiel

In this section the model will be described in some detail, s low-chart is shown in Figure 31.

The first step is to get the forecasted large-scale wisd representing the geostrophic wid, in this work this is dowe by reading a fle combaining HRLAM forecasts for all forecal times for all stationa. In as operational model for a aincle station the forecant should be either typed in from a ef fax, or electroaically obtained by a direet link to the compater running the large-scale forecasting model. Note thas the oaly contide information meeded is the $x-$ and $y$-componeat of the forecanted brge-seale wiad, at each loreciat atep. In the present model where we are doing a

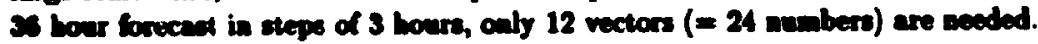


The reat of the calculations are dose locally on the PC. Since the large-scale model is run twice a day, a total of 48 numbers are needed a day.

To get the rest of the variables in the geostrophic drag law (ie $z_{0}$ and $f$ ) for the station in question, the WAPP-matrix generated as deacribed in Section 12.2 is read to get the roughneas. The latitude of the station is read from another file containing this information. This step is only necesary here because several stations are dealt with simultaneously, in the case of a forecast for an individual station these parameters would appear as constants in the program.

All the variables in the geostrophic drag law have now been determined, and it is possible to calculate the friction velocity, $u_{*} . u_{*}$ is not given implicitly in the geostrophic drag law, hence it is not possible to solve the dras law analytically, therefore a numerical iterative method, based on a combination of the NewtonRaphson method and bisection is used, see Prese et al (1986). Since $z_{0}$ (and the rest of the quantities in the WASP-matrix) is given in the 12 sectors, a function using linear interpolation is used to provide values for any direction. To start the iteration a guess for $\boldsymbol{u}$. is needed, here vilue of $0.3 \mathrm{~m} / \mathrm{s}$ is used. Furthermore, - guess of the direction at the surface is needed to get a value of $z_{0}$, the rule of thumb saying that this value is equal to the direction of the geostrophic wind less $25^{\circ}$ is used. The iteration can now be started, typically, $u$. is found after a few (< 10) iterations. It is stopped, when the difference between the gecstrophic wind calculated using $u$, and the geostrophic wind from the large-scale model is less than $\pm 10^{-2} \mathrm{~m} / \mathrm{s}$. Because of the variation of the roughness with direction, it has appeared necessary to check, whether the direction of the geostrophic wind calculated using the $\boldsymbol{u}$. from the iteration, is actually equal to the direction of the wind from the large-scale model. If this is the case the correct value of $\boldsymbol{u}_{\text {, has been }}$ found, if not the iteration is continued.

Assuming neutral conditions, it is now possible to calculate the free-stream wind at the site by using the logarithmic wind profile. To introduce the local effects of the site the fle bolding the WASP matrix is read and the corrections are applied to the free-stream wind. We have now got the predicted local wind at the site.

Hnving the forecasted largescale wind, the program runs for a few seconds per corecant time per station on a 386-PC, ie the whole 36-hour forecast in 3 bours steps is dowe in less than half a minute. 


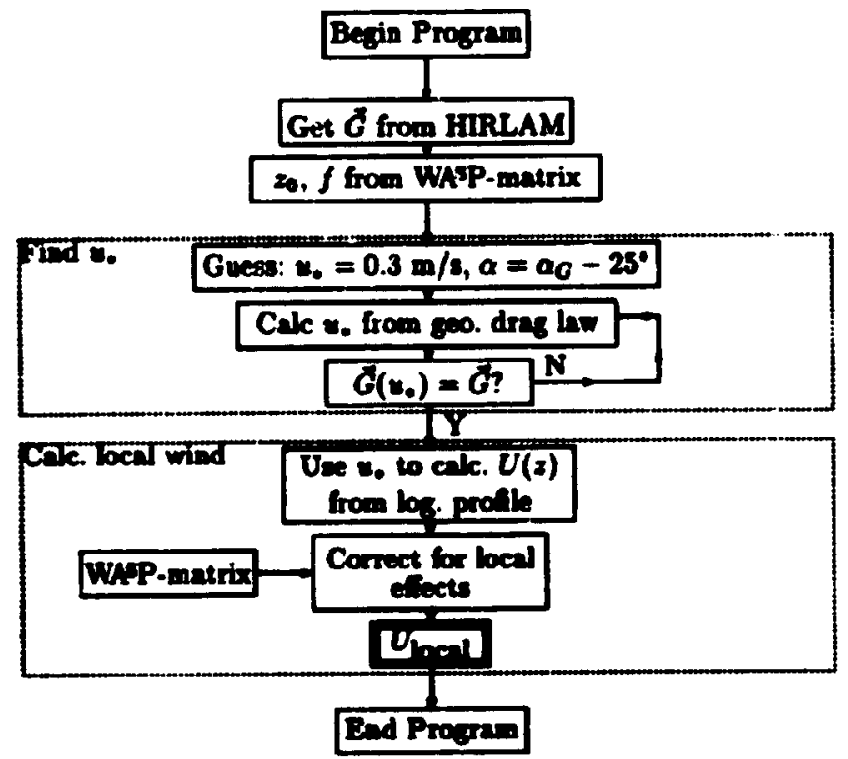

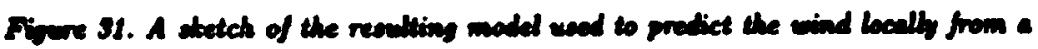
BinRAL foreonet. 


\section{Finding the right wind}

Since the type of the HIRLAM wind (ie gecotrophic or actual) and height of the level from which it is taten, are still undetermined, the first part of this analysis will be to find the wind that approximates the theoretical geostrophic wind best. This is to be understood in the sense that it is the wind that results in the smallest mean error and rms error, when inserted as $G$ in the geostrophic drag law and then used in the model for all the selected stations. This is done by focusing on two months: one representing summer conditions (June 1991) and one winter conditions (December 1990). The reason for looking in detail at two months, is to be sure to capture any "drift" in HIRLAM forced by the changing seasons. Furthermore, these two months do also represent a month (June) where the model is performing well compared to persiatence, and one where the model is performing not so well (December). For each case the two different types of winds from each level are used as an approximation to the theoretical geostrophic wind, the model is applied to all the stations and the results evaluated. Finally, the resulting forecasts of all these 'physical' winds are compared to each other and with the persistence model. The model is run for all forecast times, ie from +3 to +36 hours with increments of 3 hours.

The parameters used in this first coarse evaluation are the mean of the mean error for all stations, $\left(e_{e}\right)$, the standard deviation (taken over all stations) of the mean error $\sigma_{e,}$, and the mean of the rms error for all stations (RMSE), for a definition see Section 11.1. All these parameters give a rough idea of the general performance of the models, since they average over all the stations. Later in this section, a more detailed analysis will be carried out, when most of the different candidate winds have been ruled out. The results of runaing the nodel with the diferent candidate winds, are shown in Figure 32 and 33.

Theoretical considerations indicate that the geostrophic wind at the surface is the best candidate, since it is here that the frictional force is balanced by the pressure gradient. Looking at Figure 32 and 33 it is seen, however, that this is far from the case here: the worst results are obtained by using the model geostrophic wind at the surface. Generally it can be seen thnt any gecostrophic wind, no matter the beight, is not a good approximation. This implies that actual model winds from HIRLAM must be used. Looking at the figurea, it can be seen that the results of using the model winds at the diferent beights are very similar. Therefore, a more des ailed analysis has to be carriod out. Before continuing, it must be borne in mind that this has the consequence that the model is not very sensitive to from which level the wind is labea.

In this analywis the different actual model wiads at the difierent heights (at 30 , 137. 359, 729, 1260, $1979 \mathrm{~m}$ ), have been used to malse brecasts for half a year (March 1891 to Angust 1901) for all forecant times (from +3 to $+36 \mathrm{~h}$ in steps of 3 bours) for each station. For each rration the error, $e_{3}$ defined in Eq. 109, the abolute error, $|c$,$| , defined in Eq. 110, and the nme error. RMSE., Eq. 111$ has been calculated and every tisse the forecant bened on the wind at a certain height Gre the best revalt (ie the suallest vilues). the model got ose point. The resolt of this analyia is shom in Tubb 8 . As can be seen from thin, there is a clowe rua between the model nain the actual HIRLAM wind from the bevel at $137 \mathrm{~m}$ and we owe uding the wind from the $359 \mathrm{~m}$ kevel.

To soe which of these two produces the most sccurate brecast for the entire period and to study the individual forecant times in more detail, the two models bave been compared for the eatire year, for each forecant time in turn. To check that the conclusions drawn in the stody of the half year period are valid for the entire year, the forcants besed on the cetal HIRLAM wisd at $729 \mathrm{~m}$ are alo

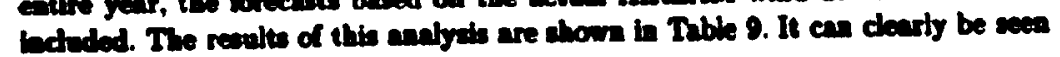




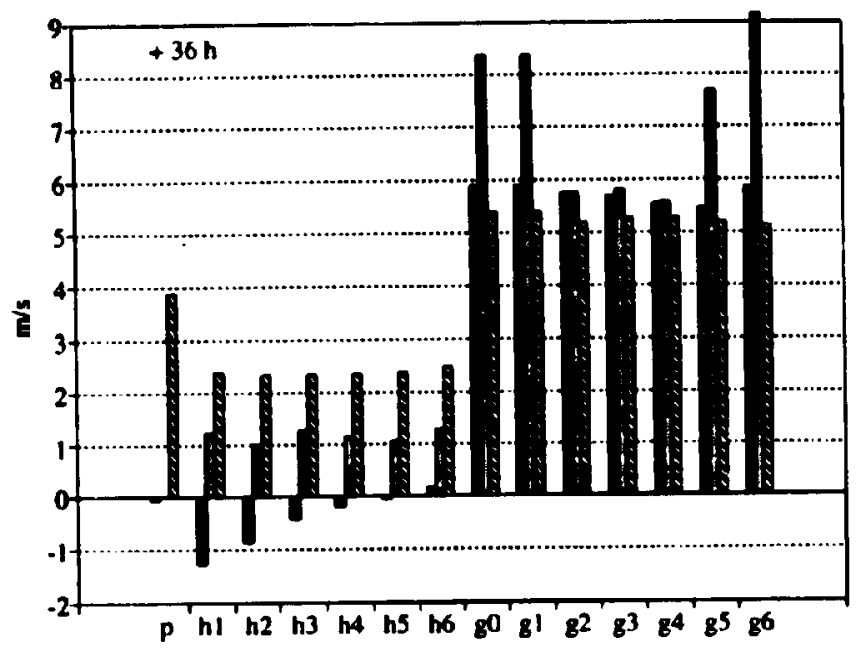

Figure 32. The 36 hour predictions for June 1991 (the summer case) using the neutml HIRLAM/WAsP-model with actual madel winds (h1-h6) and geostrophic uinds $(g 0-g 6)$ from the HIRLAM model. Level $O$ is at the surface, 1 is at $30 \mathrm{~m}$, 2 at $197 \mathrm{~m}, 9$ at $359 \mathrm{~m}, 4$ at $729 \mathrm{~m}, 5$ at $1266 \mathrm{~m}$ and level 6 at $1979 \mathrm{~m}$ ugl. The predictions are compared to persistence ( $p$ ). The first column (an each group of \$) in connection with each model is the mean value of the mean error averaged over all stations, the second is the standard deviation of the mean error taken over all stations, and the thind the mean of the rms error for the individual stations. Bars extending outside the horizontal boundaries signifies that the values they represent are outside the extreme values of the y-axis.

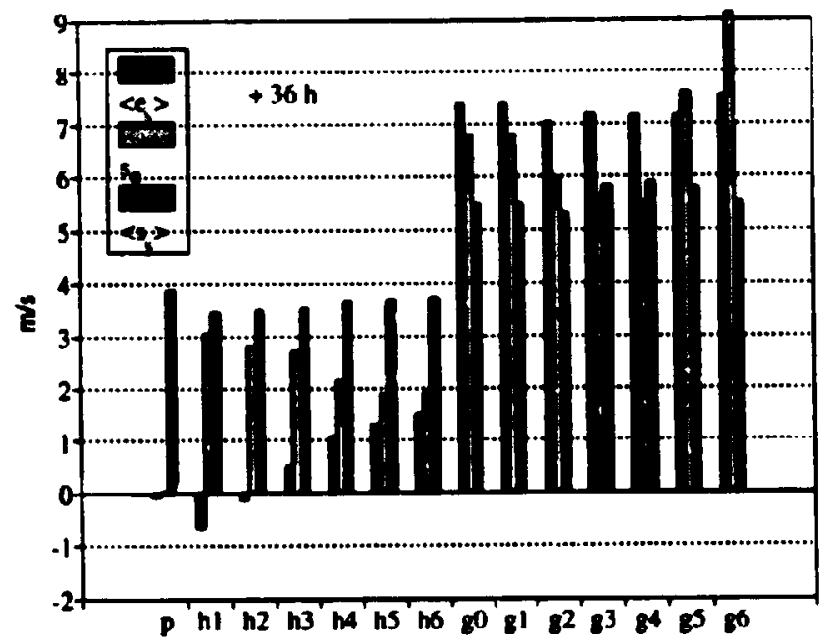

Figure 99. The 96 hour predictions for December 1990 (the winter case), see text at Figure 92 for explanation. 
Table 8. The acore of the prediction madels based on the different actual HIRLAM winds. One point is given if the model uring the wind from the level in question, for a certain station and all forecast times gives the most accurate forcosit. $A$ total of 50 stations have been used. The height of the level is given in column 2. $c_{\text {, }}$ is the error, $\left|e_{1}\right|$ the absolute error, and RMSE, the rme error of the forecaut.

\begin{tabular}{rrrrrr} 
Level & Height $(m)$ & $c_{0}$ & $\left|e_{s}\right|$ & $R M S E_{3}$ & Total \\
\hline 1 & 30 & 4 & 3 & 3 & 10 \\
2 & 137 & 9 & 18 & 14 & 41 \\
3 & 359 & 13 & 17 & 20 & 30 \\
4 & 720 & 9 & 6 & 5 & 20 \\
5 & 1266 & 7 & 5 & 7 & 19 \\
6 & 1979 & 8 & 1 & 1 & 10 \\
\hline
\end{tabular}

from this table that the model based on the actual HIRLAM wind at the $197 \mathrm{~m}$ level (level 2), is the one that produces the most accurate (wrth respect to all the tested parameters) forecasts. It is actually even more pronounced for the 1 year period than for the 1/2 year period. Studying the individual forecast times, it can also be seen here that the selected model performs bent.

Table 9. The result of comparing the two best modeld, ie the madels using the ectual HIRLAM wind at $197 \mathrm{~m}$ (level 2 , first row in each table) and $959 \mathrm{~m}$ (level $\mathrm{s}$, second row), respectively. For refienence, the forecast using the $789 \mathrm{~m}$ (level $\mathrm{b}$, third row) wind - also included. The three oub-tables contain the results of the $e_{3}$, $\left|e_{2}\right|$, and RMSE, analysis, respectively. The scoring seheme is as in Table 8.

\begin{tabular}{r|rrrrrrrrrrrrrr}
$e_{.}$ & 0 & 3 & 6 & 9 & 12 & 15 & 18 & 21 & 24 & 27 & 30 & 33 & 36 & Total \\
\hline 2 & 12 & 16 & 27 & 27 & 15 & 19 & 26 & 29 & 19 & 20 & 29 & 30 & 18 & 287 \\
3 & 18 & 19 & 12 & 15 & 20 & 19 & 12 & 11 & 17 & 19 & 10 & 10 & 18 & 200 \\
1 & 20 & 15 & 11 & 8 & 15 & 12 & 12 & 10 & 14 & 11 & 11 & 10 & 14 & 163 \\
& & & & & & & & & & & & & & \\
$\left|e_{.}\right|$ & 0 & 3 & 6 & 9 & 12 & 15 & 18 & 21 & 24 & 27 & 30 & 33 & 36 & Total \\
\hline 2 & 10 & 22 & 29 & 31 & 20 & 27 & 29 & 33 & 23 & 29 & 31 & 36 & 26 & 346 \\
3 & 25 & 16 & 9 & 12 & 17 & 13 & 11 & 11 & 15 & 13 & 9 & 8 & 12 & 171 \\
4 & 15 & 12 & 12 & 7 & 13 & 10 & 10 & 6 & 12 & 8 & 10 & 6 & 12 & 133 \\
& & & & & & & & & & & & & & \\
& & & & & & & & & & & & & & \\
RMSE. & 0 & 3 & 6 & 9 & 12 & 15 & 18 & 21 & 24 & 27 & 30 & 33 & 36 & Total \\
\hline 2 & 9 & 21 & 27 & 20 & 21 & 25 & 29 & 33 & 23 & 20 & 30 & 33 & 25 & 331 \\
3 & 25 & 15 & 12 & 16 & 14 & 14 & 12 & 10 & 14 & 10 & 9 & 10 & 12 & 173 \\
4 & 16 & 14 & 11 & 8 & 15 & 11 & 9 & 7 & 13 & 11 & 11 & 7 & 13 & 146
\end{tabular}

Others have reached rovelts abog the sume libes: Clarte and How (1974) und the actual wind in $2=0.13 \mathrm{~m}$. /f which is appecodinately $450 \mathrm{~m}$ for typical valvea, this kevel b the level with the atrongeat wiad, and where the wind is geostrophic on the average under neutral coadition. If the atmoophere is highly stable the wind in super-geostrophic, and in the highly unatable cone the wind will be subgrontrophic. In another atudy (Zilitinlevich and Clatilor, 1908) the actual wind at a fred leight (approximately $1 \mathrm{~km}$ ) wa need as $G$ is the geotrophic dres $\mathbf{~ l a w}$. 


\subsection{Results}

The model selected and developed in the preceding section is now run for all stations in the period from December 1st, 1990 to November 30th, 1991, giving one year's worth of data. The selected model will be called the 'neutral HIR. LAM/WASP model' or just the 'HIRLAM/WASP model', and abbreviated ' $H / W$ ' In the following the results are presented.

One of the tasks this work set out to undertake, was to see whether it was possible to make forecasts that performed better than persistence. Having this in mind, we have defined a 'good' station, as a station where the forecasts produced by the model are better than persistence after 6 hours, and a "bad"16 station as a station where persistence is doing better than the model for all look-ahead times. The reason for the 6 hour lower limit is that none of the stations perform better than persistence until from somewhere between 3 and 6 hours. Looking at all the stations, it has been found that $80 \%$ can be labeled as 'good' for the +18 hour forecast. For shorter range forecasts, this percentage is reduced and for longer increased. The +36 hour forecast yields $88 \%$ and the $+3 \mathrm{~h} 0 \%$. The performance as a function of look-ahead time of a 'good' and a 'bad' station can be seen in Figures 34 and 35 . For stations where the neutral model is performing better, the absolute mean error and the rms error are around 60 to $80 \%$ of the persistence model's for the +18 h forecasts, cf Figure 36 .

Returning to Figures 34 and 35, two interesting features are seen:

1. The rms error and the mean error of the HIRLAM/WASP model are constant for the 'good' as well as for the 'bad' station. This is seen generally for all the $\mathbf{5 0}$ selected stations. This is quite difficult to explain, since it would be expected that it would be harder and harder to predict rightly as the lookahead time increases; this is found to be the case for the persistence model. One possible explanation could be that only the kevel of the wind speed is predicted rightly and not the variation. If this was to be the case, the rms error of the prediction should more or leas be equal to the standard deviation of the observations themselves. This is seen not to be the case. As an example consider the forecast for Birmingham (Figure 34) where the rms error of the HIRLAM/WASP model is approximately $1.8 \mathrm{~m} / \mathrm{s}$ and $2.2 \mathrm{~m} / \mathrm{s}$ for the time series itsell, which is a difference of 18 per cent, furthermore, is it seen from Figure $\mathbf{5 8}$ that models with higher resolution have smaller rms errors.

Another explanation is that the area covered by HIRLAM (which is including the Atlantic Ocean) is so big that within a 36 hour period, generally most of the large-scale weather systems afecting any site in Europe are present in the initial analysis, with the result that major developments within the 36 hour time-frame are know equally well, and therefore predicted equally well. This is of course assuming that the physical model keepe the atmosphere on 'the right track' during the integration. This is comfirmed by Figure 58, where it is seen that the UK MESO model (covering a significantly smaller area) does show the expected behaviour of a constant and then increasing rms error with time, even within the 18 hour range. The reacon for the variability in the frat 6-9 hours is probably due to the error induced by the initialisation of the fields in HIRLAM.

There is no doubt, though, that the limited variability of atmospheric wind speeds (ie from 0 to typically around $15 \mathrm{~m} / \mathrm{s}$ ) is putting an upper limit on the rms error of any physical model, working reasonable well.

2. The mean error of the persistence model is always close to zero. This is explained in Section 11.2.

\footnotetext{
Itor not wo rood
} 


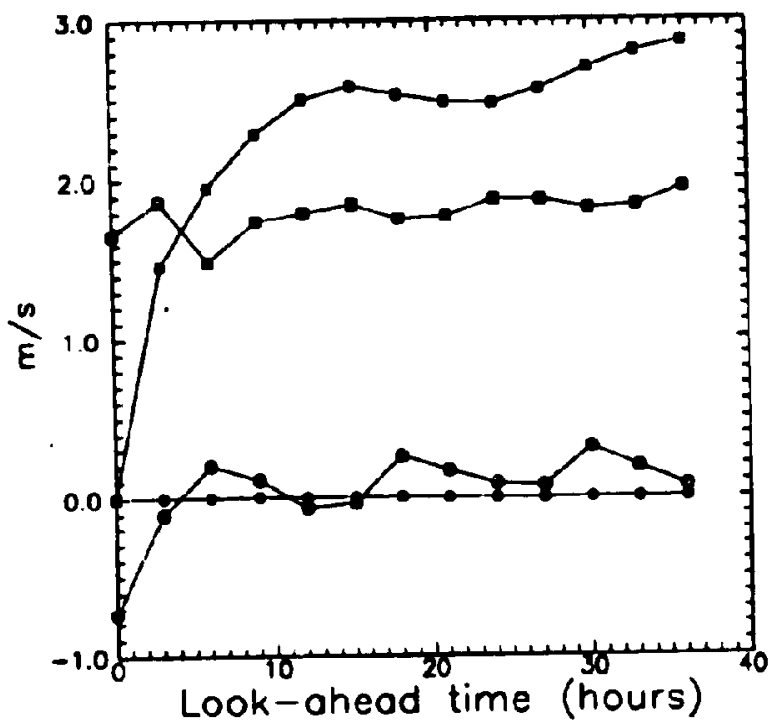

Figure 34. The mean error (in $\mathrm{m} / \mathrm{s}$, denoted by circles) and rms error (in $\mathrm{m} / \mathrm{s}$, denoted by squares) of the HIRLAM/WAP-model (open symbols) compared to persistence (solid symbals) for Birmingham (station 37, a 'gaod' station) for the entire period (December 1990 to November 1991). The look-ahead time (in hours) is along the $x$-aris.

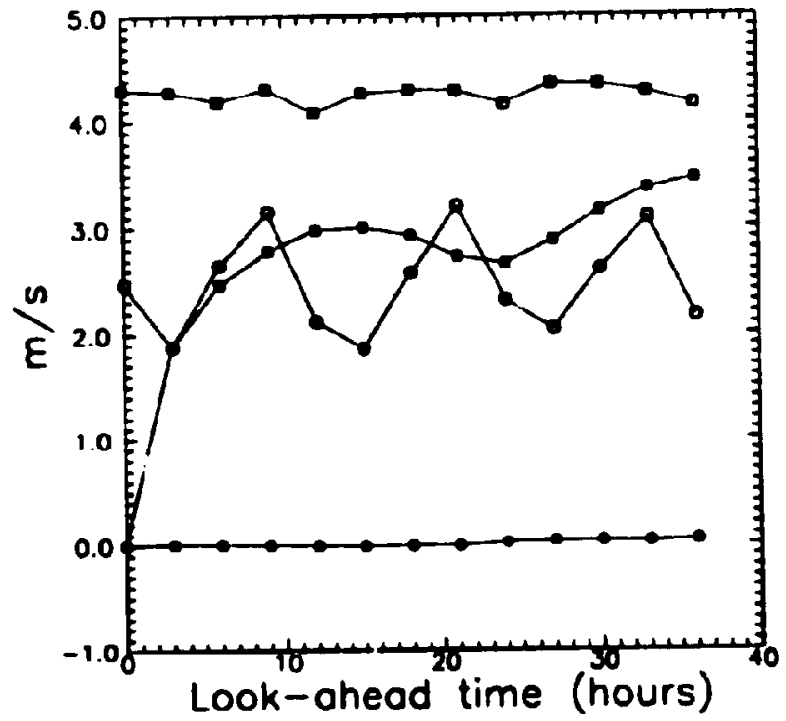

Fivere 35. As in Figure 34 but for Stlamence (stet. 89) which is o 'had'station.

In Figare 37 the selected stations bave beem habed according to their performance relative to the peraistence modal. As can be sea from this figne, the majority of the rood predictionas are foud for statbas becated in Northern Enrope, this is wery mech in line with the experience cathered from udist the WAPP

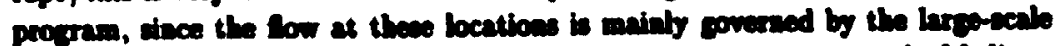

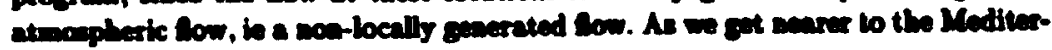




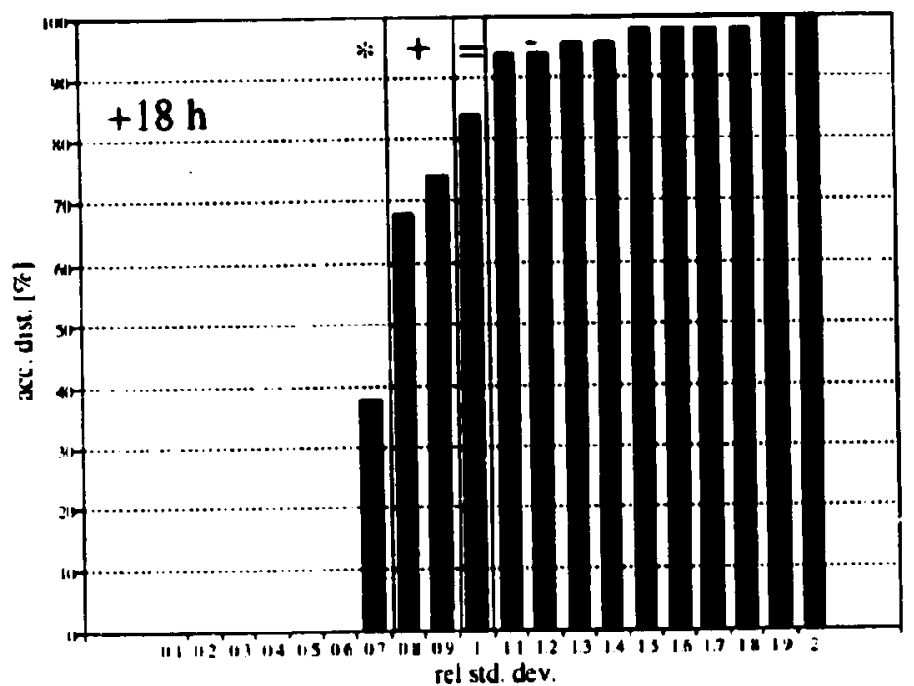

Figure 36 The accumulated distribution of the relntive rms error (ie the rms crior of the HIRLAM/WASP mudel relative to that of the persistence modcl) for all stations for the +18 hour forccast. The classification $(*,+,=$, and -$)$ applaed in Figure 37 is shoun at the top of the figure.

rancan Sea, we experience that the quality of the forerasts decreases, but note that even here does the model generally outperform persistence. Note also, as is shown in Section 14, that using. MOS improves the quality of the prenlictions for the 'bad' stations. The improvement is such that these stations, after MOS has been applied to the $\mathrm{H} / \mathrm{W}$-forecast, can be labeled 'good'.

Since the produced amount of data is quite big ( 12 sets of predictions $(+3, \ldots$, +36h) for 50 stations for one yrar), we have chosen to look in sone detail at two stations: Birmiugham (station 57) representing the 'good' stations and Salamanca (station 29) thr 'bad'. Note, that only $20 \%$ of the stations have been classified as 'bad', but it is quite illustrative tu see why the forecast failed. For a more complete reading refer to $A$ ppendix $C$, where the three error measures are listed for all stations for the $+3,+18$, and +36 hour forecasts for the HIRLAM/WAsP model as well as for the persistence model.

In Figures 38 and 39 the scatter-plot of the observed versus the forecasted wind speed for the 'good' respectively the 'bad' station are shown. As can be seen from these, the scatter from the 'bad' station is quite a bit more pronounced than for the 'good'. Studying now Figures 41 and 39 a major part of the explanation of why the WASP-method - which is dependent on directional corrections - fails, is found: it has not been possible for HIRLAM to forecast the right direction for the bad station, and as a result the correction from the WASP-matrix are of no use. Looking at the plot it seens as if there is a 180 degrees off-set of the data. As will be seen in the next section. it is actually better not to use the matrix in this case. The poorness of the forecast is probably due to the fact that at the bad station, local thermally driven wind regimes prevail. The direction for the good station is predicted quite well. 


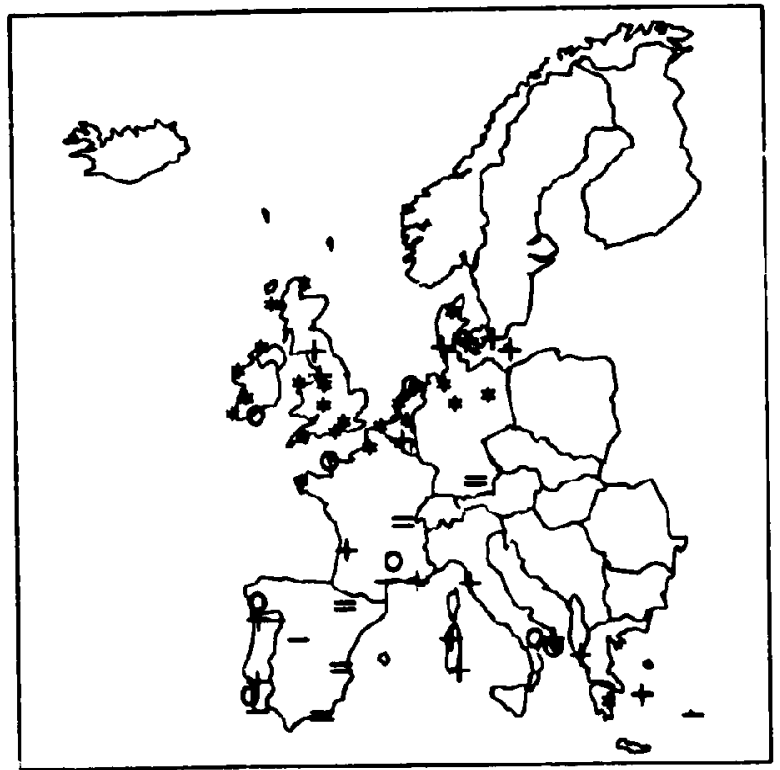

Pipure 57. The performance of the newtrd HIRLAM/WNP modd seen relative to the persidence model for all the selected stations. An * indicates that the abehte error and the rme error of the model are less than 0.7 tinnes that of the persintence

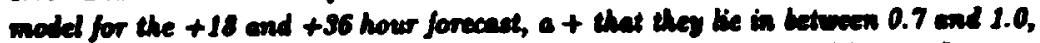
= that they ore apual, and - that the persidtence mold porformal hetter. Stations

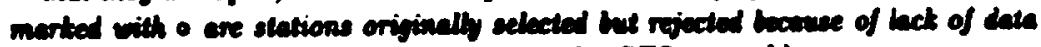
(thrically they reportal only twice a day to the OTS-netwoth). 


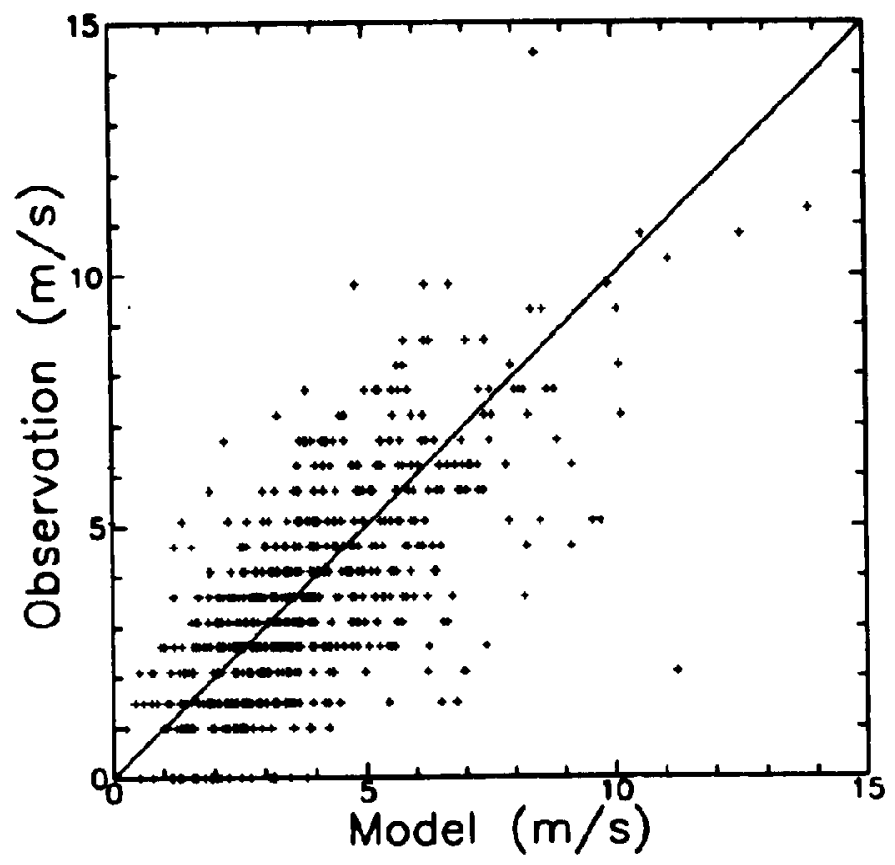

Figure s8. A scatter-plot of the forecusted wind speed versus the abserved, for the +1 sh forecast for the 'good' station (Birmingham, station 57) for the entire period. The existence of the horizontal bines in the plat is due to the resolution of the obervations (which is 1 bnot).

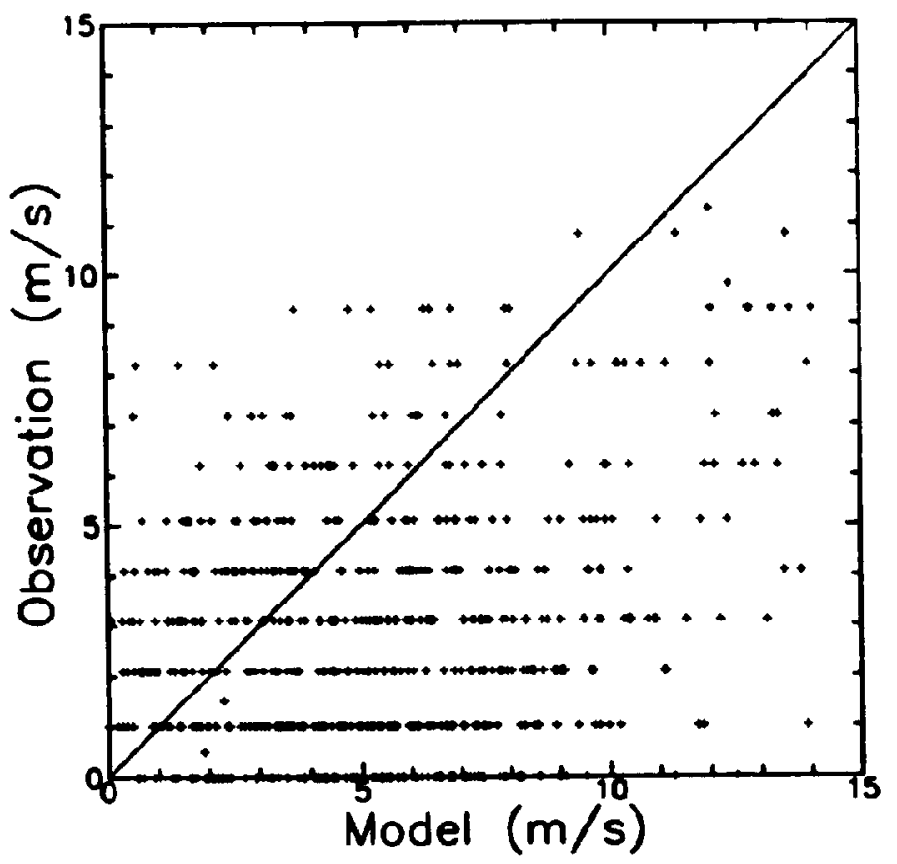

Figure 59. A scatter-plot of the forecantad wind spead vermes the obeerwed for the 'bed' station (Salamence, station s). Note that the sale th the seme as in Pigtorese. 


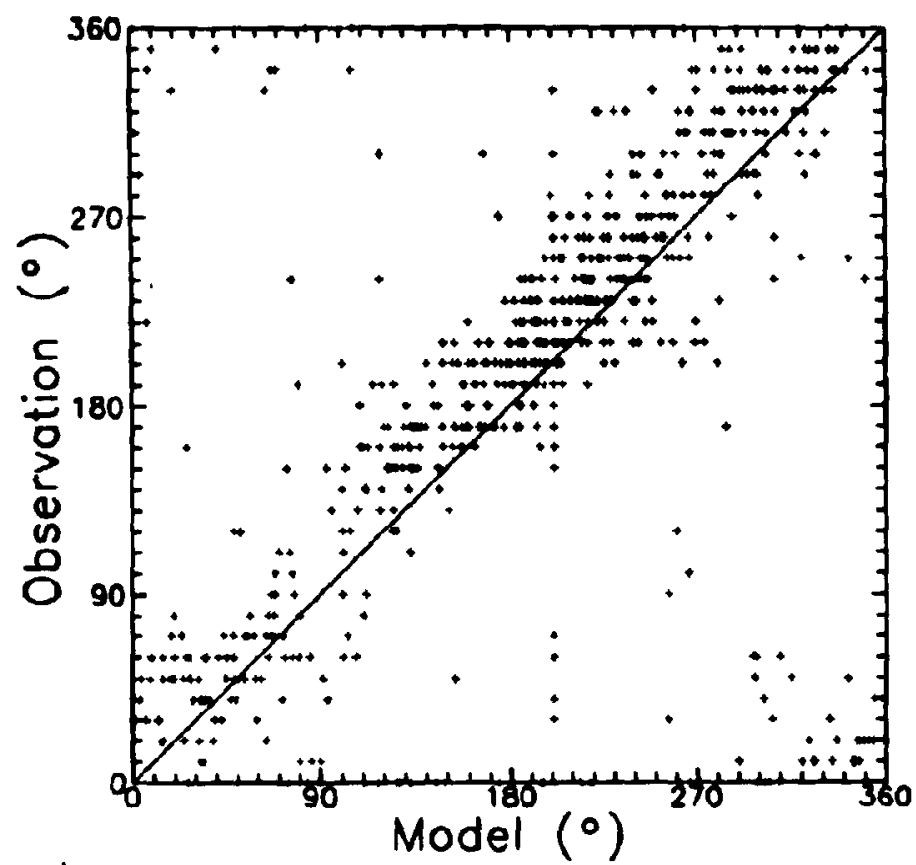

Figure 10. A scatter-plot of the forecasted wind direction versus the observed for che 'good' station (Birmmgham, station 57).

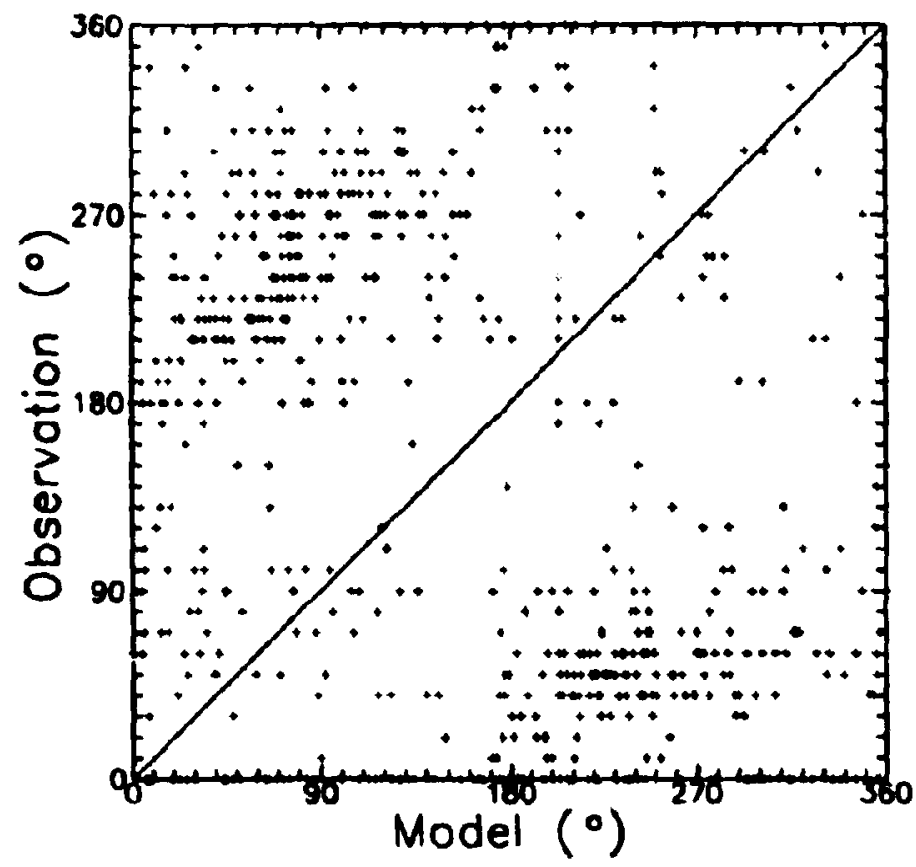

Pigure 4I. A scatter-plot of the forecasted wind dinection verow the abserved for the 'bed' station (Sclmanace, station 8)). 
It is also useful to see the distribution of the forecasted versus the observed wind, since in many applications a wind climate is represented solely by ito (Weibull) distribution. The distributions are shown in Figures 42 and 13. Comparing the distribution of the forecasted wind to the observed, a quite interesting feature leaps to the eye: the expected distribution for the 'good' station is actually predicted better (ie more smoothly and accurately) by the forecast than by the observations. cf Figure 42. This fact cals for some explanation; experience has shown that most observations of the wind speed can be represented by the 2-parameter Weibul distribution (Weibull, 1951), but as can be seen from the figure there seems to be patches of missing date in the observations (es 3,10 and 17 knots), these patches are not present in the forecast, for which reason the distribution appears more smooth. Here is also found another explanation of why the 'bad' stations are not well predicted when using the mean error and the rms error as the measure. It is obvious that measurements within the entire interval spanned should be present when looking at 1 year's worth of data. So quite some doubt can be raised concerning the quality of some the measurements.

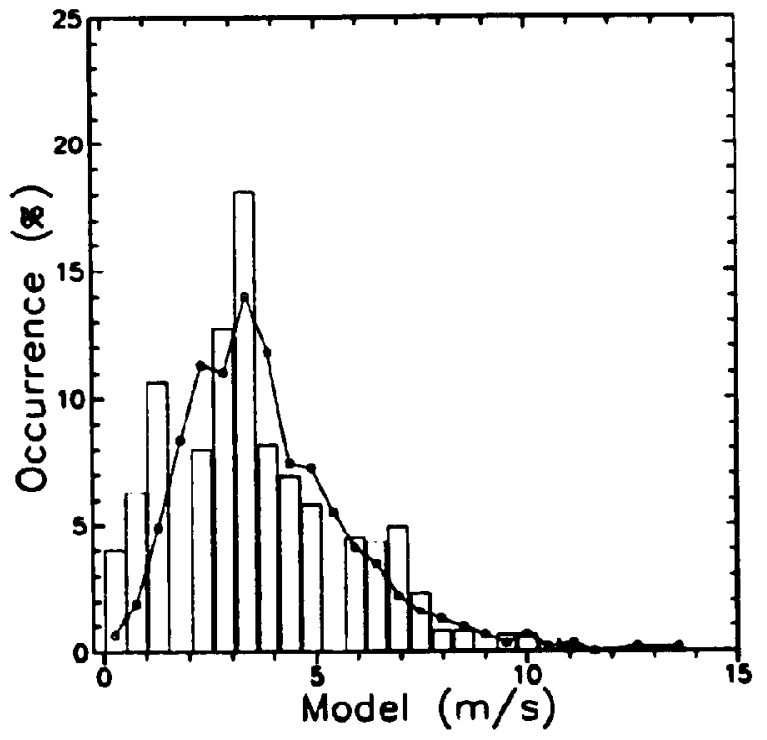

Figure 12. The distribution of the forecasted wind speed (lines) versus the observed for Birmingham (station 57, a 'good' station) (bars). The look-ahead time is +18 h and the predictions are taken for the entire 1 year period. The bin width is 1 brot. 


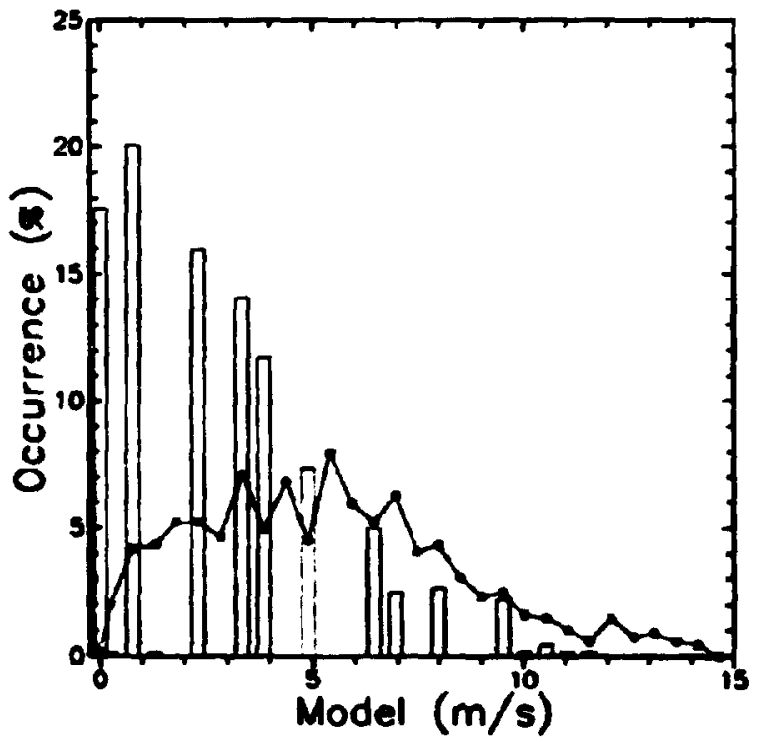

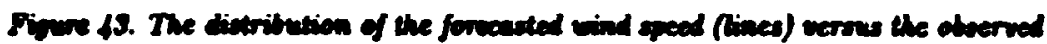

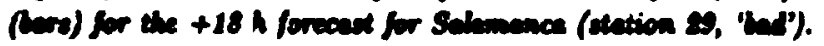


Findly, the distribetion of the exrer is bohed blo. This is impartant to know, otherwive it is not posalble to sedion any menning to the rme ernor, cee Figure 44 and 45. As can be coen from then two fanre the diveribution of the error can, to - good approcimation, be labulad Gamelan. The dipplacement (awray from vero) of the distribation enen in Figare 45, is of conne dise to the larpe error of the prediction for the 'bed' rtation.

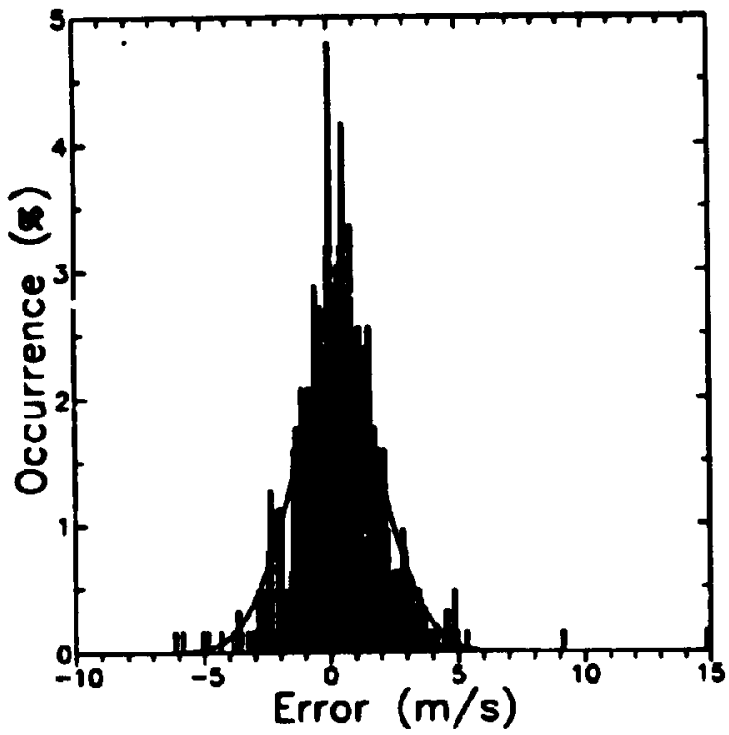

Pigure 44. The distribution of the error (model - observed), compared to the Gausvien curve having the man and werience of the distribution, for the +18 forecust for Birminghers (otation 57, a 'good' station). The bin-width is $0.1 \mathrm{~m} / \mathrm{s}$.

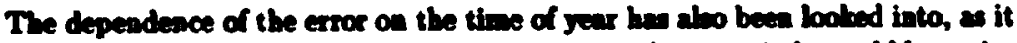
conld be expected that seacoms dominated by storma/strong winds wonld be enciet

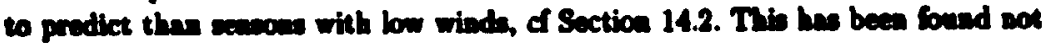

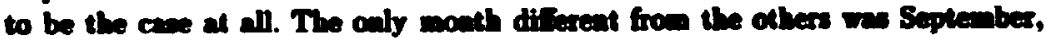
and thin we dwe to the fact that there was ene day where all BillWhM forcents nere bed.

The depeadence of the error on time of day he not been bohad into, since it is net posible to male a far comparion, becenes the prediction model (FintAM)

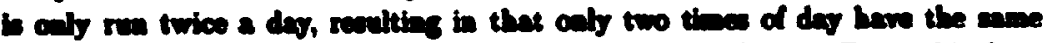

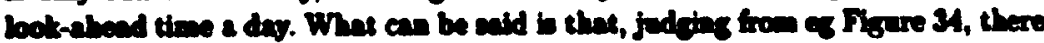

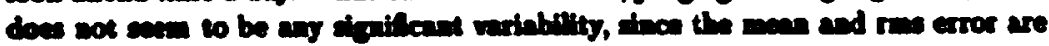
concant. 


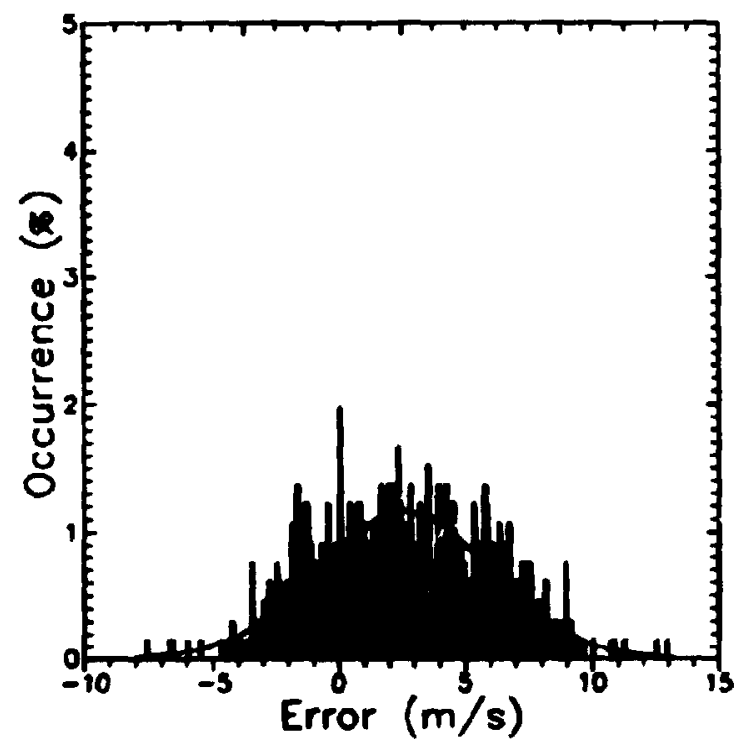

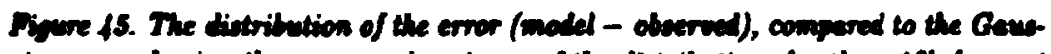
in curve having the mean and ravines of the cintribuliom, for the +1 th forecast

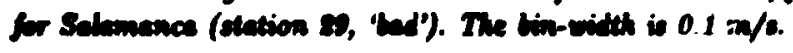




\section{Model output statistics}

When applying a physical model to real situations, errors will inevitably occur. These errors can have different causes. The model can have some inherent errors, because the physical model does not exactly match reality. In the case of the neutral HIRLAM/WASP model, the defects of the model are that it is neutral, which means that the stability dependent effects are not taken into account, and that the spatial resolution is low. Furthermore, the model assumes that the atmosphere is barotropic, which it generally is not. This constraint is partially circumvented by the fact that the wind used as the geostrophic wind, is in fact the real wind (of a baroclinic model). The conditions at the rite may have been changed since the WA:P analysis of the station was carried out, this is not at all uncommon: the mast may have been moved (this was found for station 59 (first Exeter and then Dunkeswell)) and the surroundings of the mast may have been changed, typically new buildings build or demolished. Finally, the analysis can initially be erroneous. In this study it is likely that it is the spatial resolution of HIRLAM that most contributes to the error.

The data can also be incorrect, either because the instrument is not calibrated properly, or because the instrument simply is old. Remember here, that part of the variance of the error is caused by the inexactitude (as compared to present day measuring capabilities) of the reported observations, Section 11, since the observations are reported in integer knots compared to accuracies of $0.1 \mathrm{~m} / \mathrm{s}$.

Another important cause of error related to the model, is that there is a 'gap' in between the scopes of HIRLAM and WAP, since HIRLAM covers atmospheric phenomena on scales from the semi-planetaric down to scales of the order of 100 's of kilometres. WASP, on the other hand, covers phenomens related solely to the stationary flow on scales of the order of $1000 \mathrm{~m}$ down to $1 \mathrm{~m}$. So atmospheric phenomena on the meso-scale, such as local thermally driven circulations (seabreeses, anabatic and katabatic winds), are not modeled by any of the models.

To see if it is possible to correct some (or all) of these errors, the output from the physical model is corrected using MOS (Model Output Statistics), which is basically putting the output from the piysical model through a non-physical (statistical) post-processor, see Figure 46. Normally this procedure is used to predict parameters not forecasted directly by the model, as es the minimum temperature at a specific bocation. See Glahn and Lowry (1972) for an introduction to traditional MOS. Two difierent types of MOS are used bere: a Oth order linear model that corrects only systematic under/over-prediction and scaling on a sector-bysector basis, and a neural network with difierent combinations of the output from the phyical model and measurements as input.

To teat the efiect of these (wo MOS approschen, 6 stations (out of originally 50) have been selected: 3 'good' atations where the sevtral model performed well'? stations 19, 56, 57, and 3 'bed' where the neutral model did not perform wellit: station 29, 35, 41. The parameters of the MOS systems are optimived using data from December 1990 to May 1991 (the first half of the period) and they are tested on the date from Jupe 1991 to November 1991 (the lant hall of the period).

Before the presentation of the two MOS aystrms two aspects of the forecasting problem will be andyeed: What is the eliect of not using the locel corrections (ie not using the WASP matrix)? and what is the inherent variation of the observed wind speeds?

17 Meaning that the model forecen rme ervors were better then 0.7 tima the pertidence errore Lor the +18 and +36 hour forecent.

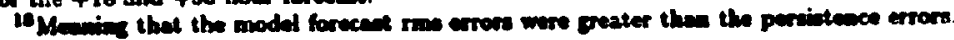




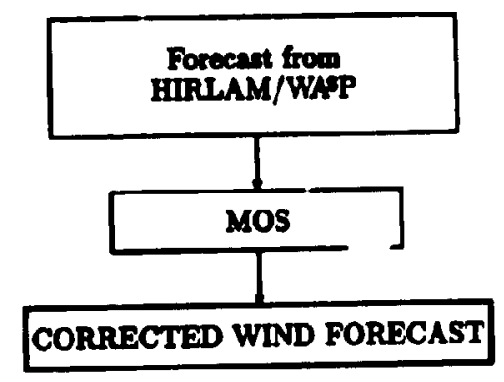

Figure 16. The idea of correcting a forecent based on a physical model with a statiotical post-processor (MOS). In this project the MOS system is either linear repression or neurel networts.

\subsection{Sensitivity to the local corrections}

To see whether the inclusion of the local corrections from WAP actually improves the forecast in transforming the HIRLAM forecast down to the surface layer, it ha been tried to run the neutral model without applying the local corrections (ie without the WAP matrix) on the 6 selected stations. Not using the local corrections can be expreased in "WAP language" as that the stations are considered as not being intuenced by obatacles and orography, and having a homogeneous roughness length in all directions of $0.03 \mathrm{~m}$. The results can be seen in Table 20 in Appendix C, an example is shown in Figure 47. It appears from the figure and the table that the local corrections improve the forecasts for the 'good' stations; muialy by reducing the mean error. For the 'bad' ones the local corrections sometimes increases the mean error and cometimes the rms error. It can be seen that come stations (eg station 29) can not be 'saved' (ie the value of the evaluation parameters of the model brought noder thowe of the persistence model) by either sethod.

The reason why the 'bad' statioas are predieted wores when urias WMP is due to the fact that the direction is predicted wroagly by HIRLM (cf Figure 41), and that, as a consequesce, the correction for the bocal eliects are taben from a wrong sector. As an example, comaider a mast bocated at a lake side: if the free-stream wiad is actually coming from land bat is predicted a coming from the lake, the revalting local wiad will be mech too high.

\subsection{Statistical properties of the observed data}

To get a butter bee of the errose given in the following metions, a lint of the

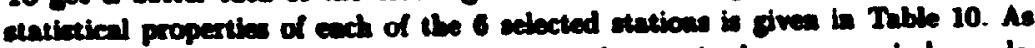
an be see from this table the 'bad' ctations have quite low moen riad speeds, and the standard deviations (from the mean) are of the same magitude as the mean valne. The 'good' station - on the other hand - have higher means and the standard deviation is of a smaller maguitede than the mean. This is a general Ceature: 'good' stations have means hifber than the standard deviation, and 'bad' lower or equal. As a rule one would place wind turbicen at aites with high wiads. is thene cases the seutral BIRLAM/WMP model is seen to perform well. 


\subsection{Oth order system}

The Oth order MOS model used bere takes output from the IIRLAM/WAPP model and calculates the linear relationship between it and the observation. This is done sector by sector $f, s$ the twelve 30 degree sectors:

$$
u_{\text {obs }}=a\left(\theta_{i}\right)+b\left(\theta_{i}\right) u_{H} / w^{\left(\theta_{i}\right)}
$$

where $u_{o b}$ is the obaerved wind, ${ }^{H} / \mathrm{W}$ the forecasted wind form the HIRLAM/WASP model coming from the direction sector $\theta_{i}$, and $a\left(\theta_{i}\right)$ and $b\left(\theta_{i}\right)$ are the regression coefficients of the twelve $\mathbf{3 0}$ degree sectors. The relationship is established using data from the first half year (ie from December 1990 to May 1991) and tested on data from the last half year. The result is shown in Table 12 for the $+3,+18$ and +36 hours forecast. There is no quantitative difference between these three look-ahead times and the ones not shown. As can been seen there is an improvement when using this method: 'good' stations are as a rule left untouched, with a slight bias toward an improvement, and the performance of the predictions Cor the 'bad' stations is without exception improved. The 'bad' stations are actually improved to such an extent that alter having applied MOS they can all be classified as 'good'.

It is likely that this method - in the limit - will perform better or as well as an optimal WAsP analysis, particularly since the data are binned in directional bins. The reason is that looking at the two methods as black-boxes they both have (if we consider speed only) one scale-factor per sector. Actually, the linear method has the theoretical possibility of being better since this method also has an off-set, ie 2 parnmeters.

\subsection{Neural networks}

Neural networks will now be used as the model for predicting the wind locally. A neural network is a network of heavily connected simple computational units and it is characterised by its number of input, hidden and output neurons (for a more detailed description of neural networks see Section 9). A network is also characterised by the type of input and output, here the measured wind is used as input and the networks are trained to give a prediction (of es the wind 18 hours abead) as output.

To select the best meural network for the desired task, involves quite a bit of trial-and-error, since no rules of thumb exist concerning the optimal number of neurons and the number of layers in the network. The straightforward rule, that the more neurons, the better the result, is not valid. However, in a study similar 10 this (with reopect to some points) Landbers (1992) found that simple neural networks (as eg the $(1,5,1)$ net, for a definition of this syatax, see Table 11) gave satiafactory results, compared to persistence as well as to more complex zetworks (as es $(5,10,10,1))$.

The searcl for the optimal network is therefore carried out among the networks isted in Talle 11. Studying the errors that these networks cause, an unexpected Gature is seen: the only thing that governs the performance of the network is the number of inpul units, ie a $(1,1)$ network gives the ame error and rms error as a $(1,8,8,1)$ network. This means that all the neural network can learn about the relation between the forecast generated by the model and the observations, can be described by very few weights and thresholds. In the case of the $(1,1)$ network, only one weight and ome threshold is involved, ie a linear relation between the cotput of the forecasting model and the observations. This is actially what has been inveatigated is the previons section. Note also that the rule stating that more wearous do not necesurily lead to higher sccurecy is confirmed. 
The interesting result of the runs is that the neural network MOS system improves the forecasts for the 'bad' stations and leaves the forecasts of the 'good' stations more or less untouched. For the 'bad' stations, the forecasts are not only improved relative to the neutral model but also relative to persistence; actually, the forecast is, after MOS has been applied, now a 'good' forecast. Two examples of this are given in Figures 48 and $\mathbf{4 9}$. Figure $\mathbf{4 8}$ shows the 36 hour forecast for Birminghem (station 57, a 'good' station), it can be seen that the HIRLAM/WAsP model is performing very much like the neural networks, especially if the smaller mean error is also considered. In Figure 49 the 36 hours forecast of Salamanca (station 29, a 'bad' station) is shown, it can be seen that all neural networks perform better than the persistence model, contrary to the HIRLAM/WASP model, and thereby converting the 'bad' station to a 'good' station.

Another way of training the neural network MOS - aimed directly at wind energy use - is to apply the power-curve (Figure 22) to the predictions and the observations before training. This would put more emphasis on the interval between the cut-in and cut-out wind speeds. This procedure has not been tried here. 


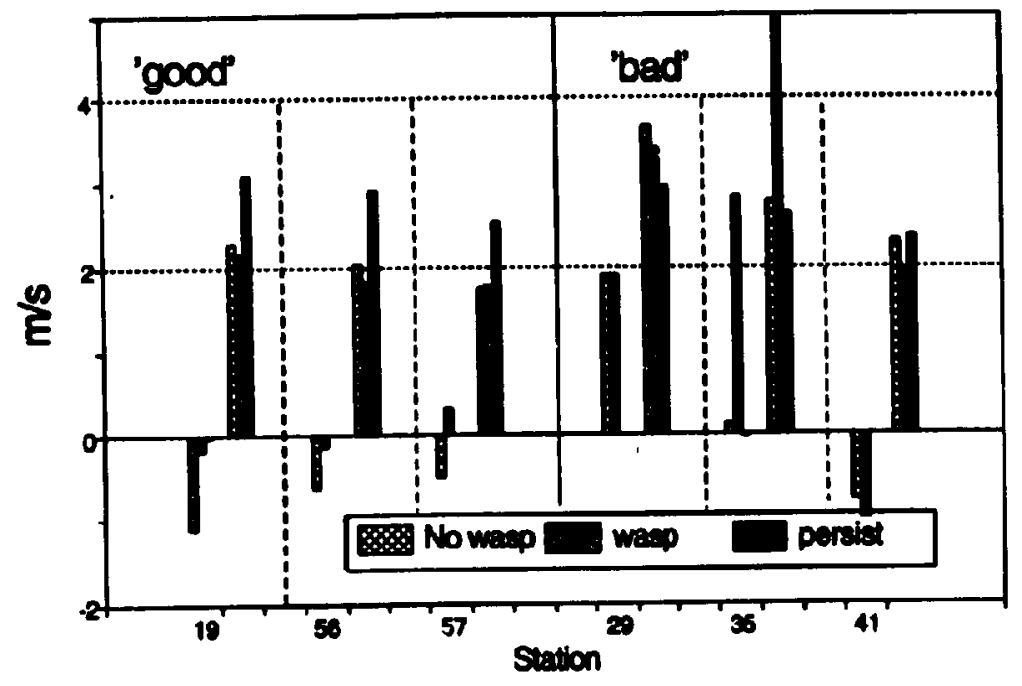

Figure 47. A comparison between using the full neutral HIRLAM/WAP model and using the model without the WAP corrections for the 6 selected stations For cach station 6 bars are displayed in groups of 9: the first three are the mean error (in $\mathrm{m} / \mathrm{s}$ ) of the model without WASP corrections ('No wasp'), the full neutral HIRLAM/WAsP model ('wasp') and persistence ('persist'), respectively; the last three bars for each station are the rms error (in $\mathrm{m} / \mathrm{s}$ ) for the $s$ different models. The comparison is made for the +18 forecast for dato from the last half of the periad (June 1991 to November 1991.)

Table 10. A list of different statistical properties of the observations from the 6 selected stations. The first column is the name and station number, the second the mean of the wind speed (in $\mathrm{m} / \mathrm{s}$ ), the thind the standand deviation (in $\mathrm{m} / \mathrm{s}$ ), and the fourth the number of observations.

\begin{tabular}{lrrr}
\hline Station & Mean & Std. dev. & No. obs. \\
\hline Abbevilk (19) & 4.57 & 2.62 & 2779 \\
Salamanca (29) & 2.96 & 2.48 & 2747 \\
Braganç (35) & 2.81 & 2.32 & 2631 \\
München (41) & 3.01 & 2.01 & 2830 \\
Manchester (56) & 4.11 & 2.70 & 2863 \\
Birmingham (57) & 3.76 & 2.20 & 2863 \\
\hline
\end{tabular}




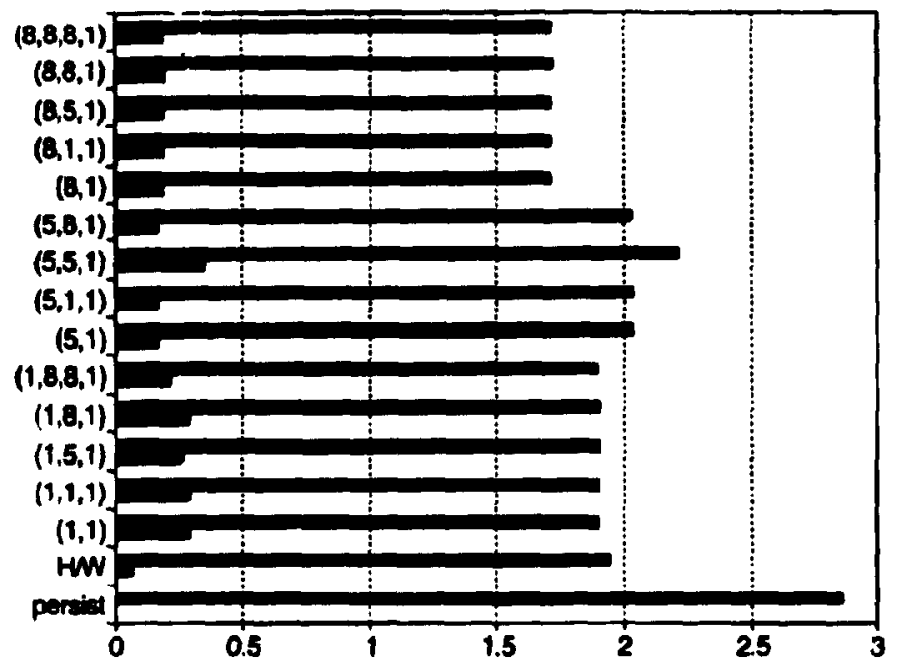

Figure 18. The performance (mean error (the lower bar of the two bars per model) and rms error, both in $\mathrm{m} / \mathrm{s}$ ) of the 11 tested neural networks compared to the HIR$L A M / W A P$ model ('H/W') and persistence ('persist') for Birningham (station 57) for the 96 hour forecast.

Table 11. The different neural networks used in the trail-and-error approach of finding the network that improves the forecast by the neutral model the most. The network architecture is read as follows: the first number in the parentheses is the number of neurons in the input layer, the last is the number of neurons in the cutput layer, and the numbers in between are the number of neurons in the hidden layers $(e g(5,8,1)$ is a 9-layer networt with 5 input units, one hidden layer with 8 units and 1 output unit).

\begin{tabular}{lll}
\hline$(1,1)$ & $(5,1)$ & $(8,1)$ \\
$(1,1.1)$ & $(1.5 .1)$ & $(1,8,1)$ \\
$(5,1.1)$ & $(5,5.1)$ & $(5,8,1)$ \\
$(8,1.1)$ & $(8,5.1)$ & $(8.8,1)$ \\
$1,8,8,1)$ & $(8,8,8,1)$ & \\
\hline
\end{tabular}




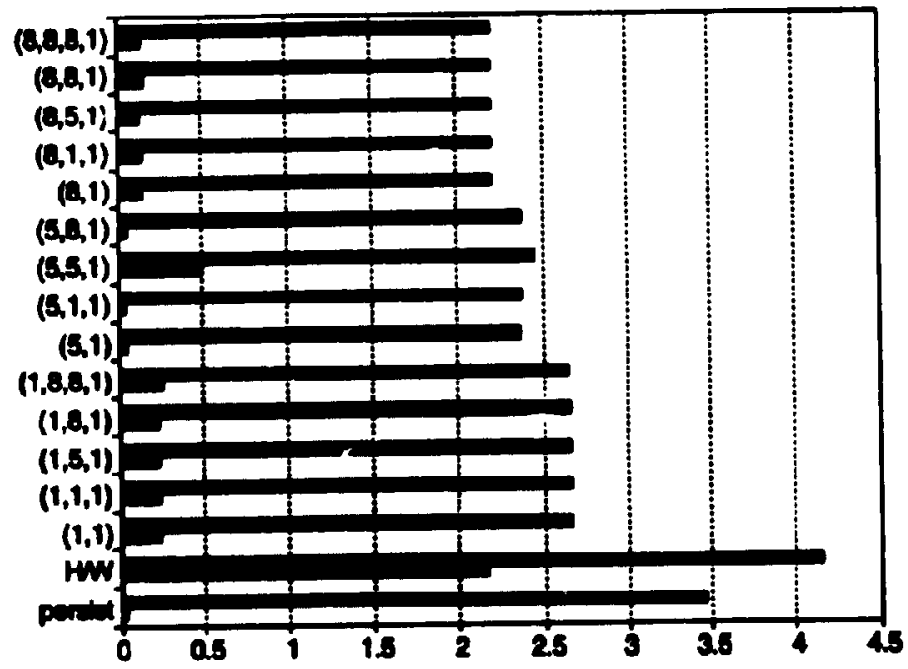

Figure 49. The performance (mian error (the lower bar of the two bars per model) and rms error, both in $\mathrm{m} / \mathrm{s}$ ) of the 14 tented neural networts compared to the HIRLAM/KMP malel ("H/W) and peroiatence ('peroist') for Salsmance (station 4) for the 96 hour forecast. 


\section{Directional dependent neural network MOS}

To whether the forecasts can be improved, having knowledge of the direction, the thresholds and weights of the $(1,5,1)$ network has been made dependent on direction. Each threshold and weight is now a function oi twelve 30 degree sectors. The network has then been retrajned. This procedure is equivalent to having 12 networks each trained on the appropriate subset of the observations. The problem here is that the grouping of the observations (of which only half a year is used) results in some rather small groups, most are sufficiently large, though. Looking at the results, of Table 21 in Appendix $C$, it is seen that no further improvement for the 'bad' stations is found, and that the 'good' stations are only slightly better as compared to MOS using neural networks not dependent on direction, but still worse than the linear model. This is somewhat surprising, since one might expect that the knowledge of the direction would make it easier for the neural network. This not being the case, confirms the fact that the neural networks mainly see the persistence.

\subsection{Conclusions MOS}

As can be seen from Table 12 does the Oth order linear MOS system perform as well as, and sometimes even better, than the neural network MOS. Since the training of neural networks is much more time-consuming and complicated, it must be concluded that for MOS, only the lineas model is needed. 
Table 18. The result of the two MOS systems applied to the 6 stations for the 9, 18 and 96 hour look-ahead times compared to the HIRLAM/WASP model and persistence. The two MOS systems are optimised on date from the period December 1990 to May 1991 and tested on the second half year (June 1991 to November 1991). The column labeled '\#' contains the station number, the ' $F$ ' calumn is the forecast time (in hours), the column marted 'Oth MOS' is the value of either the mean error ( $\left.e_{s}\right)$ (model-observed) or the ms error (RMSEs) (in $m / s$ ), the column marked 'NN MOS' is the value of either the mean error or the rms error of the $(1,5,1)$ neural network. Columns marked 'rel. $H / W$ ' are the absolute values of the statistical quentities divided by the model output from HIRLAM/WAsP, columns marked 'rel. pers.' are the absolute values of the statistical quantities divided by the result of the persistence forecast, a station is 'good' if this lest number is less than 1.0 for RMSE for the +18 and +96 hour forecest.

\begin{tabular}{|c|c|c|c|c|c|c|c|c|}
\hline \multirow[b]{2}{*}{$\#$} & \multirow[b]{2}{*}{$\boldsymbol{F}$} & & \multicolumn{3}{|c|}{ Oth order MOS } & \multicolumn{3}{|c|}{ Neural network MOS } \\
\hline & & & Oth MOS & rel. $H / W$ & rel. pers. & NN MOS & rel. $H / W$ & rel. pers. \\
\hline \multirow[t]{6}{*}{19} & 3 & e & 0.06 & 0.07 & 5.00 & 0.02 & 0.02 & 1.67 \\
\hline & & RMSE & 2.06 & 1.03 & 1.13 & 2.09 & 1.05 & 1.15 \\
\hline & 18 & $\boldsymbol{e}$ & 0.17 & 0.94 & 8.50 & -0.09 & 0.49 & 3.91 \\
\hline & & RMSE & 2.10 & 0.97 & 0.70 & 2.16 & 1.00 & 0.72 \\
\hline & 36 & e & 0.09 & 0.15 & 15.00 & 0.30 & 0.49 & 50.00 \\
\hline & & RMSE & 2.42 & 1.03 & 0.71 & 2.21 & 0.93 & 0.65 \\
\hline \multirow[t]{6}{*}{56} & 3 & $e$ & -0.11 & 0.38 & 27.50 & -0.10 & 0.34 & 25.00 \\
\hline & & RMSE & 1.51 & 0.74 & 0.98 & 2.13 & 1.04 & 1.38 \\
\hline & 18 & e & -0.09 & 0.64 & 6.92 & -0.19 & 1.36 & 14.62 \\
\hline & & RMSE & 1.72 & 0.94 & 0.62 & 1.84 & 1.01 & 0.66 \\
\hline & 36 & e & -0.04 & 0.17 & 20.00 & -0.20 & 0.89 & 100.00 \\
\hline & & RMSE & 2.38 & 1.10 & 0.77 & 2.17 & 1.00 & 0.70 \\
\hline \multirow[t]{6}{*}{57} & 3 & $e$ & 0.21 & 7.00 & 210.00 & -3.47 & 124.37 & 3470.00 \\
\hline & & RMSE & 1.51 & 0.76 & 1.14 & 2.13 & 1.06 & 1.61 \\
\hline & 18 & $e$ & 0.25 & 0.81 & 13.16 & -3.36 & 10.69 & 176.84 \\
\hline & & RMSE & 1.76 & 0.99 & 0.73 & 2.08 & 1.18 & 0.87 \\
\hline & 36 & $e$ & 0.15 & 1.25 & 15.00 & 0.27 & 2.32 & 27.00 \\
\hline & & RMSE & 1.74 & 0.91 & 0.64 & 1.90 & 1.00 & 0.70 \\
\hline \multirow[t]{6}{*}{29} & $\overline{3}$ & & 0.08 & 0.05 & 20.00 & -0.02 & 0.01 & 5.00 \\
\hline & & RM5E & 2.79 & 0.68 & 1.47 & 2.84 & 0.69 & 1.50 \\
\hline & 18 & e & -0.24 & 0.13 & 11.43 & -0.21 & 0.11 & 10.00 \\
\hline & & RMSE & 2.37 & 0.70 & 0.83 & 2.52 & 0.74 & 0.88 \\
\hline & 36 & $e$ & -0.08 & 0.04 & 0.95 & 0.23 & 0.14 & 3.65 \\
\hline & & RMSE & 2.49 & 0.71 & 0.75 & 2.66 & 0.75 & 0.80 \\
\hline \multirow[t]{6}{*}{35} & 3 & & -0.13 & 0.09 & 2.17 & -0.13 & 0.09 & 2.17 \\
\hline & & RMSE & 2.49 & 0.58 & 1.42 & 2.70 & 0.63 & 1.54 \\
\hline & 18 & $e$ & 0.06 & 0.02 & 0.88 & -0.12 & 0.04 & 1.76 \\
\hline & & RMSE & 2.48 & 0.50 & 0.96 & 3.06 & 0.62 & 1.18 \\
\hline & 36 & $\epsilon$ & 0.18 & 0.08 & 7.83 & 0.31 & 0.13 & 13.48 \\
\hline & & RMSE & 2.04 & 0.52 & 0.68 & 2.19 & 0.55 & 0.73 \\
\hline \multirow[t]{6}{*}{41} & 3 & e & -0.06 & 0.04 & 3.75 & 0.07 & 0.05 & 4.38 \\
\hline & & RMSE & 1.95 & 0.86 & 1.29 & 1.95 & 0.86 & 1.29 \\
\hline & 18 & $\boldsymbol{e}$ & -0.14 & 0.14 & 46.67 & -0.12 & 0.12 & 40.00 \\
\hline & & RMSE & 1.70 & 0.86 & 0.75 & 1.73 & 0.88 & 0.77 \\
\hline & 36 & e & -0.09 & 0.06 & 10.00 & -0.04 & 0.03 & 4.44 \\
\hline & & RMSE & 2.18 & 0.99 & 0.83 & 2.10 & 0.95 & 0.80 \\
\hline
\end{tabular}




\section{The stability-dependent model}

In onder to se whether it is posible to improve the prediction abill of the aeutral HIRLAM/WAP model, a stability dependent veraion of it will be developed. Firet of all, it must be tested if the error of the neutral model is dependent on stability or wot. To this end, the vertical buoyancy ${ }_{\text {lux }}, B_{1}$, will be used as an indicator of atmospheric stability, it is defined as

$$
B_{.}=\frac{H_{0}}{B_{\text {aurt }} c_{p}}+0.608 \frac{H_{1}}{L_{c}}
$$

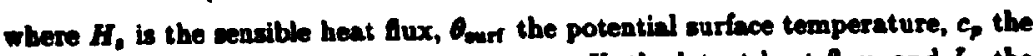
specific heat of dry air at constant preasure, $H_{l}$ the latent heat flux, and $L_{c}$ the latent heat of condensation at $0^{\circ} C$. $B$, in HIRLAM is, contrary to normal convention, positive when the heatfux is directed downwards, ie when the atmosphere is stable.

A plos of the error versus stability for May 1991, for all stations, for the neutral model with forecant length +3 hours is shown in Figure 30 . This figure shows that a the stability of the atmosphere gets further and further away from neutral, there is a tendency for the error to increace. The conclusion of this being, that if we can succeed in modelling the stability dependence - it can be expected that the inclusion of atability dependence will reduce the model error.

Another intereating fact appearing from the figure, is tha: there seems to be a majority of unstable situations, this is valid for day-time conditions, but also more surprising - for aight-time conditions. This is due to the fact that during the summer the model surface receives so much solar radiation, that it continues being warmer than the atmosphere during much of the night, Jorgensen (1891, private communication). This is obvioualy not a true model of the atmoopheric stability. Furthermore, it has been reported that due to an error, the initial andysis malkes the atmouplere more stable than it is in reality. This should force FIRLAM in the opposite direction than the one ceen. The luck of daily variation, is expected to have infuence - in a nezative way - on the performance of the stability dependeat verion of the IIILLAM/WAP model.

\subsection{The model}

Uning the tweory in Part I, it is poesible 20 construet a model that takes stability beo acoount. It is in two places that it is necesary to change the meutral HIRLAM/WAP model: in the reoctrophic dres $\mathbf{l a w}$, where the $A$ and $B$ parameters ace made stability depeadeat, and in the velocity profle, where an extra stability depeendent term une to be included.

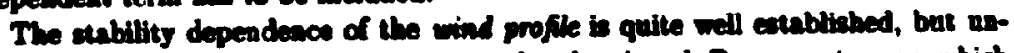
cortunatidy there is so sinde expresion for the $A$ and $B$ parameters on which consmans has been rescled, we Section 2.4. Therefore, all the difieneat sugerthons have been iried out. Furthermose, an average of the differeat curves in aleo ceoted, the averaged curves are shown in Figure $\mathbf{5 1}$.

The 7 difierent models listed in Table 13 ane texled on dats from the entire period on the 3 'good' and the 3 'bad' stations, wee Section 14 for definitions. The results are shown in Figures 32 and $\mathbf{5 3}$.

As can be ceen from the frores, the stabillty deperdent modelo periorm quite poorly compared to perviatence as well as to the neutral model. So contrary to what

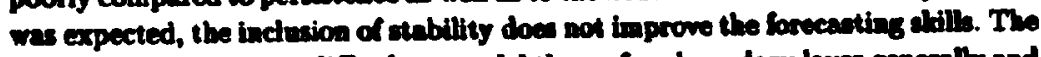

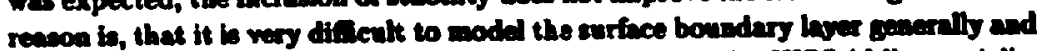
in a moded ulas parameterisation of the bousdary laye (a IIRLAM) epecially. 


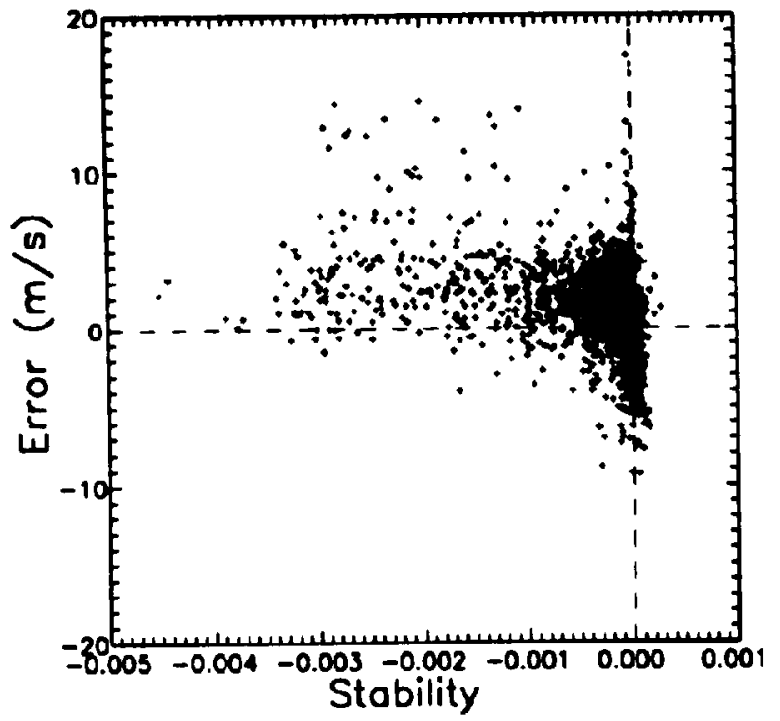

Figure 50. The error of the neutral model plotted versus stability. Data are from the $\$$ howr forecast for all stations in May 1991. As ar indicator of stability the vertical buoyancy fur, negative for unstable conditions, defined in Eq. 12s, is used.

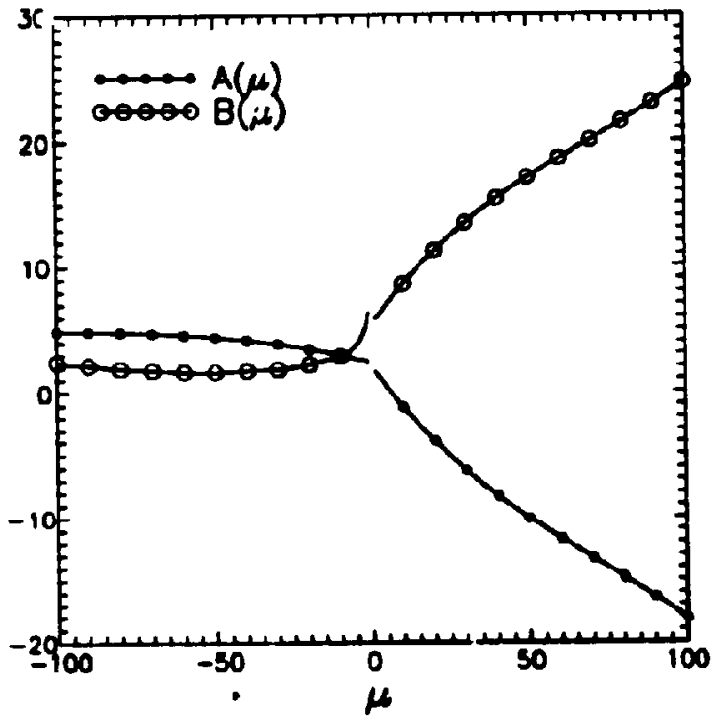

Pignve 51. The evernge A and B curves of all the proposed curves as e function of $\mu$.

As a consequence of the abomemeationed, another situation cccurs quile the queatly: with the set-up of the stablity parameters, the Coridis parameser, and the roughnes length, we get a function $G$ ( $\left.w_{*}\right)$ that has wo colution for the gecotrophic wiad, $G$, output trom HIRLAM, wee Figure 54 for reference, menning the it is imposible to obtain \& colution, *o, and as a consequence a prediction of the beal wind. This occurs between 10 to 50 per cent of the thee for all the modela. An

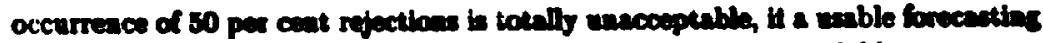

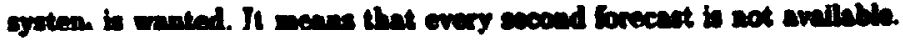



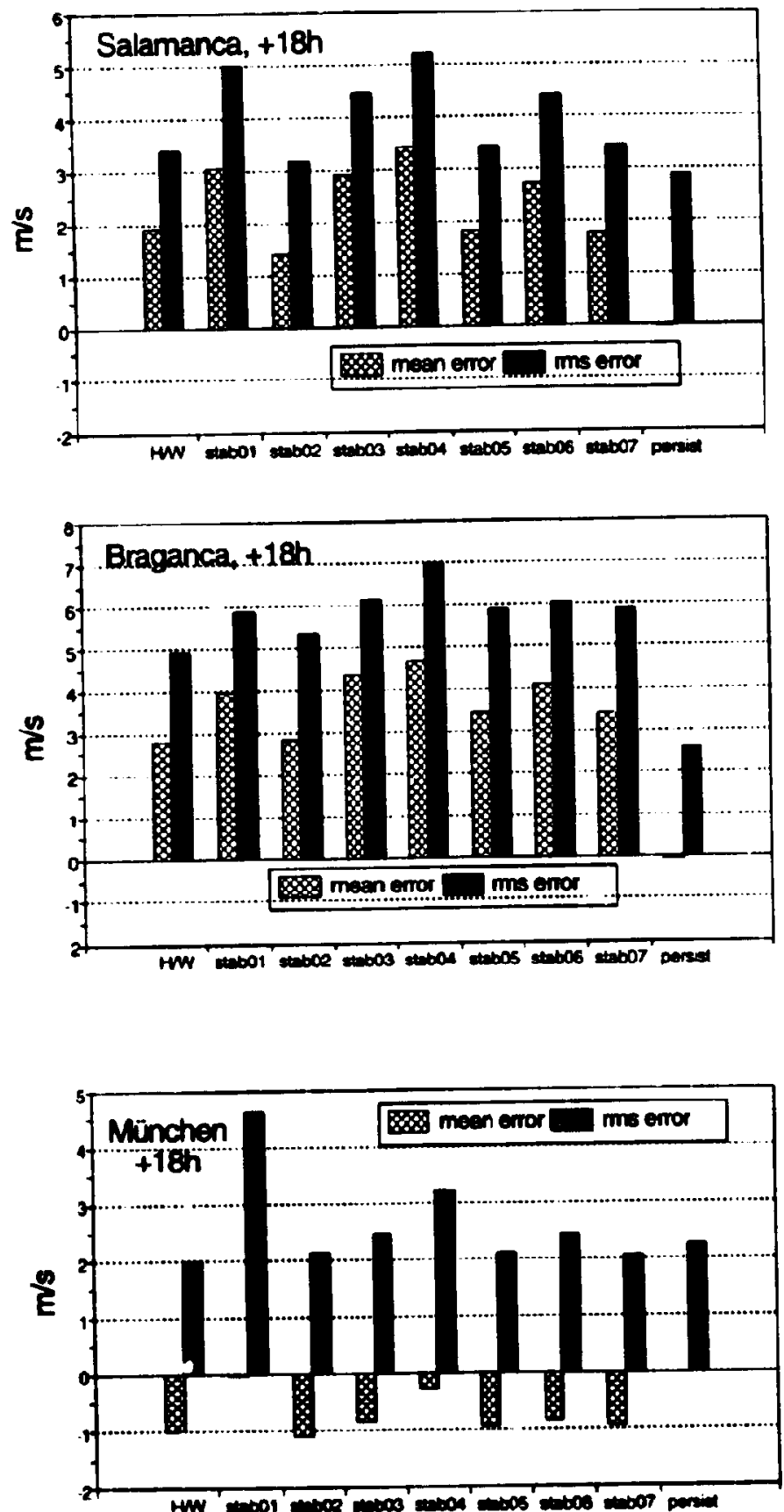

Figure 52. The mean error and the rms error of the 7 stability dependent models run for the enture period on data from the 'bad' stations $(29,35$, and 11) compared to the neutrul HIRLAM/WASP model ('H/W') and persistence ('persist'). 

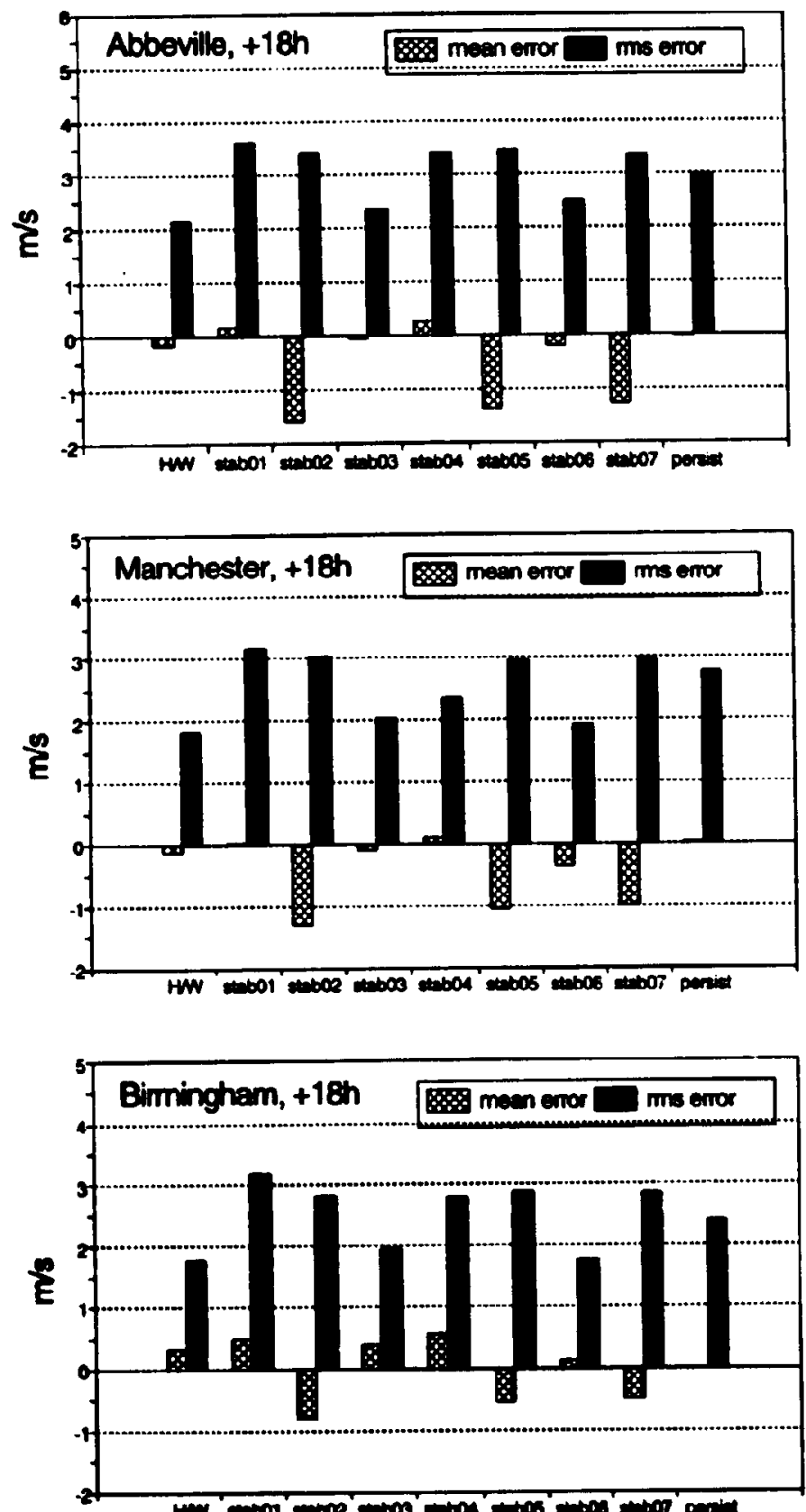

Figure 59. The mean error and the rms error of the 7 stability dependent models run for the entire period on data from the 'good' stations (19, 56, and 57) compared to the neutral HIRLAM/WASP model ('H/W') and persistence ('persist'). 
Table 13. The six stability dependent models plus the averaged $A$ and $B$ profiles.

\begin{tabular}{ll}
\hline stab01 & Zilitinkevich, 1975 \\
stab02 & Arya, 1975 \\
stab03 & Arya, 1977 \\
stab04 Long and Guffey. 1977 \\
stab05 & Billard, 1981 \\
stab06 Jensen et al, 1984 \\
stab07 Average of the above \\
\hline
\end{tabular}

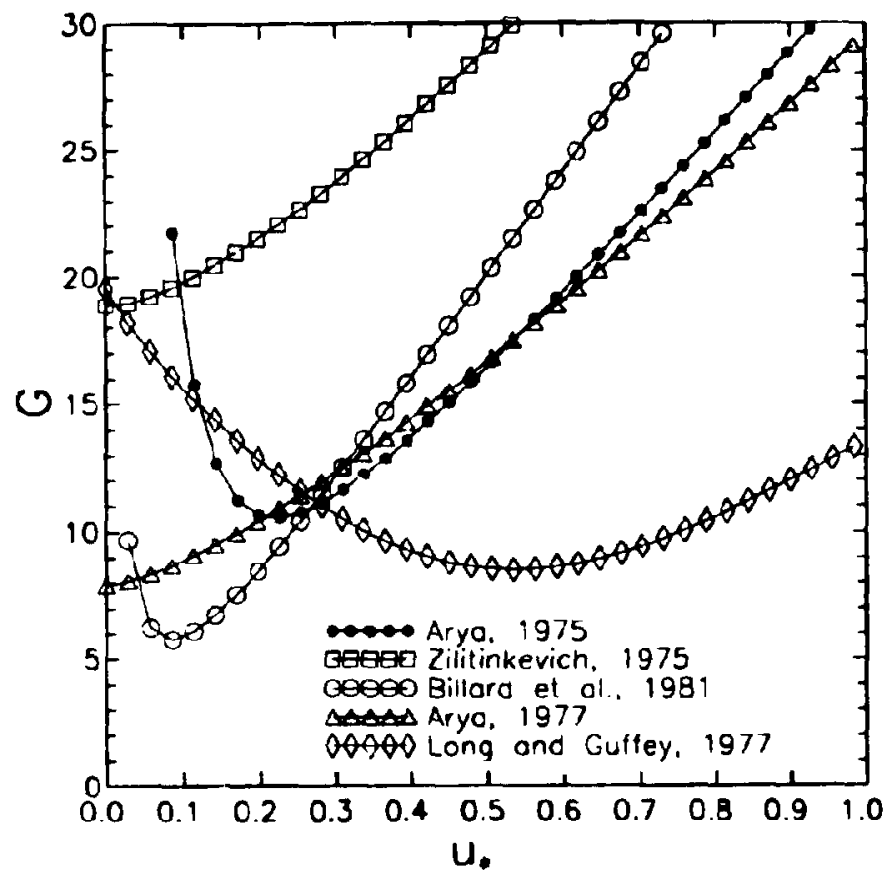

Figure 54. $G$ plotted versus $u$, using the geostropiaic drey law for a certain set of parameters $\left(i_{0}=0.03, f_{0}=1.2 \cdot 10^{-}, \mu \mu_{0}^{2}=1.78\right)$ for some of the selected models. Note that winds output from HIRLAM (ie the $G$ 's) below $5 \mathrm{~m} / \mathrm{s}$ will not have a matching $u_{*}$, and as a conseguence that no local wind can be colculated.

Studying the two stability parametes (the latent and vensible heat flux) output from HIRLAM will cast some light on the problem, since there is a lack of the expected dally variation (ef Figare 55). This bs explatued by the fact that stations sitnated up to 2 grid-spacings $(110 \mathrm{~km})$ from the const, will hove values taken from gridpoints that have a prescribed constant sea surface temperature taben moath by moath from climatolojical vales. This inhibits - of course - the variation. The displayed station (Abbeville) is $25 \mathrm{~km}$ from the coant, and tills therefore within the category mentioned above. It muat be stresed that HIRLAM is a state-of-thean forecasting model, and therefore that we cannot expect to find other models giving better results. So the aim of studying the stability dependence is as muci to see whether the stability - at present - can be modeled with sufficient accuracy to be used for short-term prediction. As can be seen from the above, this is not the case, yet. It shoulu . noted, bowever, that modelling the boundary layer (including the fuxes) in one of the major fields of ongoing rewench. 


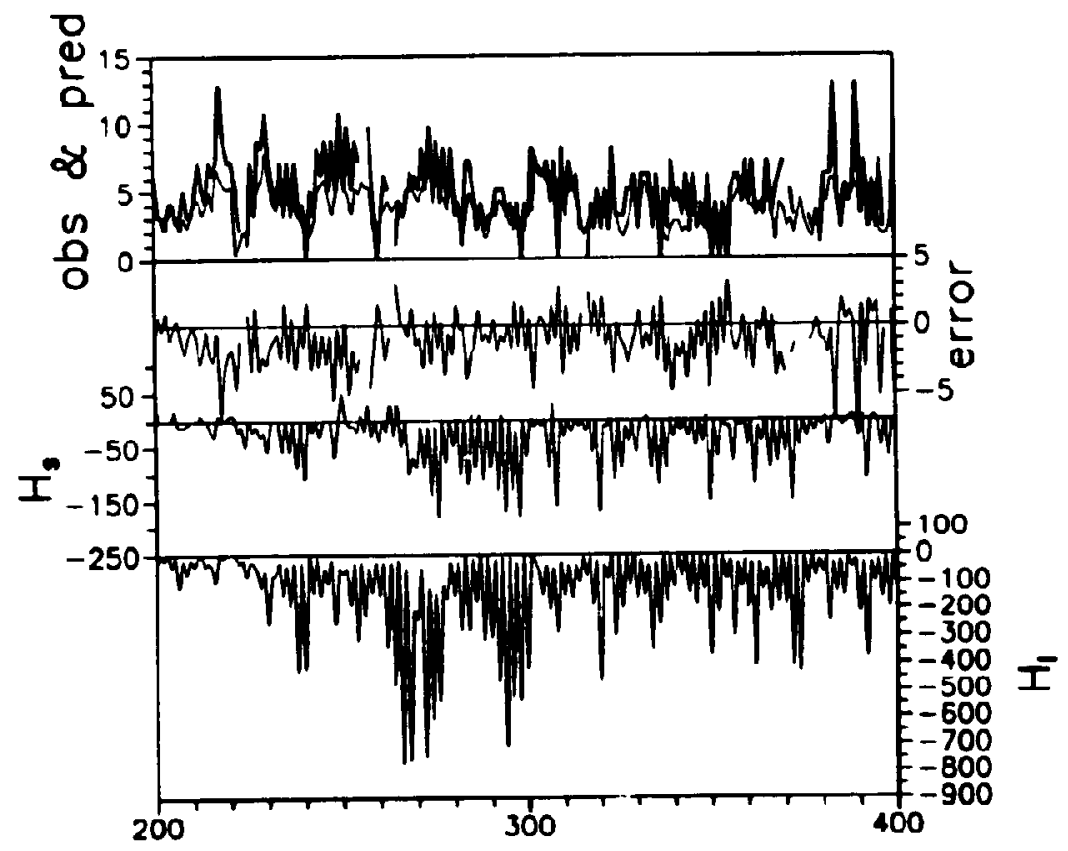

Figure 55. An example of the variation of the sensible (Ind $x$-aris from above) and the latent heat fux (th $x$-axis from above), $H$, and $H_{1}$, respectively. The data are taken from Salamanca (otation 19), and are for the +3 hour forecast, which ere taken at 09 and 15 UTC, in the period Manch 10th to June 18th 1991. The cypermast tines are the predicted (thin line) and the observed values (bold line), the bine around the Ind $x$-axis from above is the error (mnelictad - observed) in $\mathrm{m} / \mathrm{s}$. 


\section{Other prediction methods}

\subsection{Statistical methods}

In this section two other methods for short-term prediction are presented. They both base themselves solely on observed values, ie no physical modelling at all is involved. The two methods are:

- A simple linear correlation

- Neural networks

These methods are - in compliance with the testing of the other models developed so far - optimised on data from the first half year of the one year period (December 1990 - May 1991) and evaluated on the last period (June 1991 - November 1991). Note that in this case approorimately 2900 observations are available, since all of the 3 hourly observations are available. This is contrary to the HIRLAM/WASP model where only forecasts every 12 hours are at hand for each look-ahead time, because HIRLAM is only run twice a day.

\section{Linear model}

The linear model uses the same principle as the linear model in the section about MOS; however, instead of using winds output from a physical model, previous (known) observations are used. In this simple approach the linear relation between the wind 24 hours abead (say) and the presently observed wind is established, according to the following formula

$$
u(t)=a(t)+b(t) u_{o b s}(0)
$$

where $u(t)$ is the wind at look-alicau. time $t$ and $u_{\text {obs }}(0)$ is the obsel red wind at the beginniag of the forecast $p \times \cdot 0, r . c(t)$ and $b(t)$ are the coefficients linking the observed wind at time $t=0$ to he sberved wind at time $t$. Note, that no dependence on direction is modelled.

The linear model has been tried on the 6 selected stations and the results of the forecasts are found to be very good, especially for the 'bad' stations where the rms error is slightly better than that of the HIRLAM/WAP model with linear MOS applied. The mean error is of the same magnitude for the 'bad' stations. For the 'good' stations the results are of the same magaitude. Bear in mind that these models base themselves on observations oaly. The results are listed in Appendix C, Table 19. Examples of results using the linear model are shown in Figures 6010 65 in Section 17.

The seasitivity to the number of sumples uand in the optimiantion of the linear wodel bas beea investigated. It can be seen from Figure 56 that if lees than 600 samplea (ie approx 2.4 months) are used, the forecasts will be highly unreliable in the sense that the mean error is inctuating rapidly. After 600 samples is can be seen that some ceasual variation is still present even out to 1400 samples (ie apprex. 5.7 months). Clearly, at bast one whole year must be covered, to take all ceasonal variation into sccount.

\section{Porecasting with neural networks}

Two difierent neural networks have been trained on the firat 1448 observations (equal to the first half year): a very simple network $(1,5,1)$ and a more complex: $(5,10,10,1)$. Remember that one of the conctwoioas, when using newral setworbs 


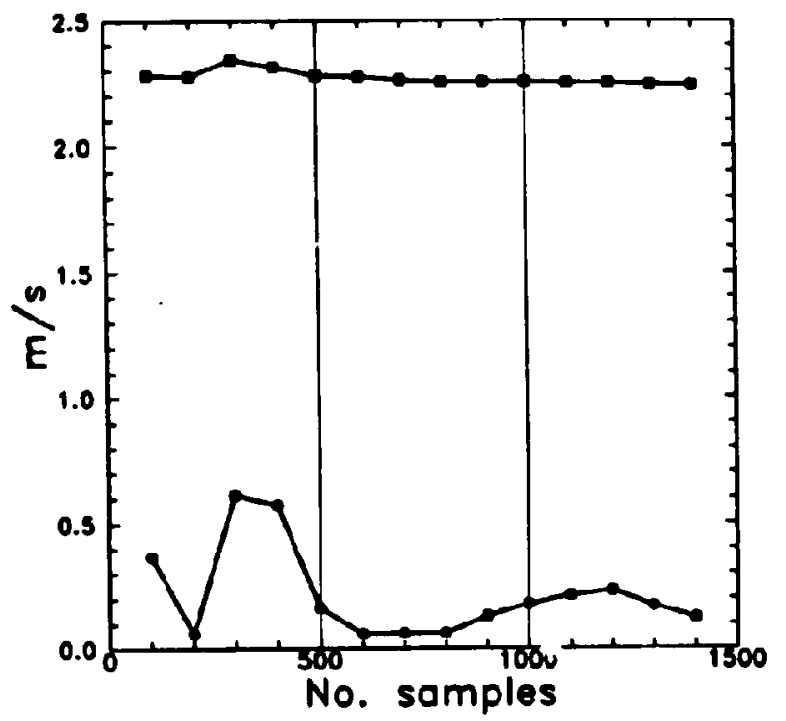

Figure 56. The mean error (in $\mathrm{m} / \mathrm{s}$, solid cincles) and the rms error (in $\mathrm{m} / \mathrm{s}$, solid squares) of the linear model predicting 18 hours ahead for Manchester (station 56) plotted against the number of samples used during the optimisation of the poremeters. All the models have been tested on the last half of the period.

to do MOS, was that the complexity did not play any role with respect to performance, and that, furthermore, the neural networks did not perform better than the simple linear MOS. The validity of these statements is tested for neural networks trained on observations only in this section.

It is found that the use of neural networks as the predicting tool for the 6 selected stations does nol perform better than the HIRLAM/WAP model with linear MOS for the 'bad' stations and without MOS for the 'good' ones. Furthermore, is it found that - in this case of oaly two different models - the more complex network performs better than the simpler one. The difference is not very pronounced, bowever. Examples of the performance of the $(5,10,10,1)$ network are shown in Figures 60 to 65 in Section 17.

It has been tested to soe bow atrong the infuence of the number of amples in the time series (ie the time spent carrying ont on-site measurements) is on the difierent evaluation parameters. Referring to Figure 87, it can be soen that especially the menn error is dependent on the number of asmples, but after approximately 700 maples the error seems to have found ita bevel, with only anall oncillations around thin. The pattern is very much bibe that found for the lisear model. The sensitivity to the number of iterations in each training semion has sto been invostigated and it wes found that within the range of 500 to 10000 iterations there was wo dependeace. All other networls in this project have been trained using 2000 iterations. Finally, the sensitivity to the magnitude of $\mathrm{e}$ ba been bobed into and so dependence of the mean error of the rms error was found for a fred number of iteration (2000) either.

\subsection{Conclusion, statistical models}

As stated above, the lisear and the seural network modeb does perform equally well. They have both performances that are equal to of better than the physical model. Sivce the training and implementation of the lhear model is much simples 


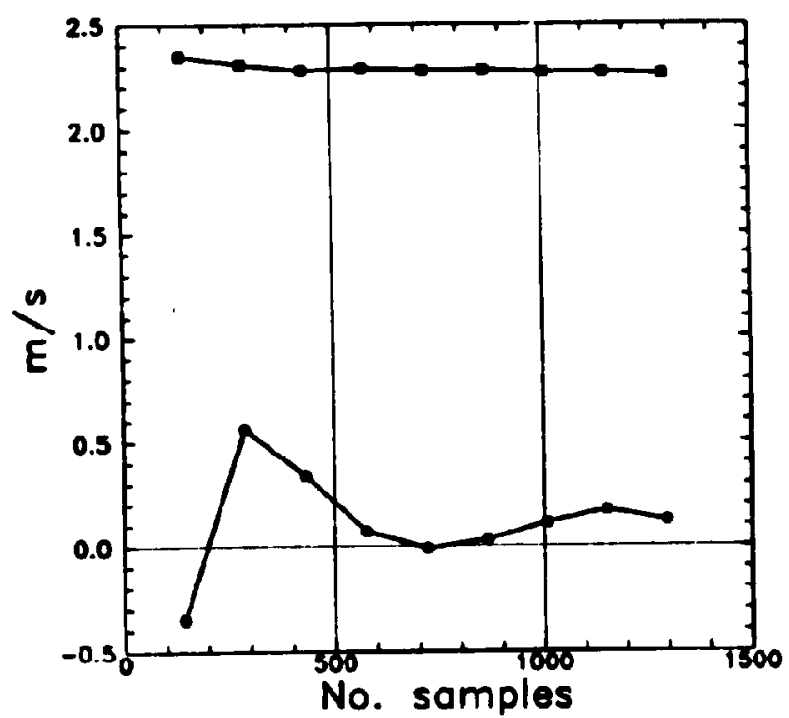

Figure 57. The mean error (in $\mathrm{m} / \mathrm{s}$, solid circles) and the rms error (in $\mathrm{m} / \mathrm{s}$, salid squares) of the $(1,5,1)$ neural network predicting 18 hours ahead for Manchester (station 56) plotted against the number of samples used during the training of the network. All the networks have been tested on the last half of the period.

than the neural network, it must be concluded, that if on-site data exists the linear model should be used. 


\subsection{Using the UK Meso-scale model}

To see the effect of the resolution (mainly spatial, but also temporal) of the weather prediction model on the performance of the model predicting local wind conditions, the British Meteorological Office's UK MESO (United Kingdom Meso-Scale) model is used instead of HIRLAM. The model is non-hydrostatic and has a spatial resolution of $15 \mathrm{~km}$ (HIRLAM: $57 \mathrm{~km}$ ). The UK-MESO covers only the United Kingdom, Ireland, and minor parts of continental Europe and can therefore only be used for the stations situated in the United Kingdom. See Golding (1990) for further information on the UK MESO model.

The out put used from the model is the $10 \mathrm{~m}$ wind. The model we then develop, is taking this wind and correcting it for the local effects. The assumption is that the $10 \mathrm{~m}$ wind out put froin the UK MESO model is cempletely unaffected by local conditions. This is of course not true, since the orography of the United Kingdom is present in the model. But because of the resolution of UK MESO, the orography is not resolved on the same scale as in WASP. Comparing the forecast using UK MESO and WASP to the HIRLAM/WASP model for all the selected stations in the UK (ie station 1, 60 and 52 to 58 ), we see, without any exceptions, that the rms error is reduced with typically $70-80$ per cent. The mean error is typically of the same magnitude as when using the HIRLAM model. An example of this is shown in Figure 58. There are, however, a few stations where the mean error is quite big: station 1,57 and 58 , where the error is typically around $1 \mathrm{~m} / \mathrm{s}$. Note that no MOS was applied to either of the models, so biases like these would have been removed if it was used.

In conclusion it can be said that - as expected - the higher spatial resolution gives improved forecasts. Note that the 'price' paid for this improvement is a significant reduction of the area covered. This fact can only be changed with the use and development of more powerful computers.

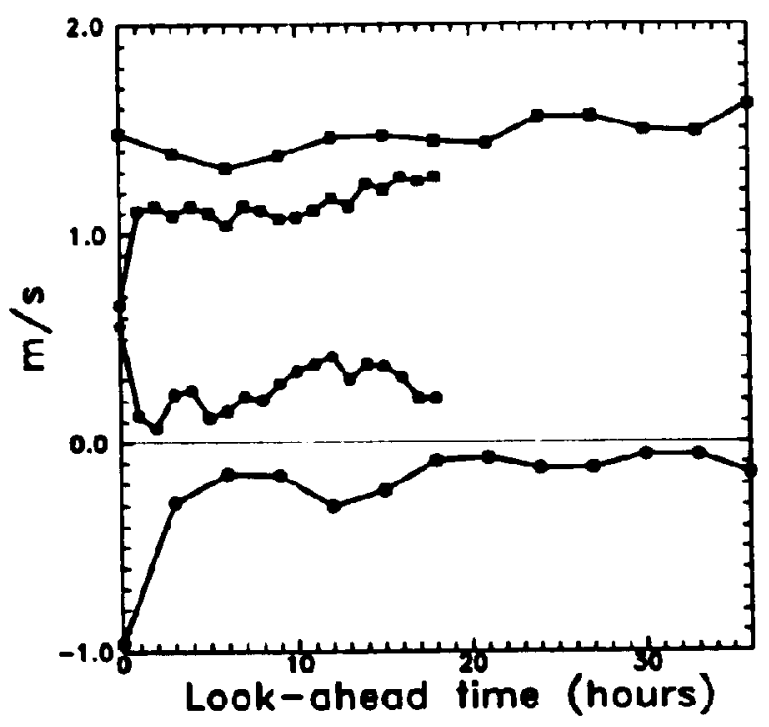

Pigure 58. The mean error (in $\mathrm{m} / \mathrm{s}$, denoted by circles) and $\mathrm{ms}$ error (in $\mathrm{m} / \mathrm{s}$, denoted by squares) of the HIRLAM/WASP-model (open symbols) compared to the UK MESO model (solid symbols) combined with WAS for Manchester for the entire period (December 1990 to November 1991). The look-ahead time (in hours) is along the $x$-aris. 


\section{Summary and conclusions}

In this section a brief overview of the study will be given, since quite a few models have been presented. Furthermore, a conclusion will be given as to which models are to be used when.

Eight different models have been used in this study, they are listed in Figure 59. They can basically be grouped in two:

1. Models that use numerical weather prediction models (NWP) (such as HIRLAM and the UK MESO model).

2. Models that base themselves solely on observations.

The first group can be subdivided into models that use physical models only (the HIRLAM/WASP in its neutral and stability dependent versions and the UK MESO/WASP models) and models that are based on some statistical knowledge of past observations (the two MOS (Model Output Statistics) models, one based on a linear relation and another based on a relation generated by a neural network). Likewise, the second group can be subdivided in two: one that does nothing to the observations (the persistense model) and one that performs some sort of transformation of the observations (the linear and the neural network models).

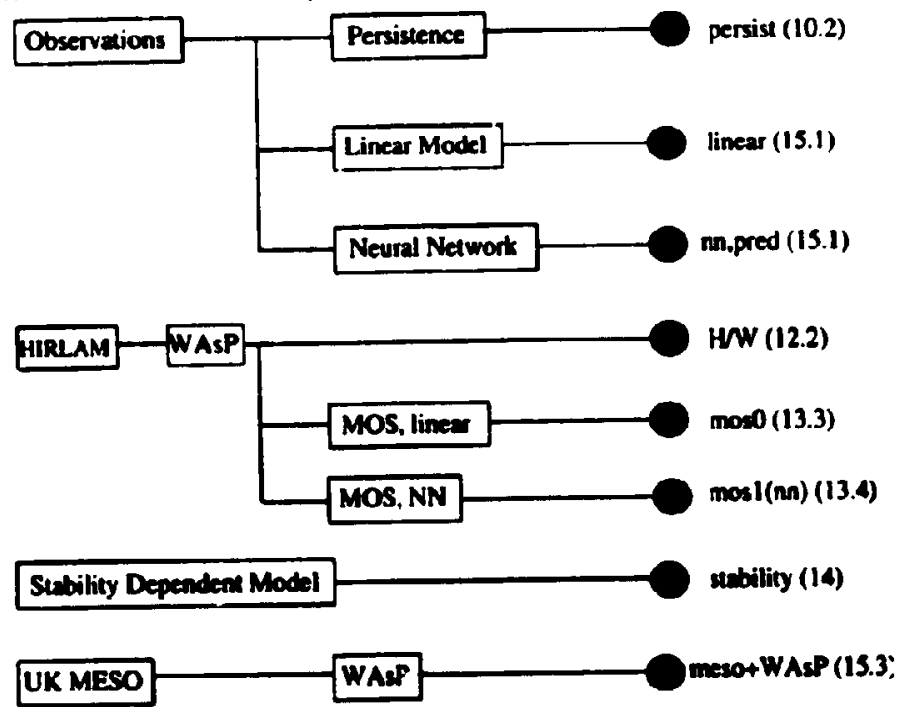

Figure 59. An overview of the different models wed to predict the local wind com. ditions. The numbers in the panenthesis refer to the section where the madel is described.

The emphasis in this study has been laid on the development of the sentral model using output from HIRLAM, traneforming this to the surface layer, and correcting the resulting free-stream wind for local effects using output from the WAP model. The neutral model has aloo been extended to include stability dependence.

\subsection{Comparing the 8 models}

In Figures 60 to 65 the mean error and the rms erroc of the eight modets are piven for the 6 stations, selected for a clower examination. Three of the stalioma 
are categorised as 'good', ie well predicted (as compared to persistence) by the neutral version of the HIRLAM/WAP model, and three as 'bad'. This ratio of 'good' to 'bad' is not representative of the $\mathbf{5 0}$ stations studied, since of least $\mathbf{8 0}$ per cent of these are labeled as 'good'. It is well known, bowever, that one learns, not from the successes, but $f \cdot m$ the failures.

To make a fair comparison of the different models, only data from the last half of the period (ie from June 1991 to November 1991) has been used In the evaluation for all the models. Or the stability dependent models only one of the 7 is presented as an example.

\subsection{Conclusions}

A number of conclusions can be drawn:

- The performance of existing forecast methods (mainly persistence) has been surpassed significantly by the methods developed and presented in this study.

- At sites with high mean wind speeds the neutral HIRLAM/WAPP model is found to perform particularly well.

- If no data is available at the site (the typical case) the neutral version of the HIRLAM/WASP model should be used. If an NWP model exists with a higher resolution than HIRLAM, it should be used instead. If the site is dominated by strong local thermally driven circulation, the model should be used with great caution.

- For bok-ahead times shorter than 3 to 6 hours, the persistence model should be used, since none of the models perform as well.

- If on-site data is available two approaches can be taken:

- If output from NWP models is at hand the forecast using the neutral version of the HIRLAM/WASP model should be used, corrected with the linear MOS model

- If no output from from NWP's is at hand, the linear correlation method based on observations only should be used.

- The stability-dependent version of the neutral model friled to produce any improvement over the neutral model, mainly because of the dificulty for the NWP model in predicting the heat luxes at the surface.

- The seural networks performed quite well, often better than the neutral HIRLAM/WAP moded, bent since the much wore simple linear models performed equally well (for the MOS version and for the prodiction based on obeervetions oaly), it must be concluded that wearal setworks - in this stedy - have nof showr any ontstanding performance. This is most bibely dwe to the fact that, even though the problem of predicting the wind boclly is a hard one, peraiatence is performing quite well, and there is wot much for the neural setwork to 'learn'. 


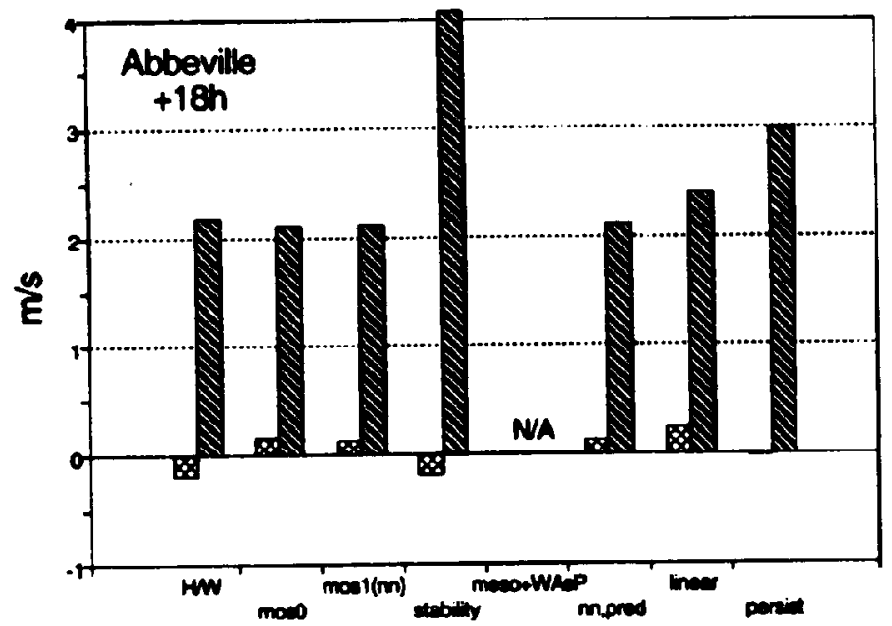

Figure 60. The comparison of the eight models for Abbeville (stat. 19). The first bar (of the two for each model) is the mean error ( $\mathrm{n} \mathrm{m} / \mathrm{s}$ ) and the second is the rms error (also in $\mathrm{m} / \mathrm{s}$ ). An explanation of the different abbreunations of the different models can be found in Figure 59. ' $N / A$ ' means that the UK MESO forecast is not available, because the station is not within the area covered by the model. Abbeville is categorised as a 'good' station meaning that the HJRLAM/WASP model predicts it well (as compared to persistence).

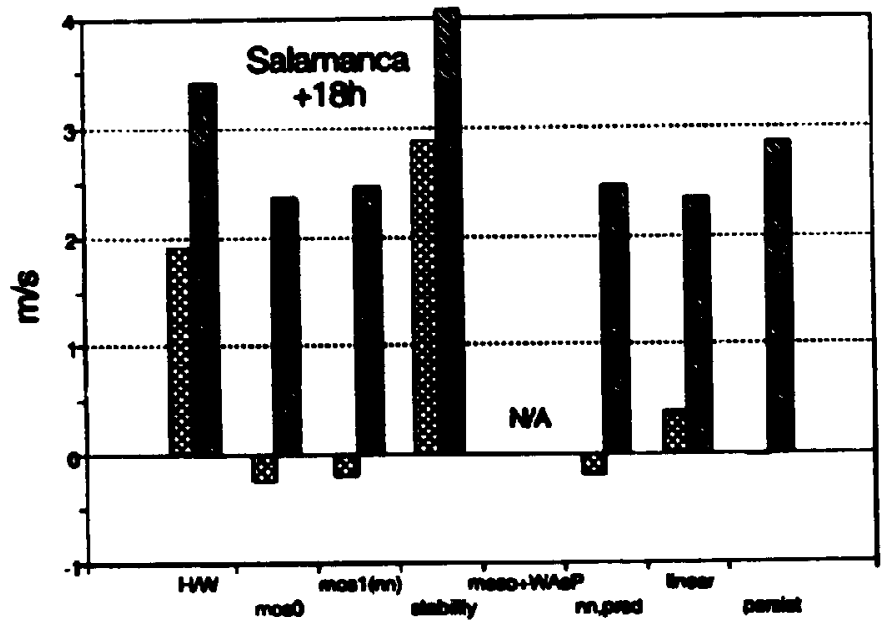

Figure 61. The comparison of the eight models for Salamanca (stat. 29). See Figure 60 for explanation. Salamance is a 'bad' station. 


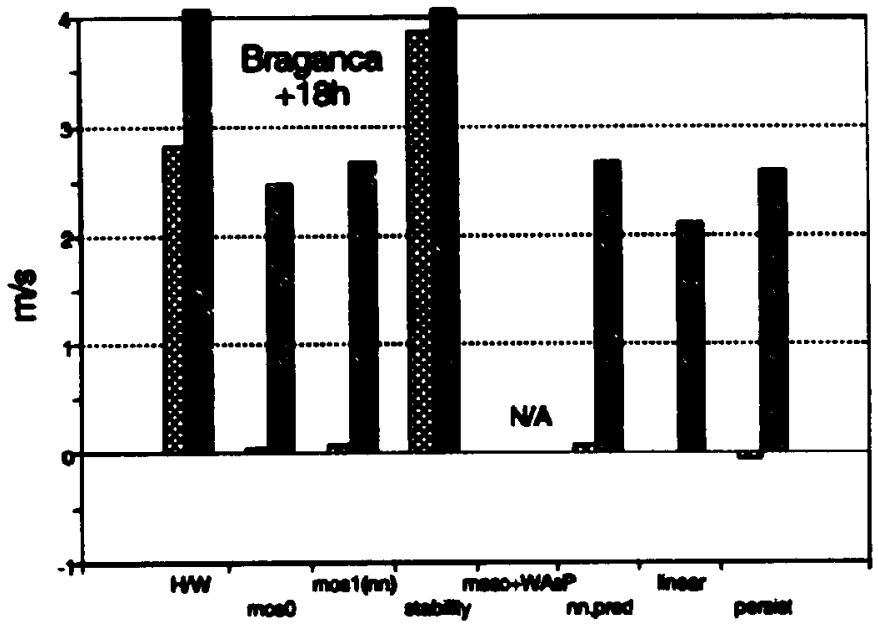

Figure 62. The comparison of the eight models for Braganga (stat. 95). See Figure 60 for explanation. Bragançe is a 'bad' station.

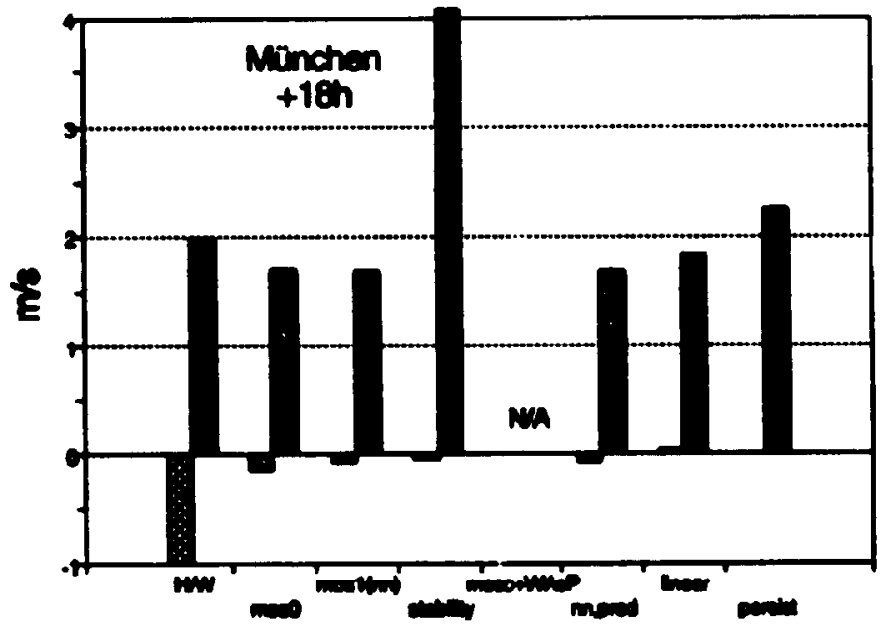

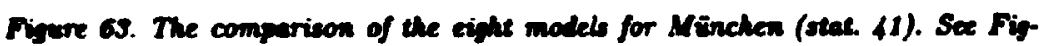
wre co for explenction. Minchen is a 'Lad' station. 


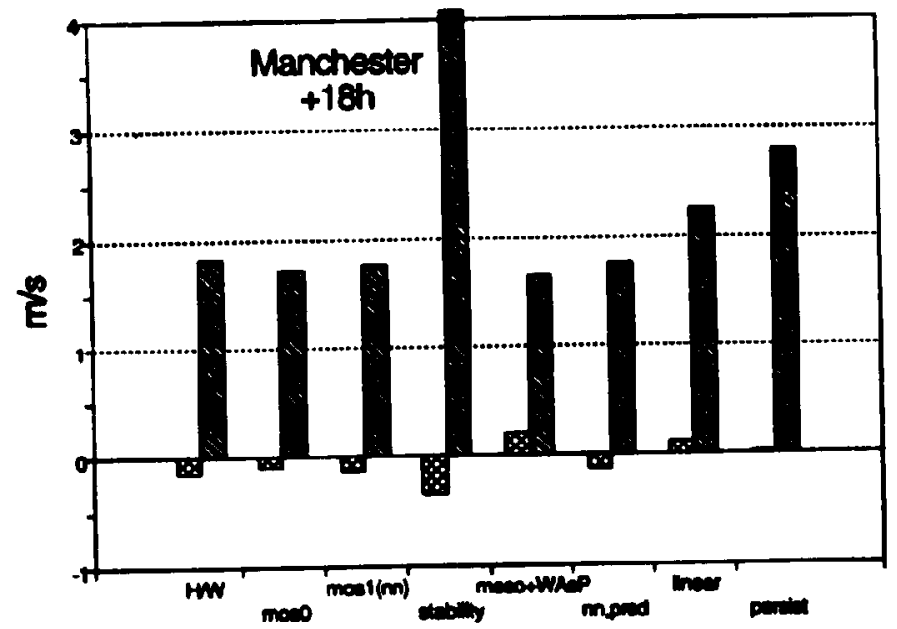

Figure 64. The companson of the eight models for Manchester (stat. 56). See Figure 60 for explanation. Manchester is a 'good' station.

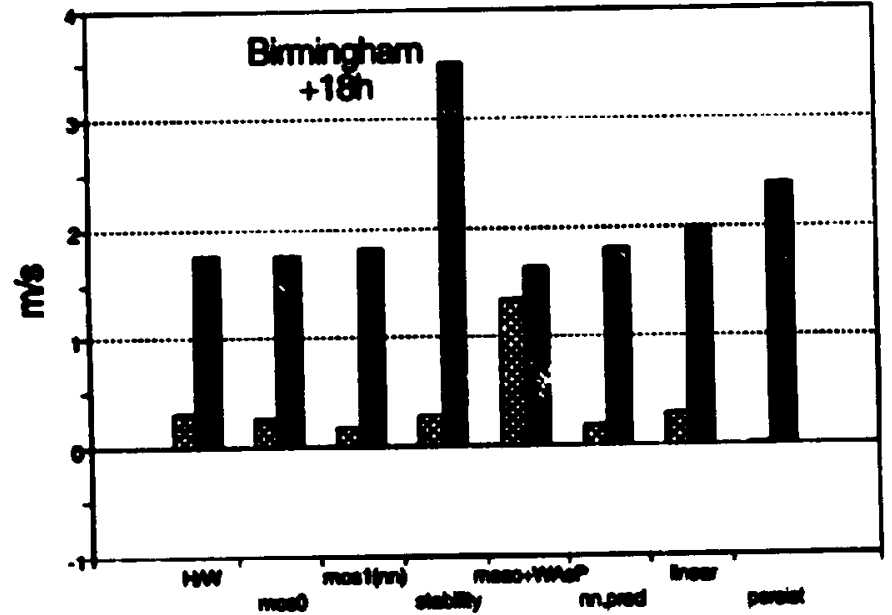

Fuswe 65. The comparieon of the eight models for Birmingham (stat. 57). See Figure 60 for explanation. Bimingham is a 'good' station. 


\subsection{Using the models}

In this last section a sketch of the possible use of the neutral version of the HIRLAM/WAP model will be given. The problem is that HIRLAM is only run twice a day (at 00 UTC and at 12 UTC). This means that for a given time of day there will only be forecasts available from a certain look-ahead time. As an example, consider the available forecasts for 09 UTC:

- the +9 hour forecast from the model run at 0O UTC on the same day.

- the +33 hour forecast from the model run the day before at 00 UTC, and

- the +21 hour forecast from the model run at 12 UTC the day before.

A complete overview of this is given in Figure 66.

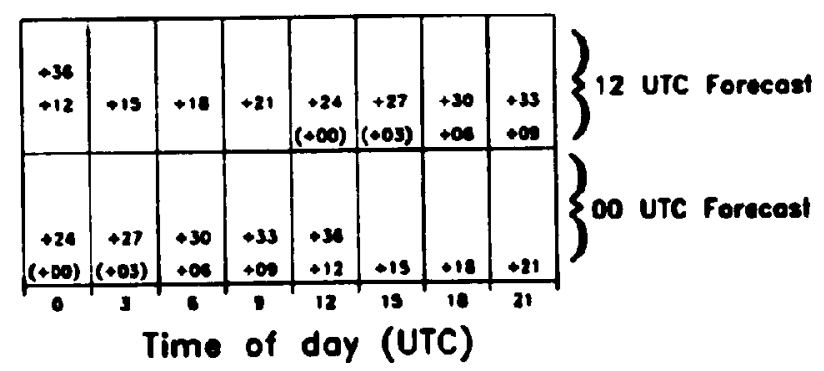

Figure 66. The available forecasts during the day from HIRLAM. Numbers in parenthesis refer to the fact that the forecasts are not evailable, until between 9 to 6 hours after the observations were made.

The implementation of the model is quite simple: In the case of a single wind turbine, only 24 values from the NWP model (the $x$ and $y$-components of the forecast wind every third hour for 12 time steps) are needed twice a day. These values can be transferred from the meteorological institute through some electronic transferal system, by fax, or by phone. When the values are received they are entered into the PC, the program developed in this study is then run (taking less than $30 \mathrm{sec}$ ) and the forecasts are output from the PC. These forecasts can then be used in the planning and scheduling of the conventional power plant. This procedure is depicted in Figure 67. Betore the first forecast is made, a WAPP analysis of the site, similar to the one sletched in Section 12.2, has to be carried out. In the analysis the following topics seed to be accessed: the distribution of the obstacles around the site, the roughnes of the surrounding terrain, and the orcgraphy of the terrain. This information has then to be entered into WASP, and the program run. The resulting correction malrix for the beal efiects can then be outpot from WAPP.

If a wind farm is considered, the power production must be andyoed using a program that tabes the fact that the turbives most libely will be in each-other's wakes into sccount. A program that doee this is PARK, see Sanderbof (1993).

If - for scheduling purpoes - forecasts with a higher temporal resolution are needed, these can be obtained either by linear interpolation between the existing forecasts or by obtaining more detailed output from the NWP. Generally NWP models have time-steps of the order of a few minutes. 


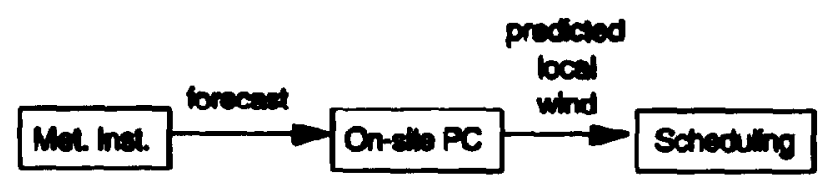

Figure 67. The implementation of the neutral model. 


\section{Acknowledgements}

This study has been funded by the Danish Research Academy and the EEC JOULE-programme under contract JOUR-0091-C(MB). The HIRLAM data and the observations have been provided by the Danish Meteorological Institute. The British Meteorological Office has through Rutberford Appleton Laboratory provided the data from the UK MESO model.

I would like to thank Dr Aksel Walloe Hansen, University of Copenhagen, Geophysical Institute, Dr Erik Lundtang Petersen, Dr Søren E. Larsen and Jakob Mann, all from Department of Meteorology and Wind Energy, Risø National Laboratory for helpful discussiors and Frances for correcting 'bad language' and for letting me share my life with her.

I would like to thank Niels G. Mortensen for being a good colleague and for scrutinising the draft, resulting in many good corrections I would also like to thank Dr Simon J. Watson, Rutherford Appleton Laboratory, for good coorporation and for being the 'yard-stick' at RAF Dunkeswell. At the met. station at RAF Dunkeswell I would like to thank Mr John Pawley for being very helpful. Finally, I would like to thank Rasmus Poulsen for digitising the maps of Dunkeswell. 


\section{Dansk sammendrag}

En model til at lave kortfristede forudsigelser (dvs op til 36 timer) af lokale vindforhold (dvs den vind, der males af anemometret pá en meteorologisk mast) er blevet udviklet og evalueret. Modellen bygger pa forudsagte vinde fra Danmarks Meteorologiske Instituts HIRLAM model. Disse vinde, der blaser i et niveau udenfor granselaget, bliver transformeret ned til overfladen ved hjalp af den neutrale version af den geustrofiske 'dras'-luv. Ved overfladen bruges den neutrale vindnmfil og vinden korrigeres for lolcale forhold ved hjælp af Forskningscenter Risos WASP model. De lokale forhold er: levirkning af nærtstiende forhindringer, indflydelsen af aerodynamisk ruhed og af orografi. Denne model vil i det folgende blive kaldt 'den neutrale model'.

Under udviklingen af modellen viste det sig, at den faktiske modelvind i $137 \mathrm{~m}$ 's hojde fra HIRLAM gav de bedste resultater. Dette i modstrid med hvad man ville forvente, nemlig at det var den geostrofiske vind, der ville give de bedste resultater. Forklaringen pd dette er formentligt, at det er forbundet med vanskeligheder at beregne geostrofvinden nøjagtigt i en model, der benytter sig af et o-koordinatsystem. Et $\sigma$-koordinatgystem er et system bvor vertikalkoordinaten er det atmosfariske tryk normaliseret med trykket ved overfiaden.

Modellen er blevet evalueret ved at bruge observationer af vindhastighed og -retning fra 50 meteorologiske stationer fordelt over hele Europa. Der er blevet brugt observationer fra et helt à (december 1990 til og med november 1991)

Resultatet af evalueringen er, at modellen er bedre end en persistensmodel efter 4-6 timer. En persistensmodel er en model, der anvender den seneste observation som forudsigelsen feks 18 timer frem. Arsagen til, at den ber udviklede model forst et bedre efter en vis tid, er, at de fejl, der uundgaligt optrader i en numerisk vejrforudsigelsesmodel, er sa store at den simple persistensmodel forudsiger mere nojagtigt $i$ begyndelsen. Som et eksempel kan det nzevnes, at for 18 timers forudsigelsen var $80 \%$ af stationerne forudsagte bedre ved bjelp af den neutrale model end af persistensmodellen. Det viste sig, at observationer fra stationer med hoje middelvindhastigheder (set $i$ forhold til standard-afvigelsen) var bedre forudsagte end stationer med lave middelhastigheder.

Endvidere blev en stabilitetsalhengig (dvs afhengis af den atmosferiske stabilitet) version af den foromtalte neutrale model udviklet of alprovet. Det viste sig, pl gruad af vanskeligheder (for dagens mntematiske modelker af atmosfaren) ved at forudsige varmefluksene ved jordovertiaden, at denne stabilitetsafhengige model ikke forbedrede den neutrale models forudsigelser.

Et andet tiltag for at forbedre den neutrale models forudsigelsesevne var at anvende MOS (Model Output Statistics). Denne metode byeser ph, at man forenger at finde en feks lineser sammenhang mellem det en fysiak model forudsiger of det alktiskt observerede. Denne metode gav meget gode resultater, ianer for de 20\% af stationerne hvis obervationer ible var forudangte serligt godt af den nevtrale model; st stor, at forudsigeben blev bedre end persintensmodellens. Hvis det er muligt, dvs hvis der elssisterer tidligere observationer of forudsigelser, bat den seutrale model derfor bombineres med MOS.

For at bed smme den neutrale models forudoigelewevne blev et antal simple (mht deres indhold af fyaik) modeller udviklet of afprsvet. Nogle af disse modeller bysget pi lineser regression of andre ph neurale netverk. Det viste sis, at begse disse typer modeller forudsagde observationerne lorbavsende godt; dette ban feks ses al Figurerne 60 til 65. Da optimeringen af modeller bysgende ph neurale netverk ex betydeligt mere beregningakravende end modeller bysgende ph lineret regresion of da begse typer modeller lavede gode forudsigeder, mi det anbefales at bruge dea model, der byrger pl liverer regremion. 


\section{References}

Abramowitz and Stegun, 1964: Handbook of Mathematical Functions. Washington: National Bureau of Standards, 504.

Arya, S.P.S., 1975: Geostrophic drag and heat transfer velations for the atmospheric boundary layer. Q. J. R. Meteorol. Soc., 101, 147-161

Arya, S.P.S., 1977: Suggested Revisions to Certain Boundary Layer Parameterization Schemes Used in Atmospheric Circulation Models. Mon. Weather Rev., 105, 215-227.

Arya, S.P.S., 1985: The Schematics of Balance of Forces in the Planetary Boundary Layer. J. Clim. Appl. Meteorol., 24, 1001-1002.

Autzen, C., 1991 : Evaluation of the Danish HIRLAM. (In Danish). Danish Meteorological Institute, Copenhagen, Denmark.

de Baas, A., 1990: The $K-\epsilon$ model in separating flows. In: Proceedings of Ninth Symposium on Turbulence and Diffusion, Roskilde. American Meteorological Society, 359-362.

Billard C., J-C. André, and R. du Vachat, 1981: On the Similarity Functions $A$ and $B$ as determined from the the 'VOVES' experiment. Boundary-Layer Meteorol., 21, 495-507.

Blackadar, A.K., 1965: A Single Layer Theory of the Vertical Jhistribution of Wind in a Baroclinic Neutral Atmospheric Boundary Layer. In: Flux of Heat and Momentum in the Planetary Boundary Layer of the Atmosphere, Final report, Penn. State Univ., Meteorology Dept., Contract AFCRL-65-531, 1-22.

Blackadar. A.K. and H. Tennekes, 1968: Asymptotic Similority in Neutral Baratropic Planetary Boundary Layers. J. Atmos. Sci., 25. 1015-1020.

Bradley, E.F. and P.J. Mulhearn, 1983: Development of velocity and shear stress distribetions in the wake of a porous shelter fence. J. Wind Eng. Ind. Aerodyn., 15, 145-156.

Bradshaw, P., 1971: Variations on a theme of Prendtl. AGARD Conf. on turbuleat Shear Flows, London.

Byun, D.W., 1991: Determination of similarity functions of the resistance laws for the planetary boundary layer using surface-layer similarity functions. Boundary-Layer Meteorol., 37, 17-48.

Castso, I.P., 1979: Relaring wakes behind surface-mounded obstacles in rough wall boundary layers. J. Fluid Mech., 83, 631-659.

Clarke, R.H., 1970: Observational Studies in the Atmospheric Boundary Layer. Q J. R. Meteorol. Scc., 89, 91-114.

Clarke, R.H., A.J. Dyer, R.R. Brooke, D.G. Reid, and A.J. Troup, 1971: The WANGARA experiment. Boundary-Loyer Date. Paper No. 19, Division of Meteorological Physics, CSIRO, Australia.

Clarke, R.H. and G.D. Hess, 1974: Gcostrophic Departure and the Aunctions A and $B$ of Rossby-Number Similarity Theory. Boundary-Layer Meteoral., 7, 267-287.

Conniban, J., J.C.R. Hunt, and P.S. Jackson, 1974: Wakes behind two-dimensional surfece obstacles in turtulent boundary losers. J. Fluid Mech., 64, 529563.

Counihan, J., 1969: An improved method of simulating an atmospheric boundary laver in a wind tunnel. Atmos. Environ., 3, 197.

Canady, G.T., 1972: Geostrophic drag, heat and mass tranefer coefficients for the diabalic Ekman layer. J. Atmos. Sci., 20, 488-496.

Deacon, E.L., 1973: Geostrophic Dre, Coeficients. Boundary-Layer Meteorol., S, 321-340.

Deardorf, J.W., 1972: Parameterization of the planetary boundery layer in general cinculation models. Mon. Weather Rev., 100, 93-106.

Dyer, A.J., 1974: A reviev of fure-profile relationaliog. Boundary-Layer Meteorol., 
7, 363-372.

Fiedler, F., 1972: The Effect of Baraclinicity on the Resistonce Law in a Diabatic Ekman Layer. Beitr. Phys. Atmos., 45, 164-173.

Finnigan, J.J., 1988: Air flow over complex terrain. In: Flow and transport in the Natural Envirorment: Advances and Applications. Eds W.L. Steffen and O.T. Denmead, Springer-Verlag, 183-229.

Glahn, H.R. and D.A. Lowry, 1972: The Use of Model Output Statistics (MOS) in Objective Weather Forecasting. J. Appl. Meteorol., 11, 1203-1211.

Golding, B.W., 1990: The Meteorological Office Mesoscale Model: An Overview. Meteorol. Mag., 119, 81-96.

Hall, C.D., 1987: A common verification Scheme for Limited Area Models. LAM Newslet ter, December, EWGLAM, U.K. Met. Ofice.

Holton, J.R., 1979: An Introduction to Dynamic Meteorology. International Geophysics Series Volume 23. Academic Press, New York, U.S.A.

Hunt, J.C.R., 1971: The effect of single buildings and structures. Philos. Trans. R. Soc. London A, 269, 457-467.

Hunt, J.C.R., C.J. Abell, J.A. Peterke, and H.G.C. Woo, 1978: Kinematical studies of the flows around free or surfoce-mounted obstacles; applying topology to flow visualization. J. Fluid Mech., 86, 179-200.

Högström, U., 1988: Non-dimensional wind and temperature profiles in the atmospheric surface layer: A re-evaluation. Boundary-Layer Meteorol., 42, 55-78.

Jackson, P. S. and J. C. R. Hunt, 1975: Turbulent flow over a low hill. Q. J. R. Meteorol. Sac., 101, 929-955.

Jensen, N.O., E.L. Petersen, and I. Troen, 1984: Extropolation of meen statistics with special negard to uind energy applications. World Meteorological Organization, World Climate Applications Programme, WCP-86, WMO/TD-No. 15. 85 pp.

Joelsen R., 1990: Subjective evaluation of the quality of sen level pressure forecast from HIRLAM (FMI), LAM(SMHI) and Fine-mesh(UKMO) for the period 2 October 1990 - 2 January 1991 ( 77 cases). SMHI, Norrköping, Sweden.

Karanski, A.B. and A.S. Monin, 1960: A Turbulent Regime above the Atmospheric Surface Layer. lav. Atmos. Ocean. Phys., 1, 165-168

Landberg, L., 1992: Neurule netvert anvendt til forndsigelse of en geofysisk tidsserie. En sammenligning (Neural networks utilized for the prediction of a geophysical time series, A comparison). In Danish. Riso-R-656(DA). Riso National Laboratcrv, Roskilde, Denmark, 76 pp.

Landberg, L. and P. Iugham, 1992: Two wind energy related prediction methods, Part I. In Proceedings of the European Wind Energy Association Special Topic Conference '92, Denmark (eds. P.H. Madsen and P. Lundanger). C12-1 - C12-4.

Landberg, L., S.J. Watson, J.A. Halliday, and J.U. Jergensen, 1993: Short-term preatiction of local wind conditions. Report to the CEC, project JOULE JOURCOSI-MB(C).

Lapedes, A. and R. Furber, 1987: Nontinear Signal Processing Using Neural Networks: Prodiction and System Modelling. Preprint LA-UR-87-2662.

Larsen, S.E., K. Hedegaard, and I. Troen, 1982: The Change of Terroin Roughness Problem Extended to Mesoscale Fetches. In Procedings of the Firat International Conference on Meteonology and Air/Sea Interaction (Amer. Meteorol. Soc., Boston, USA and KNMI, the Nerherlands), 8-13.

Lindbolm, G., E. Kristenson, and K. Nilseon, 1968: Växter som vindstydd. (Vesetation for shelter), Stad \& Land, No. 62, Aluarp (in Swedish).

Long, R.R. and L.J. Gufiey, 1977: Drag and heat transfer relations for the planetary boundary layer. Boundary-Layer Meteonol., 11, 363-373.

Lettau, H.H. and B. Davideon, 1957: Exploring the atmosphere's first mile. Vol 1 and 2, Pergamon Preas. New York. 
Machenhauer, B. (ed), 1988: HIRLAM Final Report. HIRLAM Technical Report 5, Copenhagen, December.

Machenhauer, B., U.B. Nielsen, and A. Rasmussen, 1991: Evaluation of the grality especially of the wind-forecasts by the operational meteorological High Resolution Limited Area Model. In: Proceedings of Advanced Modelling and Computer Codes for Calculating Local Scale and Meso-Scale Atmospheric Dispersion of Radionuclides and their Applications, 6-8 March, Paris (F), 152-163.

Mason, P. J. and J. C. King, 1985: Measurements and Predictions of Flow and Turbulence Over an Isolated Hill of Moderate Slope. Q. J. R. Meteorol. Soc., $111,617-640$.

Mason, P. J. and R. 1. Sykes, 1979: Flow over an isolated hill of moderate slope. Q. J. R. Meteorol. Soc., 105, 383-395.

Miyake, M., 1965: Thansformation of the Atmospheric Boundary Layer over Inhomogeneous Surfaces. Scientific report, University of Washington, Seattle.

Mortensen, N.G., L. Landberg, I. Troen, and E.L. Petersen, 1993: Wind Atlas Analysis and Application Program (WAPP) - User's Guide. Riso-l666(EN)(v.2). Risø National Laboratory, Roskilde, Denmark, 133 pp.

Nord, M., 1991: Shelter effects of vegetation belts - results of field measurements. Boundary-Layer Meteoral., 54, 363-385.

Obukhov, A.M., 1946: Turbulence in thermally inhomogeneous atmosphere. Trudy In-ta Teozet. Geofiz. AN SSSR, 1, 95-115.

Palutikof, J.P., J.H. Bass, J.A. Halliday, T.D. Davies, and C.P. Watkins, 1988: A methodology for the prediction of windspeeds at a candidate wind turbine site. In proceedings of: 10th British Wind Energy Association Conterence, London.

Panofsky, H. A., 1973: Tower Micrometeoralogy. In Workshop on Micrometeorology (Ed. D. A. Haugen), Amer. Meteorol. Soc., Boston, 151-176.

Perera, M.D.A.E.S., 1981: Shelter behind two-dimensional solid and porous fences. J. Wind Eng. Ind. Aerodyn., 8, 93-104.

Peterka, J.A., R.N. Meroney, and K.M. Kothari, 1985: Wind finw patterns about buildings. J. Wind Eng. Ind. Aerodyn., 21, 21-38.

Prandt), L., 1932: Meteorologische Andwendungen der Strömungslehre. Beitr. Phys. Atmos., 19, 188-202.

Press, W.H., B.P. Flannery, S.A. Teukolsky, and W.T. Vetterling, 1986: Numerical Recipes. The Art of Scientific Computing. Cambridge University Press, Cambridge.

Priestly, C.H.B., 1959: Turbulent transfer in the lower atmosphere. Univ. of Chicago Press, Chicagio, III.

Rao, K. S., J. C. Wyngard, and D. R. Coté, 1074: The Structure of the TwoDimensional Internal Boundary Layer over a Sudden Change of Surface Roughness. J. Atmos. Sci., 20, 432-440.

Rossby, C.G. and R.B. Montgomery, 1935: The layer of frictional infiuence in wind and ocean currents. Papers Phys. Oceanozr. Meteor., MIT and Woods Hole Oceanogr Inst., 3, No. 3, 101 pp.

Rumelhart, D. E., J. E. MeClelland and the PDP Rewearch Group. 1986: Perallel Distributed Processing. Explorations in the Microstructure of Cognition. Yolume 1: Foundations. MIT Press.

Snderboli. P.. 1993: PARK - User's Guide, A PC-progrem for calculation of wind turbine part performance. Rie-1-6es(EN), Ris National Laboratory, Deamark. 8 pp.

Saca, B.H. and L.S. Soreasen, 1992: The DMI Operational HIRLAM Forecasting Syotem, A Short Summary. Danish Meteorological Institute Technical Report, 92-12, Copenhagen.

Sempreviva, A.M., S.E. Laraen, N.G. Mortensen, and I. Troen, 19c0: Response of lieutral Boundery Loyers to Changes of Roughness. Boundary-Layer Meteonol., 
50, 205-225.

Söder, L, 1988: Benefit assessment of wind power in hydro-thermal power systems. The Royal Institute of Technology, Stockholm. ISBN 91-7170-931-2.

Taylor, P. A., J. L. Walmsley, and J. R. Salmon, 1983: A Simple Model of Neutrally Stratified Boundary-Layer Flow Over Real Terrain Incorporuting WavenumberDependent Scaling. Boundary-Layer Meteorol., 26, 169-189.

Taylor, P. A., 1988: Turbulent wates in the atmospheric boundary layer. In: Flow and transport in the natural environment, ed. W.L. Steffen and U.T. Denmead. Spriager, 270-292.

Tennekes, H. and J. L. Lumley, 1983: A First Course in Turbulence. The MIT Press.

Townsend, A.A., 1956: The structure of turbulent shear flow. Cambridge University Press.

Townsend, A.A., 1972: Flow in a deep turbulent boundary laver r,es: a surface distorted by water waves. J. Fluid Mech., 55, 719.

Tritton, D.J., 1977: Physical Fluid Dymamics. Van Nostrand MPir:hold (UK) Co. Lid., United Kingdom.

Troen, I., 1990: On Diagnostic Wind Field Models. From Collegt us Atmospheric Boundary Layer Physics, Trieste, Italy.

Troen, 1. and E.L. Petersen, 1989: European Wind Atlas. Published for CEC DGXII by Ris National Laboratory, Denmark.

Van Dyke, M.D., 1964: Perturbation Methods in Fluid Mechanics. New York, Academic Press, 229 pp.

Walmsley, J.L., P.A. Taylor, and T. Keith, 1986: A Simple Model of Neutrally Stretified Boundary-Layer Flow Over Complex Ternain with Surface Roughness Modulations (MSSDJH/SR). Boundary-Layer Meteorol., 36, 157-186.

Walmsley, J.L., I. Troen, D.P. Lalas, and P.J. Mason, 1990: Sutfoce-layer flow in complex terrain: comparison of models and full-scale observations. BoundaryLayer Meteorol., 52, 259-281.

Weibull, W., 1951: A statistical distribution function of wide applicability. J. A ppl. Mech., 18, 293-297.

Yordanov, D. and F. Wipperman, 1972: The parameterization of the turbulent fiures of momentum, heat and moisture at the ground in a baroclinic planetary Coundary-layer. Beitr. Phys. Atmos., 45, 58-65.

Zilitinkevich, S.S and D.V. Chalikov, 1968: The laws of resistance and of heat and moisture erchonge in the interaction between the atmosphere and an underbying surface. Lv. Atmos. Ocean Phys., 4, 438-441 (English ed.).

Zilitinkevich, S.S., 1975: Resistence laws and the prediction equations for the depth of the planetary boundary loyer. J. Atmos. Sci., 32, 741-752.

Zilitinkevich, S.S., 1909: Vebcity Profiles, the Resistance Law and the Disurpetion Rate of Mean Flow Kinetic Enery in a Neutralty and Staly Stratified Plometery Boundary Loyer. Bowadary-Layer Meteord., 46, 367-387. 


\section{A Detailed listing of the stations}

In this appendix the selected stations will be described in some detail. For an even more detailed description, see Troen and Petersen (1989). Station 59 (Exeter) was discontinued on May 31st, 1991, which is in the middle of the period, the nearby station RAF Dunkeswell (WMO code: 3840) was used instead from June 1st, 1991. The results shown here for Exeter are ouly from the period where the station was operational. For a detailed description of RAF Dunkeswell, see Section 11.2.

The letters in the column 'WASP code' refer to the country of the station, see Table 14.

Table 14. The country cades used in the WAs codes.

\begin{tabular}{llll}
\hline B & Belgium & D & Germany \\
DK & Denmark & E & Spain \\
EI & Ireland & F & France \\
GB & Great Britain & GR & Greece \\
I & Italy & NL & The Netherlands \\
P & Portugal & & \\
\hline
\end{tabular}

In the following a list of the selected stations will be given. 'Number' is the number of the station used in this study, 'WMO code' the World Meteorological Organization code number for the station, 'WASP code' is the code used in the European Wind Atlas, 'Name' the name of the station, 'Height station' the height of the station above sea-level in $\mathrm{m}$, 'Height anem.' is the height of the anemometer in $\mathrm{m}$ above ground level (WMO standard is $\mathbf{1 0} \mathrm{m}$ ), 'Lat.' the latitude in degrees Narth, and 'Long.' the longitude in degrees East. - means that the station was ociginally selected but later rejected because of lack of data, and t that the station only reports to the GTS-network every 6th hour.

\begin{tabular}{|c|c|c|c|c|c|c|c|}
\hline Number & $\begin{array}{r}\text { WMO } \\
\text { code }\end{array}$ & $\begin{array}{l}\text { WhP } \\
\text { code }\end{array}$ & Name & $\begin{array}{l}\text { Height } \\
\text { station }\end{array}$ & $\begin{array}{l}\text { Heicht } \\
\text { anem. }\end{array}$ & Lat. & Long. \\
\hline 01 & 3075 & GBO1 & Wick & 35.0 & 10.0 & 58.5 & -3.1 \\
\hline 02 & $\cdot N / A$ & GB22 & Lourther Hill & 727.0 & 27.0 & 55.4 & 3.8 \\
\hline 03 & $\cdot N / A$ & GB14 & Snacfell & 615.0 & 13.0 & 54.3 & -4.5 \\
\hline o4 & -3952 & Elos & Roches Point & $\mathbf{4 0 . 0}$ & 12.0 & 51.8 & -8.3 \\
\hline os & 3953 & Elos & Valentia & 28.0 & 12.0 & 51.9 & -10.3 \\
\hline $\mathbf{0 6}$ & 3982 & E1O1 & Shannon & 8.0 & 12.0 & 52.7 & -8.9 \\
\hline or & 3976 & EOA & Belmuliet & 9.0 & 12.0 & 54.2 & -10.0 \\
\hline $\mathbf{0 8}$ & 3900 & ENOS & Malin Head & 24.0 & 21.0 & 55.4 & -7.3 \\
\hline$\infty$ & 6030 & DKO1 & Abore & 3.0 & 10.0 & 57.1 & 9.9 \\
\hline 10 & 6120 & DKCS & Beldringe & 17.0 & 8.0 & 55.5 & 10.3 \\
\hline 11 & 6180 & DKa & Kastrup & 5.0 & 10.0 & 55.6 & 12.7 \\
\hline 12 & 6190 & DKos & Renme & 16.0 & 10.0 & 55.1 & 14.8 \\
\hline 13 & 6240 & NLOI & Schiphol & -4.0 & 10.0 & 52.3 & 4.8 \\
\hline 14 & .6250 & NLOS & Tersehelling & 1.0 & 10.0 & 53.4 & 5.2 \\
\hline 15 & 6240 & NLOS & Eclde & 5.0 & 10.0 & 53.1 & 6.6 \\
\hline 16 & 6370 & NLO2 & Eindhoren & 20.0 & 10.0 & 51.5 & 5.4 \\
\hline 17 & 6407 & $\mathbf{B O 1}$ & Middelkente & 4.0 & 12.7 & 51.2 & 2.9 \\
\hline 18 & 6456 & 804 & Florennes & 200.0 & 6.4 & 50.2 & 4.7 \\
\hline 19 & 7005 & F11 & Abbowille & $\pi .0$ & 11.0 & 50.1 & 1.8 \\
\hline 20 & 17024 & F15 & Chembour & 133.0 & 10.5 & 49.7 & -1.5 \\
\hline
\end{tabular}




\begin{tabular}{|c|c|c|c|c|c|c|c|}
\hline Number & $\begin{array}{l}\text { WMO } \\
\text { code }\end{array}$ & $\begin{array}{l}\text { WPP } \\
\text { code }\end{array}$ & Name & $\begin{array}{l}\text { Height } \\
\text { station }\end{array}$ & $\begin{array}{l}\text { Height } \\
\text { onem. }\end{array}$ & Lat. & Long. \\
\hline 21 & 7110 & F01 & Brest & 103.0 & 10.5 & 48.5 & -4.4 \\
\hline 22 & 17480 & F22 & Lyon & 201.0 & 12.0 & 45.7 & 5.0 \\
\hline 23 & 7510 & F03 & Bordesux & 51.0 & 11.0 & 44.8 & -0.7 \\
\hline 24 & $\cdot 7560$ & $\mathbf{F 2 4}$ & Mont Aigoual & 1565.0 & 11.5 & 44.1 & 3.6 \\
\hline 25 & 17635 & F14 & Carcassonne & 130.0 & 11.2 & 43.2 & 2.3 \\
\hline 26 & 17647 & F05 & Istres & 24.0 & 10.0 & 43.5 & 4.9 \\
\hline 27 & -8042 & E05 & Santiago de Compostela & 364.0 & 6.0 & 42.9 & -8.4 \\
\hline 28 & 8160 & E13 & Zarajoza & 247.0 & 23.0 & 41.7 & -1.0 \\
\hline $\mathbf{2 9}$ & 8202 & E19 & Salamanca & 790.0 & 10.3 & 40.9 & -5.5 \\
\hline 30 & 8280 & E17 & Albacete & 700.0 & 5.7 & 38.9 & -1.9 \\
\hline 31 & 8487 & E14 & Almeria & 20.0 & 6.7 & 36.9 & -2.4 \\
\hline 32 & 8538 & P07 & Sagres & 40.0 & 6.0 & 37.0 & -9.0 \\
\hline 33 & $\bullet 8541$ & P08 & Sines & 15.0 & 8.0 & 38.0 & -8.9 \\
\hline 34 & 8543 & POS & Viana do Castelo & 16.0 & 11.0 & 41.7 & -8.8 \\
\hline 35 & 8575 & P14 & Braganca & 691.0 & 9.1 & 41.8 & -6.7 \\
\hline 36 & 8579 & Po6 & Lisbos & 103.0 & 7.0 & 38.8 & -9.1 \\
\hline 37 & 10020 & DO7 & List/Sylt & 26.0 & 12.1 & 55.0 & 8.4 \\
\hline 38 & 10224 & DO1 & Bremen & 3.0 & 10.0 & 53.1 & 8.8 \\
\hline 39 & 10338 & D03 & Hannover & 51.0 & 10.0 & 52.5 & 9.7 \\
\hline 40 & 10384 & Dos & Berlin & 48.0 & 10.0 & $\mathbf{5 2 . 5}$ & 13.4 \\
\hline 41 & 10866 & DO4 & München & 527.0 & 10.0 & 48.1 & 11.7 \\
\hline 42 & 16158 & 113 & Pisa & 2.0 & 6.0 & 43.7 & 10.4 \\
\hline 43 & '16312 & 115 & Gioia del Colle & 350.0 & 6.0 & 40.7 & 16.9 \\
\hline 44 & 16320 & 116 & Brindisi & 15.0 & 6.0 & 40.7 & 18.0 \\
\hline 45 & $\cdot 16332$ & 117 & Lecca Galatina & 48.0 & 6.0 & 40.2 & 18.2 \\
\hline 46 & 16520 & 121 & Alghero & 40.0 & 10.0 & 40.6 & 8.3 \\
\hline 47 & 16560 & 112 & Cadiari & 18.0 & 6.5 & 39.3 & 9.1 \\
\hline 48 & 16041 & GRO3 & Kertyre & 2.0 & 4.0 & 39.6 & 19.9 \\
\hline 49 & 16716 & GR12 & Athino & 28.0 & 10.0 & 37.9 & 23.7 \\
\hline so & 16732 & GR15 & Naxos & 9.0 & 10.0 & 37.0 & 25.4 \\
\hline 51 & 16749 & GR2O & Rodos & 4.0 & 7.0 & 36.4 & 28.1 \\
\hline 52 & 3022 & G809 & Benbecula & 6.0 & 10.0 & 57.5 & -7.4 \\
\hline 53 & 3162 & G815 & Eskdalemuir & 249.0 & 10.0 & 55.3 & -3.2 \\
\hline 54 & 3302 & 6802 & Valloy & 10.0 & 16.0 & 53.3 & -4.5 \\
\hline 55 & 3318 & G810 & Blackpool & 10.0 & 12.0 & 53.8 & -3.0 \\
\hline 56 & 3334 & G803 & Mancheater & 70.0 & 10.0 & 53.4 & -2.3 \\
\hline 57 & 3534 & Goos & Bimingham & 94.0 & 10.0 & 52.5 & -1.7 \\
\hline 58 & $37 m 2$ & G:07 & Londen & 24.0 & 10.0 & 51.5 & -0.5 \\
\hline 59 & 3839 & G812 & Exeter & 31.0 & 12.0 & 50.7 & -3.4 \\
\hline 60 & 3842 & Go11 & Bournemourth & 10.0 & 13.0 & 50.8 & -1.8 \\
\hline
\end{tabular}




\section{B The WASP-matrices for each station}

In this appendix the matrices containing the local corrections generated by WASP (using dump option $\boldsymbol{P}_{63}=3$ and the ':'-dump command) are listed by station number. The first column (labeled 'DIR') is the direction from which the undisturbed wind comes. The second and third column (labeled 'INPUT') are user specified corrections of sped and direction, respectively. The fourth and fifth are the change in speed and direction, respoctively, due to obstacles (laheled 'ORSTACLES'). The sixth and seventh are the change in speed and direction, respectively, due to roughness (labeled 'ROUGHNESS'). The eight and ninth column are the change in speed and direction, respectively, due to orography (labeled 'OROGRAPHY'). '-9.608' means that the free-stream wind has to be multiplied by $(100-9.608) / 100=0.90392$. Finally is the 'meso-scale' roughness (ie the roughness calculated using Formula 100) listed, the column is labeled ' 20 '.

Station 1, Wick, Great Britain

\begin{tabular}{|c|c|c|c|c|c|c|c|c|c|}
\hline \multirow{2}{*}{$\begin{array}{r}\text { DIR } \\
0\end{array}$} & \multirow[b]{2}{*}{0.000} & \multirow{2}{*}{$\begin{array}{l}\text { Inpur } \\
0.000\end{array}$} & \multicolumn{2}{|c|}{ OBSTACLES } & \multicolumn{2}{|c|}{ HovgmuEss } & \multicolumn{2}{|c|}{ DEOGNPHY } & \multirow{2}{*}{$\begin{array}{r}20 \\
0.000406\end{array}$} \\
\hline & & & 0.000 & 0.000 & -9.608 & 0.000 & 1.000 & 0.000 & \\
\hline 30 & 0.000 & 0.000 & 10 & .000 & $-9.6 \%$ & .000 & .000 & 0.000 & 0.000551 \\
\hline 60 & .000 & .00 & .000 & .000 & -9.686 & & .000 & 0.000 & 00551 \\
\hline 80 & .000 & .000 & .000 & 0.000 & -9.706 & .000 & .000 & 0.000 & 0.000475 \\
\hline 20 & .000 & .000 & 0.000 & 0.000 & -15.263 & 0.000 & 0.000 & 0.000 & 0.000630 \\
\hline 00 & .000 & .000 & 0.000 & 0.000 & -18.539 & .000 & $\infty$ & 0.000 & 0.001095 \\
\hline & .000 & 10 & & 0.000 & -8.2 & 0.000 & .000 & 0.000 & 0.027754 \\
\hline 210 & .000 & .000 & 0.0 & 0.000 & 4.287 & 100 & 100 & 0.000 & 0.046942 \\
\hline 240 & .000 & 0 & 0.0 & 0.000 & 5.312 & 0.000 & .000 & 0.000 & 0.046225 \\
\hline 270 & .000 & .000 & 0.000 & 0.000 & 5.312 & 0.000 & $\infty$ & 0.000 & 0.046225 \\
\hline & .000 & 0.000 & 0.000 & 0.000 & 0.000 & 0.000 & 0.000 & 0.000 & 0.010000 \\
\hline & .000 & .000 & 0.000 & 0.000 & 0.000 & 0.000 & 0.000 & 0.000 & 0.010000 \\
\hline
\end{tabular}

Station 4, Roches Point, Ireland

\begin{tabular}{|c|c|c|c|c|c|c|c|c|c|}
\hline \multirow{2}{*}{ DIn } & \multirow[b]{2}{*}{0.000} & \multirow{2}{*}{$\begin{array}{l}\text { Inpert } \\
0.000\end{array}$} & \multicolumn{2}{|c|}{ OAstaCles } & \multicolumn{2}{|c|}{ novelitss } & \multicolumn{2}{|c|}{ oucoturery } & \\
\hline & & & -0.007 & 0.000 & 0.000 & 0.000 & 16.203 & -7.215 & 0.050000 \\
\hline 30 & 0.000 & 0.000 & & .000 & 17.473 & 0.000 & & -7.697 & 0.358560 \\
\hline 60 & 200 & 100 & & 0.000 & & & -5.178 & 1.053 & 000 \\
\hline so & 0 & & & 000 & $\infty$ & .000 & c.sen & 0.523 & 000 \\
\hline 20 & $\infty 00$ & .000 & & 0.000 & -18.454 & .000 & 20.145 & 4.911 & 0.00 \\
\hline 15 & & .000 & & 0.000 & -15.874 & .000 & 23.741 & -1.579 & 318 \\
\hline 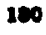 & .000 & 0.000 & & 0.000 & -11.937 & 0.000 & 13.734 & -6.178 & 1271 \\
\hline 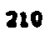 & & 0.000 & 0.000 & 0.000 & -8.306 & 0.000 & 0.9 & -8.111 & 0.000282 \\
\hline & 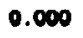 & & & & 16. & 0.1 & -4.3 & 1.412 & 0.038162 \\
\hline & & & & 0.000 & 24.67 & & & 0.695 & 6239 \\
\hline & & & & 0.0 & 1e.7 & & & 4.713 & 161 \\
\hline & .000 & & .000 & 0.000 & 0.000 & 0.000 & 10.967 & -1.083 & 0.00 \\
\hline
\end{tabular}

Station 5, Valentic, Ireland

\begin{tabular}{|c|c|c|c|c|c|c|c|c|c|}
\hline DIR & & Inot & 0 & ts & Li & & & $\sqrt{1}$ & 20 \\
\hline 0 & $\begin{array}{l}0.000 \\
0.000\end{array}$ & $\begin{array}{l}0.000 \\
0.000\end{array}$ & $\begin{array}{l}0.000 \\
0.000\end{array}$ & $\begin{array}{l}0.000 \\
0.000\end{array}$ & $\begin{array}{l}-15.503 \\
-12.841\end{array}$ & $\begin{array}{l}0.000 \\
0.000\end{array}$ & $\begin{array}{r}-0.550 \\
1.545\end{array}$ & $\begin{array}{r}1.400 \\
-1.311\end{array}$ & $\begin{array}{l}0.001756 \\
0.006257\end{array}$ \\
\hline 6 & 0.000 & 0.000 & 0.000 & 0.000 & -9.49 & 0.000 & -5.125 & -8.747 & 0.061375 \\
\hline 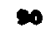 & 0.000 & 0.000 & -5.521 & 0.000 & 0.000 & 0.000 & -15.605 & -5.310 & 0.060000 \\
\hline 120 & 0.000 & 0.000 & -4.123 & 0.000 & 0.000 & 0.000 & -18.60 & 1.025 & 0.049432 \\
\hline 150 & 0.000 & 0.000 & -2.071 & 0.000 & $-12,70$ & 0.000 & -11.310 & 7.104 & 0.080207 \\
\hline 100 & 0.000 & 0.000 & -1.553 & 0.000 & 0.000 & 0.000 & -0.002 & 5.030 & 0.000300 \\
\hline 210 & 0.000 & 0.000 & 0.000 & 0,000 & 0.000 & 0.000 & $1.7 n$ & -1.323 & 0.019200 \\
\hline 240 & 0.000 & 0.000 & 0.000 & 0.000 & -6.650 & 0.000 & -4.05 & -6.252 & 0.012275 \\
\hline$m 0$ & 0.000 & 0.000 & 0.000 & 0.000 & -21.346 & 0.000 & -10.471 & -3.224 & 0.000515 \\
\hline 300 & 0.000 & 0.000 & 0.000 & 0.000 & -15.310 & 0.000 & $-16.5 \mathrm{~s}$ & 1.840 & 0.001820 \\
\hline 3 & 0.000 & 0.000 & 0.000 & 0.000 & 19.750 & $\infty$ & -10.571 & & $0.0 \mathrm{cus}$ \\
\hline
\end{tabular}


Station 6, Shannon, Ireland

\begin{tabular}{|c|c|c|c|c|c|c|c|c|c|}
\hline \multirow{2}{*}{$\begin{array}{r}\text { DIn } \\
0\end{array}$} & \multirow[b]{2}{*}{0.000} & \multirow{2}{*}{$\begin{array}{l}\text { InPOT } \\
0.000\end{array}$} & \multicolumn{2}{|c|}{ 0Astacts } & \multicolumn{2}{|c|}{ novormbss } & \multicolumn{2}{|c|}{ onoshurt } & \\
\hline & & & -6.759 & 0.000 & 6.807 & 0.000 & 0.000 & 0.000 & 0.171850 \\
\hline 30 & .000 & 0.000 & -11.254 & 0.000 & 0.063 & 0.000 & .000 & 0.000 & 0.1400 \\
\hline 60 & 0.000 & 000 & -0.676 & 0.000 & 67 & 0.000 & 0.000 & 0.000 & 0.225 \\
\hline 90 & 0.000 & .000 & -2.874 & 0.000 & -6.064 & 0.000 & 0.000 & 0.000 & 0.0133 \\
\hline 120 & 0.000 &.$\infty 0$ & -0.370 & 0.000 & -7.401 & 0.000 & 0.000 & 0.000 & 0.0128 \\
\hline 150 & .000 & 000 & 0.000 & .000 & -6.354 & 0.000 & 0.000 & 0.000 & 0.0116 \\
\hline 180 & .000 & 000 & 0.00 & 0.000 & -6.354 & 0.000 & 0.000 & 0.000 & 0.01166 \\
\hline 210 & 0.000 & .000 & 0.000 & .000 & -0.384 & 0.000 & .000 & $\infty 00$ & 0.0114 \\
\hline 240 & 1.000 & 0.000 & 0.000 & 0.000 & 0.000 & 0.000 & 0.000 & 0.000 & 0.0500 \\
\hline 270 & 0.000 & 0.000 & 0.000 & 0.000 & 9.508 & 0.000 & 0.000 & 0.0 & $0.170 \mathrm{c}$ \\
\hline 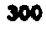 & 0.000 & 0.000 & 0.000 & 0.000 & 9.400 & 0.000 & 0.000 & & 0.1752 \\
\hline & .000 & .000 & 0.000 & 0.000 & 9.357 & 0.000 & 0.000 & & \\
\hline
\end{tabular}

Station 7, Belmullet, Ireland

\begin{tabular}{|c|c|c|c|c|c|c|c|c|c|}
\hline \multirow{2}{*}{$\begin{array}{r}\text { DIR } \\
0\end{array}$} & \multirow[b]{2}{*}{0.000} & \multirow{2}{*}{$\begin{array}{l}\text { InPUT } \\
0.000\end{array}$} & \multicolumn{2}{|c|}{ osstactes } & \multicolumn{2}{|c|}{ RODGIILS } & \multicolumn{2}{|c|}{ onoenarit } & 20 \\
\hline & & & 0.000 & 0.000 & 0.000 & 0.000 & 7.813 & 2.342 & 0.030000 \\
\hline 30 & .000 & 0.000 & 0.000 & 0.000 & .000 & 0.000 & 10.001 & -0.310 & 0.030000 \\
\hline 60 &.$\infty 00$ & .000 & 0.000 & $\infty 0$ &.$\infty 00$ & $\infty 00$ & 6.450 & -2.600 & 0.030000 \\
\hline 20 & .000 & .000 & -2.565 & .000 & $4.37 \%$ & 0.000 & 1.502 & -2.400 & 0.043974 \\
\hline 120 & .000 & .000 & -11.560 & 0.000 & 9.011 & 0.000 & -0.717 & 0.328 & 0.037749 \\
\hline 150 & .000 & .000 & -11.415 & 0.000 & 0.000 & 0.000 & $2.37 \mathrm{~T}$ & 2.531 & 0.000221 \\
\hline 180 & .000 & .000 & -2.313 & 0.000 & 11.595 & 0.000 & 6.007 & 2.030 & 0.037129 \\
\hline 210 & .000 & .000 & -0.046 & 0.000 & 10.003 & 0.000 & 8.774 & 207 & 0.032111 \\
\hline th & .000 & 1.000 & 0.000 & 0.000 & 7.865 & 0.000 & 6.104 & -2.361 & 0.041220 \\
\hline 270 & 1.000 & 0.000 & 0.000 & 0.000 & 2.913 & 0.000 & 1.392 & -2.381 & 0.046842 \\
\hline 100 & 0.000 & 0.000 & $-1 . \operatorname{ces}$ & $\infty 00$ & 0.000 & 0.000 & -0.000 & 0.351 & 0.030000 \\
\hline 3 & .000 & .000 & -0.018 & 0.000 & 0.000 & 0.000 & 2.370 & 28 & 0.05000 \\
\hline
\end{tabular}

Station 8, Malin Head, Ireland

\begin{tabular}{|c|c|c|c|c|c|c|c|c|c|}
\hline \multirow{2}{*}{$\begin{array}{r}\text { DIR } \\
0\end{array}$} & \multirow[b]{2}{*}{0.000} & \multirow{2}{*}{$\begin{array}{l}10101 \\
0.000\end{array}$} & \multicolumn{2}{|c|}{ onstactes } & \multicolumn{2}{|c|}{ nove: ins } & \multicolumn{2}{|c|}{ onsiner } & \\
\hline & & & 0.000 & 0.000 &.$\infty$ & 0.000 & 0.121 & 2.004 & 0.00028 \\
\hline 30 & 000 & & mes & .000 & 0.000 & 0.000 & 12.017 & .780 & 0.00022 \\
\hline 0 & $\infty$ & $\infty 6$ & 11 & 0 & 0.000 & & 11.547 & -2 & $0.06012 x+$ \\
\hline$\infty$ & & & 3. & & & $\infty$ & 5.535 & -2.0 & 0.000217 \\
\hline & 000 & $\infty 00$ & 3 & $\infty 00$ & 0.000 & $\infty 00$ & 0.77 & -0. & 0.050000 \\
\hline & & 000 & 0.2 &.$\infty 00$ & 0.000 & 0.060 & 3.55 & 3.028 & $0.0 \$ 1035$ \\
\hline 0 & 000 & .000 & 0.0 & $\omega$ & 0.000 & 0.000 & 10.34 & 3.376 & 0.040000 \\
\hline & $\infty$ & 0.000 & 0.000 & 0.000 & -12.182 & 0.000 & 13.029 & 0.8 & 130 \\
\hline 3 & 0.000 & .00 & 0.0 & & -12.643 & 0.000 & 11.ens & -2.411 & 0.000470 \\
\hline 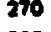 & - & 0.000 & 0.000 & 0.000 & -12.818 & 0.060 & 5.820 & -3 . & 0.07 \\
\hline & & 0.000 & -0.0 & 0.000 & -9.2 & 1.000 & 2.877 & -0. & 0.000573 \\
\hline & 0.000 & .000 & -0.012 & & & .000 & 3.710 & & 0.0000 \\
\hline
\end{tabular}

Station 9, Alborg, Denmart

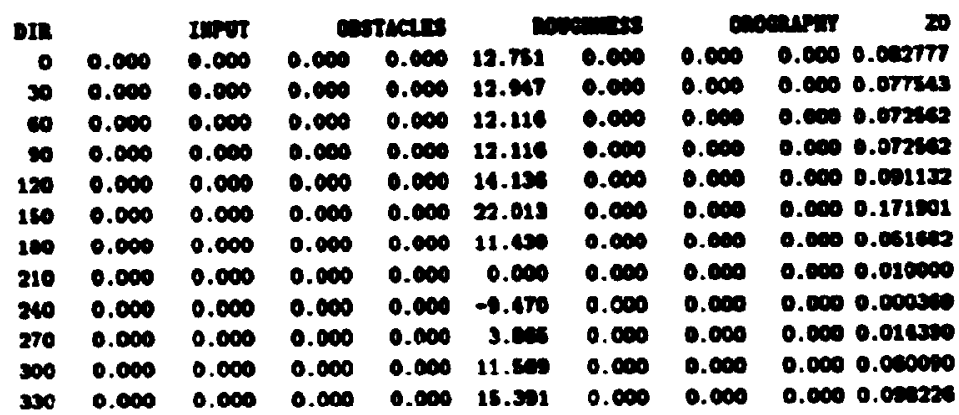


Station 10, Beldringe, Denmurk

\begin{tabular}{|c|c|c|c|c|c|c|c|c|c|}
\hline DIt & & an & & & & & & 1 & 20 \\
\hline 0 & .000 & 000 & 0.000 & 0.000 & -0.302 & 0.000 & 0.000 & 0.000 & 0.052323 \\
\hline 30 & .000 & & 0.000 & $0 . \infty 00$ & 2.310 & .000 & 0.600 & 0.000 & 0.020551 \\
\hline & .000 & .000 & 0.000 &.$\infty 0$ & 1.4en & .000 & 0.000 & 0.000 & 0.023504 \\
\hline$\infty$ & .000 & $\infty$ & 0.000 & .000 & .30 & .000 & 0.000 & 0.000 & 0.032280 \\
\hline 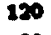 & .000 & .000 & 0.000 & 1.000 & 0.703 & .000 & 0.000 & 0.000 & 0.076444 \\
\hline & .000 & .000 & 2.553 & .000 & 18.230 &.$\infty 00$ & 0.000 & 0.000 & - D.tesese \\
\hline 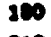 & 1.000 & 1.000 & -25.158 & 1.000 & 10.939 & .000 & 0.000 & 0.000 & 0.186068 \\
\hline & .000 & .000 & $-30.5 \mathrm{~s}$ & 0.000 & 6.543 & $\infty$ & 1.000 & 0.000 & $0.1350 \mathrm{~s}$ \\
\hline & 0.000 & 0.000 & $-14.7 \mathrm{mt}$ & 0.000 & 11.267 & 0.000 & 0.000 & 0.000 & 0.112075 \\
\hline & 0.00 & & 0.000 & 0.000 & 15.260 & 100 & 0.000 & 0.000 & 0.10797 \\
\hline & & & 0.000 & 0.000 & 4.024 & 000 & 0.000 & $\omega$ & 0.04300 \\
\hline & 0.000 & 100 & 0.000 & 0.000 & 1.389 & 100 & 0.000 & 0.000 & 0.029725 \\
\hline
\end{tabular}

Station 11, Kastrup, Denmark

\begin{tabular}{|c|c|c|c|c|c|c|c|c|c|}
\hline \multirow{2}{*}{ otin } & \multirow[b]{2}{*}{0.000} & Inrst & \multicolumn{2}{|c|}{ osstacts } & \multicolumn{2}{|c|}{$1000=198$} & \multicolumn{2}{|c|}{ соретит } & \\
\hline & & 0.000 & -3.370 & 0.000 & -9.013 & 0.000 & .000 & 0.000 & 0.000311 \\
\hline 30 & .000 & .000 & .000 & .000 & -6.60 & 0.000 & 0.000 & 0.000 & 0.000290 \\
\hline$\infty$ &.$\infty 00$ & $\infty$ & 0.000 & 0.000 & -7 & 0.000 & 0.000 & 0.000 & 0.000270 \\
\hline 0 &.$\infty 00$ & $\infty 00$ & 0.0 & .000 & . & 0.000 & 0.000 & 0.000 & 0.000275 \\
\hline 10 & .000 & .000 & 0.0 & 1.000 & -0.040 & .000 & 0.000 & 0.000 & $0.0002 \% 0$ \\
\hline a. &.$\infty 0$ & .000 & 0.000 & 1.000 & -9.60 & .000 & 1.000 & 0.000 & 0.000250 \\
\hline 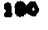 & & $\infty$ & 0.000 & 0.000 & -11.47 & 0.000 & $\infty$ & 0.000 & 0.001371 \\
\hline 210 & 000 & $\infty$ & 0.0 & .000 & 1.170 & 0.000 & $0 . \infty$ & 0.000 & 0.003012 \\
\hline & & & 0.000 & 0.000 & 18.660 & 0.000 & .000 & 0.000 & 0.053286 \\
\hline & & & 0.000 & 0.000 & D & 0.000 & $0 . \infty 00$ & 0.000 & 0.067123 \\
\hline & & & $2.7+2$ & 0.000 & 22.428 & 0.000 & 0.000 & 0.000 & 0.373772 \\
\hline & 0.000 & 0.000 & -0.144 & 0.000 & 16.204 & 0.000 & 0.600 & 0.000 & 0. 1somet \\
\hline
\end{tabular}

Station 12, Ranae, Deamark

\begin{tabular}{|c|c|c|c|c|c|c|c|c|c|}
\hline \multirow{2}{*}{ DI } & \multirow[b]{2}{*}{0.000} & Int & \multicolumn{2}{|c|}{ astuces } & \multicolumn{2}{|c|}{ Dowestest } & \multicolumn{2}{|c|}{ o:denar } & 0 \\
\hline & & & & 0.000 & $1.7 \mathrm{EA}$ & 0.000 & 0.000 & 0.000 & 0.078340 \\
\hline & $\infty$ &.$\infty$ & & & 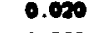 & $\infty$ & 0.000 & 0.000 & $0 . \cos 110$ \\
\hline & & & &.$\infty$ & 2.890 & D.000 & 0.000 & 0.000 & 0.076321 \\
\hline & D & & $\infty 00$ & 0.000 & $3.4 \mathrm{n}$ & & 0.00 & 3.000 & 0.032719 \\
\hline & .000 & & . & 0.000 & -10.121 & 0.000 & 0.000 & 0.000 & 0.00211 \\
\hline & .600 & .000 & 0.000 & 0.000 & -11.304 & 0.000 & 0.000 & 0.000 & 0.000292 \\
\hline & .6 & 0.000 & 0.000 & 0.000 & -4.02 & wo & 0.000 & 0.000 & 0.000242 \\
\hline & .00 & .000 & 0.000 & .000 & -2.341 & 0.000 & 0.000 & 0.000 & 0.000221 \\
\hline & & .000 & 0.000 & 0.000 & -1.180 & 0.000 & 0.000 & 0.000 & 0.000225 \\
\hline & & & 0.000 & 0.040 & & D.6. & 0.000 & 0.000 & 0.000231 \\
\hline & & & .000 & 0.6 & -6 & 0.0 & 0.000 & 0.000 & 0.002042 \\
\hline & & & 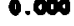 & & -10 & & 0.000 & & 0.0 \\
\hline
\end{tabular}

Scation 13, Schiphol, The Netherlands

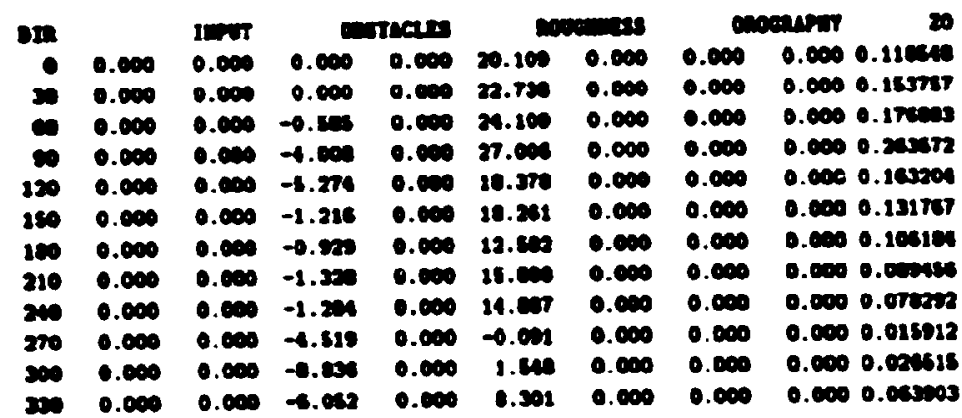


Station 14, Terachelling, The Netherlands

\begin{tabular}{|c|c|c|c|c|c|c|c|c|c|}
\hline DI & & InUT & & rictes & & $\log 3$ & & anery & 20 \\
\hline 0 & .000 & 0.000 & 0.000 & 0.000 & 0.078 & 0.000 & 0.000 & 0.000 & 0.000357 \\
\hline 30 & 0.000 & 0.000 & 0.000 & 0.000 & -0.203 & 0.000 & 0.000 & 0.000 & 0.002021 \\
\hline & 0.000 & 0.000 & 0.000 & 0.000 & 20.710 & $0 . \infty 00$ & 0.000 & 0.000 & 0.042078 \\
\hline$\infty$ & 0.000 & 0.000 & 0.000 & 0.000 & 0.000 & 0.000 & 0.00 & 0.000 & 0.000200 \\
\hline 170 & 0.000 & 0.000 & 0.000 & 0.000 & 0.000 & 0.000 & 0.000 & 0.000 & 0.000200 \\
\hline 180 & 0.000 & 0.000 & 0.000 & 0.000 & 0.000 & 0.000 & .000 & 0.000 & 0.000200 \\
\hline 100 & 0.000 & 0.000 & 0.000 & 0.000 & 0.000 & 0.000 & 0.000 & 0.000 & 0.000200 \\
\hline 210 & 0.000 & 0.000 & 0.000 & 0.000 & 0.000 & 0.000 & 0.000 & 0.000 & 0.000200 \\
\hline 60 & 0.000 & 0.000 & 0.000 & 0.000 & 0.000 & 0.000 & 0.000 & 0.000 & 0.000200 \\
\hline & 0.000 & 0.000 & 0.000 & 0.000 & 0.000 & 0.000 & 0.000 & 0.000 & 0.000200 \\
\hline & 0.000 & 0.000 & 0.000 & 0.000 & 0.000 & 0.000 & 0.000 & 0.000 & 0.000200 \\
\hline & 0.000 & 0.000 & 0.000 & 0.000 & 0.000 & 0.000 & 0.000 & 0.000 & 0.000204 \\
\hline
\end{tabular}

Station 15, Eelde, The Netherlanda

\begin{tabular}{|c|c|c|c|c|c|c|c|c|c|}
\hline \multirow{2}{*}{ DIn } & \multirow[b]{2}{*}{0.000} & \multirow{2}{*}{$\begin{array}{l}\text { Intwt } \\
0.000\end{array}$} & \multicolumn{2}{|c|}{ ontacts } & \multicolumn{2}{|c|}{ moveninges } & \multicolumn{2}{|c|}{ onociasut } & \\
\hline & & & 0.000 & 0.000 & 14.010 & 0.000 & 0.000 & 0.000 & 0.135144 \\
\hline 30 & 0.000 & $\infty 00$ & 0.000 & 0.000 & 17.07 & 0.000 & .000 & 0.000 & D. 163332 \\
\hline & $\infty$ & 000 & 3.612 & .000 & 0.000 & 0.000 & 0.000 & 0.000 & 0.200000 \\
\hline 10 & $\infty$ & $\infty$ & -9.0022 & . & 0.000 & 0.000 & 0.000 & 0.000 & 0.150000 \\
\hline 10 & .000 & $\infty 00$ & -9.750 & 0.000 & 6.837 & 0.000 & 0.000 & 0.000 & 0.142175 \\
\hline & .000 & .000 & -9.700 & 0.000 & 0.702 & 0.000 & 0.000 & .000 & 0.143200 \\
\hline & .000 & 0.000 & -9.474 & 0.000 & 0.100 & 0.000 & 0.000 & 0.000 & $0.135 \mathrm{mT}$ \\
\hline & $0 . \infty 00$ & 0.000 & -6.624 & 0.000 & 8.00 & 0.000 & 0.000 & .000 & $0.13 \mathrm{str}$ \\
\hline & 0.000 & 0.000 & -0.227 & 0.000 & 15.497 & 0.000 & 0.000 & 0.000 & 0.1023 \\
\hline & 0.000 & 0.0 & 0.000 & 0.000 & 15.260 & 0.000 & 0.000 & 0.000 & 0.110 .14 \\
\hline & & 0.0 & 0.000 & 0.000 & 15.260 & 0.000 & 0.000 & 0.000 & 0.115014 \\
\hline & 0.000 & .000 & 0.000 & 0.000 & 3.060 & 0.000 & 0.000 & 0.000 & \\
\hline
\end{tabular}

Station 16, Eindhoven, The Netherlands

\begin{tabular}{|c|c|c|c|c|c|c|c|c|c|}
\hline t & & & & & & & & & $\boldsymbol{w}$ \\
\hline 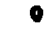 & 0.000 & 000 & 1.000 & 0.000 & 10.201 & 0.000 & 0.000 & 0.000 & 0.150301 \\
\hline 30 & .000 & .000 & 0.000 & 0.000 & 21.025 & 0.000 & $0 . \infty 00$ & 0.600 & $0.24 c 0$ s \\
\hline & .000 & b & $\infty$ & 0.000 & 20.618 & 0.000 & 0.000 & 0.000 & 0.254145 \\
\hline $\boldsymbol{c o}$ & .000 & &.$\infty 00$ & 0.000 & 24.34 & 0.000 & 0.000 & 0.000 & 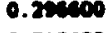 \\
\hline 220 & $\infty$ & & 0.000 & 0.00 & 10.02 & 0.000 & 1.000 & 0.000 & 0.310402 \\
\hline IN & & & 0.000 & 0.000 & 10.5e3 & 0.000 & 0.000 & 0.000 & 0.1 \\
\hline en & .000 & 19 & 1.000 & 0 & 16.116 & 0.000 & 0.000 & 0.6 & 0.2 \\
\hline 210 & 0.000 & 0 & 0.00 & & $21 . \sqrt{21}$ & 0.00 & 0.000 & 0.000 & 0.21 \\
\hline 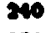 & & & .60 & 0.0 & 17.160 & 0.000 & 0.000 & 0.0 & 0.2 \\
\hline$\omega$ & 0.00 & & 0.60 & & & 0.000 & 0.000 & c. & 0.1 \\
\hline & & & $\therefore$ & & 18.632 & 0.000 & 0.000 & $\bullet$ & \\
\hline & 0.000 & & 0.6 & & 15. & & 0.000 & & 0.2 \\
\hline
\end{tabular}

Station 17, Middellerbe, Belghom

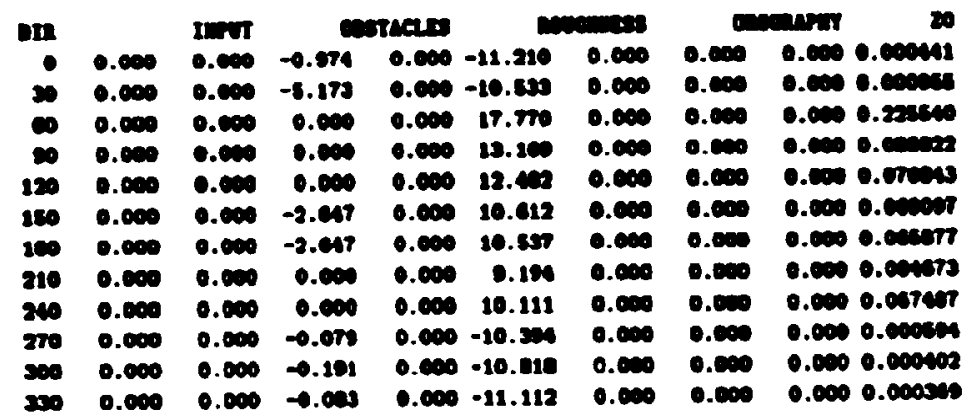


Station 18, Florennes, Belgium

\begin{tabular}{|c|c|c|c|c|c|c|c|c|c|}
\hline DIR & & Intor & & TACLS & & 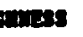 & & mirt & 20 \\
\hline 0 & 0.000 & 0.000 & 0.000 & 0.000 & 23.484 & 0.000 & 0.000 & 0.000 & 0.160443 \\
\hline 30 & 0.000 & 0.000 & 0.000 & 0.000 & 23.34 & 0.000 & 0.000 & 0.000 & 0.184579 \\
\hline 6 & 0.000 & 0.000 & 0.000 & 0.000 & 23.338 & 0.000 & 0.000 & 0.000 & 0.131767 \\
\hline 6 & 0.000 & 0.000 & 0.000 & 0.000 & 23.338 & 0.000 & 0.000 & 0.000 & 0.131787 \\
\hline 120 & 0.000 & 0.000 & 0.000 & 0.000 & 24.272 & 0.000 & 0.000 & 0.000 & 0.220351 \\
\hline 150 & 0.000 & 0.000 & 0.000 & 0.000 & 28.107 & 0.000 & 0.000 & 0.000 & 0.200059 \\
\hline 100 & 0.000 & 0.000 & 0.000 & 0.000 & 30.215 & 0.000 & 0.000 & 0.000 & 0.234633 \\
\hline 210 & 0.000 & 0.000 & 0.000 & 0.000 & 30.316 & 0.000 & 0.000 & 0.000 & 0.223045 \\
\hline 240 & 0.000 & 0.000 & 0.000 & 0.000 & 30.134 & 0.000 & 0.000 & 0.000 & 0.200500 \\
\hline 270 & 0.000 & 0.000 & 0.000 & 0.000 & 22.407 & 0.000 & 0.000 & 0.000 & 0.116197 \\
\hline 300 & 0.000 & 0.000 & 0.000 & 0.000 & 23.740 & 0.000 & 0.000 & 0.000 & 0.158607 \\
\hline 300 & 0.000 & 0.000 & 0.000 & 0.000 & 20.55 & 0.000 & 0.000 & 000 & 0.225580 \\
\hline
\end{tabular}

Station 19, Abbeville, France

\begin{tabular}{|c|c|c|c|c|c|c|c|c|c|}
\hline \multirow{2}{*}{ DIR } & \multirow[b]{2}{*}{0.000} & \multirow{2}{*}{$\begin{array}{l}\text { Inter } \\
0.000\end{array}$} & \multicolumn{2}{|c|}{ Onstacles } & \multicolumn{2}{|c|}{ DODOLIJSE } & \multicolumn{2}{|c|}{ onoctumy } & \\
\hline & & & .000 & 0.000 & 11.358 & 0.000 & .260 & -0.780 & 0.055877 \\
\hline 30 & 0.000 & .000 & 000 & .000 & & 0.000 & .540 & -0.150 & 250 \\
\hline 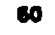 & 000 & 000 & .000 & 0.000 & 037 & 1.000 & .281 & 90 & \\
\hline $\boldsymbol{0}$ & .000 & 000 & .000 & 0.000 & & 0 & 977 & 0.034 & 0.221230 \\
\hline 20 & $\infty 00$ & & $\mathbf{x}$ & 0.000 & 4.400 & 0.000 & 7.142 & 0.221 & 350 \\
\hline 50 & 0 & 000 & & $\infty$ & 85 & 0.000 & .685 & -0.674 & 0.244542 \\
\hline & & 000 & 00 & .000 & 27.935 & 0.000 & 1.040 & -0 & 208 \\
\hline 10 & .000 & & & & 24.648 & 0.000 & 1.705 & -0.213 & 0.243457 \\
\hline & 0.0 & & .000 & 0.000 & 20.745 & 0.000 & 16 & $0.70 s$ & 0.170820 \\
\hline & 0.000 & .000 & 0.0 & 0.000 & 18.265 & & .072 & 0.073 & 0.180341 \\
\hline & 0.0 & & & 0.000 & 9.736 & & .053 & 0.269 & 0.109054 \\
\hline & 0.000 & 0.000 & 0.000 & 0.000 & 17.132 & 0 & .152 & -0.670 & 0.123440 \\
\hline
\end{tabular}

Station 20, Cherbourg, France

\begin{tabular}{|c|c|c|c|c|c|c|c|c|c|}
\hline on & & Inor & \multicolumn{2}{|c|}{ ostactes } & \multicolumn{2}{|c|}{ moces:ses } & \multicolumn{2}{|c|}{ conemarm } & 20 \\
\hline$\bullet$ & 0.000 & 0.000 & 0.600 & 0.000 & -18.025 & 0.000 & 3.074 & -6.307 & 0.001550 \\
\hline 30 & 0.000 & 0.000 & 0.000 & 0.000 & 16. 203 & 0.000 & -3.410 & -2.060 & 0.242353 \\
\hline & 0.000 & 0.000 & 0.000 & 0.000 & 21.003 & 0.000 & -2.60 & 2.04 & 0.234823 \\
\hline $\boldsymbol{\omega}$ & 0.000 & 0.000 & 0.000 & 0.000 & 22.347 & 0.000 & 6.000 & $5.0 \mathrm{M}$ & 0.15177 \\
\hline 120 & 0.600 & 0.000 & 0.000 & 0.000 & 0.391 & 0.000 & 18.236 & 2.300 & $0.2 \times 5117$ \\
\hline 160 & 0.000 & 0.000 & 0.000 & 0.000 & 0.000 & 0.000 & 14.680 & $-3.17 s$ & 0.200017 \\
\hline 10 & 0.000 & 0.000 & 0.000 & 0.000 & 0.24 & 0.000 & 5.003 & & 0.204327 \\
\hline 210 & 0.000 & 0.000 & 0.000 & 0.000 & 0.210 & 0.000 & -4.471 & -2 & 0.244527 \\
\hline o & 0.000 & 0.000 & 0.000 & 0.69 & 0.39 & 0.000 & $-3 . \cos$ & 819 & 0.76018 \\
\hline 10 & 0.000 & 0.000 & 0.000 & 0.000 & 11.62 & 0.000 & 6. & 8.021 & o.trint \\
\hline & 0 & 0.000 & 0.00 & 0.00 & $\begin{array}{l}-27.04 \\
-17.510\end{array}$ & $\begin{array}{l}0.000 \\
0.000\end{array}$ & $\begin{array}{l}13.0 \mathrm{WA} \\
10 . \mathrm{Ed}\end{array}$ & $\begin{array}{r}1.513 \\
-2.745\end{array}$ & $\begin{array}{l}0.001212 \\
0.000120\end{array}$ \\
\hline
\end{tabular}

Station 21, Breat, Jrance

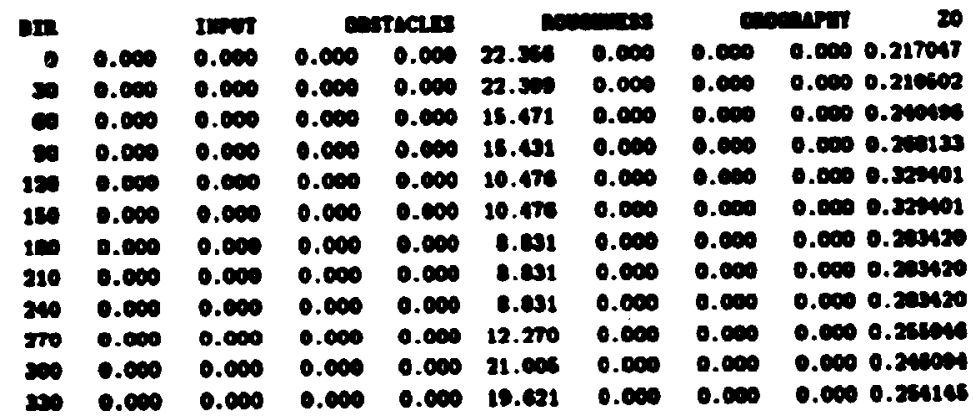


Station 22, Lyon, France

\begin{tabular}{|c|c|c|c|c|c|c|c|c|c|}
\hline \multirow[t]{2}{*}{ DIR } & \multirow[b]{2}{*}{0.000} & IIINT & \multicolumn{2}{|c|}{ ostrets } & \multicolumn{2}{|c|}{ Dosemitas } & \multicolumn{2}{|c|}{ 0nochurm } & 20 \\
\hline & & .000 & -1.147 & 0.000 & 17.772 & 0.000 & 0.000 & 0.000 & 0.130701 \\
\hline 30 & 0.000 & 0.000 & -31.800 & 0.000 & 10.008 & 0.000 & 0.000 & 0.000 & 0.161543 \\
\hline$\omega$ & 0.000 & .000 & -0.160 & 0.000 & 19.303 & 0.000 & 0.000 & 0.000 & 0.212024 \\
\hline$\infty$ & 0.000 & 0.000 & 0.000 & 0.000 & 19.305 & 0.000 & 0.000 & 0.000 & 0.216531 \\
\hline 120 & 0.000 & 0.000 & 0.000 & 0.000 & 20.041 & 0.000 & 0.000 & 0.000 & 0.267811 \\
\hline 180 & 0.000 & 0.000 & 0.000 & 0.000 & 14.265 & 0.000 & 0.000 & 0.000 & 0.147420 \\
\hline 180 & 0.000 & 0.000 & -11.731 & 0.000 & 14.204 & 0.000 & 0.000 & 0.000 & 0.301017 \\
\hline 210 & 0.000 & 0.000 & -24.000 & 0.000 & 16. 40 & 0.000 & 0.000 & 0.000 & 0.265777 \\
\hline 240 & 0.000 & 0.000 & -22.675 & 0.000 & 15.898 & 0.000 & 0.000 & 0.000 & 0.242010 \\
\hline 10 & 0.000 & 0.000 & -1.050 & 0.000 & 12.000 & 0.000 & 0.000 & 0.000 & 0.403342 \\
\hline d & 0.000 & 0.000 & -6.037 & 0.000 & 16.387 & 0.000 & 0.000 & 0.600 & $0.4565 n$ \\
\hline 100 & 0.000 & 0.000 & -4.24 & 0.000 & 19.50 & 0.000 & 0.000 & 0.000 & 0.393507 \\
\hline
\end{tabular}

Station 23, Bordeaux, France

\begin{tabular}{|c|c|c|c|c|c|c|c|c|c|}
\hline \multirow[t]{2}{*}{ DIR } & \multirow[b]{2}{*}{0.000} & Imon & \multicolumn{2}{|c|}{ costacts } & \multicolumn{2}{|c|}{ movenutes } & \multicolumn{2}{|c|}{ Dapenarent } & \\
\hline & & 0.000 & 000 & .000 & 0.910 & 0.000 & 0.000 & 0.000 & 0.433713 \\
\hline 30 & .000 & $\infty$ & 0.0 & .000 & $\infty 0$ & .000 & 100 & 0.000 & 0.311316 \\
\hline 9 & .000 & 000 & 0.000 & .000 & 8.24 & 0.000 & 0.000 & 0.000 & 0.372633 \\
\hline O & 000 & $\infty 00$ & 4.0 &.$\infty 00$ & 3.133 & .000 & .000 & 1.000 & 0.361074 \\
\hline 20 & .000 & $\infty 00$ & -11.081 & .000 & 14.102 & .006 &.$\infty 00$ & .000 & 403 \\
\hline & 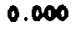 & 000 & -6.116 & 0.000 & 16.475 & 0.000 & 1.000 & 0.000 & 3762 \\
\hline 10 & $\infty$ & $\infty 00$ & -9 & & 132 & 0.000 & 0.000 & 0.000 & 0.450550 \\
\hline & & 000 & 0.0 & 0.000 & 21.070 & 0.000 & 0.000 & 0.000 & 3005 \\
\hline & 00 & .000 & & & 29.376 & 0.000 & 0.000 & 0.000 & 0.260846 \\
\hline & & 0 & 0.000 & 0.000 & 31.146 & 0,000 & 0.000 & 0.000 & 170439 \\
\hline & & & 0.0 & & 30.811 & & $\infty$ & 0.000 & 0.397481 \\
\hline & 0.000 & 0.000 & 0.000 & 0.000 & 22.780 & 0.000 & 0.000 & 0.000 & 0.334130 \\
\hline
\end{tabular}

Station 24, Moat Aigoual, France

\begin{tabular}{|c|c|c|c|c|c|c|c|c|c|}
\hline \multirow{2}{*}{$\begin{array}{r}\text { DIn } \\
0\end{array}$} & \multirow[b]{2}{*}{0.000} & \multirow{2}{*}{$\begin{array}{l}\text { Inw } \\
0.000\end{array}$} & \multicolumn{2}{|c|}{ anstactes } & \multicolumn{2}{|c|}{ noveminess } & \multicolumn{2}{|c|}{ conomint } & 20 \\
\hline & & & 0.000 & 0.000 & 0.923 & 0.000 & 200.30 & 8.002 & 0.007105 \\
\hline 30 & 0.000 & 0.000 & 0.000 & 0.000 & 0.000 & 0.000 & 193.041 & -13.344 & 0.05Ten \\
\hline$\infty$ & .000 & 100 & 0.000 & 0.000 & 0.023 & 0.000 & 113.457 & -96.237 & o.opties \\
\hline 10 & 0.000 & 0.000 & 0.000 & 0.000 & 0.750 & 0.000 & 24.530 & -12.678 & 0.0 .503 \\
\hline 120 & 1.000 & 0.000 & 0.000 & 0.000 & 0.000 & 0.000 & 00.722 & 25.234 & 0.020137 \\
\hline 160 & 0.000 & 0.000 & 0.000 & 0.000 & 0.000 & 0.000 & 160.304 & 21.070 & 0.000313 \\
\hline 180 & 0.000 & 0.000 & 0.000 & 0.000 & 0.000 & 0.000 & 214.057 & 5.04 & 0.052313 \\
\hline 210 & 0.000 & 0.000 & 0.000 & 0.000 & 0.000 & 0.000 & 103.01 & -13.344 & $0.097 \mathrm{ces}$ \\
\hline 240 & 0.000 & 0.000 & 0.000 & 0.000 & 2.399 & 0.000 & 122.612 & -25.116 & 0.05404 \\
\hline 270 & 0.000 & 0.000 & 0.000 & 0.000 & c.CS & 0.000 & 23.10 & -11.54 & 0.009175 \\
\hline 390 & 0.0 & 0.000 & 0.000 & 0.000 & 6.055 & 0.000 & 56.443 & 23.0 & 175 \\
\hline & 0.000 & 0.000 & 0.600 & 0.000 & $1.13 t$ & 0.000 & 158.84 & 21. & 37 \\
\hline
\end{tabular}

Station 25, Carcasconse, Prance

\begin{tabular}{|c|c|c|c|c|c|c|c|c|c|}
\hline & & & 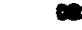 & & & & 0 & & 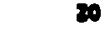 \\
\hline & 20 & $\infty$ & 0.000 & 0.600 & D.cos & 0.000 & 0.000 & D.e00 & 0.10004 \\
\hline 30 & 0.00 & .000 & 0.00 & 0.000 & 11.025 & 0.000 & e.00 & 0.00 & 0.177034 \\
\hline 6 & 0.000 & & 0.040 & 0.060 & 15.0 & 0.000 & 0.000 & 0.000 & $0.164{ }^{2}$ \\
\hline & 0.000 & & 0.000 & 0.000 & 12. & 0.000 & 0.000 & 0.000 & $0.3 \sin$ \\
\hline 120 & 0.000 & & 0.000 & 0.000 & 0.100 & 0.000 & 0.000 & 0.000 & 0.20 \\
\hline 180 & 0.000 & 0.000 & 0.000 & 0.000 & 0.000 & 0.040 & 0.000 & D.000 & 0.18 \\
\hline 10 & 0.000 & 0.000 & 0.000 & 0.000 & 0.00 & 0.000 & 0.000 & 0.000 & 0.18 \\
\hline 210 & 0.000 & & 0.000 & 0.000 & 0.000 & 0.000 & 0.000 & $0.0 \mathrm{O}$ & $0.15 \times 10$ \\
\hline 200 & 0.000 & 0.00 & 0.000 & 0.000 & 0.000 & 0.000 & 0.000 & 0.000 & 0.189200 \\
\hline 270 & 0.000 & & 0.000 & 0.000 & 0.000 & 0.000 & 0.000 & 0.00 & $0.1 \mathrm{escc0}$ \\
\hline 300 & 0.000 & 0. & 0.000 & 0.000 & 13.697 & 0.000 & 0.000 & 0.000 & 0.172914 \\
\hline 30 & 0.000 & 0.000 & 0.000 & 0.000 & 11.chs & 0.000 & 0.000 & 0.000 & 0.17ras \\
\hline
\end{tabular}


Station 26, Istres, France

\begin{tabular}{|c|c|c|c|c|c|c|c|c|c|}
\hline DrR & \multirow[b]{2}{*}{0.000} & \multirow{2}{*}{$\begin{array}{l}\text { Inrol } \\
0.000\end{array}$} & \multicolumn{2}{|c|}{ OAstACLES } & \multicolumn{2}{|c|}{ novermats } & \multicolumn{2}{|c|}{ onocurnt } & 30 \\
\hline 0 & & & 0.000 & 0.000 & 7.573 & 0.000 & 0.000 & 0.000 & 0.082410 \\
\hline 30 & 0.000 & 0.000 & 0.000 & 0.000 & 27.217 & 0.000 & 0.000 & 0.000 & 0.110001 \\
\hline 60 & 0.000 & 0.000 & 0.000 & 0.000 & 23.077 & 0.000 & 0.000 & 0.000 & 0.210602 \\
\hline 60 & 0.000 & 0.000 & 0.000 & 0.000 & 24.330 & 0.000 & 0.000 & 0.000 & 0.250444 \\
\hline 120 & 0.000 & 0.000 & 0.000 & 0.000 & 22.600 & 0.000 & 0.000 & 0.000 & 0.181434 \\
\hline 150 & 0.000 & 0.000 & 0.000 & 0.000 & 15.391 & 0.000 & 0.000 & 0.000 & 0.090286 \\
\hline 180 & 0.000 & 0.000 & 0.000 & 0.000 & 22.514 & 0.000 & 0.000 & 0.000 & 0.145271 \\
\hline 210 & 0.000 & 0.000 & 0.000 & 0.000 & 0.000 & 0.000 & 0.000 & 0.000 & 0.010000 \\
\hline 240 & 0.000 & 0.000 & 0.000 & 0.000 & 0.000 & 0.000 & 0.000 & 0.000 & 0.010000 \\
\hline 270 & 0.000 & 0.000 & 0.000 & 0.000 & 0.000 & 0.000 & 0.000 & 0.000 & 0.010000 \\
\hline 300 & 0.000 & 0.000 & 0.000 & 0.000 & 0.000 & 0.000 & 0.000 & 0.000 & 0.010000 \\
\hline 330 & 0.000 & 0.000 & 0.000 & 0.000 & 0.000 & 0.000 & 0.000 & 0.000 & 0.010000 \\
\hline
\end{tabular}

Station 27, Santiago de Compostela, Spain

\begin{tabular}{|c|c|c|c|c|c|c|c|c|c|}
\hline \multicolumn{2}{|l|}{ DrR } & \multirow{2}{*}{$\begin{array}{l}\text { InTUT } \\
0.000\end{array}$} & \multicolumn{2}{|c|}{ onstactes } & \multicolumn{2}{|c|}{ nowenutess } & \multicolumn{2}{|c|}{ OAOcRuYuY } & 20 \\
\hline 0 & 0.000 & & 0.050 & 0.000 & 31.401 & 0.000 & 6.512 & -3.246 & 0.234633 \\
\hline 30 & 0.000 & 0.000 & 0.000 & 0.000 & 30.500 & 0.000 & -2.020 & -5.542 & 0.254148 \\
\hline 60 & 0.000 & 0.000 & 0.000 & 0.000 & 30 . Ees & 0.000 & -9.760 & -2.076 & 0.264145 \\
\hline 80 & 0.000 & 0.000 & 0.000 & 0.000 & 31.411 & 0.000 & -7.557 & 3.143 & 0.234633 \\
\hline 120 & 0.000 & 0.000 & 0.000 & 0.000 & 31.411 & 0.000 & 1.408 & 5.160 & 0.234933 \\
\hline 150 & 0.000 & 0.000 & 0.000 & 0.000 & 24.927 & 0.000 & 7.430 & 1.710 & 0.161944 \\
\hline 180 & 0.000 & 0.000 & -1.274 & 0.000 & 29.331 & 0.000 & 6.150 & -3.097 & 0.173263 \\
\hline 210 & 0.000 & 0.000 & -5.289 & 0.000 & 26.718 & 0.000 & -2.038 & -5.366 & 0.192459 \\
\hline 240 & 0.000 & 0.000 & -8.420 & 0.000 & 29.201 & 0.000 & -8.842 & -2.001 & 0.255872 \\
\hline 270 & 0.000 & 0.000 & -3.737 & 0.000 & 26.390 & 0.000 & -8.446 & 4.090 & 0.275636 \\
\hline 00 & 0.000 & 0.000 & 0.000 & 0.000 & 29.775 & 0.000 & 1.318 & 5.472 & 0.262544 \\
\hline 330 & 0.000 & 0.000 & 0.000 & 0.000 & 31.118 & 0.000 & 0.203 & 1.606 & 0.24005 \\
\hline
\end{tabular}

Station 28, Zaragoea, Spain

\begin{tabular}{|c|c|c|c|c|c|c|c|c|c|}
\hline DIR & \multirow[b]{2}{*}{0.000} & \multirow{2}{*}{$\begin{array}{l}\text { Intent } \\
0.000\end{array}$} & \multicolumn{2}{|c|}{ ostactis } & \multicolumn{2}{|c|}{ novenilless } & \multicolumn{2}{|c|}{ cmochury } & 20 \\
\hline - & & & -0.013 & 0.000 & 0.000 & 0.000 & -32.301 & -14.679 & 0.300000 \\
\hline 30 & 0.000 & 0.000 & -0.080 & 0.000 & 0.000 & 0.000 & -38.550 & 11.746 & 0.3000000 \\
\hline 10 & 0.000 & 0.000 & -0.919 & 0.000 & 0.000 & 0.000 & -6.816 & 10.941 & 0.300000 \\
\hline$\infty$ & 0.000 & 0.000 & -1.437 & 0.000 & 2.755 & 0.000 & 15. 1032 & 0.477 & 0.205345 \\
\hline 170 & 0.000 & 0.000 & -2.007 & 0.000 & 0.813 & 0.000 & 15.797 & -4.934 & 0.176738 \\
\hline 180 & 0.000 & 0.000 & 0.000 & 0.000 & 9.670 & 0.000 & -1.700 & -14.273 & 0.147936 \\
\hline 100 & 0.000 & 0.000 & 0.000 & 0.000 & 0.670 & 0,000 & -25.017 & -11.751 & 0.147236 \\
\hline 210 & 0.000 & 0.000 & 0.000 & 0.000 & 10.256 & 0.000 & -30.767 & T.ces & $0.167 a s 5$ \\
\hline 240 & 0.000 & 0.000 & 0.000 & 0.000 & 12.010 & 0.000 & -0.671 & 15.947 & 0.106016 \\
\hline 270 & 0.000 & 0.000 & 0.000 & 0.000 & $12.3 \mathrm{~A}$ & 0.000 & 11.624 & 7.505 & 0.124131 \\
\hline$\infty$ & 0.000 & 0.000 & -6.475 & 0.000 & 10.250 & 0.000 & 16.000 & -4.860 & 0.188015 \\
\hline 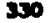 & 0.000 & 0.000 & -1.103 & 0.000 & 0.000 & 0.000 & -2.420 & -18.035 & 0.300000 \\
\hline
\end{tabular}

Station 29, Salamanca, Spain

\begin{tabular}{|c|c|c|c|c|c|c|c|c|c|}
\hline in & & 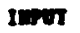 & & 13 & & & & & 2 \\
\hline • & .000 & 00 & 0.000 & 0.000 & 1.50 & 0.000 & 0.000 & 0.000 & 0.071145 \\
\hline 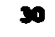 & 20 & 000 & 0.000 & 0.000 & 1.746 & $\infty 0$ & .000 & 0.000 & ant \\
\hline & 000 & &.$\infty$ & .000 & 11.024 & & .000 & 0.000 & $0.07 x+1$ \\
\hline 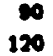 & 0 & &.$\infty 0$ & $\infty 00$ & 11.ens & & $\infty$ & & 2 \\
\hline & C & .000 & 2.002 & 0.000 & 7.074 & $\infty$ & .600 & 0.000 & 0.14736 \\
\hline & & $\infty$ & 2.77 & 0.000 & 12.647 & 1.000 & .000 & & 0.136737 \\
\hline & $\boldsymbol{c}$ &.$\infty 00$ & 0.000 & $\infty$ & 14.700 & 0.000 & 0.000 & 0.000 & $0.12+200$ \\
\hline & & 00 & 0.000 & 0.000 & 11.024 & & 0.000 & ๑. & $0.07 \times 182$ \\
\hline & 0 & .000 & $0 . \infty 0$ & 0.000 & 17.001 & 0.080 & 0.060 & 0.0 & 0.276318 \\
\hline & & & 0.000 & 0.000 & 22.412 & & 0.600 & & 0.1457 \\
\hline & & & 0.000 & 0.0 & 22. & & 0.000 & o. & 0.210602 \\
\hline & $0 . \infty 00$ & & 0.000 & 0.000 & 12.16s & & 0.000 & & 0.0 \\
\hline
\end{tabular}


Station 30, Albacete, Spain

\begin{tabular}{|c|c|c|c|c|c|c|c|c|c|}
\hline \multirow{2}{*}{$\begin{array}{r}\text { DIR } \\
0\end{array}$} & \multirow[b]{2}{*}{0.000} & \multirow{2}{*}{$\begin{array}{l}\text { Imror } \\
0.000\end{array}$} & \multicolumn{2}{|c|}{ ostacts } & \multicolumn{2}{|c|}{ opowares } & \multicolumn{2}{|c|}{ Dosolurty } & \\
\hline & & & 0.000 & 0.000 & 6.513 & 0.000 & 0.000 & 0.000 & 0.204505 \\
\hline 30 &.$\infty 00$ & & 0.000 & 0.000 & 24.221 & .000 & 0.000 & 0.000 & .10 \\
\hline 60 & .000 & 000 & $\infty 00$ & .000 & 5.353 & .000 &.$\infty 00$ & 0.000 & 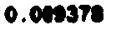 \\
\hline$\infty 0$ & .000 & $\infty 00$ & $\infty$ &.$\infty 0$ & 35 & .000 & .000 & 0.000 & \\
\hline 120 & 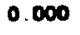 & .000 & 000 & .000 & 80 & & $\boldsymbol{\infty}$ & $\infty 00$ & c \\
\hline & $\mathbf{0}$ & .000 & & 000 & 78 & 0.000 & 200 & .000 & \\
\hline & $\mathbf{0}$ & 000 & .000 & 000 & & 100 & 000 & .000 & 0.06 \\
\hline 20 & .000 & & .000 & 0.000 & 23.710 & 0.000 & 200 & 0.000 & \\
\hline & & .000 & 0.000 & 0.000 & .344 & 100 & 000 & $\infty 0$ & 1.0 \\
\hline & 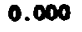 & .000 & 0.000 & 0.000 & 20.100 & 0.000 & 0.000 & 0.000 & .00 \\
\hline & 00 & 000 & $1.5 e s$ & 0.000 & 24.450 & 0.000 & 0.000 & 0.000 & \\
\hline & 0.000 & 0.000 & -0.055 & 0.000 & 20.770 & 0.000 & 0.000 & 0.000 & 0.1 \\
\hline
\end{tabular}

Station 31, Almeria, Spain

\begin{tabular}{|c|c|c|c|c|c|c|c|c|c|}
\hline \multirow{2}{*}{$\begin{array}{r}\text { DI. } \\
0\end{array}$} & \multirow[b]{2}{*}{0.000} & \multirow{2}{*}{$\begin{array}{l}\text { ImPUT } \\
0.000\end{array}$} & \multicolumn{2}{|c|}{ anstictes } & \multicolumn{2}{|c|}{ Ioveminas } & \multicolumn{2}{|c|}{ cuoctarm } & 20 \\
\hline & & & -2.246 & 0.000 & 28.352 & 0.000 & 0.000 & 0.000 & 0.254145 \\
\hline 30 & 0.000 & 0.000 & -0.327 & 0.000 & 20.382 & 0.000 & 0.000 & 0.000 & 0.254148 \\
\hline 6 & 0.000 & 0.000 & 0.000 & 0.000 & 23.375 & 0.000 & 0.000 & 0.000 & 0.275836 \\
\hline 90 & 0.000 & 0.000 & 0.000 & 0.000 & 11.001 & 0.000 & 0.000 & 0.000 & $0.2275 e$ \\
\hline 120 & 0.000 & 0.000 & 0.000 & 0.000 & -38.304 & 0.000 & 0.000 & 0.000 & 0.000753 \\
\hline 150 & 0.000 & 0.000 & 0.000 & 0.000 & -33.342 & 0.000 & 0.000 & 0.000 & 0.000321 \\
\hline 180 & 0.000 & 0.000 & 0.000 & 0.000 & $-31, \cot$ & 0.000 & 0.000 & 0.000 & 0.000256 \\
\hline 210 & 0.000 & 0.000 & 0.000 & 0.000 & -32.644 & 0.000 & 0.000 & 0.000 & 0.000306 \\
\hline 240 & 0.000 & 0.000 & 0.000 & 0.000 & -8.678 & 0.000 & 0.000 & 0.000 & 0.033642 \\
\hline 270 & 0.000 & 0.000 & -0.059 & 0.000 & 28.627 & 0.000 & 0.000 & 0.000 & 0.214100 \\
\hline 300 & 0.000 & 0.000 & -1.436 & 0.000 & 27.516 & 0.000 & 0.000 & 0.000 & 0.252544 \\
\hline 330 & 0.000 & 0.000 & -2.391 & 0.000 & 25.314 & 0.000 & 0.000 & 0.000 & 0.271310 \\
\hline
\end{tabular}

Station 32, Sagres. Portugal

\begin{tabular}{|c|c|c|c|c|c|c|c|c|c|}
\hline \multirow{2}{*}{$\begin{array}{r}\text { DIR } \\
0\end{array}$} & \multirow[b]{2}{*}{0.000} & \multirow{2}{*}{$\begin{array}{l}\text { InPT } \\
0.000\end{array}$} & \multicolumn{2}{|c|}{ OATICLES } & \multicolumn{2}{|c|}{ novemizas } & \multicolumn{2}{|c|}{ Decosury } & \\
\hline & & & .000 & 0.000 & 20.150 & 0.000 & 23.603 & 1.271 & 0.193843 \\
\hline 30 & .000 & 0.000 & & & 28.703 & 0.000 & 18.009 & 2.225 & 0.158392 \\
\hline & .000 & & & 1.000 & $-11.4 \times$ & 0.000 & 22.214 & 1.00 & 0.000191 \\
\hline 0 & 000 & $\infty$ & & .000 & 734 & 0.000 & 12.105 & -0.785 & 0.000223 \\
\hline & .000 & 000 & & 0.000 & 34 & 0.000 & b.ses & -2.234 & 0.000223 \\
\hline & & & & & 1 & 0.000 & 15.030 & -2.002 & 0.000217 \\
\hline & & .000 & .000 & 0.000 & -4.7 & 0.000 & 13.442 & 0.771 & 0.000217 \\
\hline & & & & & -4.7 & 0.000 & 17.745 & $2 . m$ & 0.000217 \\
\hline v & & & 0.000 & 0.000 & -4.7 & 0.000 & .344 & $1 . \mathbf{2 4 1}$ & 000217 \\
\hline & & 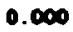 & 0.000 & 0.000 & $-\because .734$ & 0.000 & 72.16 & -0.75 & 0.000223 \\
\hline & & & & & .3 .7 & 0.000 & e.sen & -2.234 & .000223 \\
\hline & 0.000 & .000 & 0.000 & & -16.423 & 0.000 & 22.390 & -1.514 & 0.00058 \\
\hline
\end{tabular}

Station 33, Simes, Portugal

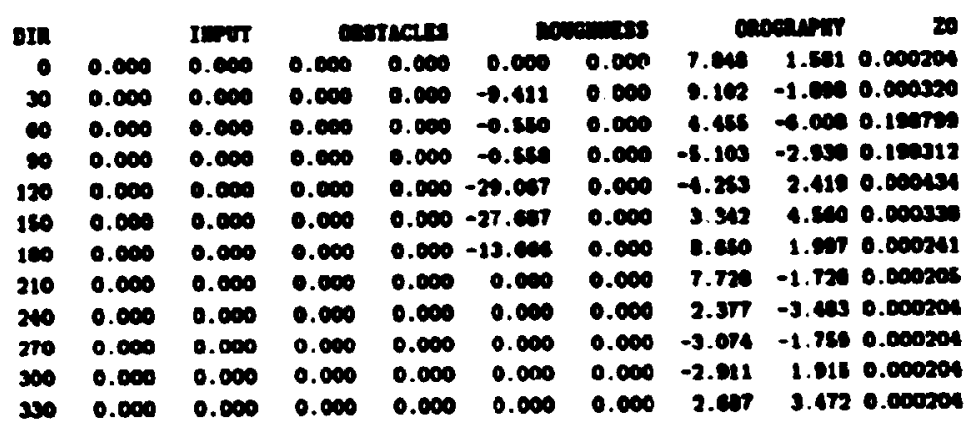


Station 34, Viana do Castelo, Portugal

\begin{tabular}{|c|c|c|c|c|c|c|c|c|c|}
\hline \multirow{2}{*}{ Dr. } & \multirow[b]{2}{*}{0.000} & \multirow{2}{*}{$\begin{array}{l}1001 \\
0.000\end{array}$} & \multicolumn{2}{|c|}{ oxticts } & \multicolumn{2}{|c|}{ nosemess } & \multicolumn{2}{|c|}{ cupanser } & 20 \\
\hline & & & .000 & 0.000 & 0.000 & 0.000 & -10.303 & 5.217 & 0.400000 \\
\hline 30 & .000 & 0.000 & 0.000 & 0.000 & 0.000 & .000 & -0.44 & 7.397 & 0.400000 \\
\hline & .000 & 000 & .000 & . & 0.000 & 0.000 & 2.342 & 2.531 & 0.300000 \\
\hline$\omega$ & 0.000 & 0.000 & .000 & .000 & 0.000 & $0 . \infty 00$ & 0.012 & -4.077 & .300000 \\
\hline & 0.000 & 0.000 & .000 & 1.000 & -2.104 &, 000 & -12.201 & -6.241 & 0.120248 \\
\hline & $\infty 00$ &.$\infty 0$ & .000 & .000 & 0.432 & .000 & -18.433 & -1.725 & .127043 \\
\hline & .000 & .000 & .000 & 0.000 & -0.242 & 0.000 & -16.140 & 4.917 & 0.152702 \\
\hline & .000 & .000 & .000 & .000 & $-21,102$ & 0.000 & -5.978 & 5.710 & 0.001407 \\
\hline & $\alpha$ & $\mathbf{0 0}$ & .000 & 0.000 & -33.094 & 0.000 & 1.973 & 2.546 & 0.002154 \\
\hline & 0.000 & .000 & .000 & 0.000 & -32.052 & 0.000 & 1.057 & -3.65 & 0.002417 \\
\hline & 0.000 & 0.000 & .000 & 0.000 & -30.378 & 0.000 & -9.889 & -7.441 & 0.000054 \\
\hline & .000 & 1.000 & 0.000 & 0.000 & 0.000 & 0.000 & -19.42 & -3.216 & 0.300000 \\
\hline
\end{tabular}

Station 35, Bragança, Portugal

\begin{tabular}{|c|c|c|c|c|c|c|c|c|c|}
\hline DIR & & InPor & & recuss & & andess & & LOGRAPTT & 20 \\
\hline 0 & 0.000 & 0.000 & 0.000 & 0.000 & 0.000 & 0.000 & 146.297 & -7.007 & 0.300000 \\
\hline 30 & 0.000 & 0.000 & .000 & 0.000 & 0.000 & 0.000 & 99.756 & -19.604 & 0.300000 \\
\hline$\omega$ & .000 & 000 & .000 & 0.000 & .000 & 0.000 & 33.454 & -15.934 & 0.300000 \\
\hline 90 & 0.000 & $\infty 00$ & .000 & .000 & 1.000 & 0.000 & 28.368 & 13.692 & 0.300000 \\
\hline 120 & 000 & .000 & .000 & .000 & 1.000 & 0.000 & 92.972 & 20.323 & 0.300000 \\
\hline 150 & .000 & .000 & .000 & 0.000 & 0.000 & 0.000 & 143.577 & 6.651 & 0.300000 \\
\hline 180 & 0.000 & 0.000 & 0.000 & 0.000 & 0.000 & 0.000 & 146.297 & -7.007 & 0.300000 \\
\hline 210 & 0.000 & 0.000 & 1.000 & 0.000 & 0.000 & 0.000 & 90.756 & -19.604 & 0.300000 \\
\hline 240 & 0.000 & 0.000 & 0.000 & 0.000 & 0.000 & 0.000 & 33.456 & -15.934 & 0.300000 \\
\hline 270 & .000 & 0.000 & 0.000 & 0.000 & 0.000 & 0.000 & 30.341 & 14.030 & 0.400000 \\
\hline 300 & 0.000 & 0.000 & 0.000 & 0.000 & 0.000 & 0.000 & 100.260 & 21.261 & 0.400000 \\
\hline 30 & 0.000 & 0.000 & 0.000 & 0.000 & 0.000 & 0.000 & 143.577 & 351 & 0.300000 \\
\hline
\end{tabular}

Station 36, Lisbon, Portugal

\begin{tabular}{|c|c|c|c|c|c|c|c|c|c|}
\hline \multicolumn{2}{|l|}{ DIn } & \multirow{2}{*}{$\begin{array}{l}\text { Imwor } \\
0.000\end{array}$} & \multicolumn{2}{|c|}{ osticts } & \multicolumn{2}{|c|}{ Rove IILSS } & \multicolumn{2}{|c|}{ cucaury } & \\
\hline$\bullet$ & 0.000 & & 000 & 0.000 & 20.602 & .000 & -3.584 & 0.179 & 0.210502 \\
\hline 30 & $\infty 00$ & 0.000 & & .000 & 14.167 &.$\infty \infty$ & $-1,202$ & 2.722 & 0.205167 \\
\hline $\boldsymbol{\omega}$ & $\infty 00$ & $\infty 00$ & 00 & $-\infty 00$ & 12.005 & .000 & 3.633 & 03 & 0.002270 \\
\hline $\boldsymbol{\omega}$ & $\infty$ & & & .000 & -33.594 & .000 & 5.604 & -0.107 & 0.001818 \\
\hline 120 & 100 & $\infty$ & 000 & .000 & $-31, c 0$ & .000 & 3. & & 0.002013 \\
\hline w & &.$\infty 00$ & .000 & $\infty$ & -22.344 & .000 & -1.810 & -2.492 & 0.0035 \\
\hline 100 & & & .000 & .000 & .602 & & -3.584 & 0.178 & 0.210502 \\
\hline 10 & 0.000 & 00 & .000 & .000 & 28.975 & 0.000 & $\rightarrow . \omega t$ & 2.64 & 0.21 \\
\hline 240 & 0.0 & .0 & 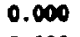 & $\boldsymbol{\infty}$ & 736 & 0.000 & 4.425 & 2.333 & 0.20594 \\
\hline & (1) & 0.0 & 0.000 & 0.000 & $27 . \mathrm{ces}$ & 0.00 & 6.316 & -0.13 & 0.28 \\
\hline & & & & & 27.135 & 0.0 & 3.020 & -2.872 & 0.25030 \\
\hline & .000 & & 0.000 & 0.000 & 20.64 & 0.000 & -1.200 & -2.618 & 0.22 \\
\hline
\end{tabular}

Station si, List/Sylt, Germany

\begin{tabular}{|c|c|c|c|c|c|c|c|c|c|}
\hline In & & lוn & & & & & & anrw & 20 \\
\hline & 000 & $\infty$ & & $\infty$ & -18.4as & $0 . \infty 6$ & 39.031 & 0.024 & 0.001744 \\
\hline & $\infty$ & .00 & 0.000 & 0.600 & -20.212 & $\infty$ & 32.0 & -1.016 & 0.000700 \\
\hline & .000 & & 0.000 & & -20.137 & 0.690 & x.ens & -1.607 & 0.000617 \\
\hline &.$\infty 00$ & $\infty$ & -1.740 & .000 & -10.220 & & $23 . \operatorname{ces}$ & -1.024 & 0.609313 \\
\hline & 0.000 & & -27.424 & 0.000 & & & 21.16 & $1.4 \mathrm{~s}$ & 0.000251 \\
\hline & 0.000 & .000 & -5.523 & $0 . \infty 00$ & & & 23.345 & 2.59 & 0.000251 \\
\hline & 0.000 & $\infty$ & 0.000 & 0.000 & -11.621 & $\infty$ & 31.4as & 1.058 & 0.000271 \\
\hline & 0.000 & 0.000 & 0.000 & 0. & -16.220 & & 31.022 & -1.110 & 0.000513 \\
\hline & 0.000 & 0.000 & 0.000 & 0.000 & -19.37 & $\infty$ & 20.06 & -1.6 & o.eolen \\
\hline & 0.000 & 0.000 & 0.000 & 0.000 & -30.41 & & 36.404 & -0. & 0.001001 \\
\hline & 0.000 & & 0.000 & 0.000 & -20.43 & & 18.600 & & 0.004 ses \\
\hline & 0.00 & 0.000 & 0.000 & 0.0 & -20.37 & & 79.828 & & 0.001383 \\
\hline
\end{tabular}


Station 38, Bremen, Germany

\begin{tabular}{|c|c|c|c|c|c|c|c|c|c|}
\hline ort. & \multirow[b]{2}{*}{0.000} & Intor & \multicolumn{2}{|c|}{ osstactes } & \multicolumn{2}{|c|}{ novermas } & \multicolumn{2}{|c|}{ oacoturn } & 20 \\
\hline 0 & & 0.000 & -10.62 & D. 000 & 26.134 & 0.000 & 0.000 & 0.000 & 0.322673 \\
\hline 30 & 0.000 & 0.000 & -6.091 & 0.000 & 23.050 & 0.000 & 0.000 & 0.000 & 0.204216 \\
\hline 60 & 0.000 & .000 & -0.000 & 0.000 & 23.058 & 0.000 & 0.000 & 0.000 & 0.204248 \\
\hline 60 & 0.000 & 0.000 & 0.000 & 0.000 & 23.058 & 0.000 & 0.000 & 0.000 & 0.204216 \\
\hline 120 & 0.000 & 0.000 & 0.000 & 0.000 & 23.058 & 0.000 & 0.000 & 0.000 & 0.204218 \\
\hline 150 & 0.000 & 0.000 & 0.000 & 0.000 & 23.056 & 0.000 & 0.000 & 0.000 & 0.204216 \\
\hline 180 & 0.000 & 0.000 & 0.000 & 0.000 & 11.932 & 0.000 & 0.000 & 0.000 & 0.000323 \\
\hline 210 & 0.000 & 0.000 & 0.000 & 0.000 & 11.032 & 0.000 & 0.000 & 0.000 & 0.000323 \\
\hline 240 & 0.000 & 0.000 & 0.000 & 0.000 & 12.075 & 0.000 & 0.000 & 0.000 & 0.077076 \\
\hline 270 & 0.000 & 0.000 & 0.000 & 0.000 & 21.240 & 0.000 & 0.000 & 0.000 & 0.157373 \\
\hline 300 & 0.000 & 0.000 & -0.440 & 0.000 & 17.036 & 0.000 & 0.000 & 0.000 & 0.124744 \\
\hline $\mathbf{3 3 0}$ & 0.000 & 0.000 & -8.072 & 0.000 & 12.484 & 0.000 & 0.000 & 0.000 & 0.096311 \\
\hline
\end{tabular}

Station 39, Hannover, Germany

\begin{tabular}{|c|c|c|c|c|c|c|c|c|c|}
\hline DIR & \multirow[b]{2}{*}{0.000} & \multirow{2}{*}{$\begin{array}{l}\text { InPur } \\
0.000\end{array}$} & \multicolumn{2}{|c|}{ osstactes } & \multicolumn{2}{|c|}{ noventitss } & \multicolumn{2}{|c|}{ oxporapir } & \\
\hline 0 & & & .000 & 0.000 & 17.957 & 0.000 & .000 & 0.000 & 0.158055 \\
\hline 30 & 0.000 & .000 & 0.000 & .000 & C. 145 & 0.000 & 1.000 & 0.000 & 0.154544 \\
\hline & .000 & .000 & 0.0 & .000 & 1.608 & .000 & .000 & 0.000 & 0.121260 \\
\hline 80 & .00 & $\infty 00$ & 21.760 & .000 & 93 & .000 & $\infty$ & 0.000 & .155601 \\
\hline & & .000 & -28.8 & .000 & 13.914 & 0.000 & 100 & 0.000 & irros \\
\hline & o & 000 & 6. & $\infty 000$ & 20.687 & .000 & & 0.000 & .144670 \\
\hline & & & -4. & .000 & 20.693 & 000 & & $\infty 00$ & 313 \\
\hline & & 000 & & .000 & 22.201 & 0.000 & 1.000 & 0.000 & 0.182165 \\
\hline & & .000 & 0.0 & 1.000 & $17.7 \%$ & 0.000 & & 0.040 & 0.147767 \\
\hline & & .000 & & $\mathbf{0 0}$ & 17.731 & 0.000 & 0.000 & 0.000 & 0.151054 \\
\hline & &.$\infty 00$ & 0.0 & .000 & 53 & 0.000 & & 0.000 & .118297 \\
\hline & & 0.000 & 0.000 & 0.000 & 18.145 & 0.000 & 0.000 & 0.000 & 0.18454 \\
\hline
\end{tabular}

Station 40, Berlin, Germany

\begin{tabular}{|c|c|c|c|c|c|c|c|c|c|}
\hline \multirow{2}{*}{$\begin{array}{r}\text { DIn } \\
0\end{array}$} & \multirow[b]{2}{*}{0.000} & \multirow{2}{*}{$\begin{array}{l}\text { Impor } \\
0.000\end{array}$} & \multicolumn{2}{|c|}{ onstnctes } & \multicolumn{2}{|c|}{ novenunss } & \multicolumn{2}{|c|}{ onoctaring } & \\
\hline & & & 0.000 & 0.000 & 21.228 & 0.000 & .000 & 0.000 & 0.246094 \\
\hline 30 & 0.000 & 000 & 0.000 & .000 & 21.925 & 0.000 & .000 & 0.000 & 0.24104 \\
\hline 6 & 1.000 & 000 & 0.000 & .000 & $19 . \mathrm{se}$ & .000 & .000 & .000 & .25514 \\
\hline $\mathbf{\infty}$ & .000 & 000 & 0.000 & 0.000 & 1e.cen & .000 & .000 & 0.000 & 0.23784 \\
\hline 120 & $\infty$ & 000 & 0.000 & 0.000 & 20.615 & 1.000 & .000 & .000 & 0.28414 \\
\hline 180 & 000 & 000 & .000 & .000 & 20.615 & .000 & .000 & 000 & 0.25 \\
\hline 100 & $\infty$ &.$\infty 00$ &.$\infty 00$ & .000 & $22 . \mathrm{m}$ & 0.000 & 0.000 & 0.000 & 0.23097 \\
\hline 210 & .000 & 0.000 & .000 & 0.000 & 23.046 & 0.000 & 0.000 & 0.000 & 0.21704 \\
\hline 240 & $\infty \infty 0$ & & & 0.000 & 23.056 & 0.000 & 0.000 & 0.000 & 0.20421 \\
\hline 870 & 0.000 & 000 & .000 & 0.000 & 1.974 & 0.000 & 0.000 & 0.000 & $0.181 \mathrm{MM}$ \\
\hline & & & .000 & 0.0 & 11.076 & 0.0 & 0.000 & 0.000 & 0.16144 \\
\hline & .000 & 0.000 & .000 & 0.000 & 23.050 & 0.000 & 0.000 & 0.000 & 0.20122 \\
\hline
\end{tabular}

Station 11, Miñnchen, Germany

\begin{tabular}{|c|c|c|c|c|c|c|c|c|c|}
\hline ort & & lown & \multicolumn{2}{|c|}{ astacits } & \multicolumn{2}{|c|}{$006=\operatorname{mins}$} & \multicolumn{2}{|c|}{ посениті } & 20 \\
\hline$\bullet$ & 0.000 & 0.000 & -9.260 & 0.000 & 0.00 & 0.000 & 0.000 & 0.000 & 0.010145 \\
\hline 3 & 0.000 & 0.000 & -7.210 & 0.000 & 0.000 & 0.000 & 0.000 & 0.000 & 0.01010s \\
\hline $\boldsymbol{C}$ & 0.000 & 0.000 & -2.117 & 0.000 & 4.477 & 0.000 & 0.000 & 0.000 & 0.03520 \\
\hline $\boldsymbol{\omega}$ & 0.000 & 0.000 & 0.000 & 0.000 & 0.000 & 0.000 & 0.000 & 0.000 & 0.010000 \\
\hline 120 & 0.000 & 0.000 & 0.000 & 0.000 & 10.710 & 0.000 & 0.000 & 0.000 & o. $10 \mathrm{~nm}$ \\
\hline 100 & 0.000 & 0.000 & 0.000 & 0.000 & 10.700 & 0.000 & 0.000 & 0.000 & $0.10 \mathrm{~mm}$ \\
\hline 160 & 0.000 & 0.000 & 0.000 & 0.000 & 21.770 & 0.000 & 0.000 & 0.000 & 0.157515 \\
\hline 210 & 0.000 & 0.000 & 0.000 & 0.000 & 22.60 & 0.000 & 0.060 & 0.000 & 0.101434 \\
\hline 200 & 0.000 & 0.000 & -8.513 & 0.000 & 20.841 & 0.000 & 0.000 & 0.000 & $0.14137=$ \\
\hline 270 & 0.000 & 0.000 & -27.703 & 0.000 & 22.70 & 0.000 & 0.000 & 0.000 & $0.103 \mathrm{ret}$ \\
\hline 300 & 0.000 & 0.000 & -28.727 & 0.000 & 22.150 & 0.000 & 0.000 & 0.000 & 0.105503 \\
\hline 34 & 0.000 & 0.000 & -20.034 & 0.000 & 0.000 & 0.000 & 0.000 & 0.000 & 0.01020 \\
\hline
\end{tabular}


Station 42, Pisa, Italy

\begin{tabular}{|c|c|c|c|c|c|c|c|c|c|}
\hline \multirow{2}{*}{ DI } & \multirow[b]{2}{*}{0.000} & \multirow{2}{*}{$\begin{array}{l}\text { IndoT } \\
0.000\end{array}$} & \multicolumn{2}{|c|}{ ostractes } & \multicolumn{2}{|c|}{ Dowelm $x$} & \multicolumn{2}{|c|}{ onoenurat } & 20 \\
\hline & & & 0.000 & 0.000 & 32.744 & 0.000 & 0.000 & 0.000 & 0.300252 \\
\hline 30 & 0.000 & .000 & 0.000 & 0.000 & 20.308 & 0.000 & 0.000 & 0.000 & 0.250117 \\
\hline & 0.000 & 0.000 & 0.000 & 0.000 & 0.305 & 0.000 & 0.000 & 0.000 & 0.250117 \\
\hline 8 & 0.000 & 0.000 & 0.000 & 0.000 & 20.308 & 0.000 & 0.000 & 0.000 & 0.250117 \\
\hline 20 & 0.000 & 0.000 & 0.000 & 0.000 & 29.772 & .000 & 0,000 & 0.000 & 0.205204 \\
\hline & 0.000 & 0.000 & 0.000 & 0.000 & 23.89 & 0.000 & 0.000 & 0.000 & .209133 \\
\hline 160 & 0.000 & $0: 000$ & 0.000 & 0.000 & 23.900 & 0.000 & 0.000 & 0.000 & 0.24113 \\
\hline & 0.000 & 0.000 & 0.000 & 0.000 & 23.741 & 0.000 & 0.000 & 0.000 & 0.205301 \\
\hline & 0.000 & 0.000 & 0.000 & 0.000 & 20.305 & 0.000 & 0.000 & 0.000 & 0.280117 \\
\hline & 0.000 & 0.000 & 0.000 & 0.000 & 23.311 & 0.000 & 0.000 & 0.000 & 0.197430 \\
\hline & .000 & .000 & 0.000 & 0.000 & 23.311 & 0.000 & 0.000 & 0.000 & 0.197630 \\
\hline & & .000 & 0.000 & 0.000 & 25.100 & 0.000 & 0.000 & 0.000 & 0.249352 \\
\hline
\end{tabular}

Station 43, Gioia del Colle, Italy

\begin{tabular}{|c|c|c|c|c|c|c|c|c|c|}
\hline \multirow{2}{*}{ DIR } & \multirow[b]{2}{*}{0.000} & Impon & \multicolumn{2}{|c|}{ Dostacuss } & \multicolumn{2}{|c|}{ rovenuss } & \multicolumn{2}{|c|}{ ondeserity } & 20 \\
\hline & & 0.000 & 0.000 & 0.000 & 14.222 & 0.000 & 0.000 & 0.000 & 0.166935 \\
\hline 30 & 0.000 & .000 & 0.000 & 0.000 & 18.222 & 0.000 & 0.000 & 0.000 & 0.166465 \\
\hline & 0.000 & 0.000 & 0.000 & 0.000 & 10.222 & 0.000 & 0.000 & 0.000 & 0.160968 \\
\hline$\infty$ & 0.000 & 0.000 & 0.000 & 0.000 & 18.222 & 0.000 & 0.000 & 0.000 & 0.140945 \\
\hline 20 & 0.000 & 0.000 & 0.000 & 0.000 & 18.222 & 0.000 & 0.000 & 0.000 & 0.160945 \\
\hline 150 &.$\infty 00$ & .000 & .000 & 0.000 & 18.222 & 0.000 & 9.000 & .000 & $0.16 e 9 s$ \\
\hline 160 &.$\infty 00$ & 0.000 & .000 & 0.000 & 18.222 & 0.000 & 0.000 & 0.000 & 0.166855 \\
\hline 210 & 0.000 & 0.000 & 0.000 & 0.000 & 18.222 & 0.000 & 0.000 & 0.000 & 0.166985 \\
\hline & 0.000 & .000 & 0.000 & 0.000 & 18.222 & 0.000 & 0.000 & 0.000 & $0.1668 \mathrm{~s}$ \\
\hline & 0.000 & 0.000 & 0.000 & 0.000 & 18.222 & 0.000 & 0.000 & 0.000 & 0.164565 \\
\hline & 1.000 & .000 & 0.000 & 0.000 & 10.222 & 0.000 & 0.000 & 0.000 & 0.166585 \\
\hline & 0.000 & 0.000 & 0.000 & 0.000 & 18.222 & 0.000 & 0.000 & 0.000 & $0.165 \times 55$ \\
\hline
\end{tabular}

Station 44, Brindisi, Italy

\begin{tabular}{|c|c|c|c|c|c|c|c|c|c|}
\hline \multirow{2}{*}{ ort } & \multirow[b]{2}{*}{0.000} & \multirow{2}{*}{$\begin{array}{l}\text { Indor } \\
0.000\end{array}$} & \multicolumn{2}{|c|}{ costicus } & \multicolumn{2}{|c|}{ nowewins } & \multicolumn{2}{|c|}{ cocosartit } & 4 \\
\hline & & & & 0.000 & -17.103 & 0.000 & 0.000 & 0.000 & 0.000451 \\
\hline 30 & & & & .000 & -10.028 & 0.000 & 0.000 & 0.000 & 0.000200 \\
\hline & & & 000 & 0.060 & -10.502 & 0.000 & 0.000 & 0.000 & 0.000232 \\
\hline & & & $\infty 6$ & .000 & -20.705 & .000 & .000 & 0.000 & 0.000448 \\
\hline & & & $\infty 00$ & .000 & -20.50 & 0.000 &.$\infty 00$ & .000 & $0.0 \mathrm{was} x$ \\
\hline SO & 000 & $\infty$ & 1.000 & .000 & 4.173 & 0.000 & 0.000 & 0.000 & $0.040 B A 6$ \\
\hline$d$ & 0 & $\infty$ & 1.000 & 0.000 & 6.776 & 0.000 & 0.000 & 0.000 & $0.05 n 4$ \\
\hline & 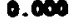 & $\infty 00$ & .000 & .000 & 0.202 & 0.000 & 0.00 & 0.000 & 0.000307 \\
\hline $\mathbf{A}$ & .000 & 0.000 & 0.000 & 0.000 & 0.000 & 0.000 & 0.000 & 0.000 & 0.100000 \\
\hline & . & 0.000 & 0.000 & 0.000 & 0.000 & 0.0 .0 & 0.300 & 0.000 & 0.100000 \\
\hline & $\mathbf{0}$ & $\infty$ & .000 & 0.000 & 0.000 & & 0.000 & 0.000 & 0.050000 \\
\hline & & &. $\cos$ & 0.000 & 21.210 & & 0.000 & & $0 . \cos 3 \pi$ \\
\hline
\end{tabular}

Station 45, Leces Golntina, Italy

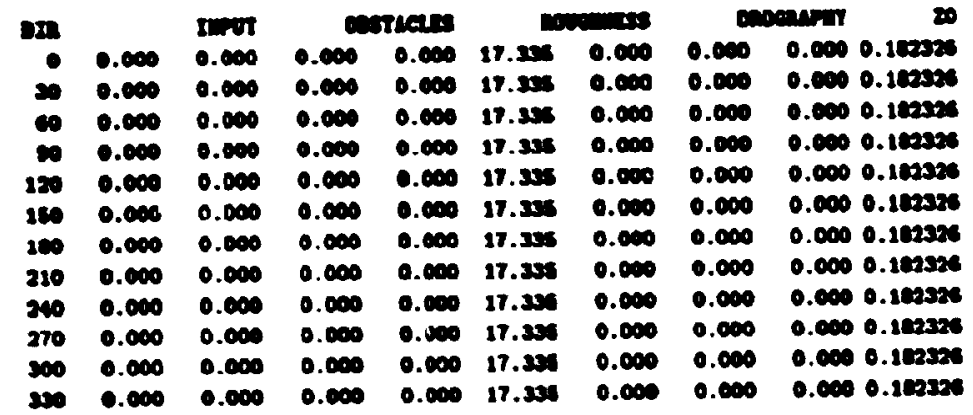


Station 46, Alghero, Italy

\begin{tabular}{|c|c|c|c|c|c|c|c|c|c|}
\hline \multirow[t]{2}{*}{ orn } & \multirow[b]{2}{*}{0.000} & \multirow{2}{*}{$\begin{array}{l}\text { Ilpor } \\
0.000\end{array}$} & \multicolumn{2}{|c|}{ onstactes } & \multicolumn{2}{|c|}{ noventats } & \multicolumn{2}{|c|}{ cacoantry } & 20 \\
\hline & & & & 0.000 & 12.637 & 0.000 & 0.000 & 0.000 & 0.071601 \\
\hline 30 & .000 & 0.000 & 0.000 & .000 & 11.637 & 0.000 & 0.000 & 0.000 & 0.071681 \\
\hline & .000 & & .000 & .000 & 11.637 & 1.000 & 0.000 & 0.000 & 0.071001 \\
\hline 60 & .00 & 000 & .000 & .600 & 11.637 & 0.000 & .000 & 0.000 & 0.071691 \\
\hline 20 & .000 & .000 & .000 & $\infty$ & 11.637 & 0.000 & .000 & 0.000 & 0.071041 \\
\hline 18 & 0 & .000 & .000 & .000 & 11.637 & 0.000 & .000 & 0.000 & 0.071051 \\
\hline & 000 & 000 & 1.000 & .000 & -10.023 & .000 & .000 & 0.000 & 0.000710 \\
\hline & .000 & .000 & .000 & .000 & -10.058 & 0.000 & .000 & 0.000 & 0.002212 \\
\hline & & & .000 & .000 & -16.091 & $\infty$ & .000 & 0.000 & 0.002812 \\
\hline & 000 & 000 &.$\infty 00$ & & -4.8 & 0.000 & 0.000 & 0.000 & 0.004037 \\
\hline & & & .000 & & -6 & 0.000 & .000 & 0.000 & 0.004037 \\
\hline & 0.000 & 0.000 & 0.000 & 0.000 & -8.505 & 0.000 & 0.000 & 0.000 & 0.007207 \\
\hline
\end{tabular}

Station 47, Cagliari, Italy

\begin{tabular}{|c|c|c|c|c|c|c|c|c|c|}
\hline \multirow[t]{2}{*}{ DIR } & \multirow[b]{2}{*}{.000} & \multirow{2}{*}{$\begin{array}{l}t w 10 t \\
0.000\end{array}$} & \multicolumn{2}{|c|}{ Onstacles } & \multicolumn{2}{|c|}{ nouetinss } & \multicolumn{2}{|c|}{ olocanrer } & 20 \\
\hline & & & .000 & .000 & 13.711 & 0.000 & 0.000 & 0.000 & 0.175282 \\
\hline 30 & .000 & .000 & 1.000 &.$\infty 00$ & 13.711 & .000 & .000 & 0.000 & 0.175242 \\
\hline & .000 & .000 & .000 & 000 & 13.7 & .000 & .000 & 0.000 & 0.175252 \\
\hline$x$ & $\infty$ & .000 & .000 & 000 & 23.020 & .000 & $\mathbf{0}$ & 0.000 & 0.202517 \\
\hline 0 & .000 & .000 & .000 & 000 & 32 & .000 & .000 & 0.000 & 0.004330 \\
\hline & 9 & .000 & 0 & .000 & -20.018 & 00 & .000 & 0.000 & 0.000540 \\
\hline & & 0 & 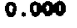 & $\infty$ & -10.180 & 0.000 & 100 &.$\infty 0$ & 0.000773 \\
\hline & & .000 & .000 & .000 & -12. & 0.000 & 0.000 & 0.000 & 0.002024 \\
\hline & 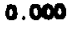 & .00 & 0.0 & .000 & -4.820 & 0.000 & 0.000 & 0.000 & 0.012248 \\
\hline & - & $\infty 00$ & .000 & $\infty$ & 1.930 & 0.0 & 0.000 & 0.000 & 0.03448 \\
\hline & & & 0.0 & 000 & c.40 & 0.0 & 0.000 & 0.000 & 0. osenos \\
\hline & 0.000 & .000 & 0.000 & 0.000 & 13.711 & 0.000 & 0000 & 0.000 & 0.175222 \\
\hline
\end{tabular}

Station 48, Kerkyra, Greece

\begin{tabular}{|c|c|c|c|c|c|c|c|c|c|}
\hline D2In & & Intor & & & & th & & & 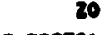 \\
\hline - & 1.000 & 0.000 & .000 & 0.000 & -23.353 & 0.000 & -0.916 & 0.760 & 0.000751 \\
\hline 30 & 0.000 & 000 & .000 &.$\infty 00$ & -25.235 & 0.000 & -0.623 & -0.40 & 0.00001 \\
\hline$\infty$ & $\infty 00$ & 0 & .000 & 0.000 & -29.176 & 0.000 & 2.845 & -1 & $0.000 \mathrm{AM}$ \\
\hline $\boldsymbol{0 0}$ & 60 & & $\infty$ & . & -23.130 & 0.000 & -4.230 & & 0031 \\
\hline 120 & & & $\infty$ & .00 & -17.112 & 0.000 & 3.038 & & 0.00042 \\
\hline 150 & 000 & $\infty$ & .000 & 0.000 & -7.51 & 0.000 & -2.161 & .816 & $\mathrm{AO}$ \\
\hline 16 & 000 & & .000 & & & .000 & -1.2 .46 & 0.475 & 0.0517 \\
\hline 220 & 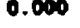 & & 000 & & 17.676 & 0.000 & -1. & & 0.093148 \\
\hline 340 & 0.000 & .00 & ס & 0.0 & 27.311 & 0.600 & -9.028 & -1.113 & 0.4 \\
\hline 0 & & & & 0.000 & 14.60 & 10 & -1. & & 0. \\
\hline & & & & & & & -4. & & \\
\hline & 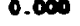 & & & & -21.23 & 0.600 & -2.011 & & \\
\hline
\end{tabular}

Station 49, Athems, Greece

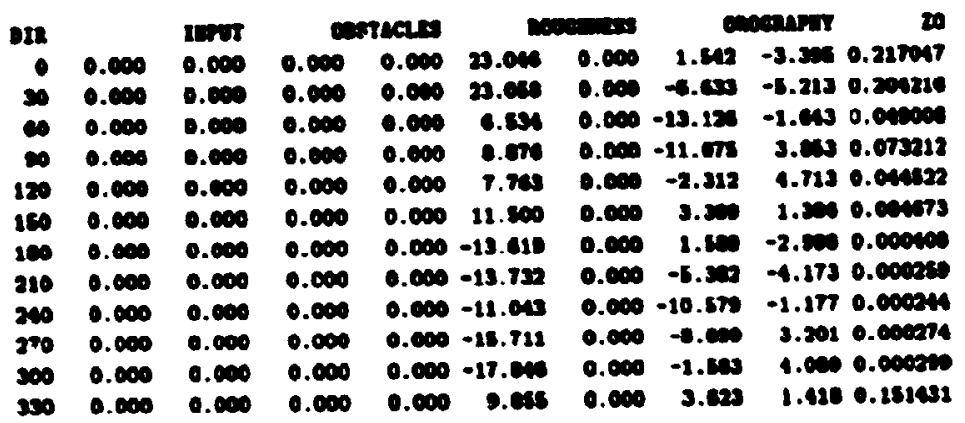


Station 50, Naxos, Greece

\begin{tabular}{|c|c|c|c|c|c|c|c|c|c|}
\hline Dta & & Inor & & Incts: & & $\operatorname{mans}$ & & Delupy & 20 \\
\hline 0 & 0.000 & 0.000 & 0.000 & 0.000 & 0.000 & 0.000 & 1.730 & 1.222 & 0.000200 \\
\hline 30 & 0.000 & 0.000 & 0.000 & 0.000 & -4.224 & $c .000$ & 0.02 & -2.310 & 0.00024 \\
\hline C. & 0.000 & 0.000 & 0.000 & 0.000 & -4.220 & 0.000 & -7.870 & -5.417 & $0.207 \mathrm{tan}$ \\
\hline 0 & 0.000 & 0.000 & 0.000 & 0.000 & -4.220 & 0.000 & -14.756 & -1.727 & $0.207 \mathrm{eat}$ \\
\hline 120 & 0.000 & 0.000 & 0.000 & 0.000 & 1.653 & 0.000 & -12.160 & 3.8 & 0.197274 \\
\hline 150 & 0.000 & 0.000 & 0.000 & 0.000 & 22.131 & 0.000 & -3.748 & 4.003 & 0.151812 \\
\hline IC4 & 0.000 & 0.000 & 0.000 & 0.000 & 26.649 & 0.000 & 1.052 & $1.27 \mathrm{~s}$ & 0.100521 \\
\hline 210 & 0.000 & 0.000 & 0.000 & 0.000 & -0.935 & 0.000 & 0.45 & -2.541 & $0.000 \$ 15$ \\
\hline 40 & 0.000 & 0.000 & 0.000 & 0.000 & -0.081 & 0.000 & -5.541 & -3.834 & 0.000350 \\
\hline 70 & 0.000 & 0.000 & 0.000 & 0.000 & 0.000 & 0.000 & -10.177 & -1.304 & 0.000200 \\
\hline 0 & 0.000 & 0.000 & 0.000 & 0.000 & 0.000 & 0.000 & -9.012 & 2.560 & 0.000200 \\
\hline 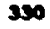 & 0.000 & 0.000 & 0.000 & 0.000 & 0.000 & 0.000 & -2.842 & 3.690 & 0.000200 \\
\hline
\end{tabular}

Station 51, Rodos, Greece

\begin{tabular}{|c|c|c|c|c|c|c|c|c|c|}
\hline \multirow[t]{2}{*}{ Den } & \multirow[b]{2}{*}{0.000} & \multirow{2}{*}{$\begin{array}{l}\text { I.TT } \\
0.000\end{array}$} & \multicolumn{2}{|c|}{ ostactos } & \multicolumn{2}{|c|}{ noventhas } & \multicolumn{2}{|c|}{ choencint } & \\
\hline & & &, 000 & 0.000 & -4.543 & 0.000 & -0.035 & 0.355 & 0.00022 \\
\hline 30 & 0.000 & .000 & 1.000 & 1.000 & 7.927 & 0.000 & -5.252 & 3.324 & 0.0002 \\
\hline & 100 &.$\infty 00$ & 0 & .000 & 3.316 & .000 & 0.760 & 3.063 & 1.00 \\
\hline$\infty$ & .000 & .000 & 1.000 & .000 & 24.484 & 0.000 & 3.711 & -0.223 & 1.202 \\
\hline 20 & 000 & .000 & .000 & .000 & .102 & .000 & -0.237 & -3.04 & 0. \\
\hline 150 & .000 &.$\infty 00$ & .000 & .000 & 14.167 & .000 & -7.678 & -3.84 & 0.20 \\
\hline & & & 0 & .000 & 13.370 & .000 & -10.716 & 0.340 & 0.116 \\
\hline 210 & 0.000 & 1.000 & 0.000 & 0.000 & 22.165 & 0.000 & -6 . & 4.122 & 0.27 \\
\hline & & .000 & 0 & 0.0 & 26.657 & $\infty$ & 0.773 & 3.407 & 0.201 \\
\hline & 0.000 & 0.000 & .000 & 0.000 & -6.063 & .000 & 3.22 & -0.378 & 0.00 \\
\hline & & 10 & .0 & & -7.1 & & -0.170 & -3.155 & \\
\hline & 0.000 & 0.000 & 0.000 & 0.000 & -4.543 & 0.000 & -4.200 & -2.891 & 0.0 \\
\hline
\end{tabular}

Station 52, Benbecula, Great Britain

\begin{tabular}{|c|c|c|c|c|c|c|c|c|c|}
\hline \multirow{2}{*}{ Pr } & \multirow[b]{2}{*}{0.000} & \multirow{2}{*}{$\begin{array}{l}\text { Inten } \\
0.000\end{array}$} & \multicolumn{2}{|c|}{ ostracts } & \multicolumn{2}{|c|}{ Dodendixas } & \multicolumn{2}{|c|}{ оломиту } & \\
\hline & & & 000 & 0.000 & -9.34 & 0.000 & 0.000 & 0.000 & 0.001278 \\
\hline & 0.000 & 0.000 & 0.000 & .000 & 2.62 & 0.000 & 0.060 & 0.000 & 0.030258 \\
\hline & & 000 & .000 & .000 & 1.025 & 0.000 & .000 & 0.000 & 0.022575 \\
\hline & & .000 & 0.000 & 0.000 & -8.484 & 0.000 & 0.000 & 0.000 & $0 . \infty$ \\
\hline & & & .000 & 0.000 & -13.220 & 0.000 & 0.000 & 0.000 & 0.000580 \\
\hline & & 0.000 & 0.000 & 0.000 & -0.450 & 0.000 & 0.000 & 0.000 & 0.050240 \\
\hline & 0 & .000 & .000 & 0.000 & -1.423 & 0.000 & 0.000 & 0.000 & 0.05 \\
\hline & 1.000 & 0.000 & 0.000 & 0.000 & -18.357 & 0.000 & 0.000 & 0.000 & 0.0 \\
\hline & & 0.000 & 1.000 & 0.000 & -23.127 & 0.000 & 0.000 & 0.000 & 0.000713 \\
\hline & G & 0.000 & 0.000 & 0.0 & -10.3 .3 & & $\theta$ & & 0.6 \\
\hline & & & $\begin{array}{l}0.000 \\
0.000\end{array}$ & 0.000 & -11.77 & & 0.000 & & 1 \\
\hline
\end{tabular}

Station 53, Eekdabemuir, Great Bricain

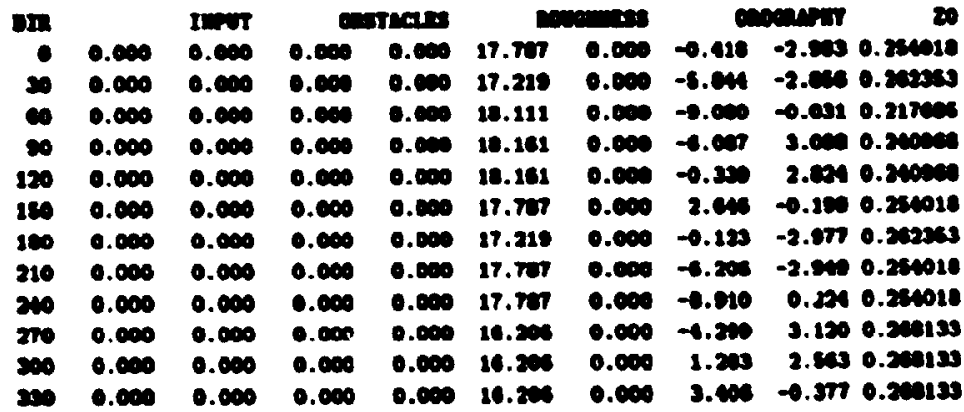


Station 34, Valley, Great Britain

\begin{tabular}{|c|c|c|c|c|c|c|c|c|c|}
\hline \multirow{2}{*}{ DII } & \multirow[b]{2}{*}{14.000} & Inor & \multicolumn{2}{|c|}{ onstactses } & \multicolumn{2}{|c|}{ moseris 25} & \multicolumn{2}{|c|}{ cocenuryt } & 20 \\
\hline & & 0.000 & -21.237 & 0.000 & 0.000 & 0.000 & 0.000 & 0.000 & 0.100000 \\
\hline 30 & 14.000 & .000 & -28.314 & 0.000 & -3.345 & 0.000 & 0.000 & 0.000 & $0.0 \mathrm{cos} 1 \mathrm{~s}$ \\
\hline 10 & 14.000 & 0.000 & 0.000 & 0.000 & -3.345 & 0.000 & 0.000 & 0.600 & All \\
\hline 10 & 14.000 & 0.000 & 0.000 & 0.000 & 0.000 & 0.000 & 0.000 & 0.000 & $0.0 \mathrm{css01}$ \\
\hline 120 & 14.000 & 0.000 & 0.000 & 0.000 & 8.320 & 0.000 & 0.000 & 0.000 & 0.0 .0323 \\
\hline 150 & 14.000 & 0.000 & 0.000 & 0.000 & 0.311 & 0.000 & 0.000 & 0.000 & $0.045 \mathrm{ct}$ \\
\hline 100 & 14.000 & 0.000 & 0.000 & 0.000 & -7.043 & 0.000 & 0.000 & 0.000 & 0.000345 \\
\hline 210 & 14.000 & 0.000 & 0.060 & 0.000 & -8.207 & 0.000 & 0.000 & 0.000 & 0.000200 \\
\hline 240 & 14.000 & 0.000 & 0.000 & 0.000 & -5.207 & 0.000 & 0.000 & 0.000 & 0.000800 \\
\hline 270 & 14.000 & 0.000 & 0.000 & 0.000 & -0.273 & 0.000 & 0.000 & 0.000 & 0.001520 \\
\hline 300 & 14.000 & 0.000 & -3.233 & 0.000 & 1.033 & 0.000 & 0.000 & 0.000 & $0.015 \sec 0$ \\
\hline 390 & 14.8 & 000 & -7.527 & 0.000 & -2.174 & 0.000 & 0.000 & 0.000 & 0.020051 \\
\hline
\end{tabular}

Station 35, Blackpool, Great Britain

\begin{tabular}{|c|c|c|c|c|c|c|c|c|c|}
\hline \multirow{2}{*}{ Dr. } & \multirow[b]{2}{*}{0.000} & \multirow{2}{*}{$\begin{array}{l}I m 0 t \\
0.000\end{array}$} & \multicolumn{2}{|c|}{ costractes } & \multicolumn{2}{|c|}{ Dobativiss } & \multicolumn{2}{|c|}{ conentrat } & 20 \\
\hline & & & .000 & 0.000 & 18.041 & 0.000 & 0.000 & 0.000 & 0.359011 \\
\hline 30 & .000 &.$\infty 0$ & 0 & .000 & 18.123 & 0.000 & .000 & 0.000 & 0.343902 \\
\hline & .000 & $\infty$ & 0.000 & 0.000 & 28.8 & 0.000 & 0.000 & 0.000 & 0.343402 \\
\hline & .000 & & .000 & .000 & 19.744 & 0.000 & 0.000 & 0.000 & 0.205186 \\
\hline & 0. & $\infty 00$ & $\infty$ & .000 & 19.74 & 0.000 & 0.000 & 0.000 & .246166 \\
\hline & 000 & 000 & 1.000 & .000 & 19.601 & 0.000 & 0.000 & 0.000 & 0.202437 \\
\hline & .000 & .000 & .0 & .000 & -5.246 & 0.000 & 0.000 & 0.000 & 0.016491 \\
\hline & 1.000 & 0.000 & 0.000 & 0.000 & -12.025 & 0.000 & 0.000 & a.t.0 & 0.000315 \\
\hline & D & 000 & 0.0 & 0.000 & -12.405 & 0.000 & 0.000 & 0.000 & $0.00034 s$ \\
\hline & 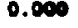 & & .000 & 0.000 & -14.410 & 0.000 & 0.000 & 0.000 & 0.000415 \\
\hline & & & 1.000 & 0.000 & -10.750 & 0.000 & 0.000 & 0.000 & 0.000521 \\
\hline & 0.000 & 0.000 & 0.000 & 0.000 & -20.510 & 0.000 & 0.000 & 0.000 & 0.000571 \\
\hline
\end{tabular}

Station 36, Manchester, Great Britain

\begin{tabular}{|c|c|c|c|c|c|c|c|c|c|}
\hline DII & & Im & & $\operatorname{set} x$ & & $=13$ & & ausis & 20 \\
\hline 0 & 000 & 0.000 & 0.000 & 0.000 & 25.976 & 0.000 & 0.000 & 0.000 & 0.203432 \\
\hline 30 & & $\infty 0$ & 0.000 & 0.000 & 24.85 & 0.000 & 0.000 & 0.000 & 0.334130 \\
\hline & $\infty$ & .000 & 0.000 & 0.000 & 24.89 & 0.000 & 0.000 & 0.000 & 0.202440 \\
\hline$\theta$ & & & 0.000 & .000 & 21.307 & 0.000 & 0.000 & 0.000 & .174201 \\
\hline 120 & 0.000 & 0.000 & 0.000 & 0.000 & 17.867 & 0.000 & 0.000 & 0.000 & 0.15035 \\
\hline se & .000 & 0.000 & 0.000 & 0.000 & 16.940 & 0.000 & 0.000 & 0.000 & 0.167 sea \\
\hline & 0.000 & 0.000 & 0.00 & 0.000 & 11.50 & 0.000 & 0.000 & $\infty$ & $\mathbf{M 7 3}$ \\
\hline 1 & 0.000 & 0.000 & 0.000 & 0.000 & 12.116 & D.⿻日 & 0.000 & 0.0 & $0.072: 9$ \\
\hline & 0.000 & 0.000 & 0.000 & 0.000 & 13.0 & 0.00 & 0.000 & 6.0 & 0.177030 \\
\hline & 0.000 & 0.000 & 0.600 & 0.000 & 18. 198 & 0.040 & 0.000 & 0.0 & 0.21214 \\
\hline & & 0.000 & 0.000 & 0.00 & -2.052 & 0.000 & 0.000 & 0.0 & $0.1867 m$ \\
\hline & 0.000 & 0.000 & 0.160 & & 28.031 & & 0.000 & & 0.2243 \\
\hline
\end{tabular}

Station 57, Birmingham, Great Brital

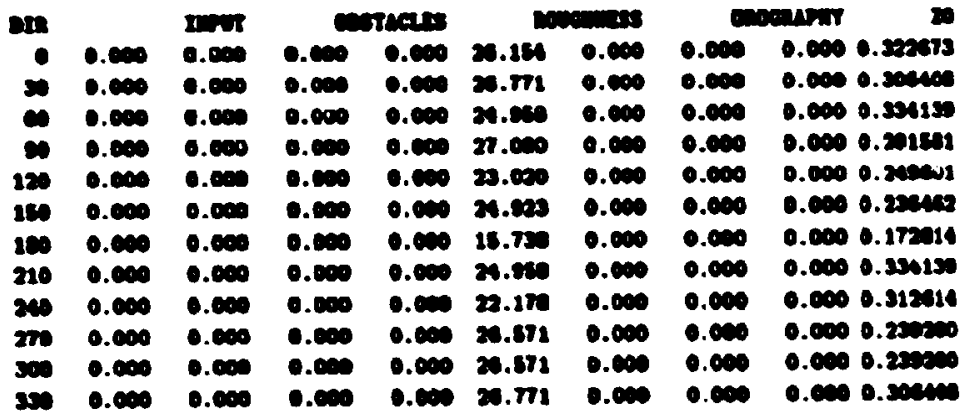


Station 58, London, Great Britain

\begin{tabular}{|c|c|c|c|c|c|c|c|c|c|}
\hline \multirow[t]{2}{*}{ DIn } & \multirow[b]{2}{*}{0.000} & \multirow{2}{*}{$\begin{array}{l}\text { IIIrT } \\
0.000\end{array}$} & \multicolumn{2}{|c|}{ cotsctes } & \multicolumn{2}{|c|}{ nootentess } & \multicolumn{2}{|c|}{ cuneasury } & 20 \\
\hline & & & 0.000 & 0.000 & 0.53 & 0.000 & 0.000 & 0.000 & 0.000370 \\
\hline $\mathbf{3 0}$ & 0.000 & 0.000 & 0.000 & 0.000 & 15.730 & 0.000 & 0.000 & 0.000 & 0.172014 \\
\hline 0 & 0.000 & 0.000 & 0.000 & 0.000 & 25.240 & 0.000 & 0.000 & 0.000 & 0.212734 \\
\hline$\infty$ & 0.000 & 0.000 & 0.000 & 0.000 & 11.032 & 0.000 & 0.000 & 0.000 & 0.020323 \\
\hline 120 & 0.000 & 0.000 & 0.000 & 0.000 & 13.358 & 0.000 & 0.000 & 0.000 & 0.375219 \\
\hline 150 & 0.0000 & 0.000 & 0.000 & 0.000 & 20.340 & 0.000 & 0.000 & 0.000 & 0.352530 \\
\hline 100 & 0.000 & 0.000 & 0.000 & 0.000 & 19.000 & 0.000 & 0.000 & 0.000 & 0.246507 \\
\hline 210 & 0.000 & 0.000 & 0.000 & 0.000 & 16.250 & 0.000 & 0.000 & 0.000 & 0.185001 \\
\hline $\boldsymbol{\omega}$ & 0.000 & 0.000 & 0.000 & 0.000 & 20.026 & 0.000 & 0.000 & 0.000 & 0.126312 \\
\hline 270 & 0.000 & 0.000 & 0.000 & 0.000 & 12.723 & 0.000 & 0.000 & 0.000 & 0.180055 \\
\hline 00 & 0.000 & 0.000 & 0.000 & 0.000 & 24.000 & 0.000 & 0.000 & 0.000 & 0.270070 \\
\hline $3 \mathbf{3 0}$ & 0.000 & 0.000 & 0.000 & 0.000 & 24.0000 & 0.000 & 0.000 & 0.000 & 0.274070 \\
\hline
\end{tabular}

Station 59, Exeter, Great Britain. Covering only the period from December 1990 to May 1991.

\begin{tabular}{|c|c|c|c|c|c|c|c|c|c|}
\hline \multirow[t]{2}{*}{ DIR } & \multirow[b]{2}{*}{0.000} & \multirow{2}{*}{$\begin{array}{l}\text { InPUT } \\
0.000\end{array}$} & \multicolumn{2}{|c|}{ OISTACLES } & \multicolumn{2}{|c|}{ woueyrisss } & \multicolumn{2}{|c|}{ onocuster } & \\
\hline & & & .000 & 0.000 & .741 & 0.000 & 1.000 & 0.000 & o. ovse73 \\
\hline 30 & 0.000 & .000 & .000 & 1.000 & .741 & .000 & .000 & 0.000 & 0.094873 \\
\hline & .000 & $\infty$ & .000 & 1.000 & 1 & .000 & .000 & 0.000 & 0.004673 \\
\hline 90 & .0 & 000 & .000 & 1.000 & 3 & .000 & .000 & .000 & 104402 \\
\hline & .000 & $\infty 00$ & 0 & .000 & 23 & .000 & .000 & 0.000 & 0.104402 \\
\hline & .000 & & 000 & 0 & -4 & .000 & .000 & .000 & 3300 \\
\hline &. & & & .000 & -4.4 & 0.000 & 1.000 & 0.000 & 1300 \\
\hline & ? & 000 & $\infty$ & & 5 & .000 & 1.000 & 0.000 & 3300 \\
\hline & & & & 0.000 & 0.028 & 0.000 & 0.8 & 0.060 & cass \\
\hline & & .000 & 00 & & & 0.000 & 0.000 & 0.000 & 0.16481 \\
\hline & & .0 & 0.0 & & 10.016 & 0.000 & 0.000 & 0.000 & 0.023775 \\
\hline & 0.000 & 0.000 & 0.000 & 0.000 & 10.702 & 0.000 & 0.000 & 0.00 & 0.060323 \\
\hline
\end{tabular}

Station 60, Bournemouth, Great Britain

\begin{tabular}{|c|c|c|c|c|c|c|c|c|c|}
\hline orn & & Imon & & $\operatorname{TACL} x$ & & aldes & & GMPIT & 20 \\
\hline 0 & 0.000 & 0.000 & 0.000 & 0.040 & 18.005 & 0.000 & 0.000 & 0.000 & 0.395751 \\
\hline 30 & 0.000 & 0.000 & 0.000 & 0.000 & 21. CAT & 0.000 & 0.000 & 0.000 & 0.311710 \\
\hline & 0.000 & .000 & 0.000 & 0.000 & 11.001 & 0.000 & 0.000 & 0.000 & 0.355500 \\
\hline $\mathbf{6 0}$ & 0.000 & 0.000 & 0.000 & 0.000 & 16.028 & 0.000 & 0.000 & 0.000 & 0.342507 \\
\hline 120 & 0.000 & 0.000 & 0.000 & 0.000 & 18.220 & 0.000 & 0.000 & 0.000 & 0.350274 \\
\hline 150 & 0.000 & 0.000 & 0.000 & 0.000 & -16.231 & 0.000 & 0.000 & 0.000 & 0.00574 \\
\hline 8: & 0.000 & 0.000 & 0.000 & 0.000 & -9.312 & 0.000 & 0.000 & 0.000 & 0.004720 \\
\hline 210 & 0.000 & 0.000 & 0.000 & 0.000 & 21.000 & 0.000 & 0.000 & 0.000 & 0.284725 \\
\hline $2 \pi$ & 0.000 & 0.000 & -0.010 & 0.000 & 19.41 & 0.000 & 0.000 & 0.000 & 0.151251 \\
\hline 270 & 0.000 & 0.000 & -7.390 & 0.000 & $10 . \mathrm{ces}$ & 0.000 & 0.000 & 0.000 & 0.13140 \\
\hline & 0.000 & & -12.150 & 6 & 22.92 & 0.000 & 0.600 & 0.60 & a.2:121 \\
\hline & 0.000 & 0.000 & 0.000 & 0.00 & 15.482 & 0.000 & $0.6 \mathrm{in}$ & 0.0 & $0.137 /$ \\
\hline
\end{tabular}




\section{Results station by station}

The results of the different model runs will be displayed in the following

\section{C.1 The neutral HIRLAM/WAsP model}

Results marked 'N/A' means that the values are not available because of either miceing data (stations reporting only every 6 hours) or division by zero.

Table 15. Results HIRLAM/WASP madel. The column marted 'H/W' is the column with the results of the runs for the entire period (December 1990 to November 1991) for the selected stations. 'pers' is the results from the persistence model, and 'rel' is the ratio of the neutral HIRLAM/WAP model to persistence (numbers smaller than 1.0 indicates that the HIRLAM/WASP model preformed belter than persistence). Results for the 9, 18, and 96 hour forecasts are displayed. $e$ is the mean error, $|e|$ the mean absolute error, and RMSE the rms error (all in $\mathrm{m} / \mathrm{s}$ ).

\begin{tabular}{|c|c|c|c|c|c|c|c|c|c|}
\hline & \multirow{2}{*}{\multicolumn{3}{|c|}{+3}} & \multicolumn{3}{|c|}{+18} & \multicolumn{3}{|c|}{+36} \\
\hline & $\mathbf{H} / \mathbf{W}$ & & rel & $\mathbf{H} / \mathbf{W}$ & pera & rel & $\mathbf{H} / \mathbf{W}$ & pers & rel \\
\hline 1 & -0.52 & 0.00 & -516.00 & .0 .07 & -0.01 & 5.67 & -0.12 & -0.02 & 6.39 \\
\hline & 1.57 & 1.54 & 1.02 & 1.67 & 2.77 & 0.60 & 1.93 & 3.22 & 0.60 \\
\hline RMSE & 2.00 & 2.07 & 0.97 & 2.25 & 3.61 & 0.62 & 2.54 & 4.17 & 0.61 \\
\hline$e$ & -0.78 & 0.00 & -196.25 & -0.46 & -0.02 & 25.72 & -0.57 & -0.02 & 25.77 \\
\hline & 2.01 & 1.61 & 1.25 & 1.97 & 3.16 & 0.62 & 2.25 & 3.50 & 0.64 \\
\hline RMSE & 2.61 & 2.21 & 1.18 & 2.64 & 4.07 & 0.65 & 2.90 & 4.42 & 0.65 \\
\hline 6 & -0.47 & -0.01 & 93.60 & -0.07 & -0.00 & 18.25 & -0.21 & -0.04 & 5.78 \\
\hline & 1.69 & 1.50 & 1.12 & 1.73 & 2.72 & 0.64 & 1.86 & 3.01 & 0.62 \\
\hline RMSE & 2.18 & 1.97 & 1.10 & 2.26 & 3.35 & 0.64 & 2.51 & 3.84 & 0.65 \\
\hline$\overline{7}$ & -0.76 & -0.02 & 44.41 & -0.23 & 0.00 & -57.75 & -0.57 & -0.01 & 47.25 \\
\hline & 1.87 & 1.61 & 1.16 & 1.99 & 3.27 & 0.61 & 2.18 & 3.66 & 0.59 \\
\hline RMSE & 2.58 & 2.21 & 1.17 & 2.62 & 4.20 & 0.62 & 2.93 & 4.65 & 0.63 \\
\hline 8 & -0.97 & -0.00 & 973.00 & -0.72 & -0.01 & 89.88 & -0.63 & -0.03 & 19.12 \\
\hline & 2.04 & 1.25 & 1.04 & 2.20 & 3.69 & 0.68 & 2.49 & 4.12 & 0.60 \\
\hline RMSE & 2.63 & 2.62 & 1.01 & 3.08 & 4.73 & 0.65 & 3.21 & 5.30 & 0.61 \\
\hline 9 & -0.32 & -0.01 & $\overline{24.09}$ & 0.12 & -0.01 & -8.43 & -0.17 & -0.02 & 8.74 \\
\hline & 1.54 & 1.29 & 1.20 & 1.53 & 2.40 & 0.64 & 1.91 & 2.88 & 0.66 \\
\hline RMSE & 2.01 & 1.73 & 1.16 & 2.12 & 3.00 & 0.6 & 2.49 & 3.64 & 0.68 \\
\hline & -1.06 & -0.00 & 2.5 .50 & -0.72 & 0.03 & -25.71 & -1.03 & 0.01 & -171.00 \\
\hline & 1.75 & 1.10 & 1.47 & 1.50 & 2.15 & 0.73 & 1.94 & 2.60 & 0.75 \\
\hline RMSE & 2.47 & 1.50 & 1.58 & 2.11 & 2.70 & 0.76 & 2.50 & 3.28 & 0.7 \\
\hline & -0.61 & -0.01 & 121.20 & -0.48 & -0.00 & 457.00 & -0.50 & 0.00 & -165.33 \\
\hline$|e|$ & 1.53 & 1.22 & 1.26 & 1.51 & 2.19 & 0.69 & 1.85 & 2.45 & 0.76 \\
\hline RMSE & 2.07 & 1.00 & 1.20 & 2.07 & 2.80 & 0.74 & 2.48 & 3.11 & 0.80 \\
\hline & -0.41 & -0.00 & 204.00 & -0.37 & 0.02 & -17.71 & -0.45 & 0.01 & .56 .63 \\
\hline & 1.70 & 1.16 & 1.47 & 1.72 & 2.31 & 0.74 & 1.02 & 2.73 & 0.70 \\
\hline RMSE & 2.41 & 1.55 & 1.36 & 2.35 & 2.88 & 0.70 & 2.51 & 3.48 & 0.72 \\
\hline
\end{tabular}


Talle 16. Results HIRLAN/WAPP madel.

\begin{tabular}{|c|c|c|c|c|c|c|c|c|c|}
\hline & \multicolumn{3}{|c|}{+3} & \multicolumn{3}{|c|}{+18} & \multicolumn{3}{|c|}{+38} \\
\hline & $\mathbf{H} / \mathbf{W}$ & pers & rel & $\mathbf{H} / \mathbf{W}$ & pers & rel & $\mathbf{H} / \mathbf{w}$ & pers & rel \\
\hline 13 & -0.37 & 0.00 & -122.00 & -0.11 & -0.01 & 21.40 & -0.33 & 0.02 & -21.80 \\
\hline & 1.57 & 1.31 & 1.20 & 1.53 & 2.49 & 0.61 & 1.89 & 3.04 & 0.62 \\
\hline RMSE & 2.20 & 1.73 & 1.27 & 2.04 & 3.25 & 0.63 & 2.48 & 3.88 & 0.64 \\
\hline 13 & -0.11 & 0.00 & $N / A$ & 0.21 & 0.00 & 207.00 & -0.05 & 0.01 & -5.30 \\
\hline & 1.42 & 1.11 & 1.28 & 1.38 & 2.07 & 0.66 & 1.63 & 2.52 & 0.65 \\
\hline $\mathbf{R M}$ & 1.96 & 1.55 & 1.26 & 1.83 & 2.72 & 0.67 & 2.16 & 3.24 & 0.67 \\
\hline 16 & 0.27 & 0.00 & 67.50 & 0.68 & 0.00 & $\mathbf{N} / \mathbf{A}$ & 0.23 & -0.00 & -230.00 \\
\hline & 1.27 & 1.11 & 1.15 & 1.34 & 1.95 & 0.69 & 1.59 & 2.35 & 0.68 \\
\hline MSE & 1.80 & 1.51 & 1.19 & 1.78 & 2.53 & 0.70 & 2.08 & 2.98 & 0.70 \\
\hline 17 & -0.84 & 0.00 & -280.33 & -0.36 & -0.02 & 19.11 & -0.63 & 0.01 & -105.50 \\
\hline & 1.77 & 1.38 & 1.28 & 1.75 & 2.74 & 0.64 & 1.89 & 3.13 & 0.60 \\
\hline RMSE & 2.37 & 2.06 & 1.15 & 2.43 & 3.62 & 0.67 & 2.49 & 4.07 & 0.61 \\
\hline 18 & -1.02 & 0.01 & -102.00 & -0.55 & -0.01 & 68.75 & -0.86 & -0.01 & 61.71 \\
\hline & 1.62 & 1.08 & 1.50 & 1.37 & 1.97 & 0.69 & 1.70 & 2.35 & 0.72 \\
\hline RMSE & 2.23 & 1.45 & 1.53 & 1.84 & 2.56 & 0.71 & 2.22 & 2.93 & 0.75 \\
\hline 19 & -0.82 & 0.00 & $N / A$ & -0.27 & -0.03 & 8.58 & -0.70 & -0.02 & 46.80 \\
\hline & 1.62 & 1.39 & 1.17 & 1.53 & 2.38 & 0.64 & 1.86 & 2.80 & 0.66 \\
\hline RMSE & 2.06 & 1.88 & 1.10 & 2.03 & 3.09 & 0.66 & 2.40 & 3.51 & 0.68 \\
\hline 21 & -0.65 & 0.00 & -322.50 & -0.20 & -0.01 & 39.40 & -0.55 & .0 .04 & $15 .{ }^{50}$ \\
\hline & 1.56 & 1.20 & 1.30 & 1.44 & 2.23 & 0.65 & 1.74 & 2.56 & 0.68 \\
\hline & 2.14 & 1.64 & 1.30 & 1.88 & 2.90 & 0.65 & 2.24 & 3.25 & 0.69 \\
\hline 22 & 0.88 & N/A & $\mathrm{N} / \mathrm{A}$ & -1.91 & 0.03 & -70.59 & -2.01 & 0.04 & -45.64 \\
\hline & 0.88 & $\mathbf{N} / \boldsymbol{A}$ & $N / A$ & 2.65 & 2.37 & 1.11 & 2.69 & 2.90 & 0.93 \\
\hline & 1.33 & $N / A$ & $N / A$ & 3.44 & 3.17 & 1.09 & 3.62 & 3.75 & 0.97 \\
\hline 23 & -0.73 & 0.01 & -146.80 & -0.20 & 0.00 & -2.04 .00 & -0.31 & 0.01 & -34.80 \\
\hline & 1.64 & 1.23 & 1.33 & 1.44 & 1.89 & 0.76 & 1.70 & 2.22 & 0.77 \\
\hline MSE & 2.20 & 1.67 & 1.32 & 1.90 & 2.46 & 0.80 & 2.26 & 2.81 & 0.80 \\
\hline 23 & 1.30 & $\mathbf{N} / \mathbf{\Lambda}$ & $M / A$ & -2.85 & 0.01 & -223.25 & -3.32 & -0.00 & 1107.67 \\
\hline & 1.3 & $N / A$ & $N / A$ & 3.25 & 2.85 & 1.10 & 3.74 & 3.53 & 1.06 \\
\hline$\sigma$ & 1.97 & $\mathbf{N} / \mathbf{A}$ & $N / A$ & 4.03 & 3.72 & 1.03 & 4.63 & 4.37 & 1.06 \\
\hline & $\overline{3.20}$ & $N / A$ & $N / A$ & -2.11 & 0.04 & -25.74 & -1.73 & 0.02 & -78.77 \\
\hline & 3.28 & $N / A$ & $N / A$ & 2.13 & 2.76 & 0.77 & 2.63 & 3.33 & 0.78 \\
\hline MASE & 4.4 & $\mathbf{N} / \mathbf{A}$ & $N / \boldsymbol{A}$ & 2.86 & 3.75 & $0 . \pi$ & 3.4 & 4.40 & 0.83 \\
\hline & -1.23 & 0.01 & -153.10 & -1.22 & 0.04 & -30.00 & -1.22 & 0.08 & -37.65 \\
\hline & 3.19 & 1.72 & 185 & 3.00 & 2.84 & 1.07 & 3.14 & 3.38 & 0.93 \\
\hline $\operatorname{lns}$ & 4.16 & 23 & 1.70 & 3.1 & 3.17 & 1.07 & 4.11 & 4.31 & 0.85 \\
\hline & 1.8 & 0.01 & 313.50 & 2.57 & 0.01 & -4.50 & 2.16 & 0.04 & 30.28 \\
\hline & 3.41 & 1.37 & 2.0 & 3.4 & 2.23 & 1.57 & 3.30 & 2.68 & 1.23 \\
\hline MSE & 4.28 & 1.00 & 2.23 & 400 & 2.6 & 1.47 & 4.16 & 3.43 & 1.20 \\
\hline & -120 & 9.00 & 125.00 & 0.30 & 0.01 & -35.45 & -1.01 & 0.02 & -63.31 \\
\hline & 3.08 & 1.67 & 1.84 & 2.76 & 2.60 & 1.06 & 2.85 & 3.05 & 0.84 \\
\hline RMSE & 3.96 & 2.41 & 1.4 & 3.51 & 3.55 & 0.90 & 3.74 & 4.05 & 0.92 \\
\hline & -2.32 & -0.02 & 134.00 & -1.58 & 0.02 & -83.10 & -1.60 & 0.01 & -380.40 \\
\hline je & 3.18 & 1.80 & 1.73 & 2.75 & 2.75 & 1.00 & 3.01 & 3.21 & 0.94 \\
\hline & 4.23 & 2.58 & 1.4 & 3.76 & $3 . n$ & 1.02 & 3.90 & 4.22 & 0.85 \\
\hline
\end{tabular}


Talle 17. Results HIRLAM/WAP model.

\begin{tabular}{|c|c|c|c|c|c|c|c|c|c|}
\hline & \multicolumn{3}{|c|}{+3} & \multicolumn{3}{|c|}{+18} & \multicolumn{3}{|c|}{+36} \\
\hline & $\mathrm{H} / \mathrm{W}$ & pers: & rel & $\mathbf{H} / \mathbf{W}$ & pers & rel & $\mathbf{H} / \mathbf{W}$ & pers & rel \\
\hline 32 & 1.17 & -0.04 & -32.56 & 2.29 & -0.01 & $-: 90.67$ & 2.22 & 0.05 & 47.23 \\
\hline & 2.44 & 1.38 & 1.76 & 2.90 & 2.17 & 1.24 & 2.84 & 2.43 & 1.17 \\
\hline & 3.07 & 2.14 & 1.44 & 3.80 & 2.97 & 1.28 & 3.74 & 3.25 & 1.15 \\
\hline 34 & -1.68 & -0.01 & 167.80 & -0.48 & 0.00 & -159.00 & -0.76 & -0.02 & 42.44 \\
\hline & 2.09 & 1.33 & 1.56 & 1.47 & 1.99 & 0.74 & 1.51 & 2.01 & 0.75 \\
\hline & 2.59 & 1.81 & 1.43 & 1.97 & 2.55 & 0.77 & 2.03 & 2.65 & 0.77 \\
\hline 35 & 1.47 & 0.05 & 31.87 & 2.54 & -0.0 & -65.23 & 2.22 & 0.02 & 123.06 \\
\hline & 3.20 & 1.29 & 2.47 & 3.78 & 1.94 & 1.95 & 3.22 & 2.36 & 1.36 \\
\hline RMSE & 4.04 & 1.81 & 2.23 & 4.85 & 2.61 & 1.85 & 4.21 & 3.08 & 1.36 \\
\hline 36 & -0.50 & 0.01 & -35.86 & -0.19 & 0.03 & -7.11 & 0.15 & 0.04 & 3.69 \\
\hline & 1.83 & 1.53 & 1.19 & 1.84 & 2.47 & 0.74 & 1.75 & 2.97 & 0.59 \\
\hline & 2.35 & 2.06 & 1.14 & 2.26 & 3.15 & 0.72 & 2.23 & 3.67 & 0.61 \\
\hline 37 & -0.88 & -0.01 & 73.42 & -0.74 & $-0.0 i$ & 92.00 & -0.75 & -0.02 & 39.63 \\
\hline & 1.95 & 1.34 & 1.45 & 2.12 & 2.79 & 0.76 & 2.35 & 3.39 & 0.69 \\
\hline RMSE & 2.69 & 1.78 & 1.52 & 2.99 & 3.61 & 0.83 & 3.17 & 4.29 & 0.74 \\
\hline$\overline{38}$ & 0.11 & 0.01 & 14.13 & 0.38 & -0.00 & -126.00 & 0.05 & -0.01 & -6.86 \\
\hline & 1.43 & 1.13 & 1.27 & 1.42 & 1.96 & 0.73 & 1.53 & 2.35 & 0.65 \\
\hline MSE & 2.06 & 1.49 & 1.38 & 1.87 & 2.54 & 0.74 & 1.97 & 2.99 & 0.66 \\
\hline 39 & -0.09 & -0.01 & 12.86 & 0.25 & -0.01 & -41.33 & -0.06 & -0.00 & 18.33 \\
\hline & 1.29 & 1.08 & 1.19 & 1.19 & 1.85 & 0.64 & 1.50 & 2.28 & 0.66 \\
\hline & 1.77 & 1.46 & 1.22 & 1.64 & 2.39 & 0.68 & 1.95 & 2.86 & 0.68 \\
\hline 40 & -0.34 & -0.00 & 114.67 & -0.18 & 0.01 & -19.67 & -0.37 & 0.03 & .14 .80 \\
\hline & 1.28 & 1.04 & 1.23 & 1.18 & 1.82 & 0.65 & 1.44 & 2.18 & 0.66 \\
\hline & 1.90 & 1.39 & 1.37 & 1.60 & 2.39 & 0.67 & 1.96 & 2.79 & 0.70 \\
\hline 41 & -1.32 & 0.01 & -147.00 & .0 .76 & -0.00 & 762.00 & -1.21 & 0.01 & -100.92 \\
\hline & 2.19 & 1.14 & 1.92 & 1.71 & 1.78 & 0.96 & 2.08 & 2.09 & 1.00 \\
\hline & 2.77 & 1.54 & 1.80 & 2.28 & 2.30 & 0.96 & 2.69 & 2.72 & 0.99 \\
\hline & -1.69 & 0.01 & -211.25 & .1 .27 & 0.02 & -84.60 & -1.45 & -0.00 & 1451.00 \\
\hline & 2.19 & 1.48 & 1.48 & 1.78 & 2.06 & 0.87 & 2.05 & 2.28 & 0.90 \\
\hline & 2.90 & 1.90 & 1.51 & 2.46 & 2.69 & 0.91 & 2.80 & 2.97 & 0.94 \\
\hline & -0.65 & 0.00 & -163.25 & -0.20 & -0.01 & 28.00 & -0.81 & 0.00 & $\mathbf{N} / \mathrm{A}$ \\
\hline & 1.80 & 1.32 & 1.50 & 1.92 & 2.41 & 0.80 & 2.00 & 2.85 & 0.73 \\
\hline & 2.68 & 1.93 & 1.30 & 2.04 & 3.17 & 0.83 & 2.72 & 3.68 & 0.74 \\
\hline & 0.30 & 0.01 & 24.83 & 1.12 & -0.01 & -70.79 & 0.49 & 0.01 & 0.57 \\
\hline & 1.78 & 1.47 & 1.21 & 1.70 & 2.30 & 0.75 & 1.6 & 2.81 & 0.70 \\
\hline$\Delta 20$ & 2.48 & 2.13 & 1.17 & 2.37 & 3.17 & 0.75 & 2.57 & 3.57 & 0.72 \\
\hline 47 & -2.12 & 0.08 & -88.37 & -1.32 & -0.01 & 118.92 & -1.85 & 0.02 & -123.40 \\
\hline & 2.61 & 1.38 & 1.66 & 2.10 & 2.30 & 0.08 & 2.38 & 2.78 & 0.88 \\
\hline ASE & 3.34 & 2.26 & 1.48 & 2.00 & 3.24 & 0.50 & 3.00 & 3.00 & 0.80 \\
\hline & -0.09 & 0.01 & -57.03 & 0.11 & -0.01 & -11.80 & -0.74 & -0.00 & 247.00 \\
\hline & 2.23 & 1.34 & 1.67 & 2.10 & 2.37 & 0.88 & 2.27 & 2.80 & 0.76 \\
\hline RMSE & 3.02 & 2.24 & 1.35 & 2.70 & 3.44 & 0.79 & 2.84 & 4.02 & 0.73 \\
\hline 48 & -0.68 & 0.00 & $N / A$ & -0.33 & -0.01 & 39.78 & -0.61 & -0.01 & 55.27 \\
\hline |et & 2.2 .0 & 1.63 & 1.35 & 2.01 & 2.61 & 0.77 & 2.13 & 3.20 & 0.67 \\
\hline & 2.85 & 2.31 & 1.28 & 2.58 & 3.42 & 0.75 & 2.85 & 4.03 & 0.68 \\
\hline
\end{tabular}


Thlle 18. Reoults HIRLAM/WASP model.

\begin{tabular}{|c|c|c|c|c|c|c|c|c|c|}
\hline & \multicolumn{3}{|c|}{+3} & \multicolumn{3}{|c|}{+18} & \multicolumn{3}{|c|}{+36} \\
\hline & $\mathbf{H} / \mathbf{W}$ & pers & rel & $\mathbf{H} / \mathbf{W}$ & pers & rel & $H / W$ & pers: & rel \\
\hline 50 & -2.22 & 0.00 & -2216.00 & -1.29 & -0.12 & $10 . \overline{78}$ & .2 .80 & -0.10 & 27.19 \\
\hline & 3.22 & 1.93 & 1.66 & 3.29 & 3.66 & 0.80 & 3.79 & 4.86 & 0.78 \\
\hline RMSE & .4 .21 & 2.64 & 1.59 & 4.31 & 4.77 & 0.90 & 4.85 & 6.24 & 0.78 \\
\hline$e$ & -2.10 & 0.01 & -180.73 & -1.53 & -0.03 & 47.78 & -2.36 & -0.03 & 81.24 \\
\hline & 2.87 & 1.46 & 1.86 & 2.48 & 2.39 & 1.04 & 3.11 & 2.99 & 1.04 \\
\hline RMSE & 3.66 & 2.00 & 1.83 & 3.09 & 3.10 & 1.00 & 3.85 & 3.79 & 1.01 \\
\hline 52 & -1.42 & -0.00 & 353.75 & -0.99 & 0.00 & -331.00 & -1.03 & -0.02 & 60.88 \\
\hline & 2.06 & 1.54 & 1.34 & 2.11 & 3.29 & 0.64 & 2.32 & 3.59 & 0.65 \\
\hline RMSE & 2.96 & 2.11 & 1.40 & 3.04 & 4.24 & 0.72 & 3.34 & 4.67 & 0.72 \\
\hline 53 & -0.84 & -0.00 & 417.50 & -0.45 & -0.02 & 28.00 & -0.64 & -0.01 & 49.08 \\
\hline & 1.87 & 1.38 & 1.35 & 1.80 & 2.49 & 0.72 & 2.04 & 2.93 & 0.70 \\
\hline RMSE & 2.50 & 1.89 & 1.35 & 2.42 & 3.27 & 0.74 & 2.65 & 3.74 & 0.71 \\
\hline 34 & -0.52 & 0.00 & -515.00 & 0.06 & -0.03 & -2.07 & -0.14 & .0 .06 & 2.47 \\
\hline & 1.85 & 1.46 & 1.27 & 1.97 & 3.22 & 0.61 & 2.34 & 3.61 & 0.65 \\
\hline RMSE & 2.65 & 2.02 & 1.32 & 2.86 & 4.21 & 0.68 & 3.16 & 4.63 & 0.68 \\
\hline 55 & -0.88 & -0.00 & 293.67 & -0.60 & .0 .05 & 12.93 & -0.54 & -0.03 & 19.43 \\
\hline & 1.77 & 1.32 & 1.34 & 1.80 & 2.46 & 0.73 & 1.95 & 2.90 & 0.67 \\
\hline RMSE & 2.23 & 1.81 & 1.23 & 2.34 & 3.26 & 0.72 & 2.66 & 3.71 & 0.72 \\
\hline$\overline{56}$ & -0.28 & 0.00 & -95.00 & -0.09 & 0.00 & $\mathbf{N} / \mathbf{A}$ & -0.15 & -0.01 & 11.46 \\
\hline$|e|$ & 1.39 & 1.21 & 1.15 & 1.45 & 2.21 & 0.66 & 1.61 & 2.58 & 0.62 \\
\hline RMSE & 1.97 & 1.64 & 1.20 & 1.89 & 2.88 & 0.66 & 2.11 & 3.29 & 0.64 \\
\hline 57 & -0.11 & 0.00 & -105.00 & 0.26 & 0.01 & 51.40 & 0.07 & -0.00 & -66.00 \\
\hline$|e|$ & 1.27 & 1.08 & 1.18 & 1.27 & 1.95 & 0.65 & 1.45 & 2.23 & 0.65 \\
\hline RMSE & 1.87 & 1.46 & 1.28 & 1.76 & 2.53 & 0.70 & 1.95 & 2.86 & 0.68 \\
\hline 38 & 0.12 & 0.00 & 58.50 & 0.43 & 0.00 & 426.00 & 0.31 & -0.00 & .102 .67 \\
\hline & 1.32 & 1.06 & 1.25 & 1.41 & 1.95 & 0.72 & 1.52 & 2.30 & 0.66 \\
\hline RMSE & 1.90 & 1.42 & 1.33 & 1.89 & 2.55 & 0.74 & 1.90 & 2.92 & 0.68 \\
\hline 39 & 0.15 & 0.01 & 24.50 & 0.74 & -0.01 & -52.57 & 0.41 & -0.03 & -14.75 \\
\hline$|e|$ & 1.66 & 1.47 & 1.12 & 1.79 & 2.59 & 0.69 & 1.80 & 2.83 & 0.64 \\
\hline RMSE & 2.10 & 2.01 & 1.05 & 2.23 & 3.42 & 0.65 & 2.28 & 3.61 & 0.63 \\
\hline$\overline{C 0}$ & -0.05 & 0.01 & -6.00 & 0.48 & -0.01 & -96.40 & 0.10 & -0.01 & -10.80 \\
\hline & 1.62 & 1.30 & 1.25 & 1.51 & 2.37 & 0.64 & 1.77 & 2.73 & 0.65 \\
\hline RMSE & 2.17 & 1.80 & 1.21 & 1.91 & 3.10 & 0.68 & 2.32 & 3.49 & 0.66 \\
\hline
\end{tabular}




\section{C.2 The linear prediction model}

Table 19. Results from running the linear prediction model described in Sectson 15.1 for the 5,18 and 96 hour forecast for the 6 selected stations. The model is evaluated using data from the last half of the period (June to November 1991).

\begin{tabular}{rrrrr}
\hline$*$ & $F$ & $e$ & $|e|$ & RMSE \\
\hline 19 & +3 & 0.103 & 0.503 & 0.623 \\
& +18 & 0.242 & 1.897 & 2.395 \\
& +36 & 0.387 & 1.996 & 2.475 \\
29 & +3 & 0.157 & 0.541 & 0.659 \\
& +18 & 0.389 & 1.912 & 2.345 \\
& +36 & 0.627 & 1.953 & 2.368 \\
35 & +3 & -0.002 & 0.563 & 0.703 \\
& +18 & 0.006 & 1.692 & 2.100 \\
& +36 & 0.052 & 1.669 & 2.072 \\
41 & +3 & 0.020 & 0.439 & 0.570 \\
& +18 & 0.042 & 1.409 & 1.823 \\
& +36 & 0.075 & 1.434 & 1.866 \\
56 & +3 & 0.035 & 0.373 & 0.455 \\
& +18 & 0.116 & 1.823 & 2.241 \\
& +36 & 0.167 & 1.896 & 2.326 \\
57 & +3 & 0.103 & 0.390 & 0.475 \\
& +18 & 0.295 & 1.595 & 1.972 \\
& +36 & 0.382 & 1.672 & 2.040 \\
\hline
\end{tabular}




\section{C.3 Sensitivity to the local corrections}

Table 20. The neutral madel run without corrections for local effects, using the WASP matrix $(" \div W$ ') for the 6 selected stations compared to persistence for the +9 , +18 and +96 hour forecast for the last half of the period (June 1991 to November 1991) compared to peroistence ('persist') and the neutrul HIRLAM/WASP model $(H / W)$, see Section 19.1 for further details.

\begin{tabular}{|c|c|c|c|c|c|c|c|c|c|}
\hline & \multicolumn{3}{|c|}{+3} & \multicolumn{3}{|c|}{+18} & \multicolumn{3}{|c|}{+36} \\
\hline & $\div \boldsymbol{W}$ & pers & $H / W$ & $\div W$ & pers & $H / W$ & $\div \mathbf{w}$ & pers & $\mathbf{H} / \mathbf{W}$ \\
\hline 19 & -1.63 & 0.00 & -0.82 & -1.11 & -0.03 & -0.18 & -1.35 & -0.02 & -0.62 \\
\hline & 2.08 & 1.39 & 1.69 & 1.78 & 2.38 & 1.59 & 2.24 & 2.80 & 1.82 \\
\hline RMSE & 2.70 & 1.88 & 2.00 & 2.28 & 3.09 & 2.16 & 2.87 & 3.51 & 2.36 \\
\hline 29 & 1.23 & 0.01 & 1.46 & 1.90 & -0.01 & 1.90 & 1.52 & 0.04 & 1.67 \\
\hline & 3.04 & 1.37 & 3.47 & 2.99 & 2.22 & 3.13 & 2.88 & 2.68 & 3.02 \\
\hline RMSE & 3.78 & 1.90 & 4.09 & 3.66 & 2.93 & 3.41 & 3.65 & 3.46 & 3.53 \\
\hline 35 & -0.54 & 0.05 & 1.39 & 0.13 & -0.04 & 2.81 & 0.03 & 0.02 & 2.38 \\
\hline & 2.26 & 1.29 & 3.61 & 2.24 & 1.94 & 4.54 & 1.95 & 2.36 & 3.45 \\
\hline RMSE & 2.90 & 1.81 & 4.31 & 2.77 & 2.61 & 4.95 & 2.52 & 3.08 & 3.95 \\
\hline 41 & -1.28 & 0.01 & -1.55 & -0.79 & -0.00 & -1.00 & -1.22 & 0.01 & -1.48 \\
\hline & 2.21 & 1.14 & 2.17 & 1.74 & 1.78 & 1.66 & 2.13 & 2.09 & 2.05 \\
\hline RMSE & 2.91 & 1.34 & 2.26 & 2.30 & 2.36 & 1.97 & 2.88 & 2.72 & 2.21 \\
\hline 56 & -0.84 & 0.00 & -0.29 & -0.63 & 0.00 & -0.14 & -0.66 & -0.01 & -0.23 \\
\hline & 1.57 & 1.21 & 1.29 & 1.53 & 2.21 & 1.33 & 1.72 & 2.58 & 1.61 \\
\hline RMSE & 2.15 & 1.64 & 2.05 & 2.03 & 2.88 & 1.83 & 2.31 & 3.29 & 2.17 \\
\hline 57 & -0.85 & 0.00 & 0.03 & -0.51 & 0.01 & 0.31 & .0 .69 & -0.00 & 0.11 \\
\hline$|e|$ & 1.46 & 1.08 & 1.25 & 1.30 & 1.95 & 1.28 & 1.56 & 2.23 & 1.35 \\
\hline RMSE & 2.00 & 1.46 & 2.00 & 1.74 & 2.53 & 1.77 & 2.13 & 2.86 & 1.91 \\
\hline
\end{tabular}




\section{C.4 Directional dependent neural network for MOS}

Table 21. Results for the directional dependent neural network MOS model $(1,5,1)$, see Section 13.4. $S$ is the station number, $F$ the look-ahead time (in hours), e the mean error, $|e|$ the mean absolute error, and RMSE the rms error.

\begin{tabular}{rrrrrr}
\hline$S$ & $F$ & $e$ & $e \mid$ & RMSE \\
\hline 19 & +3 & 0.17 & 1.68 & 2.09 \\
& +18 & 0.13 & 1.56 & 2.11 \\
& +36 & 0.20 & 1.87 & 2.50 \\
\hline 29 & +3 & 0.04 & 2.32 & 2.82 \\
& +18 & -0.18 & 1.94 & 2.46 \\
& +36 & -0.13 & 2.05 & 2.72 \\
\hline 35 & +3 & -0.27 & 2.15 & 2.75 \\
& +18 & 0.08 & 2.08 & 2.67 \\
& +36 & 0.28 & 1.74 & 2.30 \\
\hline 41 & +3 & 0.07 & 1.56 & 1.99 \\
& +18 & -0.08 & 1.29 & 1.69 \\
& +36 & -0.06 & 1.59 & 2.05 \\
\hline 56 & +3 & -0.15 & 1.36 & 2.27 \\
& +18 & -0.12 & 1.35 & 1.76 \\
& +36 & -0.13 & 1.67 & 2.37 \\
\hline 57 & +3 & 0.23 & 1.34 & 2.19 \\
& +18 & 0.18 & 1.32 & 1.81 \\
& +36 & 0.10 & 1.31 & 1.75 \\
\hline
\end{tabular}




\section{The effect of data resolution}

In this section a brief (and seneral) derivation of the efiect of resolving a timeseries with a realution $\rho$. It is aseumed that diatribution of the masurements is stepwice constant, ie constant in stepa centred around integer multiples of $p$, and having the width $\rho$. In the following $e$ is the mean extor, $x_{m}$ the wind apeed from the model, $u$, the obnerved wind apeed, and $N$ the number of obnervations.

\section{The mean error}

Since the distribution is asumed homogeneous there will be no effect on the mean error of the resolution.

\section{The mean absolute error}

The efect on the mean aboolute error is calculated in the following:

$$
\begin{aligned}
\left|e_{0}\right| & \sim\left|u_{m}-u_{0}\right| \\
& =\int_{u_{m}-t_{0}}^{u_{m}+t_{\rho}}\left|u-u_{0}\right| d u \\
& =\int_{u_{m}-t_{0}}-\left(u-u_{0}\right) d u+\int_{u_{m}}^{u_{m}+t_{0}}\left(u-u_{0}\right) d u \\
& =\frac{1}{4} \rho^{2}
\end{aligned}
$$

If this is divided by the width of the interval we get that the effect of the resolution on the mean abeolute error for each obeervation is

$$
\frac{1 \rho^{2}}{\left(u_{m}+\frac{1}{\partial} \rho\right)-\left(u_{m}-\frac{1}{f} \rho\right)}=\frac{1}{4} \rho
$$

\section{The rms error}

The efiect on the rias errot is

$$
\begin{aligned}
& \text {. } \sim \sqrt{\frac{1}{2 \cdot \frac{1}{3} p} \int_{m-t p}^{u+1 p}\left(u-w_{0}\right)^{2} d u} \\
& =\sqrt{\frac{1}{2 \cdot \frac{1}{2} p} \int_{-m-1 p}^{u+1 p}\left(u^{2}+u^{2}-2 u_{0}\right) d x} \\
& =\frac{1}{\sqrt{3}} \frac{1}{2}
\end{aligned}
$$


Treb aed antwor(s)

Shart-term prodiction of beal wind conditions

Lass Landberg

\begin{tabular}{|c|c|c|}
\hline $\begin{array}{l}\text { ISBN } \\
87-550-1916-1\end{array}$ & & $\begin{array}{l}158 N \\
0106-2840\end{array}$ \\
\hline Dept. or group & & Dale \\
\hline Meteorology and Wind Energy & & March 1904 \\
\hline Groupe own nes nusober(0) & Project/contract No(D) & \\
\hline MET 02431-00 & JOUR-COS1-C(MB) & \\
\hline Tables: & Illudrations & Reforencen \\
\hline 143 & 67 & 81 \\
\hline
\end{tabular}

Abresect (Max. 2000 char.)

This report describes the development and evaluation of difierent methods for predicting the wind locally. The look-ahead time of the forecante ranges from 3 to 36 hours. The main model developed bere is based on forecusts from a numerical woather prediction model. In this study MIRLAM (HIgh Recolution Limited Ares Model) has been used. These forecants are transformed to the surface usiag the geostrophic drag law and the logarithmic wind profle in their neutral versions. To tale local efiects ineo account, corrections output form WNPP (Wiad Adne Analyais and Application Program) are used. The conclusion is that the model developed here performs significantly better than persiatence. The model performs best when applied to sites in Northern Europe (hoving high wiad speed). When using MOS (Model Outpet Statiotica) it is ponible to improve the forecants, mainly those that do sot perform well.

Decriplese IN1S/EDB

complex terrain; thom modeb; forecanting; H codes; meteorology; seural setworks; somerical dath; roughneas; timoseries andyia; W codes; moather; wisd

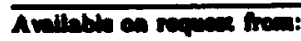

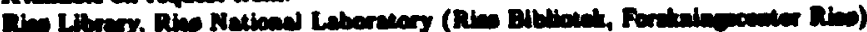

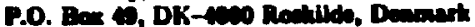

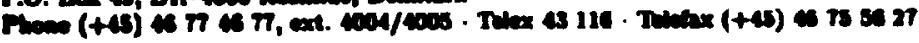

